Universidad de Salamanca

Facultad de Educación

Departamento de Geografía

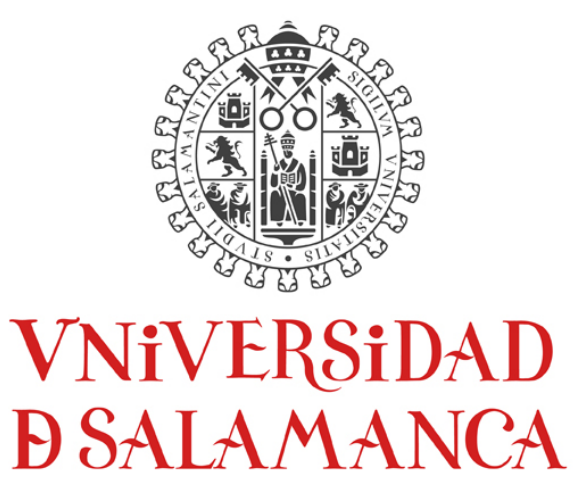

CAMPUS DE EXCELENCIA INTERNACIONAL

\title{
REPRESENTACIONES SOBRE EL PAISAJE EN LOS FUTUROS MAESTROS/AS DE EDUCACIÓN INFANTIL Y PRIMARIA. UN ESTUDIO DE CASO
}

\author{
Ma JESÚS BAJO BAJO
}

2016

DIRECTORAS:

Dra. $D^{a}$. Valentina Maya Frades

Dra. $D^{a}$. Monsterrat Oller Freixa 
$D^{a}$. Valentina MAYA FRADES, profesora Contratada Doctora de la Universidad de Salamanca y $\mathrm{D}^{\mathrm{a}}$. Montserrat OLLER FREIXA, profesora Titular de la Universidad de Barcelona.

HACEN CONSTAR:

Que $D^{\mathrm{a}}$. M $\mathrm{M}^{\mathrm{a}}$ Jesús BAJO BAJO ha realizado el trabajo "REPRESENTACIONES SOBRE EL PAISAJE EN LOS FUTUROS MAESTROS/AS DE EDUCACIÓN INFANTIL Y PRIMARIA. UN ESTUDIO DE CASO", en la Universidad de Salamanca.

Que a nuestro juicio, el trabajo reúne los requisitos de originalidad, dedicación y labor investigadora; así como de formación en el ámbito investigador de su autora, exigibles a un trabajo de Tesis Doctoral.

Por todo ello, dan el visto bueno para la presentación de dicho trabajo para su defensa y lectura.

En Salamanca, a 14 de julio de 2016,

Dra. $\mathrm{D}^{\mathrm{a}}$. Valentina Maya Frades $\quad$ Dra. $\mathrm{D}^{\mathrm{a}}$. Montserrat Oller Freixa 


\section{AGRADECIMIENTOS}

Me gustaría recordar a todas aquellas personas que de un modo u otro han colaborado en esta tesis doctoral.

En primer lugar deseo manifestar mi agradecimiento a las Directoras de mi Tesis Doctoral Valentina Maya y Montserrat Oller, que sin su dedicación, ayuda y ánimos en todo momento me hubiera sido imposible presentar esta investigación.

También quiero agradecer de forma especial a la profesora Ana $\mathrm{M}^{\mathrm{a}}$ Aranda, mi maestra, compañera y amiga. Sus enseñanzas, experiencias e inquietudes me han orientado en el campo de la Didáctica de las Ciencias Sociales y me ha ayudado a clarificar ideas para la realización de esta tesis.

De la misma manera quiero reflejar mi más sincero reconocimiento a todas las personas que han colaborado para que hoy este proyecto haya dejado de serlo para convertirse en realidad. A todos/as mis compañeros y compañeras que han colaborado para que pudiese realizar las encuestas en sus horas de docencia y me han animado de manera incondicional a continuar hacia delante. Tampoco quiero olvidar a Noelia Morales por las sugerencias y apoyo que me ha dado en la finalización de este trabajo.

Finalmente con un cariz más emocional quiero recordar a mis padres, que a pesar de los esfuerzos que tuvieron que hacer, siempre intentaron darme la mejor formación posible. Y así mismo quiero dedicársela a ellos y a mis hermanos y hermana. 
"El Paisaje es memoria. Más allá de sus límites, el Paisaje sostiene las huellas del pasado, reconstruye recuerdos, proyecta en la mirada las sombras de otro tiempo que sólo existe ya como reflejo de sí mismo en la memoria del viajero o del que, simplemente sigue fiel a ese Paisaje. I../ El Paisaje es eterno y sobrevive en todo caso al que lo mira." (El Río del Olvido) Julio LLamazares. 


\section{ÍNDICE}

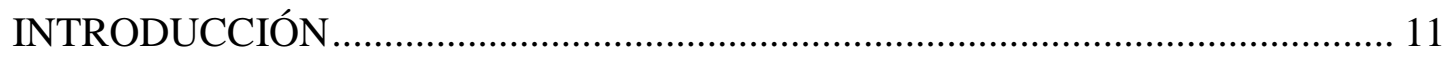

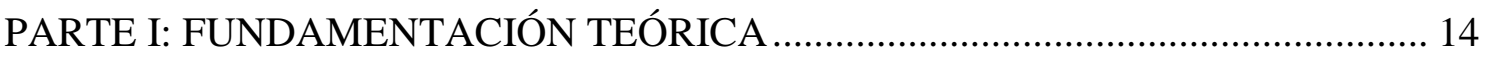

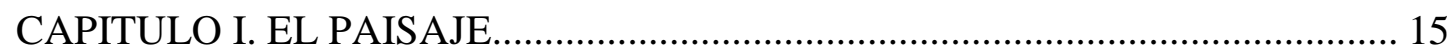

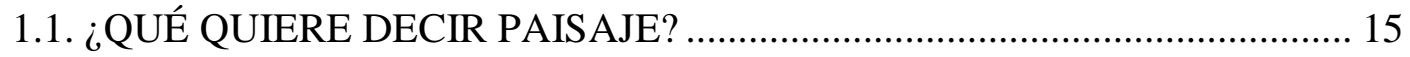

1.2. EL PAISAJE, UN CONCEPTO EN PROCESO DE CAMBIO .................... 17

1.3. DIVERSAS INTERPRETACIONES QUE EXPLICAN EL PAISAJE ......... 22

1.3.1 Análisis de los elementos naturales ......................................................... 24

1.3.2 Análisis de los elementos antrópicos................................................... 26

1.4. CLASIFICACIÓN DE PAISAJES............................................................. 28

1.4.1 Clasificación basada en la dinámica del geosistema ............................... 29

1.4.2 Clasificación de los Paisajes por sus características zonales..................... 30

1.4.3 Clasificación de los Paisajes según la escala temporal.............................. 32

1.4.4. Clasificación de los Paisajes según su funcionalidad............................... 33

1.4.5. Clasificación regionalista de los Paisajes ................................................. 34

CAPÍTULO II. EL PAISAJE EN LA EDUCACIÓN ................................................. 37

2.1. EL PAISAJE COMO RECURSO EDUCATIVO ......................................... 44

2.2. EXPERIENCIAS E INICIATIVAS EDUCATIVAS DEL PAISAJE ............. 46

2.3. EXPERIENCIAS E INICIATIVAS EN ESPAÑA ....................................... 49

2.4. EL PAISAJE Y LAS CIENCIAS SOCIALES ............................................. 58

CAPÍTULO 3. EL PAISAJE EN EL CURRÍCULUM DE EDUCACIÓN INFANTIL

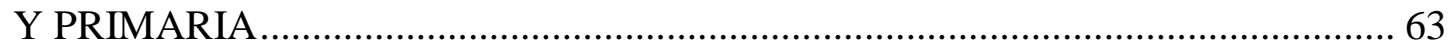

3.1. LEY GENERAL DE EDUCACIÓN (LGE) ................................................... 63

3.1.1. Las Ciencias Sociales en el Currículum de Preescolar.............................. 65

3.1.2. Las Ciencias Sociales en el Currículum de Primaria............................... 65

3.2. LEY ORGÁNICA DE ORDENACIÓN GENERAL DEL SISTEMA

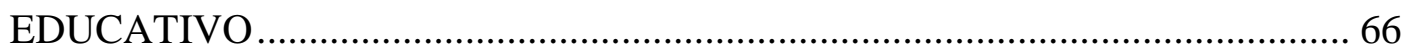

3.2.1. El Paisaje en Área del Conocimiento del Medio...................................... 66

3.2.2. El Conocimiento del Medio en el currículum de Educación Infantil....... 68

3.2.3. El Área del Conocimiento del Medio Natural, Social y Cultural en el

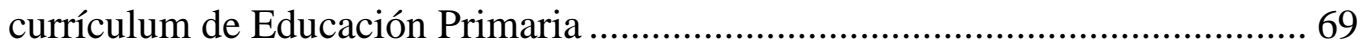

3.2.4. El «Paisaje» en los distintos bloques de contenidos................................ 72

3. 3. LEY ORGÁNICA DE EDUCACIÓN (LOE) ................................................. 75

3.3.1. El Conocimiento del Medio Social y Cultural y el Conocimiento del Entorno en el currículum de Educación Infantil............................................... 75 
3.3.2. El área del Conocimiento del Medio Natural, Social y Cultural en el currículum de Educación Primaria (LOE) ........................................................ 78

3.3.3. El «Paisaje» en los distintos bloques de contenidos.............................. 79

3.4. LEY ORGÁNICA PARA LA MEJORA DE LA CALIDAD EDUCATIVA 81

3.4.1. Las Ciencias Sociales en el Currículum de Educación Infantil................ 81

3.4.2. Las Ciencias Sociales en el Currículum de Educación Primaria............... 81

3.4.3. El «Paisaje» en los distintos bloques de contenidos................................ 82

CAPÍTULO 4. EL PAISAJE EN EL GRADO DE MAESTRO EN EDUCACIÓN INFANTIL Y EN EDUCACIÓN PRIMARIA ......................................................... 85

4.1. FORMACIÓN DEL PROFESORADO DE EDUCACIÓN INFANTIL Y DE EDUCACIÓN PRIMARIA

4.2. EL GRADO DE MAESTRO EN EDUCACIÓN INFANTIL Y PRIMARIA EN LA UNIVERSIDAD DE SALAMANCA

4.2.1. Antecedentes de los estudios de Magisterio en la Universidad de Salamanca.

4.2.2. El Plan de Estudios del grado de Maestro en Educación Infantil y Primaria

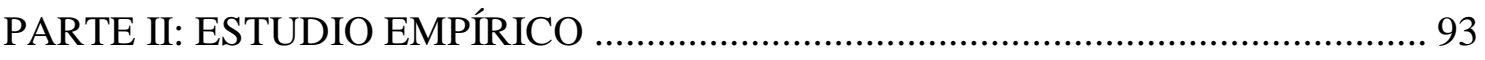

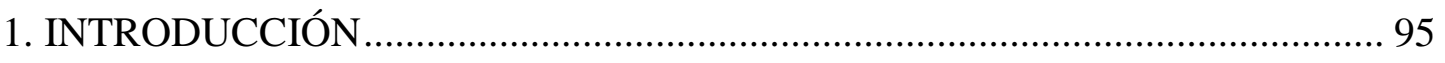

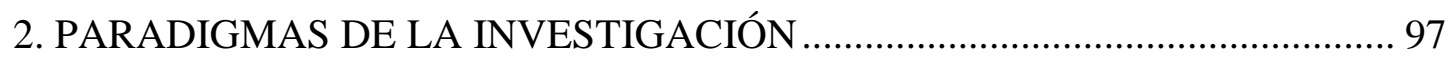

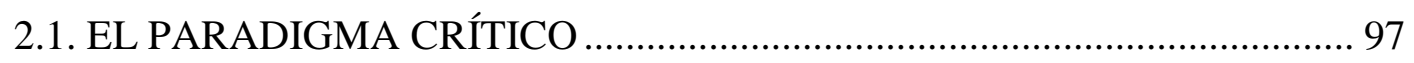

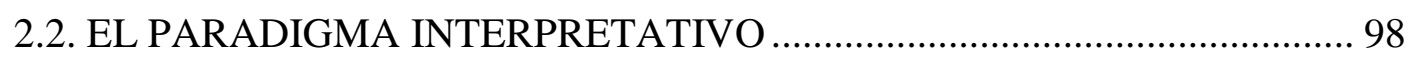

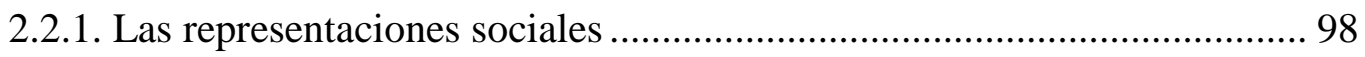

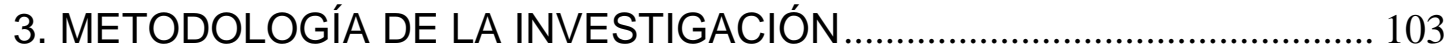

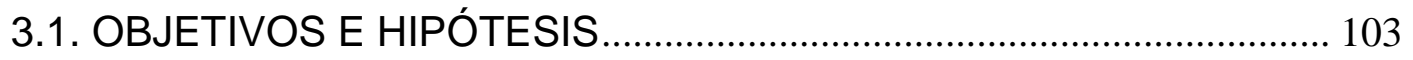

3.2. MÉTODOS CUANTITATIVOS Y CUALITATIVOS EN LA

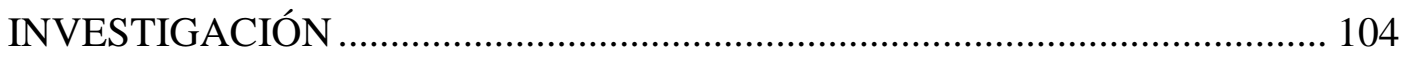

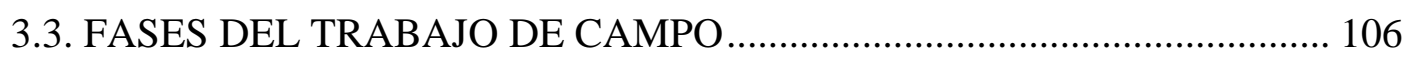

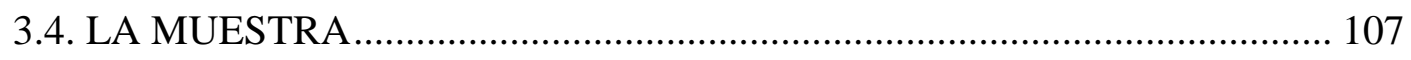

3.5. INSTRUMENTO CUANTITATIVO: EL CUESTIONARIO ....................... 108

3.6. INSTRUMENTO CUALITATIVO: ANÁLISIS DE FOTOGRAFÍAS ....... 109

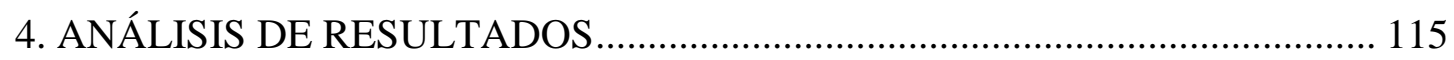

4.1. DATOS SOCIODEMOGRÁFICOS DE LOS/AS ESTUDIANTES DEL GRADO DE MAESTRO/A DE EDUCACIÓN INFANTIL Y PRIMARIA....... 116

4.1.1. Sexo, edad y procedencia de los alumnos encuestados ......................... 116

4.1.2. Estudios anteriores del alumnado participante en la encuesta................ 119

4.1.3. El entorno familiar y el lugar de residencia de los alumnos encuestados

4.2. REPRESENTACIONES Y CONOCIMIENTOS DEL ALUMNADO DE INFANTIL Y PRIMARIA SOBRE EL PAISAJE 
4.2.1. Categorización de las respuestas 123

4.2.2. Análisis de los datos obtenidos.............................................................. 125

4.3. PERCEPCIONES DEL PAISAJE A TRAVÉS DE LA IMAGEN................. 191

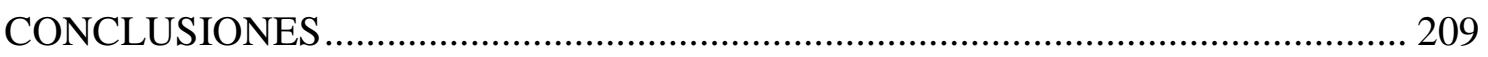

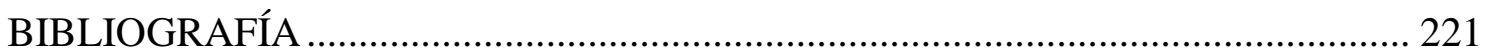

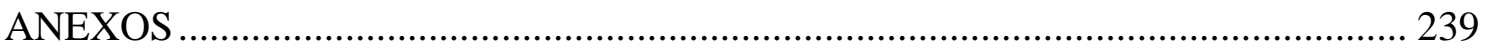




\section{INTRODUCCIÓN}

Una de las finalidades de la investigación del área de Didáctica de las Ciencias Sociales es la formación de ciudadanos comprometidos con la construcción de un mundo distinto, donde tenga un lugar importante la conservación del Medio Ambiente y la protección del Paisaje. Esta finalidad choca con la realidad de la enseñanza del Paisaje; hoy día aunque se ha avanzado mucho, sobre todo desde el año 2000 con el Convenio Europeo del Paisaje, sigue prevaleciendo una enseñanza desvinculada de las experiencias cotidianas de quienes deben aprender y conocer el Paisaje.

La situación actual hace necesario revisar la función de la escuela, y cómo puede convertirse el Paisaje en un conocimiento significativo para los estudiantes, ya sea porque se muestra más cercano a su vida, o porque les enseña a respetar, conservar y actuar. Los niños y los jóvenes son los protagonistas de los cambios que pueden incidir en la protección y conservación de los Paisajes. Partiendo de esta consideración, pensamos que era conveniente conocer y analizar qué contenidos y representaciones tienen los futuros profesores sobre el Paisaje, como vía para planear la construcción de su conocimiento profesional, favoreciendo la Educación en Paisaje, y así poder mejorar la enseñanza y el aprendizaje de las Ciencias Sociales en la formación de los futuros docentes.

La educación en Paisaje en el marco de la educación formal, debe responder a un proyecto progresivo en todas las etapas y ciclos, transversal con la integración de contenidos de diversas áreas y cívico promoviendo pautas éticas con el medio y con otros ciudadanos. Para conseguirlo se deben actualizar los contenidos sobre el Paisaje en la escuela e introducir el paradigma de Paisaje recogido en el Convenio Europeo del Paisaje a la enseñanza. Es decir, educar a las nuevas generaciones transmitiendo interés y estima por el Paisaje. Esto no será posible sin una buena formación del profesorado en general y más concretamente, del profesorado de formación inicial especialista en Didáctica de las Ciencias Sociales; ya que en ellos recae parte de la responsabilidad de conseguir la educación en Paisaje de los futuros maestros de Educación Infantil y Primaria. La formación que hemos recibido en el ámbito geográfico, primero como maestra de la especialidad de Ciencias Humanas y posteriormente como licenciada en Geografía nos ha ayudado a decantarnos por este objeto de estudio para la presente tesis doctoral.

Nuestro interés por el Paisaje ha sido constante durante nuestra etapa de formación, aunque de una forma más explícita se inicia en el curso 2002-2003 cuando comenzamos 
a trabajar los conocimientos que tienen del Paisaje los alumnos/as de tercer y cuarto curso de Educación Primaria y cómo trabajan el tema del Paisaje los maestros/as en las aulas.

Mi experiencia profesional centrada en la formación de los futuros docentes de educación Infantil y Primaria, en el área de Didáctica de las Ciencias Sociales, puede experimentar una mejora sustantiva con la introducción del estudio del Paisaje en los contenidos de ambos grados. La educación en Paisaje es educación en todos los niveles: intelectual, emocional y práctico. Implica el conocimiento, los sentimientos y las actividades que favorecen el proceso educativo general y mejoran las potencialidades como persona.

Esta investigación se estructura en dos partes bien diferenciadas: una primera parte sobre el marco teórico del Paisaje y la segunda, que recoge el trabajo de campo sobre el conocimiento, percepción y valoración que tiene el alumnado del Grado de Maestro/a en Educación Infantil y Primaria.

La primera parte se desarrolla en cuatro capítulos teóricos, donde se abordan y analizan diversas cuestiones vinculadas con el objeto de estudio. El capítulo uno está dedicado al Paisaje, intentando definir qué se entiende por Paisaje, ya que se trata de un concepto en proceso de cambio. El interés por el Paisaje en el último siglo se ha incrementado a medida que se ha producido un mayor deterioro de su calidad ambiental, de tal manera que hay numerosas definiciones de dicho concepto. Por otra parte, es utilizado en muchos ámbitos, desde los protagonizados por expertos en el tema, hasta en los ambientes más coloquiales y populares que podamos imaginar. También en este capítulo se analizan las diversas interpretaciones que configuran el Paisaje atendiendo a los elementos que lo determinan ya sean naturales o antrópicos y se analizan las distintas clasificaciones del Paisaje.

El capítulo dos analiza el Paisaje como recurso educativo, reconociendo su valor para estimular un modelo educativo crítico y participativo. El Convenio Europeo del Paisaje del año 2000 supone un punto de inflexión en el tratamiento del Paisaje en educación. Es importante recordar que la educación en Paisaje es un aspecto importante de la educación de los ciudadanos del futuro respecto a cuestiones relacionadas con el desarrollo sostenible. El Paisaje representa las cuatro dimensiones del desarrollo sostenible: la natural, la social, la cultural y la económica. En este mismo capítulo se enumeran y analizan las distintas experiencias e iniciativas que han surgido en Europa y también en España, a raíz de las recomendaciones dadas por el Convenio Europeo del Paisaje. 
En el capítulo tres se describe y analiza el Paisaje en el currículum de Educación Primaria e Infantil a través de las últimas leyes educativas; desde la Ley General de Educación (LGE) de 1970 hasta la Ley Orgánica para la Mejora de la Calidad Educativa (LOMCE) de 2013.

Esta primera parte concluye con el capítulo cuarto, que hace referencia al tratamiento del Paisaje en la formación del Profesorado de Educación Infantil y Primaria y al Grado de Maestro en Educación Infantil y Primaria en la Universidad de Salamanca y en concreto en su Facultad de Educación.

La segunda parte se corresponde con la parte empírica y describe los paradigmas y las metodologías de la investigación aplicadas a través de instrumentos cuantitativos y cualitativos. La parte cuantitativa se basa en una encuesta aplicada a una muestra de 554 alumnos y alumnas de los Grados de Maestro en Educación Infantil y Primaria. En la parte cualitativa se han analizado las descripciones y percepciones de los alumnos/as de los cursos de primero y tercero de Educación Infantil y Primaria en relación a cuatro imágenes de diferentes Paisajes. Una vez realizado el estudio de campo se han analizado e interpretado los datos obtenidos de cada una de las técnicas empleadas.

El trabajo se consuma con unas conclusiones que aúnan los contenidos teóricos y prácticos recogidos con anterioridad para desembocar en unas orientaciones que servirán para mejorar la práctica docente en torno a la educación en Paisaje.

Finalmente se relaciona la bibliografía utilizada así como dos anexos que incluyen respectivamente el guion del cuestionario y las imágenes empleadas para su análisis por parte de los estudiantes. 


\section{PARTE I: FUNDAMENTACIÓN TEÓRICA}




\section{CAPITULO I. EL PAISAJE}

La idea más "difundida" de Paisaje es la de una extensión de terreno que se ve desde un lugar, captada por la visión de un observador, pero un concepto más riguroso exige adoptar el punto de vista de alguna de las disciplinas que se interesan por él. Esta noción ha evolucionado desde una reducción a los elementos naturales y antrópicos hasta la visión actual, en la que los seres humanos tienen un papel fundamental, porque el Paisaje es el escenario donde las sociedades crecen y evolucionan, y por lo tanto, es un espacio donde se desarrolla la vida.

El interés por el Paisaje desde distinto ámbitos en el último siglo, desde el campo de las ciencias hasta las humanidades, pasando por el conocimiento artístico o técnico, ha estimulado la necesidad de trabajar sobre conceptos, ideas y propuestas de carácter abierto e interdisciplinar. El Paisaje ha sufrido un rápido proceso de transformación, las sociedades desarrolladas han ido alterando de forma progresiva el medio al aumentar el grado de desarrollo tecnológico, de forma que las personas han ido edificando una estructura vital más confortable y segura a costa de un mayor deterioro de su calidad ambiental. Este escenario es el que ha provocado la más reciente atención hacia el Paisaje.

El objetivo principal de esta tesis es analizar el Paisaje como recurso educativo. No obstante, empezamos exponiendo y examinando algunas definiciones de Paisaje aportadas por investigadores, intelectuales y profesionales que han trabajado en este tema, porque somos conscientes de las dificultades que hay para definir este concepto para su uso didáctico, debido a la multitud de aspectos que el término encierra, y dado que abarca una gran diversidad y complejidad de enfoques.

\section{1. ¿QUÉ QUIERE DECIR PAISAJE?}

La palabra Paisaje forma parte del lenguaje cotidiano, es un concepto cuyo tratamiento didáctico puede resultar difícil de abordar desde una perspectiva global, por su amplitud y por su diversidad de significados, pero que, en cualquier caso, creemos potencialmente muy útil si se concibe como un "modo de expresión" del territorio y como una "herramienta multidisciplinar capaz de proporcionar, por su dimensión sintética, una comprensión integral e integradora de todo lo que acontece en nuestro entorno" Tort (2004, p. 135). 
En la misma línea Nogué (2000) concibe el Paisaje como multitud de significados o polisemia:

Pocas palabras tienen un abanico de significados y de connotaciones tan amplio como la del Paisaje. Pocos términos se emplean con tal asiduidad, tanto por parte de estudiosos como de la población en general. Es una palabra que podemos oír desde las mesas de debate más selectas y sofisticadas hasta los registros más coloquiales y populares que podamos imaginar. De ahí, la complejidad de este concepto y de ahí, también, su riqueza y utilidad en numerosos campos (p.29).

El Diccionario de la Real Academia Española, referencia esencial de nuestro lenguaje cotidiano, define el término de Paisaje como "Extensión de terreno que se ve desde un sitio" o como "extensión de terreno visto desde un lugar determinado", pero el Diccionario de voces de uso actual lo define como "Entorno de una persona o cosa"

Es por tanto posible considerar la palabra como sinónimo de naturaleza, territorio, medio ambiente, sumatoria de sistemas, recurso natural, hábitat, escenario, ambiente cotidiano y entorno de un punto, o como resultado de los rasgos naturales o modelados por el hombre que tienen un reflejo visual en el espacio, pudiéndose concluir que el Paisaje puede ser definido por sus formas naturales o humanizadas, y está formado por componentes abióticos, bióticos y antrópicos que se articulan entre sí (Aguiló, 2000)

Para Ortega Cantero (2010) el Paisaje es la expresión fisonómica concreta de la realidad geográfica y del orden que la vértebra. Dicho de otro modo: los hechos geográficos naturales y humanos- dejan huellas en la superficie terrestre, configuran un conjunto de formas y de signos, una especie de escritura, que el conocimiento geográfico debe saber mirar, es decir, debe saber leer e interpretar. Y esa superficie terrestre escrita, marcada por las huellas de los hechos geográficos, es el Paisaje.

Martínez de Pisón (1998) puntualiza que el Paisaje es, al mismo tiempo, "la manifestación formal de la realidad geográfica" y un conjunto de cualidades, valores y significados de cariz cultural, concluyendo que "el Paisaje es (...) la misma realidad geográfica, la formalización del sistema, totalizada, que reposa en una estructura espacial y que está nutrida por sus representaciones, imágenes y sentidos" (p. 152).

Y Zoido y Venegas (2002) afirman:

El Paisaje es considerado en la actualidad un valioso integrante del bienestar y la calidad de vida en los ciudadanos; es también expresión del patrimonio natural y cultural de toda la sociedad y manifestación visible de sus relaciones con el territorio propio, sobre el que muestra de manera inmediata su adecuación o inconveniencia (p. 15). 


\subsection{EL PAISAJE, UN CONCEPTO EN PROCESO DE CAMBIO}

A pesar de su uso y difusión actuales, y a pesar de la pluralidad de sus significados, el término Paisaje tiene en el conjunto de las lenguas románicas un origen relativamente reciente. Según el lingüista Joan Coromines, su primera aparición literaria en lengua castellana es de 1708, palabra tomada del francés, lengua en la que dicho término se encuentra consolidado en su acepción artística, o sea, de "pintura", ya en el siglo XVI; sin embargo Maderuelo (2005) señala que el idioma donde se afianza el término Paisaje es el italiano, para nombrar el territorio, “il paesetto, il paessagio". En cualquier caso, respecto al origen y a la evolución del vocablo que nos ocupa conviene recordar en especial dos aspectos: por un lado, su formación por vía derivativa a partir del sustantivo latín pagus (que equivalía aproximadamente a la idea genérica de "tierra" o "campo"); por el otro, la circunstancia que la acepción artística de esta palabra ha tenido por lo general un carácter prevaleciente, y que tan sólo en la época actual -y no en todas las lenguas- la acepción territorial (o geográfica) del término ha ido tomando carta de naturaleza. Es más, lo que podríamos denominar el "sesgo artístico" que históricamente ha tenido el concepto de Paisaje ha llegado al propio campo académico de la geografía.

Monkhouse (1978) se hace eco de esta particularidad a propósito de la definición de la palabra " Paisaje. Término que en su origen empleaban los artistas para referirse a una panorámica rural. Actualmente es un término general que indica el aspecto total de un área, sea urbana o rural" (pp. 333-334). Monkhouse, en su definición llega a distinguir, en este sentido, hasta seis tipos de "Paisaje": Paisaje cultural, Paisaje físico, Paisaje humano, Paisaje natural, Paisaje relicto y Paisaje urbano". Siguiendo a este autor es posible subrayar el trasfondo unitario e integrador que tiene, en su esencia, el concepto mismo de Paisaje. Veamos la comparación de las dos definiciones siguientes de este mismo autor:

"Paisaje humano. Resultado de las modificaciones aportadas por el hombre al Paisaje natural o físico. Se le conoce también con la denominación de ' Paisaje cultural'. Algunos autores insisten en que existe un solo Paisaje, unidad indivisible de la cual el hombre forma parte integral, por lo cual no tiene sentido distinguir un Paisaje natural de otro humano. "

"Paisaje natural. El Paisaje no afectado por el hombre, como opuesto a ' Paisaje humano'. Se considera como sinónimo de ' Paisaje físico', esto es, relacionado con el relieve y la vegetación natural. Pero es tan poco el Paisaje de la tierra no afectado por el hombre que es mejor no plantear cualquier distinción, y referirse a los elementos naturales y culturales en el Paisaje como un conjunto". 
Tort (2004) cree que Monkhouse intenta por una parte evitar la disociación entre "hombre" y "medio" en la construcción del concepto de Paisaje, una disociación que tal vez tenga sentido desde una perspectiva de análisis específica, pero que desde luego no lo tiene si nos atenemos a la vinculación que tradicionalmente ha mantenido este concepto con la idea de "tierra" o "país" y singularmente expresada en la raíz etimológica pagus, antes aludida. Por otra parte, tal razonamiento se inscribe claramente en la tesitura de quienes defienden, desde la óptica del urbanismo y de otras disciplinas territoriales de orientación aplicada, una consideración unitaria e integral del territorio, capaz de superar las limitaciones de la dicotomía entre "lo rural" y "lo urbano".

Las ideas que expresa Monkhouse tienen cierto valor porque defiende la noción de Paisaje como una totalidad reflejando una realidad compleja, idea que ha estado presente en todas las concepciones geográficas que han tomado al ser humano y el medio dentro de un mismo eje de pensamiento. Pero, la noción de Paisaje no tiene sólo un planteamiento geográfico, es una idea creada en la mente, un concepto con cierta subjetividad y valores, por tanto, es necesario abordar la variedad de significados de tal noción desde distintas vertientes.

El Paisaje es, no obstante un concepto fundamental en la disciplina de la Geografía tanto por su objeto de estudio, el espacio y sus dinámicas naturales y sociales, como por la situación que ocupa dentro de las Ciencias Sociales, tanto a nivel profesional como a nivel académico. Desde el nacimiento de la Geografía como ciencia, con Humboldt, Kant, Ritter, y otros, prevalece la visión de las variaciones espaciales. En aquel momento el ámbito espacial es planteado como superficie terrestre, de utilidad comercial y logística, concepto que paulatinamente se va adaptando a las necesidades y dinámica de la sociedad a lo largo del tiempo. Siguiendo este planteamiento, Martínez de Pisón (2008) señala que: "El Paisaje nació, como la filosofía lo hiciera, de la perplejidad, de la admiración por el mundo tal como es" (p. 16). Este mismo autor nos señala que el Paisaje como corriente cultural con una actitud conjunta de sensibilidad y ciencia no nace en Europa hasta el siglo XVIII, aunque la acepción artística aparezca en el siglo XVI, como se ha comentado anteriormente.

Para entender esa doble presencia de la ciencia y el sentimiento en la visión moderna del Paisaje, hay que conocer cómo se conformó ésta históricamente. La visión moderna del Paisaje se formó en el horizonte cultural del romanticismo, aunque hay autores como Terán (1977) que alegan que el análisis del Paisaje como manifestación visual del territorio se inició en el Renacimiento de mano de naturalistas y humanistas, encuadrado en los estudios de los grandes maestros de la pintura europea, como Leonardo, 
Brueghel o Canaletto. Ese interés se mantuvo en los siglos posteriores, acompañando las diferentes corrientes artísticas y el creciente interés de las personas por la naturaleza: de este modo la naturaleza se convierte en la clave para entender el mundo que nos rodea. Además, si el ser humano quiere saber cómo es ese mundo, el lugar que ocupa en él, y aclarar cuál es el papel que en él le corresponde, tiene que acercarse a esa naturaleza. Es a partir de este momento, según Ortega Cantero (2008), cuando el Paisaje tiene un lugar destacado, convirtiéndose en la expresión visible de ese orden natural que comprende al ser humano y que nos ofrecerá un modo de ver y entender lo que nos rodea para poder vernos y entendernos a nosotros mismos.

El primer paisajismo moderno surge en el S. XVIII como consecuencia de la unión de dos puntos de vista distintos: el punto de vista artístico representado por Rousseau y Bernardin de Saint-Pierre, que se centraba en el sentimiento del Paisaje, y el punto de vista científico representado por naturalistas como Saussure o Ramond, inclinados al conocimiento científico aunque valorando la percepción de sus cualidades estéticas. Sin embargo no será hasta la primera mitad del S. XIX cuando se produzcan nuevos enfoques sobre el paisajismo de la mano de los geógrafos alemanes Humboldt y Ritter. Ambos autores hicieron del Paisaje, de su conocimiento y su valoración, una de las principales finalidades de su estudio. En su concepto de Paisaje hay que unir por tanto la mirada científica y la artística, hay que explicar las cosas pero también hay que comprenderlas. O, con palabras de Humboldt (1874-1875, t. II, p.69), buscar la convergencia del «rigor de la ciencia» y el «soplo vivificador de la imaginación». Fue precisamente en ese horizonte intelectual —y paisajístico — en el que nació la visión de la geografía moderna. Humboldt y Ritter, sus fundadores, incorporaron los renovados planteamientos de ese horizonte, incluyendo, claro está, su concepción de la naturaleza y su modo de entender el Paisaje.

El conocimiento del Paisaje, en términos artísticos y científicos, se resuelve a través de la visión, de la experiencia visual. Hay que ver —o, mejor, saber ver- el Paisaje para lograr entenderlo, para llegar a explicar sus formas y comprender sus significados. Y esa preeminencia de lo visual no hace sino manifestar la coherente inserción de esta perspectiva paisajística en el panorama artístico y científico de su tiempo. La influencia del paisajismo geográfico de Humboldt fue notable, y no sólo en el terreno de la geografía. Humboldt abrió la puerta al paisajismo geográfico moderno, un paisajismo interesado al tiempo en explicar el Paisaje y en comprenderlo, en acercarse a lo qué es y a lo que significa. Ésa es la visión del Paisaje, el modo de entenderlo que adoptó la geografía moderna a lo largo de los siglos XIX y XX y que constituyó sin duda una de sus aportaciones más interesantes, valiosas y fecundas (Ortega Cantero, 2008). Éste 
mismo autor opina que, la dimensión natural y formal del Paisaje no debe ser separada de la dimensión perceptiva y cultural, concluyendo que en la geografía moderna, naturaleza y cultura, objetividad y subjetividad, forma y sentido, son dualidades que "se dan la mano" en la visión moderna del Paisaje.

No debemos olvidar que el Paisaje está lleno de lugares que encarnan la experiencia y las aspiraciones de la gente; lugares que se convierten en centros de significado, en símbolos que expresan pensamientos, ideas y emociones varias. El Paisaje no sólo nos presenta el mundo tal como es, sino que es también, de alguna manera, una construcción de este mundo, una forma de verlo. El Paisaje es, en buena medida, una construcción social y cultural, siempre anclada —eso sí- en un substrato material, físico (Nogué, 2011)

Es en la primera mitad del S. XX cuando Sauer y Parsons, de la Escuela de Berkeley, profundizaron en el concepto de Paisaje cultural, como consecuencia de los cambios introducidos por las personas en el medio natural. La gran mayoría de definiciones y acepciones del término Paisaje incluyen esta dimensión cultural ya aludida, porque prácticamente no existen lugares en nuestro planeta dónde la acción de las personas no sea perceptible. Por tanto,

el Paisaje puede ser entendido por la interrelación que se produce entre territorio y cultura, pues ambos aspectos se complementan ya que, por un lado, los diferentes componentes del medio físico condicionan la cultura humana y, por otro, la sucesión de diferentes culturas a lo largo de la historia, produce transformaciones en el territorio y, consecuentemente, en el Paisaje percibido (Fidalgo, 2014, p. 8)

Las tendencias actuales en la concepción del Paisaje subrayan la importancia de la globalidad y la interacción de los elementos en el espacio a lo largo del tiempo. Es a partir de principios del siglo XXI cuando surgen conceptos como el de glocalización"piensa globalmente y actúa localmente"-(Robertson, 1995, 2003); para Martínez de Pisón el Paisaje es: "encuentro, lugar de todos, intercambio de ideas" (2008, p. 9). Este mismo autor (2009) considera que el Paisaje es un documento histórico, un hecho cultural. Además señala que todas las disciplinas territoriales ofrecen unos síntomas de recuperación o acercamiento a la dimensión paisajística de su objeto de estudio en los últimos años. Estaríamos hablando, por una parte, de disciplinas como la geología, la geomorfología, la geografía, la ecología, la jardinería, la arquitectura, el urbanismo, la ingeniería del Paisaje, entre otras. Y, por otra parte, en las artes como la pintura, la literatura. Finalmente, de la psicología de la percepción paisajística, la historia y la arqueología del Paisaje, las técnicas de visualización del Paisaje, o de las encuestas de 
la sociología, entre otras. Todas estas perspectivas, conformarían lo que se ha llamado la ciencia del Paisaje.

Debemos también destacar las aportaciones de María de Bolós, la primera catedrática de Geografía Física de la universidad española y una figura relevante en el campo de la Ciencia del Paisaje. Pionera en la década de los setenta, cuando ya advertía desde la geografía acerca de la globalidad e integración de elementos que definen el Paisaje. Su obra Manual de Ciencia del Paisaje, Teoría, métodos y aplicación (1992), que dirigió, además de redactar algunos capítulos, tuvo y conserva una gran aceptación e interés.

La progresiva concienciación ambiental y una mayor sensibilidad estética por parte de determinados grupos y colectivos ha beneficiado indirectamente al Paisaje; así se convierte en un concepto fundamental en la tradición académica geográfica de los dos últimos siglos. Hoy, además, es un elemento clave en las nuevas políticas de ordenación del territorio. Zoido, (2002) señala que el objetivo de estas políticas es hacer frente a su creciente deterioro. En este contexto, el Paisaje, según Nogué, (2011) es uno de los conceptos geográficos con una dimensión comunicativa más notable, ya que estamos asistiendo a un renovado interés por las relaciones afectivas y emotivas de la gente con sus lugares, con sus Paisajes, y este hecho, precisamente, vincula de manera muy estrecha la geografía con la teoría de la comunicación. De esta forma entramos de lleno en una geografía del mundo vivido, centrada en los valores y en el concepto de lugar como centro de significado, de identificación personal y foco de vinculación emocional. Se evoca un Paisaje que ya no es solo visual, sino también sonoro, táctil, olfativo, e incluso gustativo.

En los últimos años, el Convenio Europeo del Paisaje $(C E P)^{1}$ ha supuesto un paso importante en relación con el tratamiento y objetivos del Paisaje. El Convenio define el Paisaje como "cualquier parte del territorio tal como lo percibe la población, cuyo carácter sea el resultado de la acción y la interacción de factores naturales y/o humanos" (Consejo de Europa, 2000). La percepción es fundamental en su definición: el Paisaje es lo que se ve y se percibe y, por tanto, es diferente del espacio, es un concepto con su propia individualidad". Liceras, (2013) sensible a estos aspectos por ser a un tiempo geógrafo y profesor en la Facultad de Educación, señala:

el Paisaje es una realidad espacio temporal concreta, una expresión formal percibida e integrada por un conjunto de elementos, tanto visibles como invisibles, de origen natural, biológico y antrópico, relacionados entre sí, que constituyen un conjunto en continua

\footnotetext{
${ }^{1}$ El consejo de Europa impulsó la elaboración del Convenio Europeo del Paisaje firmado en la ciudad de Florencia en el año 2000
} 
evolución y transformación, al que cabe asignarle valores culturales y estéticos, y descubrir significados que interesa apreciar y proteger (p. 86).

Así mismo reconoce que el Paisaje es un elemento importante de la calidad de vida de las poblaciones y que es un elemento clave del bienestar individual y social, recomendando reforzar la educación en el Paisaje.

Hoy día el Paisaje puede retratarse como una realidad compleja en la que se mezclan naturaleza y cultura, una fusión de materia y espíritu (Liceras, 2013). El mundo educativo, que debe ser permeable a los cambios y a los progresos sociales, tiene que encontrar las fórmulas más adecuadas para alcanzar, en el ámbito de la enseñanza, los objetivos de sensibilización y formación establecidos en el capítulo segundo de la Convención Europea del Paisaje. Tal como propone la Convención, la enseñanza del Paisaje debe tener un carácter transversal, es decir, que debe afectar a las diversas disciplinas y niveles de enseñanza. Precisamente por eso nosotros creemos que la formación del profesorado constituye un ámbito idóneo para el efecto cascada que provoca la formación de los futuros educadores.

\subsection{DIVERSAS INTERPRETACIONES QUE EXPLICAN EL PAISAJE}

El conocimiento y comprensión de un Paisaje, especialmente si se considera desde su vertiente de recurso educativo, implica identificar sus elementos constitutivos, que son múltiples y diversos, jerarquizarlos, clasificarlos e interpretarlos, así como reconocer e interpretar los procesos que se generan en su seno y explican su evolución. Para su mejor comprensión, en la descripción y análisis de los elementos que forman un Paisaje conviene tratar sus características más importantes y las interrelaciones sistémicas más significativas que se originan entre ellos, teniendo en cuenta que cada uno de los elementos del sistema evoluciona de acuerdo a su propio ritmo.

Las formas y las apariencias manifiestan la naturaleza, las funciones y los usos del Paisaje, a la vez que constituyen los referentes perceptivos que incitan las apreciaciones subjetivas y estéticas sobre el Paisaje. Se habla de fenosistema para referirse al semblante que expone el Paisaje, al conjunto de sus elementos percibidos por los sentidos, y de criptosistema para aludir al conjunto de elementos y procesos no visibles que completan la realidad de los Paisajes. Todo Paisaje tiene una o varias funciones que crean su propia estructura (Liceras, 2013). 
Un observador que examinara el Paisaje podría conjeturar que, durante el largo período de desarrollo de la Tierra, este habría presentado distintas formas y relaciones. En un principio el Paisaje habría estado constituido solamente por los elementos físicos o abióticos. La aparición de vida sobre la tierra habría aportado nuevos elementos al Paisaje, pasando éste a ser físico y biótico. Con, la humanidad el Paisaje se habría convertido gradualmente en un sistema físico-biótico-antrópico, y como consecuencia, en este momento es posible agrupar los distintos elementos que configuran el Paisaje en tres conjuntos: abiótico, biótico y antrópico. Los tres tienen en común los elementos químicos de que están compuestos, pero cada uno de ellos está organizado de forma distinta, y todos cambian continuamente. El ser humano que es un organismo biológico, debido a su naturaleza, necesidades y tecnología interviene en el Paisaje de forma muy distinta al resto de los elementos bióticos. La propia existencia del hombre pensante es la que hace que su actuación sobre el Paisaje se estudie, y se distinga de la de otros seres vivos o de las fuerzas de la naturaleza.

En los últimos años se está utilizando una terminología renovada para referirse a los elementos del Paisaje. Según las aportaciones de diferentes autores, entre ellos Fidalgo

la apreciación de un Paisaje está condicionado por un sistema complejo y dinámico en el que los diferentes componentes y variables (elementos pertenecientes a la estructura física del medio como expresión visual y a la percepción y valoración del Paisaje) se relacionan influyen mutuamente, determinando y siendo determinados por una coyuntura global (2014, p. 9).

De esta forma, el estudio del Paisaje está definido por dos vertientes distintas: una relacionada con los componentes visibles del territorio y otra relacionada con las variables que condicionan la percepción y valoración del entorno (Froment y Joye, 1987).

Además Fidalgo, (2014), para analizar los elementos del Paisaje utiliza la expresión Elementos visuales determinantes del Paisaje. En esta clasificación, los componentes visibles que configuran el Paisaje serían: antrópicos, bióticos, abióticos e introduce un nuevo componente el cósmico.

Partiendo de la complejidad que presentan los distintos elementos del Paisaje y teniendo en cuenta que el objetivo de este trabajo es analizar el Paisaje como recurso educativo, dividiremos los elementos en naturales y en antrópicos. 


\subsubsection{Análisis de los elementos naturales}

Los elementos de la estructura natural o geoecológica son múltiples y su elección responde a las relaciones que se establecen entre ellos y con los elementos de la estructura socioeconómica. Los elementos naturales que suelen tratarse en los estudios de Paisaje, sus características más importantes y algunas de las interrelaciones que originan son los siguientes y quedan recogidos en el cuadro 1.

\section{Cuadro 1. Elementos naturales}

\begin{tabular}{|l|l|}
\hline Relieve: & Morfología, altitud, orientación, pendiente. \\
\hline Litología: & Morfodinámica, dureza, permeabilidad, composición química. \\
\hline Clima: & $\begin{array}{l}\text { Temperaturas, precipitaciones, humedad atmosférica, evapotranspiración, } \\
\text { vientos, insolación. }\end{array}$ \\
\hline Agua: & Estado físico, cuantificación, localización, calidad del agua. \\
\hline Suelo: & $\begin{array}{l}\text { Profundidad, textura o composición granulométrica, porosidad, pedregosidad, } \\
\text { contenido de agua, características químicas. }\end{array}$ \\
\hline Vegetación: & $\begin{array}{l}\text { Estructura, composición florística, especies dominantes, grado de cobertura, } \\
\text { parámetros de las especies arbóreas, fitopatología. }\end{array}$ \\
\hline Fuente: elaboración propia
\end{tabular}

Se estudia el relieve porque el modelado de la superficie terrestre tiene un sinfín de relaciones con los demás elementos del Paisaje, es causa de varios procesos naturales y condiciona ciertas actividades antrópicas. Se destacan en él la morfología, de la que interesa tanto la forma (llano, ladera, montes, valle) como los procesos resultantes de ella (erosión, acumulación); la altitud, determinante de variaciones climáticas, de tipos de vegetación, de instalación humana entre otros aspectos; la orientación, asociada a variaciones climáticas por efecto de su exposición a factores externos (vientos, insolación y humedad), y la pendiente, limitante de ciertas actividades humanas y aspecto a considerar en la formación de suelos y en los procesos de erosión.

El estudio de las rocas - Litología- tiene relación con otros elementos de la estructura natural, como los tipos de suelo y de vegetación, la disponibilidad de agua y las formas del Paisaje. También se relaciona con la estructura antrópica en casos como la extracción de minerales y la construcción de infraestructuras. Se destacan en los estudios de Paisaje los tipos de roca y los procesos morfodinámicos asociados. El tipo de roca y la forma de erosión que registra ofrece distintas formas al Paisaje. Es el caso, entre otros, de los escarpes calcáreos, domos graníticos y los badlands. La dureza proporciona información sobre la aptitud de la roca para la formación de suelos y como recurso para la construcción, la permeabilidad se relaciona generalmente con los procesos de escorrentía y aguas 
subterráneas, y también es útil para destacar problemas de localización de infraestructuras. Por fin, la composición química y sus influencias, de gran importancia por los fenómenos que comporta, como su disolución y el ph de los suelos, y por su influencia en la riqueza de nutrientes y en los tipos de vegetación y de fauna.

El clima es otro de los elementos que configuran los distintos tipos de Paisaje. Generalmente se analizan, entre otras, las siguientes variables dependientes: Temperaturas máximas y mínimas, medias, distribución anual, etc. que influyen en los procesos abióticos, bióticos y en la actividad antrópica. Las precipitaciones, que en sus diversas formas y frecuencias posibilitan el desarrollo de la vegetación, el ciclo del agua y actividades humanas; la humedad atmosférica, cuyo mayor o menor contenido de vapor de agua en el aire influye en varias actividades humanas; la existencia de ciertos tipos de vegetación y fauna, y algunos procesos morfodinámicos como la hidrólisis. La Evapotranspiración, puesto que la pérdida de agua por la vegetación y la superficie del suelo es un dato a considerar en muchos estudios relativos a las comunidades vegetales, principalmente en bosques, prados y áreas agrícolas. Los Vientos se analizan generalmente por su procedencia, variación e intensidad con el fin de estimar sus efectos: polinización, dispersión de contaminantes, desecación y formas adaptativas de la vegetación. En cuanto a la Insolación, el número de horas de sol es un factor importante para el crecimiento de la vegetación, así como las variaciones topoclimáticas y para el desarrollo de actividades antrópicas como el turismo y los deportes.

El agua es esencial para la vida en la Tierra. Importan, entre otros aspectos, el Estado físico en que se presenta: líquido, hielo o nieve, vapor de agua, etc. que comportará fenómenos muy variados. Su Cuantificación permitirá conocer si es condicionante para la existencia de comunidades vegetales y para la instalación humana y su Localización es de suma importancia para cualquier estudio, así como la forma en que la masa del agua se dispone (ejemplo: lagos, ríos, corrientes subterráneas o manto freático). La Calidad del agua debe analizarse, cuando así se requiera, atendiendo a las características significantes en cuanto a utilización y consumo, tales como dureza, turbidez, potabilidad, salinidad o contaminación.

El suelo es la interfase de los elementos abióticos y bióticos, y soporte de las actividades humanas. El suelo determina las relaciones entre todas las formas de vida vegetal y es factor limitante para ciertos usos. Los aspectos más estudiados son su Profundidad, de la que depende en gran parte el desarrollo de las plantas; su Textura o composición granulométrica, que permite estimar su capacidad de retención de agua; la Porosidad, importante para conocer su aireación y drenaje; la Pedregosidad y afloramientos rocosos, 
que condicionan entre otras, las actividades humanas relativos a cultivos; su Contenido de agua, que determina la aptitud para el crecimiento de las plantas e informa de posibles problemas de intervención antrópica, como la contaminación de acuíferos, y por fin sus Características químicas: el contenido en materia orgánica, ph, sales, etc.; define las características del suelo y condiciona la existencia de las comunidades vegetales.

La vegetación es uno de los elementos más significativos de la estructura geoecológica por su interrelación con los demás elementos bióticos, y por su influencia sobre los elementos y procesos abióticos. En los estudios de vegetación suelen analizarse la Composición florística y estructura, pues la determinación de las especies que constituyen los distintos estratos permite una descripción y clasificación de la comunidad vegetal e informan sobre su estado dinámico. En actividades y ámbitos más especializados se analizan el Número de plántulas y plantones de las especies dominantes: su inventario permite conocer el poder regenerador de la comunidad vegetal y avanzar pronósticos; el Recubrimiento de los estratos: el porcentaje de cobertura de los estratos informa sobre la abundancia y grado de desarrollo de la masa vegetal; los Parámetros de las especies del estrato arbóreo: la altura, el diámetro de los troncos o su número de anillos informan sobre la madurez de las especies medidas e, indirectamente, junto con los datos de recubrimiento, dan idea de la biomasa de la comunidad. La Fitopatología: las enfermedades, plagas y otros síntomas informan del estado que presenta la vegetación.

El estudio de la fauna se concentra en las especies en estado salvaje. Debido a su movilidad, y porque depende básicamente de otros elementos, la fauna no desempeña un papel destacado en los estudios de Paisaje.

\subsubsection{Análisis de los elementos antrópicos}

La humanidad, a través de la historia, ha mantenido una profunda interacción con el Paisaje. Las primitivas actividades de recolección y caza incidían mínimamente en el Paisaje. Con la aparición de la agricultura y la explotación de recursos: madera, minería y agua, la intervención en el Paisaje fue ampliándose. Tras la revolución industrial y con el aumento progresivo de la población mundial, pocos son los Paisajes que no registran en algún modo la influencia humana.

El papel que la humanidad ejerce en el Paisaje es el de modificador e incluso el de creador de otros nuevos con el propósito de que se adapten mejor a sus necesidades. De esta forma puede llegar a supeditar el resto de los elementos del Paisaje a sus intereses, alterándolos o destruyéndolos o incluso transformándolos enteramente, aunque por otra parte intervenga también en su desarrollo y conservación. 
La influencia de las personas sobre el Paisaje suele resultar muy patente; no obstante, sus actividades, necesidades y cultura son muy complejas y de difícil evaluación. Para hacer el estudio de la intervención humana en el Paisaje suelen considerarse los siguientes aspectos que quedan recogidos en la siguiente tabla y que se explican en el cuadro 2 :

Cuadro 2. Elementos antrópicos

\begin{tabular}{|l|l|}
\hline Infraestructuras: & Distribución, localización, tipificación. \\
\hline Usos del suelo: & Funcionalidad \\
\hline $\begin{array}{l}\text { Explotación de } \\
\text { recursos: }\end{array}$ & Modalidades, frecuencia e intensidad, emisión de contaminantes. \\
\hline Datos demográficos: & Densidad de población, distribución de la población \\
\hline $\begin{array}{l}\text { Datos } \\
\text { socioeconómicos: }\end{array}$ & $\begin{array}{l}\text { Actividades económicas principales, renta per cápita e inversiones } \\
\text { de capital. }\end{array}$ \\
\hline Datos culturales: & $\begin{array}{l}\text { Vestigios y formas de explotación tradicionales del Paisaje, } \\
\text { preferencias culturales. }\end{array}$ \\
\hline Fuente: elaboración propia &
\end{tabular}

Las Infraestructuras, constituidas por elementos artificiales o construidos necesarios para que un lugar pueda ser utilizado en el desarrollo de algunas actividades. De estas interesa su Distribución y su Localización, para conocer el grado de antropización que registra el Paisaje. Por otra parte será útil conocer su Tipificación: la categoría y el tipo de infraestructuras permiten disponer de una información más completa que facilitará el conocimiento de la estructura socioeconómica y las posibilidades de actuación posterior.

Los Usos del suelo reflejan la distinta intervención espacial humana sobre el Paisaje para adaptarlo a sus necesidades. Su determinación es de fácil análisis con la ayuda de documentación gráfica. La Funcionalidad trata de indicar el uso de cada porción del territorio y del Paisaje en cuestión.

La Explotación de recursos se refiere a las Modalidades: la forma de explotación del Paisaje es muy diversa, y es preferible agruparla en actividades genéricas como agrícola, ganadera, caza, forestal, minería o recreación, si bien, en ocasiones conviene detallar su tipificación. La Frecuencia e intensidad de la explotación muestra que en muchas ocasiones las actividades no se desarrollan de manera continua, y debe por tanto examinarse en qué forma se realizan los distintos tipos. La explotación de recursos puede comportar Emisión de contaminantes de los que se identifican formas y tipos de contaminación. 
Los Datos demográficos informan sobre la antropización potencial del Paisaje. La Densidad de población puede informar acerca de la ocupación potencial del Paisaje y de la expansión de la actividad antrópica.

Los Datos socioeconómicos son los parámetros que pueden indicar una mayor o menor intensificación de la intervención antrópica en el Paisaje: Actividades económicas principales, Renta per cápita e inversiones de capital.

Los Datos culturales ilustran, en parte, la evolución del Paisaje y su estado actual cuando se registra una fuerte dominancia antrópica. Los Vestigios y formas de explotación tradicionales del Paisaje pueden condicionar la imagen del Paisaje actual, herencia de las actividades del pasado. Las Preferencias culturales orientarán sobre la forma de actuación y el grado de sensibilización respecto al medio.

Muchos de estos elementos pueden ser contenidos de las Ciencias Sociales en los diversos niveles educativos, y como tales los alumnos deberían de observarlos para comprender las relaciones e interacciones que se establecen entre ellos. Esto les permitirá la comprensión no solamente de elementos naturales y antrópicos que hay en un territorio y que configuran los Paisajes.

\subsection{CLASIFICACIÓN DE PAISAJES}

Ninguna ciencia puede existir sin disponer de una taxonomía y de una clasificación del objeto de estudio. La clasificación puede ser considerada como la etapa principal, y también como la Primaria y previa, de cualquier estudio científico. Hay que considerar, no obstante, la gran complejidad del objeto "Paisaje", puesto que hay gran cantidad y diversidad de elementos, formas, colores, dimensiones, escalas y relaciones que pueden establecerse en los Paisajes, haciendo que sea muy difícil establecer una clasificación única de Paisajes, multiplicando sus posibilidades de clasificación y sistematización.

Como señala Liceras, (2013):

cada Paisaje es único, no sólo desde la percepción individual de cada observador, sino también desde la expresión material de un sistema biofísico y natural, y el producto final de un proceso y una configuración histórica característica para cada territorio (p. 88).

Sigue diciendo este autor que el Paisaje es algo vivo que cambia y evoluciona a lo largo del tiempo, por tanto, tiene una historia. La evolución de un Paisaje nos muestra los cambios experimentados como resultado de las dinámicas naturales o de las acciones 
humanas. Yarham (2011) indica que: "La historia del Paisaje es nuestra propia historia" (p. 9). Es decir, el Paisaje es también un producto social, una obra colectiva, en definitiva un espacio cultural en la que el hombre desarrolla sus capacidades y valores, surgiendo así el concepto de Paisaje cultural. El concepto de Paisaje cultural se refiere al Paisaje como proyección de una sociedad en un territorio determinado (Liceras, 2013)

Existen diversas formas de clasificación del Paisaje y pueden ser tantas como los distintos enfoques que pueden seguirse al analizarlo. Si únicamente se persigue denominar un tipo de Paisaje para distinguirlo de otros adyacentes o próximos, cualquier baremo puede ser válido. Puede clasificarse por tamaño, por funcionalidad, por la descripción de uno o de varios elementos constituyentes, con relación al tiempo, al espacio, etc. Por tanto, son muchas las tipologías y clasificaciones del Paisaje que se han realizado y su validez estará en relación con el uso que se pretenda hacer de esa clasificación.

Para esta investigación hemos seleccionado varias clasificaciones que reflejan los aspectos más importantes del "Paisaje" $y$ las hemos analizado para estimar su utilidad para el objetivo de la tesis: el uso didáctico del Paisaje. Se resumen en el cuadro 3.

Cuadro 3. Clasificaciones de Paisajes

\begin{tabular}{|l|l|}
\hline Clasificación basada en la dinámica del geosistema & $\begin{array}{l}\text { Elementos abióticos } \\
\text { Elementos bióticos } \\
\text { Elementos antrópicos. }\end{array}$ \\
\hline Clasificación por sus características zonales. & $\begin{array}{l}\text { Zonalidad latitudinal } \\
\text { Zonalidad vertical } \\
\text { Azonalidad }\end{array}$ \\
\hline Clasificación según la escala temporal. & Período precuaternario \\
& Período cuaternario \\
& Paisajes históricos: \\
& Fase preindustrial \\
& Fase industrial. \\
\hline Clasificación según su funcionalidad & Paisajes naturales \\
& Paisajes artificiales \\
& Paisajes rurales \\
& Paisajes urbanos \\
\hline Clasificación regionalista & Tipos de Paisajes \\
& Unidades de Paisaje \\
& Asociaciones de tipos \\
\hline
\end{tabular}

\subsubsection{Clasificación basada en la dinámica del geosistema}

Para el modelo teórico de Geosistema, desarrollado entre otros geógrafos por De Bolós (1992) el Paisaje es el geosistema concreto que ocupa un espacio geográfico determinado. Aceptando que el Paisaje responde al modelo geosistema, se entiende por elementos estructurales aquellos que están interrelacionados entre sí formando un 
sistema y evolucionando en bloque, de tal forma que la alteración o modificación de uno de los elementos afecta al resto y, por consiguiente, al propio sistema, al Paisaje.

Según el esquema del geosistema, existen tres tipos de elementos estructurales del mismo: elementos abióticos, bióticos y antrópicos. Cualquier Paisaje responderá a una combinación determinada de estos elementos de modo que puede haber tantos Paisajes como posibilidades combinatorias puedan alcanzarse.

El objetivo primordial que persigue esta clasificación es poder dar cabida a cualquier tipo de Paisaje y permitir una comparación entre Paisajes de diversas partes del planeta ordenados según su estructura y funcionamiento como sistema. Es decir, un Paisaje de la zona templada y otra de la zona tropical probablemente funcionarán de forma similar independientemente de la zona climática en la que están enclavadas, ya que el intercambio de materia y energía y el tipo de elementos estructurales y su jerarquía de dominancias será similar. De esta forma pueden encontrarse Paisajes dentro del mismo rango clasificatorio independientemente de la zona geográfica en la que están ubicados, mientras que la mayor parte de las clasificaciones suelen encasillar los Paisajes de acuerdo a su localización geográfica. Esta clasificación por dominancias será, pues, aplicable a cualquier tipo de Paisaje, pero además puede utilizarse a diferentes escalas espaciales, hecho que no resulta posible en otras clasificaciones.

Para el docente que espera aplicar la clasificación al uso didáctico del Paisaje esta resulta extraordinariamente abstracta, pero el conocimiento de las interrelaciones puede en cambio facilitar la caracterización de Paisajes en otro modelo de clasificación.

\subsubsection{Clasificación de los Paisajes por sus características zonales}

La zonalidad se puede definir como la disposición regular de unidades, en cualquiera de las diferentes escalas espaciales, en relación con un gradiente de cualquier tipo, de energía, agua, etc. En este sentido se pueden considerar los Paisajes por su localización geográfica y por su disposición zonal o azonal.

La zonalidad latitudinal se define como la modificación regular de los rasgos del Paisaje correspondientes a las unidades que se extienden desde el Ecuador a los Polos de acuerdo con la latitud. La causa principal de la zonalidad latitudinal es la distribución de la radiación solar en las diferentes estaciones del año, debida a la esfericidad de la Tierra, unida a la rotación diaria que condiciona la desviación de los cuerpos en movimiento, incluyendo las masas de aire. La zonalidad latitudinal debe considerarse como un cambio regular de los diferentes Paisajes que se definen en ellas, cuyos geosistemas tienen rasgos, especialmente los de intercambio de materia y energía, 
semejantes. Se disponen más o menos simétricamente en relación al Ecuador y según unos determinados gradientes de energía que incluyen las aportaciones de las masas de aire que se difunden latitudinalmente. Se definen como Paisajes zonales todos aquellos que se distinguen dentro de cada zona por mantener igual su entrada de energía y riqueza en humedad. La teoría de la zonalidad latitudinal tiene como base, no sólo los cambios del balance de radiación y de la cantidad anual de precipitaciones, sino también las relaciones existentes entre ellos. La primera ley periódica de la zonalidad fue formulada por M. A. Grigoriev y M. I .Buduko (1992).

La Zonalidad vertical es la modificación de los rasgos del Paisaje de acuerdo con la altitud, que se ve influenciada por cambios en las temperaturas, en la presión atmosférica y en la humedad relativa del aire. Esta zonalidad define tanto a las zonas llanas, de acuerdo a su altitud, como a las montañosas, si bien las montañas se distinguen por la zonalidad vertical de las áreas planas por los contrastes creados por las vertientes. La modificación de los Paisajes debida a la altitud se aprecia en que difieren de los propios de la zona latitudinal donde se halla la zona. Con el aumento de altitud la temperatura del aire desciende. En áreas montañosas es característico el aumento (hasta determinada altitud) de las precipitaciones atmosféricas y la nubosidad; se acentúa la intensidad de los procesos erosivos con la escorrentía superficial, y se modifican las características de los suelos, de la vegetación y de la fauna así como las posibilidades de ocupación por parte de la comunidad humana.

La zonalidad altitudinal, en el fondo, es un conjunto azonal, ya que se halla condicionada básicamente por factores tectónicos. De tal forma, la zonalidad vertical es una manifestación directa de la interrelación entre las dos regularidades principales de la diferenciación: la zonalidad y la azonalidad.

La azonalidad, cambio o variante en la zonalidad, es un fenómeno regular debido principalmente a la distribución entre los continentes y los océanos, unida a las diferencias litogeomorfologicas, la correlación entre la superficie topográfica y el nivel freático y las diferencias en el carácter del drenaje de la superficie, que influyen directamente sobre suelos y vegetación. Las diferencias que muestran los Paisajes según su alejamiento o proximidad al océano se deben a que las masas de aire en el interior de los continentes son mucho más pobres en humedad, por lo que las precipitaciones se reducen notablemente.

La clasificación zonal de los Paisajes ayuda al docente a analizar las condiciones en las que se individualizan los Paisajes debido a las variables que se utilizan. Didácticamente 
presentan posibilidades de aplicación en determinados niveles educativos, uniendo el estudio del Paisaje a conceptos como la continentalidad, la latitud etc.

\subsubsection{Clasificación de los Paisajes según la escala temporal.}

La escala temporal nos presenta unidades de Paisaje de rango muy diferente según sea su distancia respecto al presente, la duración del período considerado y, naturalmente, el mayor o menor detalle de conocimientos que permiten obtener. Los Paisajes correspondientes en la "megaescala" a los períodos más antiguos de la historia de la Tierra, que son también los más largos, tan sólo disponen de los subsistemas abiótico y biótico. Durante el largo período precuaternario tiene lugar el establecimiento de las líneas básicas de la estructura abiótica de la epigeosfera.

Los Paisajes cuaternarios, período que se inicia, aproximadamente, hace $\mathbf{1 . 8 0 0 . 0 0 0}$ años y se prolonga hasta la actualidad, se caracterizan por unas determinadas formas de relieve, una flora y una fauna muy parecidas a las actuales. En su determinación destacan sus variaciones térmicas y de humedad debidas a las glaciaciones y, muy particularmente, la aparición de la especie humana.

Los Paisajes históricos arrancan naturalmente con la aparición del hombre, pero su acción sobre el Paisaje ha registrado fases muy diferentes. Durante el Paleolítico el hombre no tuvo una acción muy importante sobre el Paisaje. En el período Neolítico los avances técnicos y culturales del hombre son muy importantes para el Paisaje, pues se inicia la explotación de recursos para utilizar primero la piedra pulida y la cerámica y después los metales, así como la agricultura y la ganadería. A partir del momento en que el hombre nos empieza a ofrecer documentación escrita, aumenta extraordinariamente la información y la escala temporal del Paisaje que estudiamos se va reduciendo de manera que las unidades de medida pasan a tener unos años o incluso unidades menores. Aún dentro de esta etapa distinguimos una fase preindustrial en la que la humanidad explota los recursos minerales, construye infraestructuras y centros urbanos, aunque vive esencialmente de la agricultura, la ganadería y la explotación del bosque, mediante la cual se lleva a cabo una de las más graves destrucciones del Paisaje natural. El siglo XVIII marca un hito muy importante para el Paisaje con el paso de la primacía del subsistema agrario al industrial. Las industrias y las ciudades engendran polución y acumulación de residuos. Se sintetizan sustancias que no existían en los sistemas naturales y que pueden tener efectos inesperados. A ello se une el rápido crecimiento de la población desde mediados del siglo XIX. No es hasta mediados del siglo XX que una parte cada vez mayor de la población toma conciencia de su acción 
agresiva sobre el medio natural y se inicia una fase de reflexión y estudio de las reservas naturales.

La clasificación de los Paisajes de acuerdo al grado de persistencia de elementos de periodos históricos pasados puede ayudar al docente al decidir qué tipos de Paisajes puede trabajar en cada nivel, aunque no sea de aplicación directa.

\subsubsection{Clasificación de los Paisajes según su funcionalidad}

Carl Sauer (1889-1975) padre de la geografía cultural muy próxima a la antropogeografía de Ratzel y de la geografía humana de Vidal de la Blache - propuso que consideráramos dos tipos de Paisaje, el natural y el artificial. Argumentaba que a medida que el hombre se enfrenta a la naturaleza, existe entre los dos una relación cultural, que también es política, técnica, etc. Se trata de la huella del hombre sobre la naturaleza, perceptible de acuerdo a la función que desempeña en su vida social. Una división funcional del Paisaje puede clasificarlo en Paisaje rural, urbano o natural, con las respectivas divisiones dentro de cada tipo, y la función primordial en cada caso variará considerablemente: conseguir una producción agrícola-ganadera o forestal, en el Paisaje rural; cumplir unas funciones estratégicas, comerciales, administrativas, etc., en el Paisaje urbano, o la conservación del medio, en los Paisajes naturales.

El Paisaje natural es aquel que todavía no ha sido modificado por el esfuerzo humano. Si en el pasado hubo un Paisaje natural hoy prácticamente no existe, y aun así se consideran como tales aquellos en que el elemento dominante no es el antrópico, aunque puede estar presente. La dominancia corresponderá a los elementos abióticos, a los bióticos, o a los dos simultáneamente, y la ausencia de función, si se considera como un Paisaje anterior a la acción humana, se puede entender también como una función actual de conservación del medio. Los Paisajes naturales que quedan actualmente en la Tierra se localizan en áreas con rigurosas condiciones para la vida del hombre, desde zonas montañosas a desiertos y selvas.

Los Paisajes artificiales comparten el elemento antrópico como factor fundamental. No obstante, mientras en los Paisajes urbanos el elemento antrópico es predominante, en el Paisaje rural los elementos abióticos y bióticos tienen una importancia considerable.

Los Paisajes rurales se definen por lo relativo al campo y a las funciones relacionadas con actividades Primarias: agricultura, ganadería, silvicultura, y su diversidad se debe a las características físicas o abióticas del territorio, a la climatología, a las técnicas de cultivo o explotación empleadas, al régimen de propiedad y a la propia orientación 
económica. El Paisaje rural incluye el hábitat propio de las áreas donde se desarrollan estas actividades. La complejidad de los Paisajes rurales da lugar a una gran variedad, puesto que las interrelaciones y el juego entre elementos abióticos, bióticos y antrópicos es considerable.

La clasificación de los Paisajes rurales ha sido extensamente tratada por muchos autores, y realizada en muchos casos en función de las zonas terrestres, especialmente de áreas climáticas - Paisajes rurales mediterráneos, de la Europa del noroeste, del Asia monzónica etc.- junto con el tipo de explotación -tradicional o tecnificado- de tales áreas.

Los Paisajes urbanos se caracterizan por el predominio de los elementos antrópicos sobre los bióticos y abióticos. Su desarrollo es uno de los fenómenos característicos del siglo XX que afecta en la actualidad a todas las regiones mundiales, pero especialmente a los países menos desarrollados o emergentes, que están sufriendo una urbanización acelerada.

La energía que mantiene en funcionamiento la estructura urbana es básicamente antrópica. Una ciudad lo es cuando desempeña una o varias funciones urbanas: residencial, comercial, industrial, administrativa, intelectual, terapéutica, religiosa, militar etc. No obstante, los Paisajes urbanos vienen determinados también por la combinación de la morfología y las estructuras heredades y actuales (Bastie y Dezert, 1980), estructuras que son las que han dado lugar a las numerosas clasificaciones.

En esta clasificación, los elementos que determinan las características de los Paisajes proporcionan muchas nociones que están al alcance de los escolares de diversos niveles, por lo que se aproximan a las necesidades del docente que trata de definir sus objetivos sobre el conocimiento de los Paisajes. .

\subsubsection{Clasificación regionalista de los Paisajes}

Después de la firma del Convenio Europeo del Paisaje, los estudios del Paisaje han experimentado un impulso que se ha traducido en la realización de numerosos trabajos de ámbito regional. Uno de ellos es el trabajo realizado para el Atlas de los Paisajes españoles por Mata Olmo, y Sanz Herráiz, (2003), que en la línea de los estudios regionalistas clásicos consideran los territorios como únicos e irrepetibles, aunque se pueden estudiar a partir del análisis de la totalidad de los valores biofísicos y socioeconómicos. Este modelo permite alcanzar un buen conocimiento del territorio, aunque dificulta el establecimiento de generalidades y por tanto la clasificación. Mata y Sanz (2003) identifican, clasifican y cartografían los Paisajes de España con tres rangos jerárquicos en función de la escala de trabajo: «unidades de Paisaje», 1.263 en total, 
que se definen por su homogeneidad interna y las diferencias respecto de las unidades vecinas, los «tipos de Paisajes», son 116 y se definen agrupando «unidades de Paisaje» con estructuras que se repiten, y finalmente las «asociaciones de tipos», son 34, concretadas por semejanzas de elementos naturales.

Se trata de una clasificación que tiene el interés de referirse al ámbito más próximo y del que se pueden conseguir más y mejores conocimientos directos. Por lo demás no se podría transponer directamente con fines didácticos aunque sea un excelente instrumento de consulta. Ahora bien, puesto que en el Atlas se muestra la diversidad de los Paisajes españoles desde bases ecológicas y culturales estrechamente relacionadas, incluyendo la necesidad de intervención y la valoración patrimonial, resulta útil para seleccionar, a modo de ejemplos, aquellos Paisajes cuyo análisis pueda servir de modelo al docente. 


\section{CAPÍTULO II. EL PAISAJE EN LA EDUCACIÓN}

El tema central de esta tesis es el Paisaje como recurso educativo entendido no solo como aprendizaje geográfico, o de Ciencias Sociales sino entendido como un recurso que puede estimular un modelo educativo crítico y participativo. Por ello me gustaría comenzar con algunas reflexiones expuestas por el filósofo Joan Manuel del Pozo (2011), en relación con el Paisaje como valor universal partiendo de la característica de interdisciplinariedad que tiene el concepto de Paisaje con la adquisición de nuevas perspectivas en el libro Paisatge i educació (2011). Este autor, asume el reto de pensar sobre una materia que no le es conocida -el Paisaje- en beneficio de otra que le es muy próxima - la educación. En su aportación, del Pozo subraya que la perspectiva es determinante para el resultado final de la percepción de un Paisaje; es decir, existe, si existen las miradas desde diferentes perspectivas sobre él. Para este autor el Paisaje se trata como un valor, la ciudadanía como depositaria de tal valor, y la educación como la clave que ha de permitir al titular acceder plenamente al disfrute de ese valor ${ }^{2}$ (Del Pozo, 2011, p. 20)

Partiendo de esta idea, podemos decir que la educación es la clave con la que la ciudadanía, titular y depositaria del derecho al Paisaje, puede acceder al pleno uso y disfrute de su bien, de su valor y además, nos ayudará a fomentar una sensibilización adecuada respecto a los valores que tiene el Paisaje.

Para Spranger (Del Pozo, 2011): "Educar es transferir a otro, con abnegado amor la resolución de desarrollar de dentro afuera toda su capacidad de recibir y forjar valores" $y$, el Paisaje, es uno de los muchos valores que el educando puede recibir o forjar. Algunas personas pueden y quieren ser estudiosos del Paisaje, pero tenemos la necesidad de que todas las personas puedan ser educadas para acceder a su disfrute, como beneficio directo para su bienestar personal y colectivo.

Según Castiglioni (2011) el valor educativo del Paisaje se ha ido reconociendo progresivamente, cada vez con más intensidad a medida que se extendía la preocupación por el medio ambiente y la valorización del patrimonio. La educación, tanto la formal como la no formal y la informal en Paisaje es una condición renovadora e inexplorada para el desarrollo no sólo del individuo, sino de toda la ciudadanía.

\footnotetext{
2 "Per això, tractaré el paisatge com un valor, la ciutadania com a dipositària o titular d'aquell valor i l'educació com la clau que ha de permetre al titular accedir plenament al gaudi d'aquell valor. La noció de valor és, doncs, central".
} 
El Paisaje, considerado desde la perspectiva del currículo educativo, no es un objeto de estudio nuevo. Es motivo de atención disciplinar para cualquier docente en todos los sistemas escolares y en todas las etapas educativas. Sin embargo, el protagonismo del Paisaje y su tratamiento en la escuela ha cambiado a lo largo del tiempo.

De acuerdo con Liceras (2013)

el estudio del Paisaje es posible incluirlo en cualquier nivel de enseñanza, por su riqueza conceptual, procedimental y axiológica, su carácter de materia interdisciplinaria, su aplicabilidad y funcionalidad, y la posibilidad de adecuar su tratamiento didáctico al desarrollo progresivo de las capacidades cognitivas de los sujetos (p. 85).

Hay que enseñar y aprender a leer los Paisajes, sus hechos y sus símbolos como forma de conocer sus sentidos, de alcanzar la información necesaria para valorarlos como expresiones del patrimonio cultural de las sociedades que lo han vivido y lo habitan en la actualidad. Es decir, crear una sensibilidad y conciencia que mueva a la protección de los Paisajes, necesaria en la formación de toda persona.

Para Busquets (2010) el concepto de educación en Paisaje es relativamente reciente y responde a la reformulación actual de este concepto. Ha evolucionado de acuerdo con el progreso y con los distintos enfoques de las disciplinas que han dado una mayor atención a su estudio, principalmente la geografía y las ciencias naturales, pero ha sido con el Convenio Europeo del Paisaje (CEP), aprobado en el año 2000 en la ciudad de Florencia, cuando se ha producido el reconocimiento de la dimensión ciudadana y ética del Paisaje.

Siguiendo esta idea, Busquets (2010) define la educación en Paisaje "como la transmisión significativa de conocimientos y la generación de actitudes positivas hacia el Paisaje y sus valores". Además, señala que los vínculos que establecen los alumnos con el Paisaje varían según su edad, su grado de desarrollo cognitivo, sus capacidades intelectuales y su estadio de socialización.

Por tanto, desde la etapa de educación Infantil hasta la etapa de educación secundaria, e incluso de educación universitaria, existe un largo recorrido que permite utilizar una gran variedad de estrategias didácticas y de procedimientos de aprendizaje. En la definición de Busquets quedan recogidas las iniciativas promovidas por el Convenio Europeo del Paisaje, que parten del reconocimiento de los vínculos emocionales que establecemos las personas con los Paisajes y la interdependencia con la sociedad y los valores, todo ello, en el ámbito de la educación formal y no formal, dirigida tanto a los alumnos como al conjunto de la población. Es decir, se trata de incorporar la dimensión 
perceptiva y social en el estudio del Paisaje en la escuela, de tal manera, que el Paisaje sea algo vivido y experimentado por los alumnos para conseguir así desarrollar un sentimiento de ciudadanía con dimensión incluso europea.

El Consejo de Europa impulsó la elaboración del Convenio Europeo del Paisaje, firmado en Florencia en el año 2000. Este texto constituye el primer tratado internacional dedicado al desarrollo sostenible, un aspecto que comprende la dimensión cultural.

De comienzos del siglo XX datan iniciativas como -la Primera Conferencia Internacional sobre Protección de los Paisajes Naturales que se celebró en Berna en 1913relacionadas ante todo con la planificación y gestión del Medio Ambiente, y en algunas de ellas se incluye el concepto de Paisaje o referencias al mismo, como la Convención de 1940 para la protección de la flora y fauna de las bellezas escénicas naturales de los Países de América. No obstante, las referencias explícitas al Paisaje no reaparecen hasta 1972, año en que el Paisaje es expresamente mencionado por la Convención de la UNESCO sobre patrimonio mundial, cultural y natural. En efecto, dice el texto en su Artículo 1:

"A los efectos de la presente Convención se considerará «patrimonio cultural»:

- los monumentos: ...

- los conjuntos: grupos de construcciones, aisladas o reunidas, cuya arquitectura, unidad e integración en el Paisaje les dé un Valor Universal Excepcional desde el punto de vista de la historia, del arte o de la ciencia"

En esta Convención, dentro del Patrimonio mundial se incluyen los Paisajes culturales, considerados como una creación de las personas

"Los Paisajes culturales son bienes culturales y representan las 'obras conjuntas del hombre y la naturaleza'... Ilustran la evolución de la sociedad humana y sus asentamientos a lo largo del tiempo, condicionados por las limitaciones y/o oportunidades físicas que presenta su entorno natural y por las sucesivas fuerzas sociales, económicas y culturales, tanto externas como internas".

En los términos que se expresa el documento, está claro que existen y han sido consultados comités de expertos en la materia, y por tanto el concepto de Paisaje cultural viene siendo utilizado con anterioridad y durante bastante tiempo, como lo hacen otros documentos de UNESCO y del Consejo de Europa de los años 60. 
El antecedente inmediato del CEP fue la Carta del Paisaje Mediterráneo (Carta de Sevilla, 1992) un documento centrado en los problemas medioambientales y firmado a iniciativa de tres regiones mediterráneas, Andalucía, Languedoc-Rosellón y Toscana, con motivo del Día Mundial del Medio Ambiente y en ocasión de la Exposición Universal de 1992. Para valorar correctamente el CEP es primordial conocer si en los anteriores documentos e iniciativas se habían definido propuestas de sensibilización de la población y con qué alcance.

El documento de UNESCO de 1972 efectivamente tenía previstas acciones de sensibilización y educación, como es habitual en todos los de esta organización, pero su efectividad con respecto al Paisaje quedaba limitada por el carácter secundario atribuido al mismo. La Carta de Sevilla del 1992 en cambio recogió explícitamente entre las medidas a adoptar "Fomentar la sensibilización de las poblaciones y el desarrollo de una conciencia colectiva de los problemas del Paisaje" porque este ha ocupado ahora un lugar destacado. Esas medidas se han traducido hasta la actualidad en numerosas actuaciones para el conocimiento y disfrute de los Paisajes; no obstante, la gran mayoría son posteriores al año 2000, año de la firma del Convenio Europeo del Paisaje. En España su ratificación no llegó hasta el año 2008.

Ideas destacables del Convenio (Zoido, 2001) son, en primer lugar, la propia definición de "Paisaje", que según el Convenio Europeo del Paisaje es "cualquier parte del territorio tal como la percibe la población, cuyo carácter sea el resultado de la acción y la interacción de factores naturales y/o humanos": El Paisaje tiene que ser considerado por sí mismo, no reducido al medio ambiente o con otras significaciones, no tiene por qué ser adjetivado, pues todo territorio -se refiere tanto a los Paisajes que puedan considerarse excepcionales como a los Paisajes cotidianos o degradados- debe ser considerado como Paisaje, merecedor de protección jurídica y de gestión sostenible, así como de cooperación en el ámbito europeo. El Convenio Europeo del Paisaje no distingue entre el Paisaje cultural y el Paisaje natural. Su objetivo primordial es promover la protección, gestión y ordenación de los Paisajes, así como organizar la cooperación europea en ese campo, es decir, el Paisaje:

- desempeña un papel importante de interés general en los campos cultural, ecológico, medioambiental y social;

- constituye un recurso favorable para la actividad económica, y su protección, gestión y ordenación pueden contribuir a la creación de empleo; 
- es un componente fundamental del patrimonio natural y cultural europeo que contribuye a la formación de las culturas locales, al bienestar de los seres humanos y a la consolidación de la identidad europea;

- y por último un elemento importante de la calidad de vida de las poblaciones en todas partes, aunque la actividad humana está acelerando en muchos casos su transformación, por tanto, la base del Convenio Europeo del Paisaje es la relación entre población (sociedad) y Paisaje. Esto significa que la protección, gestión y planificación del Paisaje "implican derechos y responsabilidades para todos" y que "el Paisaje es algo que hay que cuidar y que si sólo es considerado como bien de consumo, perderá inevitablemente su valor, además de su atractivo" (Pedroli y Van Mansvelt, 2006, p. 129). Es más, el Paisaje se convierte así en una fuente de aportaciones para los jóvenes y contribuye a su crecimiento como personas, de esta forma no sólo es un objeto a enseñar sino de una herramienta educativa.

Desafortunadamente de forma paralela al aumento de la valoración social del Paisaje, se están produciendo importantes y rápidas transformaciones paisajísticas mal controladas y sin evaluación de sus consecuencias, con los subsiguientes efectos de degradación y alteración incontrolada de los Paisajes europeos. Las medidas propuestas por la Convención Europea del Paisaje pueden ser el instrumento decisivo para hacer frente a la paradójica situación del incremento del aprecio social de los Paisajes europeos frente a su progresiva degradación, y entre ellas la educación puede ser una herramienta fundamental para conseguir sus objetivos.

Así, en el capítulo II del Convenio Europeo del Paisaje, en el Art. $6^{\circ}$ se detalla un conjunto de medidas específicas, entre las cuales están las del ámbito de la educación. Comienzan éstas por la sensibilización, "Cada Parte se compromete a incrementar la sensibilización de la sociedad civil, las organizaciones privadas y las autoridades públicas respecto del valor de los Paisajes, su papel y su transformación". En consecuencia, en el apartado B. Formación y educación, cada parte se compromete a promover, entre otras actuaciones, "cursos escolares y universitarios que, en las disciplinas correspondientes, aborden los valores relacionados con los Paisajes y las cuestiones relativas a su protección, gestión y ordenación".

En el año 2008 el Comité de Ministros de los estados firmantes dictaron una Recomendación para la aplicación del Convenio Europeo del Paisaje (Consejo de Europa 2008) que tiene en cuenta los avances en el concepto de Paisaje en Europa y las diferentes experiencias, desarrolladas o en curso, que favorecen una aplicación del convenio. Lo hacen a través de una serie de Principios y Disposiciones. Los principios 
generales tienen por objeto proporcionar indicaciones sobre algunos de los artículos fundamentales del Convenio Europeo del Paisaje, y entre los Objetivos de los principios generales se pueden resaltar por su interés en el ámbito educativo los siguientes:

- Reconocer el papel fundamental del conocimiento. La identificación, caracterización y cualificación de los Paisajes constituye la fase preliminar de cualquier política de Paisaje. Esto implica un análisis del Paisaje en los planos morfológico, histórico, cultural y natural, y de sus interrelaciones, así como un análisis de las transformaciones. La percepción del Paisaje por la población debe ser también analizada, desde el punto de vista tanto de su desarrollo histórico como de su significado reciente.

- Promover la sensibilización. La implicación activa de la población supone que el conocimiento especializado sea accesible a todos, es decir, estructurado y presentado de un modo que pueda ser comprendido incluso por no especialistas.

- Poner en práctica la participación pública. "Todas las acciones emprendidas para la definición, realización y seguimiento de políticas de Paisaje deberían estar precedidas y acompañadas por procedimientos de participación de la población y los agentes afectados, con el objetivo de permitirles jugar un papel activo en la formulación de los objetivos de calidad paisajística, su puesta en práctica y su seguimiento."

Aunque el apartado que promueve la sensibilización más implicada en la educación ciudadana, los aspectos de conocimiento, percepción y participación se deben considerar como fundamentales.

El Consejo de Europa ha aprobado, entre otros, dos textos de referencia en relación con el Paisaje y la educación. El primero, la Recomendación CM/ Rec (2008) 3 del Comité de Ministros a los Estado miembros que está orientado a reforzar la educación en Paisaje a partir de la enseñanza de diferentes disciplinas en todos los niveles educativos. El segundo, la Recomendación R (98) 5 afirma que las acciones de pedagogía del patrimonio son una de las mejores maneras de dar sentido al futuro a la vez que se refuerza el conocimiento del pasado.

Así mismo, el Consejo de Europa ha llevado a cabo numerosos proyectos relacionados con el Paisaje y la educación. En concreto se puso en marcha en 1989 el proyecto Rin sin fronteras, considerado el punto de partida de las clases europeas de patrimonio, pasando por las Jornadas Europeas del Patrimonio iniciadas en 1991 que se celebran anualmente, y que desde 1999 organizan conjuntamente con La Comisión Europea dando a conocer bienes culturales inéditos, que pusieron de relieve la diversidad de los 
patrimonios y los diferentes conocimientos vinculados. La página del Ministerio de Cultura dedicada a estas jornadas informa, ilustra y constituye un recurso inestimable para los docentes. Las Jornadas del 2014 estuvieron dedicadas "Vivir nuestros Paisajes culturales."

Relacionados con los Paisajes urbanos, se han realizados los proyectos La Ciudad (1995) y Europa, de una Calle a Otra (2002). También los Paisajes rurales han sido objeto de atención de la guía del CEMAT (Guide européen d'obsevation du patrimoine rural) (2003), para invitar a todos los europeos a conocer, valorar y promover este patrimonio. Aunque no fuera ese objetivo, la guía es manejable y puede ser también utilizada por los docentes desde la enseñanza Secundaria.

A parte de los proyectos realizados directamente por el Consejo de Europa, esta institución ha apoyado otros proyectos que vinculan pedagogía y Paisaje. Destacan, por un lado, Experiencia Fotográfica Internacional de los Monumentos, impulsado desde el Gobierno de Cataluña y el Museo de Historia de Cataluña, centrada en la valoración de los monumentos dentro del Paisaje, y por otro lado, las universidades de verano sobre el Paisaje, organizadas por la fundación II Nibbio con la colaboración de la presidencia italiana y del secretariado general del Consejo de Europa con el objetivo de difundir el Convenio Europeo del Paisaje. Hay que mencionar también la revista del Consejo de Europa Naturopa, ahora Futuropa, pour une nouvelle vision du paysage et du territoire, ha dedicado diferentes números al Paisaje visto desde distintas perspectivas, con un número monográfico editado en 2005 y centrado en la relación entre Paisaje y literatura. EI No 03 / 2012 está dedicado a Espace public et paysage l'echelle humaine

Para terminar, no debemos olvidar dos informes muy relevantes encargados por la misma institución en relación con la educación en Paisaje: el primero titulado "Sensibilisation, formation et éducation" presentado en el 2002 y el segundo informe titulado "Education on Landscape for Children" (Castiglioni, 2009) que se presentó en la $5^{\circ}$ Conferencia del Consejo de Europa sobre el Convenio Europeo del Paisaje, celebrada en Estrasburgo en el año 2009. En este informe se recogen los contenidos del Convenio Europeo del Paisaje en relación con la educación en Paisaje, proponiendo metodologías, objetivos e instrumentos para este propósito y presentando incluso actividades y experiencias en el ámbito europeo, haciendo hincapié en la educación Primaria y secundaria, que han servido como ejemplos en la práctica educativa fuera y dentro de nuestro país

El informe (Castiglioni, 2010) está dirigido principalmente al ámbito de la escuela, en todos los grados de enseñanza; sus contenidos y métodos se indican en términos 
generales y, por tanto, pueden adaptarse a unas necesidades específicas. Además, estos contenidos del informe pueden aplicarse también a contextos extraescolares y a diversos lugares de formación. No obstante, aunque van dirigidos preferentemente a alumnos de enseñanza obligatoria, el informe puede proporcionar ideas para construir propuestas de educación en el Paisaje en la formación universitaria y en la educación permanente, implicando a los profesores y fomentando el desarrollo cultural en los estudios tanto científicos como humanísticos.

El informe consta de dos partes. En la primera se presentan los principios contenidos en el Convenio Europeo del Paisaje que sirven de referencia para la educación en el Paisaje, destacando la estrecha relación con la educación para el desarrollo sostenible. En la segunda parte, se enumeran los objetivos específicos, los instrumentos de la educación y propuestas de actividades en el Paisaje. Se parte de la definición de Paisaje propuesta por el Convenio, se identifican las etapas necesarias para adquirir una capacidad de lectura del Paisaje, considerado el eje de la educación en Paisaje, teniendo en cuenta los aspectos pedagógicos en relación con la educación de los sentidos y la educación científica y los instrumentos utilizados. En el mismo informe, se hace mención de las distintas responsabilidades de las personas involucradas en los proyectos educativos sobre el Paisaje e invita a prestar atención a la formación de los profesores y de los educadores.

Estos documentos trazan pues el camino a seguir en la educación: adoptar estrategias de enseñanza-aprendizaje transversales sobre el Paisaje, que incidan en el conocimiento, en la sensibilización y en la implicación activa.

\subsection{EL PAISAJE COMO RECURSO EDUCATIVO}

Los profesionales implicados en el cumplimiento de las medidas propuestas por el Convenio Europeo del Paisaje merecen una atención especial, sobre todo, el mundo de la escuela, en el que se sientan las bases de una ciudadanía responsable. Es el lugar donde deben descubrirse las potencialidades educativas que los procesos de educación en el Paisaje pueden ofrecer (Castiglioni, 2002). Estas potencialidades se pueden percibir tanto en el plano de las habilidades cognitivas, susceptibles de ser desarrolladas, como en el plano de los valores que es posible madurar. Pues la educación en el Paisaje, será una parcela especifica del contexto más amplio de la educación ambiental, tiene como finalidad "aprender a ver" como condición para "aprender a actuar." No debemos olvidar, como señalan Torruella y Hernández (2015): 
"los valores del Paisaje deben considerarse en los procesos educativos desde ópticas múltiples, como objeto de conocimiento, como instrumento procedimental y como factor proactivo en la formación de una ciudadanía crítica que debe decidir la gestión de su entorno y el futuro del planeta" (p. 10).

El Paisaje, tal como definía Bernáldez (2010) es "percepción plurisensorial de un sistema de relaciones ecológicas" y por eso ofrece una fuente de estímulos y recursos educativos inagotables que pueden ser utilizados como base de programas educativos y de sensibilización Benayas y López Santiago (2010). Estos autores añaden que se debe promover el enfoque adecuado de la sensibilización, la educación y la formación a través de unas metodologías y prácticas que nos permitan conocer de una forma más profunda y compleja el Paisaje.

Además, con respecto a programas sobre el Paisaje nos recuerdan algunos precedentes que tuvieron lugar a finales de los ochenta. La Countryside Commission en el Reino Unido editó unos excelentes materiales didácticos LooK at the Changing Countryside (1984) y Learning through Landscape (1990) cuya finalidad era implicar a la comunidad educativa en acciones concretas para la recuperación del Paisaje. Esta amplia trayectoria anglosajona se ha visto reflejada en España con diversas publicaciones centradas en la interpretación paisajística, como por ejemplo: Cañal, García y Porlan (1982), Heras (1989), Franquesa et al. (1996) Benayas (1992), Benayas et al. (1994) entre otras y fueron desarrolladas antes del Convenio Europeo del Paisaje.

El CEP, partiendo de los currículos escolares, recomienda desde el punto de vista pedagógico, que las actividades didácticas que se desarrollen a lo largo de la enseñanza obligatoria promuevan lo que Castigioni (2011) ha denominado los "valores asociados al Paisaje," no de una forma abstracta, sino abordando aspectos concretos relacionados con la protección, gestión y planificación. Estos valores serían: valores ecológicos, valores funcionales y económicos, valores históricos y culturales, valores emocionales, valores sociales, valores estéticos y valores del conocimiento de los procesos de transformación del Paisaje. De esta manera, las actividades educativas tienen que explorar tanto el campo de los sentimientos y las sensaciones como el campo racional, con un enfoque emocional y cognitivo a la vez, exigiendo una implicación muy personal de los niños/as y con una metodología tanto de análisis como de síntesis necesaria para comprender la compleja estructura sistémica del Paisaje.

Uno de los objetivos más importante de la educación sobre el Paisaje, desde el punto de vista metodológico, no es dar información a los niños sobre cada Paisaje, sino ayudarles a encontrar el modo de acercarse al Paisaje, es decir a leerlo, a valorarlo y 
finalmente a cuidarlo. Es más, deben entender que el Paisaje ha sufrido transformaciones tanto en el presente como en el pasado $\mathrm{y}$, por lo tanto, deben comprender las variaciones en la relación entre los seres humanos y su entorno a lo largo del tiempo.

Haciendo referencia a la dimensión social del Paisaje, el Convenio propone que las actividades educativas desarrolladas a lo largo de la escolaridad, no se centren sólo en un enfoque personal del Paisaje, sino que es necesario organizar actividades de grupo que pongan de manifiesto la importancia de compartir percepciones y opiniones diferentes para así aprender a aceptar la diversidad de opiniones, mejorar la capacidad para el debate y asumiendo el compromiso de que todos los ciudadanos tienen responsabilidad hacia el Paisaje. Es importante recordar que la educación en Paisaje es un aspecto importante de la educación de los ciudadanos del futuro respecto a cuestiones relacionadas con el desarrollo sostenible. Castiglioni (2011, p. 387) precisa que la "educación en Paisaje se puede considerar un modo de desarrollar la educación sobre desarrollo sostenible". El Paisaje representa las cuatro dimensiones del desarrollo sostenible: la natural, la social, la cultural y la económica.

En los últimos años la educación para el desarrollo sostenible ha sido y es un tema muy presente, ya que la ONU declaró la década (2005-1014), como el Decenio de la Educación para el Desarrollo Sostenible.

Resumiendo diremos que la educación en Paisaje tendría varias vertientes: la primera se trataría en educar en el Paisaje (conociéndolo); la segunda educar para el Paisaje (asumiendo responsabilidades) y la tercera educar por medio del Paisaje, utilizándolo como un instrumento en el crecimiento tanto individual como el de la sociedad.

\subsection{EXPERIENCIAS E INICIATIVAS EDUCATIVAS DEL PAISAJE}

En los últimos años han sido numerosos autores los que han reclamado la necesidad de potenciar el diseño y la aplicación de programas educativos basados en la interpretación del Paisaje, aunque éste no haya sido objeto de un tratamiento educativo sistemático en los currículos. No obstante, hay que resaltar que han existido y existen múltiples iniciativas: investigaciones, proyectos, jornadas, encuentros, experiencias, dirigidas a educar territorialmente a través del Paisaje, al principio de forma más dispersa y después del Convenio Europeo del Paisaje de una forma más organizada. 
Enumerar todos las iniciativas, los proyectos y las experiencias que se han realizado en el ámbito educativo en relación con el Paisaje es tarea casi imposible; seleccionaremos las que creemos han sido fundamentales para facilitar su aplicación y por su influencia posterior. La mayoría de éstas van dirigidas al alumnado de Primaria y Secundaria, pero es necesario trabajar con todos los niveles educativos desde la educación Infantil hasta llegar a la educación universitaria. Empezaremos por hacer referencia a la educación superior, ya que esta investigación tiene como protagonistas al alumnado universitario de la Facultad de Educación de Salamanca.

Hay tres redes que se han asociado para facilitar la aplicación del Convenio Europeo del Paisaje: RECEP-ENELC (Red Europea de Administraciones Locales y Regionales para el Convenio Europeo del Paisaje), la red de entidades universitarias UNISCAPE y, por último, CIVILS-CAPE, una red para ONGS dedicadas al Paisaje. Entre ellas, destacamos UNISCAPE cuyo objetivo es fomentar el desarrollo de programas de educación universitaria para poder aumentar la calidad de la educación del Paisaje e impulsar los intercambios de estudiantes y profesores. Según Pedroli (2009) para los estudiantes es muy importante practicar una observación consciente del Paisaje antes de recibir los conocimientos transmitidos por los profesores. El estudiante debe conocer un Paisaje concreto, distinguir las características observadas en el mismo Paisaje y los conocimientos teóricos que se le atribuyen. La finalidad de la educación universitaria, por tanto, sería fomentar el diálogo sobre el futuro de los Paisajes europeos y para ello se han puesto en marcha varias iniciativas, entre ellas destaca una página web ATLAS (www.atlas-eu.org), donde se ofrecen cursos sobre educación del Paisaje realizados en Europa, fomentando así la movilidad de los estudiantes y la formación en el ámbito afectivo.

En relación con la red RECEP-ENELC (entidad observadora) es importante señalar también del proyecto PAYS. MED.URBAN ${ }^{3}$ inscrito en el programa de cooperación territorial de la Unión Europea para el espacio mediterráneo. Este proyecto se ha desarrollado entre los años 2009 y 2011 con la participación de 14 regiones mediterráneas. Este proyecto ha culminado con la reciente publicación Sensibilización en Paisaje: un reto para el siglo XXI. En las recomendaciones de este texto se transmite que la sensibilización se ha de entender como un proceso de transmisión de conocimientos que se ejerce en todas las direcciones, desde quienes hacen las políticas

\footnotetext{
${ }^{3}$ El proyecto Pays.Med.Urban, ha reunido durante tres años a catorce regiones mediterráneas de diferentes Estados (España, Italia, Portugal y Grecia) y a la organización RECEP-ENELC alrededor del objetivo común de reflexionar y promover líneas de acción destinadas a facilitar la implementación del Convenio Europeo del Paisaje.
} 
hasta la población local, y al revés. Así mismo, recomienda establecer planes de estudio de Paisaje incluyendo disposiciones relativas a la sensibilización, la formación y la información de la población

En el año 2004, la Asociación Eslovena de Paisajistas elaboró El proyecto Nosotros Hacemos Nuestro Paisaje para fomentar la percepción que tienen los niños/as y los adultos de su entorno cotidiano y sensibilizarlos respecto a la calidad del Paisaje. El proyecto buscaba animar a todas las personas a observar el Paisaje y percibir sus cualidades con el objetivo de fomentar la sensibilización con el medio ambiente, el espacio y el Paisaje desde las edades más tempranas. La principal finalidad consistió en observar el Paisaje propio y representarlo por medio de dibujos, maquetas y fotografías. Participaron niños desde 4 hasta 15 años. Este proyecto obtuvo un gran reconocimiento por estar basado en la creatividad, así como por promover la reflexión sobre los valores del Paisaje entre niños y educadores. Este proyecto puede servir de modelo para programas educativos y de sensibilización. Es fundamental que la educación sobre el Paisaje y su papel en la vida cotidiana estén presentes en las diferentes etapas educativas (Bratina Jurkovic, 2011)

Entre las diversas experiencias destacaríamos "El Paisaje como instrumento de mediación cultural en las escuelas" (De Nardi, 2011) desarrollada por el Departamento de Geografía de la Universidad de Padua (Italia). Esta experiencia formó parte de las investigaciones sobre el Paisaje y las investigaciones sobre inmigración: si el Paisaje habla de la sociedad que lo produce, éste habla casi en todas partes de sociedades cada vez más multiétnicas, en la que los movimientos migratorios representan ya fenómenos estructurales. (Rotondi, 2007) El estudio se centró en adolescentes de origen no italiano, comparando sus percepciones sobre el Paisaje con las de sus compañeros autóctonos. La finalidad era estudiar en qué medida puede el Paisaje considerarse un punto de referencia para la identidad de las personas, especialmente de los inmigrantes. También se tomó como punto de partida la importancia de compartir lugares, sentimientos y emociones y cultivar actitud de diálogo y comprensión mutuos entre diferentes culturas.

Otra experiencia es Landscape Seeds "Un experimento de sensibilización con niños y para niños" (Romeo, 2011). Uno de los objetivos principales del Convenio Europeo es sensibilizar a la población sobre las cuestiones y los aspectos del Paisaje. Para conseguir este objetivo se planteó una experiencia en forma de taller en un parvulario del Ente Nazionale Canossiano di Formazione de Aci Bonaccorsi, localidad de la provincia de Catania (Sicilia) en el 2009. El taller está dedicado a niños de 4 y 5 años. 
El objetivo era sensibilizar a los niños sobre el Paisaje y las características del lugar donde viven, despertando su curiosidad y educándoles para mirar los elementos característicos del territorio, de modo que pudieran distinguirlos y que le diesen un valor, primero sensorial y emotivo y después se convirtiese en cognitivo.

Es necesario mencionar también la publicación "A Guide toUndertaking a Landscape Circle Study in Seven Easy Steps", escrita por Terry O'Regan (2011) en Irlanda, concebida como herramienta paralela de formación y de sensibilización. En esta guía, se señala que la visión circular del Paisaje puede aplicarse a proyectos concretos desde una perspectiva crítica.

Y por último, hablaremos de la Academia Europea para la cultura del Paisaje Petrarca, creada en el 2000 con el objetivo de aplicar el CEP, centrándose en la relación entre las poblaciones y el Paisaje. La Academia Petrarca está convencida de que para comprender los Paisajes y para buscar vías de desarrollo sostenible del Paisaje, el primer paso es educar la conciencia de las personas. Para conseguirlo organiza seminarios, conferencias y clases centradas en el Paisaje. Destacan sobre todo las prácticas de observación y planificación paisajística que se enmarcan dentro de proyectos organizados por granjas ecológicas, instituciones terapéuticas y sociales, empresas, organismos e instituciones vinculados a la protección de la naturaleza y el medio Ambiente (Bockemühl, 2011). Una vez enumeradas las experiencias a nivel europeo nos vamos a centrar en las que se han desarrollado en el ámbito español.

\subsection{EXPERIENCIAS E INICIATIVAS EN ESPAÑA}

La búsqueda de experiencias y recursos relacionados con el Paisaje en diversas fuentes y bases de datos bibliográficos arroja unos resultados muy significativos al respecto. E tema "Paisaje" con la materia "Educación y Psicología" aparece en 349 documentos, mientras que de "Patrimonio" con la misma materia "Educación y Psicología", hay 970, de "Medio ambiente" 1.560 documentos, de "Medio" 14.730 y de "Entorno" 4.921 documentos encontrados.

Delimitando más el tema, solo hay 88 documentos que asocian Paisaje y Educación, 349 en el caso del Patrimonio, 463 en Medio Ambiente o 2430 en Entorno. Este último concepto es el que primero aparece en aportaciones educativas de los años 70 , mientras que Medio Ambiente aparece en los 80; el Paisaje como tema educativo apenas aparece en esos años. Lo hará posteriormente, cuando el Paisaje se integre explícitamente en el Currículo de Educación Primaria en 1991. Visto desde la 
perspectiva del año 2015, resulta llamativo el interés que el Paisaje tiene en aquel currículo de Primaria -más que en el de Secundaria- de 1991, ya que en los posteriores currículos el Paisaje prácticamente deja de mencionarse.

Gráfico 1. Documentos: Paisaje y educación

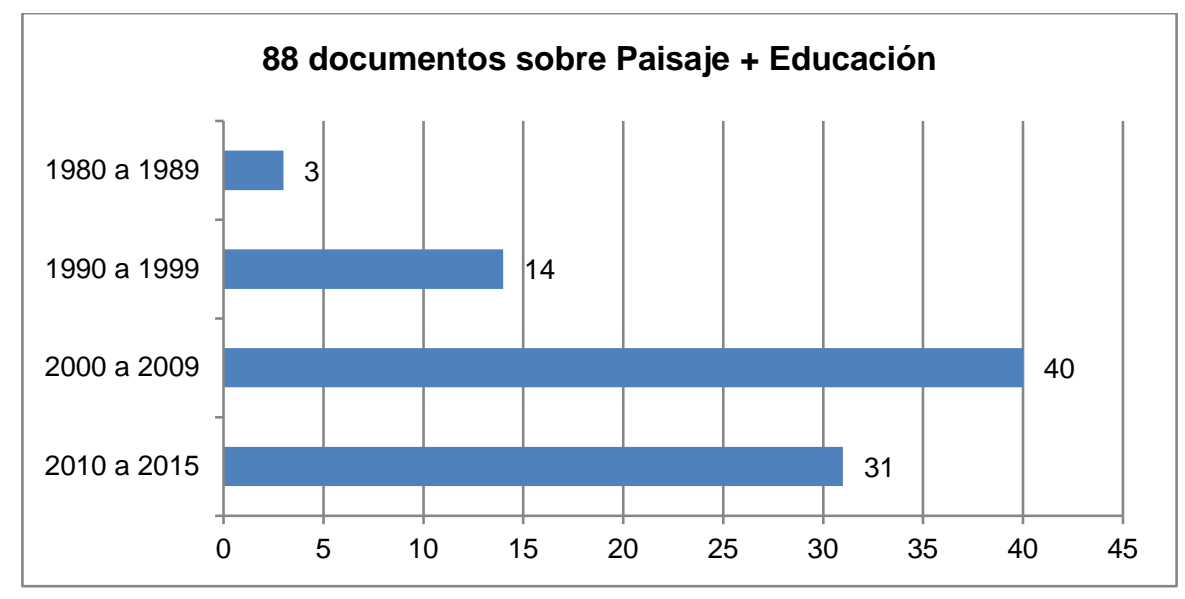

Fuente: elaboración propia

Gómez Ortiz (1993) puso de relieve el interés por el Paisaje en estos currículos, y reflexionó acerca de ello tomando el concepto geográfico de Paisaje -asimilado al de Medio natural y humano- cuando hablaba de la sensibilidad ante los temas de medio ambiente $y$ por derivación de los Paisajes que definen la superficie de la Tierra, en particular por su uso racional y conservación. En esos años hay efectivamente mucho trabajo hecho sobre el Medio en las escuelas, y por extensión, de acuerdo con lo citado de Gómez Ortiz, del Paisaje como medio ambiente y punto de encuentro entre Ciencias Sociales y Naturales, y como objeto de estudio geográfico que estudia las interacciones entre fenómenos naturales y culturales. Gómez Ortiz resaltaba también que

los actuales estudios sobre Paisaje tienden hacia una pluridisciplinariedad, dada la complejidad de los contenidos que lo definen, sobre todo, desde aquellos propios de las Ciencias de la Naturaleza a aquellos otros de Ciencias Sociales, lo que supone sin duda, una dificultad metodológica a la hora de abordar el "objeto de estudio" anticipándose y acercándose así a las formulaciones del Convenio Europeo del Paisaje.

Busquets Fàbregas (1993) advertía por las mismas fechas que el estudio del Paisaje en el ámbito de las Ciencias Sociales estaba siendo relegado a un segundo plano, mientras que el principal lo ocupaban las Ciencias Naturales desde la vertiente de la Educación Medioambiental. En cambio, el Paisaje considerado como la expresión de una combinación dinámica entre la naturaleza, la técnica y la cultura de la humanidad, quedaba desvirtuado por el tratamiento del Paisaje con carácter auxiliar, ilustrativo, en 
el desarrollo de temas de geografía, que se encontraba en muchos libros de texto. Deploraba la idea de Paisaje como sinónimo de vista panorámica, escenario natural singular o lugar de gran belleza, dentro del ámbito de la enseñanza, puesto que refleja sólo parcialmente, e incluso de un modo muy subjetivo, el concepto de Paisaje, mientras que tratarlo más allá de esos tópicos enriquecería notablemente sus posibilidades didácticas.

Las aportaciones más importantes a la educación en Paisaje realizadas por grandes organizaciones o instituciones se concentran principalmente en cinco entidades de diversa naturaleza: la Junta de Andalucía, a través de la revista Aula Verde, la Generalitat de Cataluña a través del Observatorio del Paisaje, El Instituto del Paisaje de la fundación Duques de Soria, la Asociación de Geógrafos Españoles (AGE) a través de la Revista Didáctica Geográfica, aunque frecuentemente su labor se refleja también en muchas revistas universitarias de Didácticas Específicas. La AGE enlaza a su vez con los numerosos recursos del Instituto Geográfico Nacional (IGN). A ellos habría que añadir los portales dedicados al Medio Ambiente de las Comunidades autónomas y el importante papel de la Editorial Graóo, a través de sus diversas publicaciones.

- La revista Aula Verde desde su creación en 1990 ha contribuido activamente al conocimiento del Paisaje y a su preservación desde un punto de vista medioambiental. Desde 1996 se convierte en una e-revista que ofrece abundante información en artículos completos de acceso libre sobre cómo se aborda la educación medioambiental en el territorio andaluz. Sus propuestas son siempre muy prácticas, dirigidas a la acción educativa y a la actuación sobre el medio, con lo que concurren en ellas el conocimiento, la concienciación y el comportamiento sobre el medio y por asociación, del Paisaje. Como ejemplo, el $\mathrm{n}^{\circ} 42$ del 2014 está íntegramente dedicado al Paisaje. Aunque en sus artículos el término "Paisaje" no aparece con frecuencia en los textos, es por el contrario muy abundante asimilado en la dirección mencionada de Gómez Ortiz, y explica que es fuera en Andalucía donde se gestará la iniciativa que culminó en el Convenio Europeo del Paisaje.

- La Asociación de Geógrafos Españoles encabeza la labor de promover y divulgar entre los docentes la educación en Paisaje de acuerdo con el CEP. En colaboración con el Instituto Geográfico Nacional / Centro Nacional de Información Geográfica mantiene un recurso didáctico en su página web destinado a profesores de Geografía. Es un complemento de los manuales de la asignatura de Geografía de España de Bachillerato: un conjunto de fichas de Paisajes españoles que proporcionan ejemplos donde se puede encontrar información geográfica integrada, que normalmente aparece dispersa 
en distintas fuentes. Las imágenes (mapas, fotografías aéreas y fotos) se complementan con un breve texto explicativo. El recurso contiene también una experiencia piloto y unas sugerencias didácticas basadas en los primeros resultados obtenidos en esa experiencia piloto: objetivos, contenidos, metodología, criterios e instrumentos de evaluación y una breve bibliografía. Es un recurso que podrían haber utilizado los profesores de bachillerato de los alumnos que cursan actualmente los estudios de maestro. Son muy interesantes los comentarios acerca de la metodología aplicable, que señala que el material estaba pensado inicialmente para el profesorado, pero que "los resultados han sido más satisfactorios cuando los alumnos lo han utilizado directamente en las aulas de ordenadores de los centros". Proponen actividades muy variadas que dependen de los recursos disponibles como búsquedas en la web, comentarios de textos mapas e imágenes, localización, observación, descripción, identificación y análisis de procesos espaciales, evolución, transformaciones recientes, problemas y propuestas de mejora, búsqueda de semejanzas y diferencias o comparación entre dos o más ejemplos.

La AGE además, a través de la documentación complementaria de su recurso didáctico, difunde una aportación de la Fundación La Caixa a la educación en Paisaje, dentro de su Portal de recursos educativos. Dentro de ella el recurso: es el más ajustado al concepto Paisaje, del cual se proporciona una descripción muy en la línea del Convenio Europeo del Paisaje, unos objetivos didácticos, competencias a adquirir y ejemplos de uso. El recurso es interactivo y permite trabajar el concepto de la intervención humana en el Paisaje y sus repercusiones. Finalmente, como prueba de la importancia de la labor de la AGE para la educación en, por y para el Paisaje, el grupo de Didáctica de Geografía de la AGE publica la revista Didáctica Geográfica, en la cual se recogen asimismo numerosas aportaciones. La segunda época de revista editada desde 1996, tiene una versión on-line y libre. En estos nueve años, de un centenar de artículos se han publicado 10 con el Paisaje como tema central, y otros 19 con conceptos directamente asimilables.

- Por su parte el Instituto Geográfico Nacional (IGN), dispone también de un conjunto de recursos muy útiles para el estudio del Paisaje. En su web se encuentran en septiembre del 2015 hasta 275 resultados de Documentos sobre Paisaje, incluyendo enlaces a otros organismos, instituciones o editoriales que multiplican las posibilidades de hallar recursos, como por ejemplo el del Centro Virtual Cervantes de Paisajes de España:

- El Observatori del Paisatge es, desde el 2005, una entidad de asesoramiento de la administración catalana y de concienciación de la sociedad en general en materia de 
Paisaje. Creado para estudiar el Paisaje, elaborar propuestas e impulsar medidas de protección, gestión y ordenación del Paisaje de Cataluña en el marco de un desarrollo sostenible, uno sus principales objetivos es incrementar el conocimiento que tiene la sociedad catalana de sus Paisajes y apoyar la aplicación en Cataluña del Convenio Europeo del Paisaje, en concurrencia con la generalitat de Cataluña, la administración local, universidades, colectivos profesionales y el conjunto de la sociedad. El Observatorio se organiza en forma de consorcio y se incluye en la Ley de protección, gestión y ordenación del Paisaje de Cataluña. El Observatorio ha iniciado una nueva etapa bajo el nombre de CATPAISATGE 2020. Una de sus diez líneas de trabajo prioritarias es la dedicada a Educación, Formación y Comunicación.

No basta con educar en el Paisaje, también es necesario saber comunicar el valor de la educación en el Paisaje. La comunicación es una pieza clave en las sociedades contemporáneas y, en este sentido, debe aprovecharse el enorme valor comunicativo del Paisaje, auténtico portador de mensajes fácilmente descifrables para el conjunto de la ciudadanía.

Entre sus aportaciones recientes a la educación en relación con el Paisaje, en el marco de las propuestas del CEP, está la celebración del seminario internacional que, con el nombre Paisatge i educació se celebró en Barcelona el mes de noviembre de 20094. En 2011 se publicó el libro del mismo nombre, recogiendo las reflexiones allí expuestas por autores de diferentes países sobre la educación en el Paisaje de ámbito europeo y en el marco del Convenio Europeo del Paisaje. En él se recoge un conjunto de experiencias e iniciativas didácticas de distintas zonas y niveles educativos europeas entre ellos tres españolas: El Proxectoterra, el proyecto Ciudad, Territorio, Paisaje y el programa Paisaje dentro del portal Educalia (Actualmente Educaixa).

M. Déjeant-Pons (Nogué et al eds. 2011) sostiene que es posible y deseable fomentar la educación en Paisaje, la educación a través del Paisaje y la educación para el Paisaje, al igual que la educación para la ciudadanía engloba la educación sobre la ciudadanía, a través de la ciudadanía y en la ciudadanía. Este enfoque establecería un vínculo con el conjunto de la experiencia educativa de los alumnos, a la vez que desarrollaría una nueva conciencia de ellos mismos y de los otros, contribuyendo a reforzar el tejido social y las competencias y las aptitudes individuales y sociales. Nos parece muy interesante hacer una breve descripción de cada una de estas experiencias por la influencia que

\footnotetext{
${ }^{4}$ Celebración del seminario internacional Paitsage i educación, auspiciado por el Consejo de Europa, los Departamentos de Territorio y Sostenibilidad y de Enseñanza de la Generalitat de Cataluña, la red Europea RECEP-ENELC y la Obra social de CatalunyaCaixa.
} 
han tenido posteriormente tanto en nuevas publicaciones y en propuestas didácticas concretas.

El Observatori del Paisatge mantiene desde su creación una línea de trabajo educativa que se ha aplicado en numerosos centros con los materiales didácticos 'Ciutat, Territori y Paisatge", diseñados por los profesores Roser Batllori i Joan M. Serra. Este proyecto educativo "persigue potenciar el conocimiento del patrimonio paisajístico y sensibilizar a los estudiantes sobre la necesidad de preservar los valores paisajísticos y la toma de consciencia de la incidencia de la acción humana en el medio natural". Se trata de una propuesta interdisciplinaria que ofrece la posibilidad de trabajar los elementos naturales y humanos del territorio de forma integrada y a partir de la observación de Paisajes concretos y reales, sometidos a intensas transformaciones.

El proyecto es un recurso innovador para la educación del Paisaje que pretende sensibilizar y educar a los estudiantes en los valores del Paisaje, reforzando las competencias básicas y usando las posibilidades que las nuevas tecnologías ofrecen a la educación. Los materiales están diseñados para ser utilizados en la Educación Secundaria Obligatoria (12 a 16 años), pese a que, en función de la modalidad del trabajo adoptado y el nivel de profundización, pueden servir para otros niveles educativos. Se trata de unos materiales que pueden ayudar al profesorado en su tarea educativa. Desde el punto de vista didáctico el proyecto integra conocimientos y habilidades de distintas áreas de conocimiento, promueve el trabajo y el aprendizaje autónomo, así como el trabajo en equipo y la autoevaluación. Los contenidos y el análisis de cada Paisaje se articulan a partir de cinco conceptos clave: función, continuidad y cambio, conflicto y consenso, sostenibilidad e identidad; junto con conceptos sociales, naturales, de Paisaje o ambientales. Por tanto, se trataría de realizar un estudio interdisciplinar: espacial, temporal y social. Todos los materiales de este proyecto van dirigidos a los profesores de Ciencias Sociales y de Educación para la Ciudadanía, incluso para profesores de Ciencias de la Tierra y todos son susceptibles de adaptación para adecuarlos a las necesidades del grupo de clase.

El observatorio del Paisaje de Cataluña ha sido objeto de un reconocimiento especial de su labor por parte del Convenio Europeo del Paisaje en 2011.

El Comité Europeo de Ministros ha concedido una mención especial del Premio del Paisaje del Consejo de Europa porque consideran que la diversidad y riqueza de su proyecto educativo promueven responsabilidad de los ciudadanos y crear un modelo ejemplar para la educación basada en la participación y la conciencia pública. 
Para finalizar nos resulta muy interesante señalar una sugerencia que hacen los autores de este proyecto "es que los profesores analicen con sus alumnos, el Paisaje de su entorno siguiendo el mismo esquema propuesto en el proyecto Ciutat, territori, paisatge porque así se ayuda al alumnado a reflexionar y a implicarse en su comarca, ciudad o barrio" (Batllori y Serra, 2010, p. 25).

- El proxectoterra "El lugar dónde vivimos" es un proyecto educativo organizado por el Colegio Oficial de Arquitectos de Galicia en el año 2000. Estaba dirigido a las distintas etapas de la educación obligatoria con la finalidad de contribuir a mejorar la formación que los escolares de Galicia deben tener sobre la población, los espacios y los lugares que habitan. Se trataba de ampliar materiales específicos que amplíen o mejoren los contenidos que en la actualidad están a disposición del alumnado y el profesorado. Las ideas básicas de este proyecto fueron: universalidad, globalidad, integración curricular, generalidad, permanencia, diversidad, experimentación, interdisciplinariedad, vivencia e interterritorialidad. El objetivo del Proxectoterra era promover un pensamiento crítico sobre los espacios propios, sobre sus procesos de génesis y transformación a lo largo del tiempo. El Paisaje propio es un elemento fundamental en la configuración de la memoria personal y colectiva.

Este proyecto compartía objetivos con el currículo de Ciencias Sociales de la educación secundaria y con el Conocimiento del Medio de Educación Primaria. La finalidad de las propuestas era que el profesorado y el alumnado identificaran, los distintos ámbitos, contextos y formas de organización del territorio gallego. Para ello, establecieron escalas espaciales y temporales ajustadas a cada uno de los ciclos en la educación Primaria y para la educación Secundaria establecieron ámbitos de reflexión como la arquitectura popular y contemporánea e identidad territorial.

Se trataba de poner al alcance del profesorado nuevos recursos, formación y ámbitos de trabajo que posibilitarán el desarrollo de competencias del alumnado sobre realidades espaciales y temporales presentes y vividas con la mayor riqueza sensorial (Rosales Díaz y González, 2011).

- El programa Paisaje creado en el 2005 dentro del portal Educalia es un recurso que tiene como objetivo principal facilitar la labor educativa situando las tecnologías de la información y de la comunicación al servicio de finalidades pedagógicas concretas. Nace del resultado de más de 10 años de experiencia en el campo de la educación medioambiental del Departamento Educativo y Social de la fundación "La Caixa". Hay que mencionar que Educalia hoy, es propiedad de la Fundación Telefónica. Las actividades que se plantean en el programa Paisaje sobe pasan el ámbito escolar. Con 
la ayuda de los propios padres, familiares y educadores la web de Paisaje se convierte en una autovía que enlaza de manera natural y fluida el mundo real con el virtual y pasa a ser en un recurso con muchas posibilidades para descubrir, conocer y valorar el Paisaje cotidiano, ya sea natural, rural o urbano. Adquiriendo actitudes dirigidas a entender que el Paisaje es un indicador fundamental de la calidad de vida.

El programa se basa en el concepto de Paisaje como sistema abierto que intercambia materia y energía con el exterior y que está estructurado por una serie de elementos abióticos, bióticos y antrópicos interrelacionados y dinamizados por energías naturales y antrópicas que les permiten evolucionar en el tiempo. El programa presenta cinco apartados:"Observa", "Clasifica," "Investiga" y "Actúa" estos cuatro proponen juego virtual mientras que el quinto"Explora" invita a descubrir el Paisaje real, cercano o lejano con una guía que nos orienta para entender el Paisaje.

El programa Paisaje como instrumento educativo se convierte en tecnologías de aprendizaje y conocimiento al ser puesto en práctica por el profesorado, y éste a su vez, ve reforzado su papel de maestro y guía en el proceso de aprendizaje. El trabajo individual y colectivo que promueve el programa Paisaje está en la línea de los nuevos métodos dinámicos e interactivos de la virtualidad, pero el profesor será imprescindible para conducir logros y finalidades pedagógicas.

- El Instituto del Paisaje, responde a una propuesta de Eduardo Martínez de Pisón director del ciclo de seminarios de Medio Ambiente de la Fundación Duques de Soria entre 1996 y 1998. Está dirigido por un consejo rector compuesto por geógrafos, ingenieros, urbanistas, juristas y biólogos. Nace de la enorme preocupación surgida en los últimos años por la preservación del Paisaje. A partir del año 2010 colabora con la Universidad Autónoma de Madrid en la realización de Seminarios y Talleres sobre el Paisaje. Estos talleres iniciaron su trabajo en 2006 y tienen como objetivo elaborar un catálogo razonado de Paisajes castellano-leoneses, empezando por la provincia de Soria. La metodología es básicamente práctica y sobre el terreno

- Las Comunidades Autónomas a través de sus consejerías de Medio Ambiente y Educación, tienen siempre algún espacio de carácter educativo y orientación medioambiental, en ocasiones elaborados en colaboración con otras instituciones. Suelen ofrecer recursos didácticos sobre Medio Ambiente, Patrimonio, Identidad territorial etc., dentro de los cuales aparecen algunos dedicados al Paisaje, como el de Paisaje y toponimia trabajo plurianual del CPR de Nor-Occidente, orientado a la investigación, elaboración, experimentación y difusión de materiales sobre el entorno y el Paisaje; realizado por profesorado de Primaria y Secundaria, contiene doce unidades 
temáticas para trabajar el Paisaje y la toponimia en diversas áreas y materias a lo largo de la educación obligatoria.

Se pueden encontrar pues numerosos programas que no tienen como objetivo directo la educación en Paisaje, aunque en algunos de ellos se integra explícitamente, como en el curso Paisaje y Medio Ambiente: El Paisaje en la educación ambiental, algo más que un recurso. Organizado por el Centro de Documentación y Recursos para la Educación Ambiental de Cantabria en su Programa de Formación 2009, sus objetivos, esencialmente educativos pretenden comprender el Paisaje como una herramienta práctica de educación ambiental, entender la percepción del Paisaje como parte importante en un proceso educativo y exponer experiencias prácticas de educación ambiental, además de conocer los diferentes Paisajes, tanto naturales como urbanos, de Cantabria.

Otras Comunidades Autónomas, además de las actuaciones de Educación ambiental, tienen líneas de trabajo en las que el Paisaje cultural es el protagonista, y se centran en el ámbito del patrimonio. En esta misma línea se inscribe el Plan Nacional de Paisaje Cultural, en el cual el Paisaje cultural es definido como el "resultado de la interacción en el tiempo de las personas y el medio natural, cuya expresión es un territorio percibido y valorado por sus cualidades culturales, producto de un proceso y soporte de la identidad de una comunidad".

En esta línea en la Comunidad de Valencia se ha realizado una serie de experiencias escolares innovadoras que ponen en evidencia la necesaria reeducación emocional con respecto a la percepción y valoración de nuestro Paisaje. Partiendo de la pregunta ¿Cómo podemos contribuir, desde la escuela a la construcción de la cultura del Paisaje? un grupo de profesores de la Universidad de Valencia y de los CEIP de varios pueblos de Valencia han elaborado varios proyectos para trabajar tanto en aulas de educación infantil, como Primaria y secundaria.

En el proyecto de educación Infantil "Cuidamos los árboles" participaron los niños y niñas del CEIP de San Juan de Ribera de Burjassot. Los autores de dicho proyecto pretendían que el alumnado se relacione con los árboles de su entorno y de esta manera aprendan de una manera global y funcional la importancia del respeto al medio ambiente. Estos profesores piensan que es necesario que el alumnado esté en contacto con el ecosistema, por la enorme desconexión que se ha detectado entre las personas y el medio ambiente que le rodea. 
En Primaria el proyecto "Bon día, Turia" se desarrolla en el CEIP Mas de Escoto (Ribaroja de Túria), con la finalidad de mejorar el medio ambiente y la educación crítica en su alumnado. Los profesores que diseñaron dicho proyecto incidieron además, en abrir la educación a las necesidades reales del entorno. Es decir, se trató de un proceso de adquisición de competencias para la vida centrado en la pedagogía de la experiencia, la participación, la cooperación y la reflexión. Con estas experiencias los autores quieren evitar un conocimiento memorístico del entorno, pero si contribuir en los procesos de identidad e implicación ciudadana en la construcción de la cultura del Paisaje (AAVV, 2015)

- El Plan Nacional de Paisaje Cultural fue aprobado en la sesión del Consejo de Patrimonio Histórico celebrada en Madrid en 2012. Tiene como objetivo general la salvaguarda de los Paisajes de interés cultural. En el contexto de los compromisos del Convenio europeo del Paisaje, El Plan Nacional de Paisajes Culturales reconoce que puede contribuir a la introducción de los Paisajes culturales en la educación, y entre sus propuestas de actuación se contemplan acciones de formación, encaminadas a fomentar el conocimiento de los Paisajes culturales.

\subsection{EL PAISAJE Y LAS CIENCIAS SOCIALES}

El estudio del Paisaje está indiscutiblemente integrado en la Geografía desde que los geógrafos comienzan a interesarse por su definición y su objeto de estudio. El interés por el estudio del Paisaje se ha extendido no obstante sin haber adquirido suficiente trascendencia para la población, formada desde su infancia en nociones geográficas que no lo tienen por objeto de estudio. Por otra parte la concepción escenográfica del Paisaje como algo acabado, como el compendio de los elementos geográficos característicos de un lugar, persiste y predomina en el modo más común de conocer el mundo.

Algunos de los temas fundamentales para las CCSS están presentes en el estudio del Paisaje. En él se integran de forma indiscutible aspectos patrimoniales, sociales, históricos y naturalmente, geográficos. En el preámbulo del Convenio Europeo del Paisaje se recogen explícitamente estas relaciones:

Tomando nota de que el Paisaje desempeña un papel importante de interés general en los campos cultural, ecológico, medioambiental y social, y que constituye un recurso favorable para la actividad económica y que su protección, gestión y ordenación pueden contribuir a la creación del empleo. 
Conscientes de que el Paisaje contribuye a la formación de las culturas locales y que es un componente fundamental del patrimonio natural y cultural europeo, que contribuye al bienestar de los seres humanos y a la consolidación de la identidad europea.

Reconociendo que el Paisaje es un elemento importante de la calidad de vida de las poblaciones en todas partes: en los medios urbanos y rurales, en las zonas degradadas y de gran calidad, en los espacios de reconocida belleza excepcional y en los más cotidianos.

Tomando nota de que la evolución de las técnicas de producción agrícola, forestal, industrial y minera, así como en materia de ordenación del territorio y urbanística, transporte, infraestructura, turismo y ocio y, a nivel más general, los cambios en la economía mundial están acelerando en muchos casos la transformación de los Paisajes.

Deseosos de responder a la aspiración general de disfrutar de Paisajes de gran calidad y de participar activamente en el desarrollo de los Paisajes.

Convencidos de que el Paisaje es un elemento clave del bienestar individual y social y de que su protección, gestión y ordenación implican derechos y responsabilidades para todos.

En estos aspectos cabría resaltar que existen valores sociales colectivos atribuidos al Paisaje como espacio vivido, a su ordenación y formas resultantes, hasta el punto de interpretarlos como elementos o señas de identidad, así como instrumentos de participación democrática.

Así pues, el Paisaje se relaciona con la geografía y con la historia, en definitiva con las Ciencias Sociales, a través de los aspectos medioambientales, patrimoniales, económicos, identitarios y políticos. La consideración del Paisaje como integrador de todos estos aspectos le dota así de un gran potencial educativo. Además la utilidad del Paisaje para el buen gobierno del territorio redundaría en la educación para la ciudadanía, y haría más comprensibles las tareas de protección, gestión y ordenación del Paisaje. Las Ciencias Sociales son por tanto idóneas para acometer la educación ciudadana acerca del Paisaje, sin menoscabar la importancia de las Ciencias de la Naturaleza, imprescindibles para el ámbito del conocimiento, y las primeras en abordar los temas medioambientales. Es ineludible mencionar aquí la figura de Fernando González Bernáldez (1933-1992) salmantino, pionero de la ecología terrestre en España que tanto ha representado, por sí y a través de sus discípulos, para la educación medioambiental. Bernáldez tomó parte en iniciativas como participar en la elaboración de las recomendaciones de la Unesco en medio ambiente. Su obra más conocida es Ecología y Paisaje, publicada en 1981, en la que sintetizó sus aportaciones en torno a 
la estructura ecológica del Paisaje y a los modos en los que los humanos lo percibimos y apreciamos. La convicción de que en la educación ambiental se encuentra la clave para la solución de los problemas ambientales llevó al profesor González Bernáldez a tomar numerosas iniciativas en este campo. Inició las primeras investigaciones tendentes a valorar los efectos derivados de la aplicación de programas de educación ambiental.

Durante años, incluso siglos, las sociedades han ido modificando el medio, con la falsa idea de que el ser humano era su propietario. Este pensamiento ha ido perdiendo fuerza y en los últimos decenios, conceptos como medio ambiente, desarrollo sostenible y otros están más presentes en los contenidos del currículum, pero aún no de forma plena en todos los ámbitos sociales. Para producir un cambio es necesario partir de la educación, sobre todo de la educación formal, dónde el sistema educativo señale conceptos teóricos y prácticos (qué Paisaje enseñar), procedentes del ámbito científico y el docente haga una transposición didáctica para que los futuros ciudadanos los entiendan y los hagan suyos. Todo ello permitirá alcanzar un grado de competencia en su conocimiento y valoración. Esto es, conocer sus elementos y comprender el cambio que en ellos se produce y su proyección en la modificación del Paisaje, en definitiva de nuestro entorno. $\mathrm{Y}$ todo ello, sin olvidar la responsabilidad de las acciones individuales y colectivas

En el último año han surgido propuestas que consisten en enseñar y aprender a través del Paisaje cultural, entendido no sólo como contenido conceptual sino como procedimiento complejo pero fundamental en las ciencias sociales. Dice Rivero y Hernández (2015): “El cambio, la permanencia y los ritmos del tiempo histórico se observan en el proceso de creación del Paisaje cultural, que es modelado en función del uso del territorio, que no es ajeno a los valores compartidos de las sociedades que lo han habitado" (p. 7). La aparición de las nuevas tecnologías (TIC) junto con los recursos que ya se venían utilizando permite elaborar materiales didácticos que faciliten la interpretación y comprensión del Paisaje.

El Paisaje ha sido y es un objeto de estudio tradicional en la escuela, sin embargo a lo largo del tiempo los modelos pedagógicos y los enfoques geográficos le han otorgado un tratamiento diverso en los sistemas educativos españoles. A principios del siglo XXI, el Paisaje, sigue siendo objeto de conocimiento, desde una perspectiva interdisciplinaria y educativa. Los factores vinculados al Paisaje, definen escenarios interdisciplinarios e invitan desde una óptica didáctica, a las correlaciones entre variables espaciales y temporales (Torruella y Hernández, 2015). Estas autoras afirman que el interés por el Paisaje aparece de forma explícita e implícita en las distintas propuestas curriculares 
estatales y autonómicas de los últimos años, y tanto en los objetivos de área como en las competencias básicas. Analizaremos, por tanto, las propuestas sobre las Ciencias Sociales y en concreto sobre el Paisaje, que se recogen en los distintos, currículos de Educación Infantil y Primaria en las últimas leyes educativas de nuestro país.

El punto de partida va a ser la Ley General de Educación de 1970 en la que se regula y estructura, por primera vez en el siglo XX, todo el sistema educativo español. Conviene recordar que antes de esta ley, la Ley Moyano publicada en 1857 y a la Institución Libre de Enseñanza, y a su director y creador Gíner de los Ríos, cuya labor es ampliamente conocida en el ámbito escolar, demostrando la eficacia de la práctica de los itinerarios geográficos o excursiones dentro de la disciplina de Geografía. Y aunque no se menciona el Paisaje, la finalidad última de estas prácticas al aire libre era poner en contacto y dar a conocer los elementos que formaban parte de esa naturaleza, de ese medio en definitiva del Paisaje, que rodeaba al alumnado. Desde la perspectiva geográfica la tradición del itinerario continúa arraigada en el desarrollo de la práctica escolar. García de la Vega (2004) vincula los itinerarios geográficos con la valoración de los Paisajes. Para este autor

el itinerario geográfico es un recurso didáctico motivador, útil y valioso para el alumno, pues permite el desarrollo del conocimiento (crea y consolida conceptos e ideas) y conduce a valorar el significado del Paisaje (genera actitudes, comportamientos sociales y éticos) ( $p$. 81). 


\section{CAPÍTULO 3. EL PAISAJE EN EL CURRÍCULUM DE EDUCACIÓN INFANTIL Y PRIMARIA}

\subsection{LEY GENERAL DE EDUCACIÓN (LGE)}

La Ley General de Educación fue poco explícita en cuanto a los contenidos relacionados con el entorno en las Escuelas de Párvulos: dispuso una formación que "comprende juegos, actividades de lenguaje, expresión rítmica y plástica, observación de la naturaleza, ejercicios lógicos y prenuméricos, desarrollo del sentido comunitario, principios religiosos y actitudes morales" (MEC LGE 1970).

Mucho más explícitas fueron las Orientaciones pedagógicas para los Planes y Programas de Estudios de la Educación General Básica, que recogían entre otros objetivos generales "...el desarrollo de la capacidad de observación", así como "...la adquisición de un conjunto de conocimientos que familiaricen al alumno con la realidad y el mundo natural y social que le rodea", y "...la incorporación y desarrollo de actitudes básicas y de conductas deseables para facilitar la adaptación e integración del alumno en la sociedad y para vigorizar el sentido de pertenencia a la comunidad" (MEC 1970). Estos objetivos son los que se refieren más explícitamente al Área de Experiencia, que aparece así por primera vez en el currículo escolar español.

Decía el documento que estamos citando que en la primera etapa de la EGB, en el Área de Experiencia, se habían de integrar de modo global la iniciación a las Ciencias Sociales y de la Naturaleza, proporcionando la ocasión para poner en contacto a los escolares con la realidad circundante e iniciarlos en la observación y en la experimentación elemental y directa. Pretendía también a través de esta área despertar actitudes de convivencia y el sentido de responsabilidad y de pertenencia a la comunidad. Así pues las "Orientaciones" adoptaron por una parte un modelo de currículo que partía de las características psicológicas y madurativas de los niños que comenzaban su escolaridad, y por otra parte abandonaban el viejo currículo con asignaturas de Geografía e Historia, adoptando el modelo anglosajón que bajo la denominación de Ciencias Sociales agrupaba a un conjunto de conocimientos que detallaba más adelante y que actualmente conocemos bien.

Las sugerencias metodológicas advertían que es de singular importancia el contacto con el medio ambiente mediante salidas al campo y visitas en la localidad. Unas y otras deben ser cuidadosamente preparadas y motivadoras de trabajos de carácter complementario o de ampliación. Los aspectos susceptibles de desarrollo en estas salidas son muy 
variados, así como la recogida de material de todo tipo para su estudio y clasificación" (MEC 1970).

Los contenidos de Primera Etapa de EGB se presentaban en dos opciones indicativas, advirtiendo que no eran las únicas posibles, y que fuese cual fuese la selección que se hiciera de tópicos y unidades, el criterio que debía presidirla era el de poner a los alumnos en contacto con el mundo social y el de la naturaleza. Por lo que se refiere al medio social, lo destacable es que los entonces llamados tópicos partían del entorno más cercano al niño, proponiendo temas en los cuales se podían llevar a cabo experiencias directas: Nuestra Escuela, Nuestra casa, La ciudad o pueblo en que vivimos, Edificios importantes del pueblo o ciudad La familia, Participación en la vida familiar, El hombre trabaja, Las personas se necesitan entre sí, Convivencia humana en la familia, en la escuela, en el pueblo, Nuestra patria. Excepto éste último, los restantes temas admitían ser tratados con un talante educativo nuevo y distinto, circunstancia esta que fue aprovechada por muchos maestros.

La llamada Opción B, incluso, decía que esta opción tiene por objeto el estudio del medio y de la realidad circundante y partirá siempre del estudio de la localidad. En sus aspectos sociales, geográficos, históricos y culturales, se tratarán temas que aborden el medio ambiente, partiendo de la observación directa del entorno para ir incrementando paulatinamente los aspectos de contenido y profundidad" (MEC 1970). No olvidemos que es una opción que concierne a toda la primera etapa, hasta el quinto curso de EGB Sin embargo es interesante el recurso al medio ambiente como núcleo de la observación y la experimentación. Los tópicos que en este caso proponía para el Primer Nivel eran: Tu familia, Tu participación en la vida familiar, Tus compañeros, Tu casa, La calle, El pueblo en que vives, Tu escuela, Tu participación en la vida de la escuela, Las vacaciones, Tu patria.

Como podemos observar en el currículo no se menciona el concepto de Paisaje, sin embargo, si aparece el concepto de entorno, se trata de contenidos relacionados con el espacio próximo en el que vive y se relaciona el alumnado. También se empieza a utilizar por primera vez el concepto de Medio.

A finales de los años setenta el panorama sociopolítico de España comenzaba a cambiar velozmente. El fin de la etapa franquista y la nueva Constitución de 1978 que consagraba un Estado de las Autonomías, tiene su reflejo en la escuela. El año 1981 comenzó con la publicación de los Programas Renovados que regulaban las enseñanzas de Educación Preescolar y Ciclo Inicial de EGB (MEC 1981). 


\subsubsection{Las Ciencias Sociales en el Currículum de Preescolar}

La regulación de las enseñanzas de Preescolar se realizó de acuerdo con las directrices pedagógicas que habían inspirado la renovación del Ciclo Inicial de la EGB. Las enseñanzas mínimas estaban aquí también expresadas en forma de objetivos y perseguían fundamentalmente la socialización del niño y la formación de hábitos, actitudes y valores (MEC 1981). Un rápido repaso del contenido de las Enseñanzas para el Ciclo Inicial y Preescolar pone en evidencia la subordinación de los contenidos del Preescolar con respecto al Ciclo Inicial; las diferencias entre ambos se aprecian en los objetivos de cada nivel. En Preescolar el espacio objeto de las enseñanzas mínimas se extendía sólo hasta el pueblo (familia, barrio, pueblo).

\subsubsection{Las Ciencias Sociales en el Currículum de Primaria}

La Primera Etapa se había dividido en dos ciclos, Inicial y Medio. El ciclo Inicial correspondía a los dos primeros años de la anterior Primera Etapa, y en el currículo seguía existiendo el Área de Experiencia Social y Natural. Las enseñanzas se expresaban en forma de objetivos. Formaban el área tres bloques temáticos, de los cuales el primero, el Conocimiento de sí mismo, tenía un contenido propio del área de Ciencias Naturales, e incluía algunos objetivos sociales. En el segundo bloque temático: Conocimiento del medio, se relacionaban estrechamente aspectos sociales y de naturaleza, aunque en su mayor parte sus contenidos se referían también a la naturaleza. El tercer bloque temático, Desenvolvimiento en el medio, desarrollaba los contenidos propios del medio social, con una aproximación al mundo del niño que parte de su propia casa (familia, barrio, pueblo, comarca, provincia, región o nacionalidad y nación), ampliando progresivamente el espacio de referencia hasta el espacio-nación.

La Constitución de 1978 atribuyó a todos los españoles el derecho a la educación. Este derecho aparece en el Título Primero, artículo 27. Los principios que propugna la Constitución quedaron recogidos y desarrollados, en los últimos años en las siguientes Leyes: "Ley Orgánica reguladora del derecho a la educación" (LODE) en 1985; "Ley Orgánica de Ordenación General del Sistema Educativo” (LOGSE) en 1990; "Ley Orgánica de Calidad de la Educación" (LOCE) en 2002 (no entró en vigor); "Ley Orgánica de Educación" (LOE) en 2006 y "Ley Orgánica para Mejora de la Calidad Educativa" (LOMCE) en 2013. 


\subsection{LEY ORGÁNICA DE ORDENACIÓN GENERAL DEL SISTEMA EDUCATIVO}

Ley General de Educación representó la primera gran reforma educativa en España, veinte años, después, en 1990, se produjo la segunda reforma importante con la promulgación de la Ley Orgánica de Ordenación General del Sistema educativo (LOGSE). Esta ley transformó la estructura y la ordenación del sistema educativo español en profundidad. Nació tras una etapa de reflexión y movilización de distintos sectores de la sociedad hasta su aprobación. Y su principal aportación consistió en la ampliación de la escolarización universal hasta los 16 años de edad, haciendo efectiva su obligatoriedad y gratuidad durante un periodo de diez años, distribuidos entre Educación Primaria y Educación Secundaria Obligatoria. Además, se reorganizó y potenció la Educación Infantil hasta los 6 años, con una firme defensa del derecho de los niños/as a la educación desde su nacimiento. La nueva ley también produjo un cambio notable en la concepción del currículo escolar y su articulación a lo largo de las sucesivas etapas.,

"Ley Orgánica de Ordenación General del Sistema Educativo" (LOGSE) se publica en octubre de 1990, más concretamente en el B.O.E. de 4 de octubre de 1990. En su preámbulo dice que

\footnotetext{
Los sistemas educativos desempeñan funciones esenciales para la vida de los individuos y de las sociedades. Las posibilidades de desarrollo armónico de unos y de otras se asientan en la educación que aquellos proporcionan. El objetivo primero y fundamental de la educación es el de proporcionar a los niños y a las niñas, a los jóvenes de uno y otro sexo, una formación plena que les permita conformar su propia y esencial identidad, así como construir una concepción de la realidad que integre a la vez el conocimiento y la valoración ética y moral de la misma.
}

\subsubsection{El Paisaje en Área del Conocimiento del Medio}

Con la aplicación práctica de estos nuevos programas educativos se pretendía en el futuro un incremento en los niveles de concienciación de la población hacia sus Paisajes y un cambio apreciable en sus actitudes hacia el medio ambiente. En el marco de esa enseñanza globalizada e interdisciplinar a lo largo de la educación obligatoria, parecía adecuado científica, psicológica y didácticamente comenzar con el entorno concreto de Ios niños: la casa, la calle, el barrio, su Paisaje cercano. Con la reforma del Sistema Educativo y la implantación de Educación Primaria de 6 a 12 años, se reestructuraron las áreas de Conocimiento de EGB adjudicándoles nuevas denominaciones y enfoques. De esta forma, en esta ley y en las siguientes enumeradas hasta la entrada en vigor de LOMCE, los contenidos de las Ciencias Sociales se impartirán en el Área del Conocimiento del Medio Natural, Social y Cultural. 
LA LOGSE introduce un nuevo concepto, ya comentado, de Educación Infantil y el cambio se refleja también en el conjunto de documentos conocidos como Diseño Curricular (DC). En el de Educación Infantil (El), la organización del currículo en áreas y los contenidos de éstas tiene un carácter netamente diferente al de Educación Primaria (EP), y los objetivos para El responden a la autonomía real que se quiere dar a este nivel. Ambas comparten los objetivos de desarrollo de la autonomía personal del alumnado y la capacidad de actuar en ámbitos sociales en los que se integra, con confianza pero con conciencia de sus posibilidades y limitaciones. Se diferencian en los grupos sociales de pertenencia, que en EP se extienden a colectividades más amplias y más abstractas. Comparten la observación y exploración del entorno inmediato, pero El persigue más el fomentar la curiosidad, el interés, el respeto, el aprecio; EP trata de proporcionar a los alumnos los rudimentos de la aproximación científica al análisis del medio, y de fomentar una actitud indagadora, sensible y respetuosa con distintos puntos de vista pero crítica ante los distintos aspectos de la actuación humana (MEC 1992). Al comparar los currículos de Infantil y Primaria, no son precisamente los contenidos conceptuales los que marcan las diferencias citadas, sino los contenidos procedimentales y actitudinales. El acceso al denominado medio desde la escuela ha sido una aportación constante desde los distintos planteamientos de los movimientos de renovación pedagógica en el transcurso del siglo $X X$.

En los Diseños Curriculares Base, regulando las enseñanzas mínimas, se consagra el estudio del medio como elemento vertebrador de conocimientos y centro de acción educativa de un área específica de contenidos, la del Conocimiento del Medio Natural, Social y Cultural. La adopción, por primera vez, en el currículum oficial del sistema educativo de nuestro país, de un área de conocimientos directamente centrada en el estudio del medio se justifica porque si se acepta como válida la idea de que la sociedad, debe ser la fuente primera del currículum escolar, nos encontramos con la plasmación concreta y real de dicha sociedad en la vida del alumno, la constituye el medio o entorno donde el niño vive, se manifiesta y donde se desenvuelve diariamente.

En el Currículo oficial dice:

Se entiende por "medio" el conjunto de elementos, sucesos, factores y/ o procesos de diversa índole que tienen lugar en el entorno de las personas y donde, a su vez, la vida y la acción de las personas tienen lugar y adquieren una significación. El medio no es sólo el escenario donde transcurre la vida y se produce la actividad humana. Además, desempeña un papel condicionante y determinante de la vida, la experiencia y la actividad humanas, al tiempo que sufre transformaciones continuas como resultado de esa misma actividad. El ser humano no es ajeno al medio: antes bien, forma parte de él, e incluso la 
noción de medio alude no tanto al conjunto de fenómenos que constituyen el escenario de la existencia humana, cuanto a la interacción de ese conjunto con el agente humano (MEC 1992).

El análisis del currículo sobre el conocimiento del medio es relativamente reciente, al menos en nuestro país. Son las propuestas de autores como Stenhouse, Elliot, Carr y Kemmis o Gimeno, entre otros, las que abren la posibilidad de investigar sobre el currículum como instrumento para el desarrollo y mejora de la Educación. Los grandes proyectos curriculares, como el Humanities Curriculum Project, el Humanities Core Curriculum, Place, Time and Society 8/13, History 13-16 project han impulsado un cambio profundo no sólo en el papel del profesor, al promover su rol como investigador de los problemas profesionales que se plantea y formula, sino también del propio concepto de investigación didáctica y de desarrollo del currículo, abriendo el camino a estudios sobre, para y por el currículo. Esta tendencia, originada por la descentralización curricular que tuvo lugar en nuestro país durante la implantación de la LOGSE, estimuló el diseño y desarrollo de importantes proyectos curriculares, entre otros las propuestas del Grupo Cronos, Ínsula Barataria e IRES.

Las diversas Comunidades Autónomas con competencias educativas han interpretaron y adaptaron los currículos de acuerdo a sus peculiaridades. Esteve, Ramirez y Souto (1997) encuentran dos diferentes opciones respecto a la finalidad de esta área de conocimiento: por una parte la finalidad medioambiental, reflejada en los currículos de Andalucía y Canarias, y por otra la de la socialización en los valores de pertenencia a una determinada sociedad, caso de Cataluña y Galicia. Estas adaptaciones tienen su reflejo también en el currículo de Educación Infantil.

\subsubsection{El Conocimiento del Medio en el currículum de Educación Infantil}

El currículo de Educación Infantil se estructura en torno a tres áreas o ámbitos de experiencia: el área de Identidad y autonomía personal, el área del Medio físico y social y el área de Comunicación y representación. Cada una de las áreas tiene sus objetivos generales de etapa y contenidos, expresados en forma de conceptos, procedimientos y actitudes. No obstante, el trabajo en el aula debe ser presidido por el criterio de globalidad, y servirse de experiencias significativas para los niños (MEC 1992).

El área del medio físico y social se propone facilitar el descubrimiento, el conocimiento y la comprensión del mundo que rodea al niño en la El, su socialización en relación con grupos sociales de su entorno más próximo. Así lo expresan los objetivos del área del Medio físico y social para la etapa 3-6 años del ciclo de El, objetivos que dan una 
importancia tan notable a la socialización de los niños que todos excepto uno se dirigen a conseguir que el niño tome conciencia de su entorno social y se sienta parte de él. Los contenidos parten de la percepción sincrética, global, del mundo circundante en la infancia, y por ello los objetos, espacios, personas y grupos más próximos al niño son fuente de experiencias que, por medio de unas reglas de comportamiento y trabajo en el aula, y a través de la observación y la experimentación, provocan aprendizajes significativos. Esta área integra dos aspectos inseparables desde el punto de vista del trabajo en el aula, pero perfectamente distinguibles tanto por la especificidad de sus contenidos como por las disciplinas universitarias que han hecho de su estudio objeto de especialización. El conocimiento del medio físico corresponde a contenidos propios de las Ciencias Experimentales o de las Ciencias. El conocimiento del medio social y cultural corresponde a contenidos propios de las Ciencias Sociales. Los contenidos propios del conocimiento del medio social y cultural se distinguen perfectamente dentro del conjunto de los que componen el conocimiento del Medio: son todos aquellos que van dirigidos a la formación del pensamiento social de los niños, y que se refieren a grupos, fenómenos y productos sociales, al tiempo en el que estos suceden, y a espacios transformados por la humanidad.

\subsubsection{El Área del Conocimiento del Medio Natural, Social y Cultural en el currículum de Educación Primaria}

Con la aplicación práctica de estos nuevos programas educativos se pretendía en el futuro un incremento en los niveles de concienciación de la población hacia sus Paisajes y un cambio apreciable en sus actitudes hacia el medio ambiente. En el marco de esa enseñanza globalizada e interdisciplinar a lo largo de la educación obligatoria, parecía adecuado científica, psicológica y didácticamente comenzar con el entorno concreto de los niños: la casa, la calle, el barrio, su Paisaje cercano. Con la reforma del Sistema Educativo y la implantación de Educación Primaria de 6 a 12 años, se reestructuraron las áreas de Conocimiento de EGB adjudicándoles nuevas denominaciones y enfoques. De esta forma, en esta ley y en las siguientes enumeradas hasta la entrada en vigor de LOMCE, los contenidos de las Ciencias Sociales se impartirán en el Área del Conocimiento del Medio Natural, Social y Cultural.

En el Diseño Curricular Base dirigido a la enseñanza Primaria (6-12 años) se recoge la importancia del Paisaje como tema globalizador del Conocimiento del Medio. En este documento se hace referencia de forma directa a la necesidad de crear en los escolares una serie de actitudes, valores y normas que les permitan sensibilizarse hacia la conservación del Paisaje, incrementar su interés y curiosidad por identificar los 
elementos más característicos que lo componen y valorar la diversidad de los Paisajes existentes en el conjunto geográfico del Estado español.

El alumnado, a lo largo de la etapa de Educación Primaria, comprenderá y establecerá relaciones entre los hechos y fenómenos del entorno natural, social y cultural y contribuirá activamente a la defensa, conservación y mejora del medio ambiente. Por tanto, este tema va a estar interrelacionado con el Área del Conocimiento del Medio que sitúa el Paisaje como un contenido curricular básico de esta etapa. Tanto el tema transversal Educación Ambiental como los objetivos de etapa, de área y los contenidos del Conocimiento del Medio contribuirán a desarrollar su conocimiento y aprendizaje. La finalidad del área del Conocimiento del Medio, es la de ayudar a los alumnos a constituir un conocimiento de la realidad, en este caso del Paisaje que, arrancando de sus propias percepciones, vivencias y representaciones, se haga progresivamente más compartido, más racional, más descentrado con respecto a su propia subjetividad y, por ello más objetivo. El aprendizaje en esta área, como en el resto de las áreas, ha de arrancar de la experiencia global del alumno como punto de partida y como referente constante del proceso de enseñanza, introduciendo de forma progresiva una aproximación más segmentada y también más metódica. Este punto de vista más analítico permitirá discernir los diferentes componentes del Paisaje y profundizar en ellos sin perder de vista la perspectiva integradora.

Esta adecuación a la percepción y comprensión del Paisaje en los niños, y niñas se justificaría por el desarrollo intelectual y motórico que tienen en estas primeras edades y que le ayuda a introducirse en un universo mental y social cada vez más amplio, produciendo la estimulación de ciertos aspectos del desarrollo y de la adquisición de nuevas capacidades. Sólo cuando el niño y la niña consiguen una cierta sincronización entre los datos sensoriales y motrices propios, adquieren conciencia de la posición que ocupa su cuerpo frente al medio circundante. Para conseguirlo se parte de los preconceptos o esquemas cognitivos previos de los niños y niñas, en general, del conjunto de ideas, representaciones, disposiciones emocionales y afectivas, o modos de acción que el alumnado ha construido previamente y que traen a la escuela al comienzo de la etapa de Primaria. Estas representaciones son esquemas de conocimiento, sin embargo, intensamente subjetivos y rudimentarios, distorsionados por incoherencias y poco maduros, que han de ser inicialmente recogidos, pero finalmente rotos en una educación que permita acceder a la comprensión de la diversidad y complejidad de la realidad, en este caso concreto del Paisaje. 
Ausubel (2009) estableció una diferencia entre aquellos conocimientos provenientes de los aprendizajes espontáneos y los que constituyen el resultado de experiencias educativas anteriores. Y, como afirma Coll (1997), estos aprendizajes significativos son utilizados por el alumnado como instrumento de lectura e interpretación de los nuevos aprendizajes, que condicionan en alto grado los resultados obtenidos. Los aprendizajes significativos constituyen una inflexión en los conocimientos previos, que el alumnado debiera tener en cuenta en la articulación curricular. Más aún, en cuanto que configuran el arranque conceptual para generar nuevos aprendizajes.

Aisenberg (2006) concede relevancia al trabajo de los conocimientos previos en el proceso de aprendizaje para construir y transformar la realidad. Ahora bien, señala una condición, la existencia de una interacción con el objeto de estudio, en este caso el Paisaje. Esto significa que el docente, debe establecer un vínculo con el alumnado que le permita desarrollar su aprendizaje. Este vínculo corresponde a la motivación, interés, afectividad, en suma, depende de la estrategia didáctica adoptada por el profesorado.

Gurevich (1998) pretende alcanzar la organización sistemática y la clarificación de los conceptos, puesto que constituyen el entramado latente del propio currículo. Esta misma autora insiste sobre la estructura conceptual de la geografía para conocer e interpretar el sentido de los procesos actuales en la organización territorial. Por consiguiente, habrá que buscar aquellos objetivos afines a otras áreas, con el fin de implantar un currículo interdisciplinar e integrado en torno al Paisaje. Las aportaciones educativas al estudio del Paisaje recogen desde aspectos epistemológicos referidos al currículo como propuestas didácticas hasta distintas perspectivas disciplinar y globalizadora.

Gómez Ortiz (1993) ya resaltó el interés pedagógico del estudio del Paisaje y su vínculo con el currículo. Por un lado, el Paisaje se halla en la conjunción de diversas disciplinas, que analizan sus distintos elementos. Por otro lado, dicho análisis permite consolidar hechos, procesos y principios científicos. Por último, según Gómez Ortiz, la interpretación permite elaborar actitudes, valores y normas de interés social y cívico.

Liceras Ruiz (2003) ha ofrecido una aproximación psicoevolutiva del alumno al Paisaje, destacando dos fases. La primera corresponde a la percepción del entorno, como consecuencia del desarrollo espacial, una fase intuitiva regida por la exageración y el prejuicio. La segunda fase es reflexiva y atañe a la observación, donde la reflexión permite construir aprendizajes sobre el hecho observado.

Precisamente, García de la Vega (2004 y 2008) planteó la realización de un trabajo de campo como recurso didáctico para la valoración del Paisaje desde una perspectiva 
educativa. La clave de este trabajo estriba en la estrategia didáctica empleada, esto es, concebir un proyecto de trabajo donde el itinerario sea el núcleo de la trama.

\subsubsection{El «Paisaje» en los distintos bloques de contenidos}

La consideración conjunta del concepto de medio, de las dimensiones que lo configuran y de las capacidades de los alumnos cuyo desarrollo se intenta promover mediante esta área, permite establecer cuatro grandes apartados en torno a los cuales se organizan los contenidos propuestos. Éstos serán secuenciados en 10 bloques temáticos que se desarrollarán a lo largo de los tres ciclos de Enseñanza Primaria.

- Primer bloque de contenidos, «El ser humano y la salud»: el concepto Paisaje no aparece de una forma explícita. Sin embargo, al hablar del ser humano y de su salud, sí haría referencia, puesto que la conservación de los Paisajes y de la naturaleza es básica para el bienestar de las personas. En estas edades es oportuno iniciar el desarrollo de actitudes relacionadas con las conductas sociales que favorecen o perturban la salud ambiental, fomentando la sensibilidad hacia la limpieza y el respeto hacia la conservación y mejora del medio ambiente y tomando conciencia de las consecuencias de la propia actuación.

- Del segundo al quinto bloque de contenidos, los incluye en un ámbito denominado «el medio físico y sus relaciones». Siguiendo los criterios de secuenciación de contenidos del DCB:

- en el primer ciclo, el conocimiento del medio físico se caracteriza por su referencia al entorno físico inmediato y por el estudio de las características observables del Paisaje y de los elementos que lo constituyen.

- en el segundo ciclo, el medio físico de referencia se amplía a la localidad y a la comarca, capaces de interiorizar y de reconocer de forma comprensiva;

- en el último ciclo se observan y describen los elementos que configuran el Paisaje de la propia Comunidad y de España. Es necesario trabajar conjuntamente contenidos de distintos bloques. En concreto, el segundo y el tercero, por el tema que nos ocupa. En el segundo bloque, el concepto principal es el « Paisaje», centrándose en la vinculación del Paisaje con el medio natural mientras que en el tercero, el concepto principal es «medio físico».

Desde el último tercio del siglo XIX se han llevado a cabo investigaciones geográficas sobre las relaciones entre el hombre y el medio natural, integrando en ellas los procesos históricos de adaptación al ser humano y de la sociedad al medio, y dando contenido a 
muchos conceptos geográficos concernientes al ámbito rural y urbano. Es de esta forma como se venían entendiendo los conceptos de Paisaje rural y de Paisaje urbano, con su multiforme contenido.

Si analizamos los temas del bloque del « Paisaje», constatamos que comienzan con los elementos del Paisaje natural: el relieve, el clima, las aguas, la fauna y la flora. Para continuar con sus características más importantes y su ubicación y distribución en distintos espacios como son la comarca, la comunidad autónoma y España. Se hace una división del territorio en función de las características naturales del Paisaje. Finaliza con nociones en las cuales se pone en relación el medio natural y la acción del hombre. Los procedimientos se caracterizan por el estudio de las características observables del Paisaje y los elementos que lo constituyen. Esto les permitirá comparar, señalar semejanzas y diferencias y realizar sencillas clasificaciones de los distintos Paisajes que van conociendo. Las actitudes se centran en despertar en el alumnado la sensibilidad y la curiosidad por los Paisajes, partiendo de los que les rodean, para conocer y valorar su diversidad y riqueza. Y así hacer partícipe a los niños y niñas en su conservación.

- Del sexto al noveno bloque de contenidos formarían parte del ámbito denominado «Medio social y sus interacciones con el medio físico»:

- en el primer ciclo de Primaria, los contenidos están en relación con el conocimiento de los grupos sociales de pertenencia y referencia, que se concretan en el grupo familiar y el aula dejando las agrupaciones más amplias como la localidad, Comunidad Autónoma y Estado para los ciclos siguientes. La complejidad de la organización social aconseja trabajar en este ciclo los contenidos referidos a los grupos sociales cercanos a la experiencia del alumnado;

- en el segundo ciclo se inicia el conocimiento de las instituciones de participación y de gobierno locales. También aumenta la capacidad de comprender las interacciones que se dan entre las personas y el medio físico ampliándose con la identificación y clasificación de actividades laborales más relevantes de su localidad y algunos problemas asociadas a ellas. En este ciclo se trabaja la relación entre los usos que hacen las personas de los recursos naturales (agua, aire y suelo) y algunos de los problemas ambientales que se generan;

- en el tercer ciclo los contenidos que se desarrollan se refieren a las organizaciones sociales y políticas, a los órganos de participación y gobiernos autonómicos y estatales junto con el funcionamiento de los servicios básicos que estas instituciones gestionan. Así mismo, trata sobre el impacto de la actividad 
humana en el ambiente que contribuye a comprender las interacciones hombremedio y desarrollar actitudes positivas hacia la conservación del medio e intentan mejorarlo a través de su propia acción.

En el análisis de los bloques de contenidos referidos a la dimensión del «Medio social y sus interacciones con el medio físico», observamos que las relaciones de las personas con su entorno se analizan a partir del concepto de población como unidad de estudio, prescindiendo de la valoración de los comportamientos individuales. Pero la unidad «población» no es sino una, dentro del conjunto de variables que, constituyen, lo que denomina Plata Suárez, (1993) «ecosistema Social»: El medio ambiente, la población, la organización social y la tecnología (arte y técnica). Además es evidente la correlación que hay entre el «ecosistema social» y los ecosistemas naturales.

- El décimo y último bloque de contenidos del área del Conocimiento del Medio natural, social y cultural es: «cambios y Paisajes históricos». Los contenidos históricos en Educación Primaria tienen como finalidad que el alumnado llegue a alcanzar un conocimiento del medio, en sus distintos componentes: natural, social y cultural. Esta etapa, por las características psicopedagógicas y evolutivas que presenta el alumnado, no permite un aprendizaje del conocimiento histórico en profundidad. Sin embargo, el análisis histórico que se hace permite abordar las cuestiones ambientales dentro de un marco amplio de relaciones espacio-temporales en el que la dialéctica hombre/medio se constituye en factor explicativo de los acontecimientos del pasado a la vez que viene condicionada por ellos.

La Historia se convierte, por tanto, en una disciplina eficaz para el análisis de algunos aspectos básicos dentro de la panorámica ambiental. El estudio de las relaciones de las personas con su entorno natural y urbano se enriquece desde la perspectiva histórica, porque nos ayuda a comprender la forma en que se han ido conformando a través del tiempo las pautas de comportamiento de los grupos humanos respecto al medio ambiente. En este bloque aparece el término « Paisaje histórico» que enlazaría con el de Paisaje como Patrimonio. La Convención de UNESCO sobre Patrimonio mundial, cultural y natural de 1972 definió el Patrimonio Cultural y el Patrimonio Natural (Bajo Bajo, 2001).

En la nueva concepción de los contenidos (conceptos, procedimientos y actitudes), significa que los tres tipos de contenidos deben trabajarse con los 10 bloques, incluido el de "Cambios y Paisajes históricos". Normalmente se han trabajado los conceptuales y procedimentales, siendo los contenidos actitudinales los menos desarrollados. Sin embargo, de los que se proponen en el área, son varios los que deberían desarrollarse en 
relación con el Paisaje. Se observa que la interiorización de actitudes, normas y valores coincide con los principios de la educación ambiental, que propugna una educación a favor del uso racional del medio.

Es importante señalar que cuando se implanta esta ley, aunque había ya numerosos estudios en relación con el Paisaje, todavía no estaba aprobado el Convenio Europeo del Paisaje, que supuso un punto de partida para trabajar el Paisaje en el S XXI. Desde la década de los noventa hasta el momento actual, la política educativa se ha debatido en torno a la aplicación de tres principios clave: la calidad, la libertad y la equidad. En este periodo de veinticinco años se han aprobado varias leyes educativas, pero no se han hecho grandes reformas. Es más, la estructura del sistema educativo continúa siendo la establecida en la LOGSE, con algunos cambios de cierta importancia. Por tanto haré referencia a Ley Orgánica de Educación (LOE) y Ley Orgánica de Mejora de la Calidad Educativa (LOMCE), ya que Ley Orgánica de Calidad de Educación (LOCE) no entró en vigor.

\section{3. LEY ORGÁNICA DE EDUCACIÓN (LOE)}

La Ley Orgánica de Educación es aprobada en el año 2006. La estructura es similar a la establecida en la LOGSE, siendo una de las novedades la incorporación a esta ley las competencias básicas al currículo que permite caracterizar de manera precisa la formación que deben recibir el alumnado y reforzar el aprendizaje a lo largo de la vida, dentro y fuera del sistema educativo. Torruellas y Hernández (2015) señalan que desde el punto de vista de las competencias, las posibilidades del Paisaje son versátiles, pudiendo considerarse indistintamente desde las competencias básicas comunicativas, metodológicas, personales y las específicas de conocimiento e interacción con el mundo físico, sociales y ciudadanas.

\subsubsection{El Conocimiento del Medio Social y Cultural y el Conocimiento del Entorno en el currículum de Educación Infantil}

El currículo de Educación Infantil está regulado por el Real Decreto 1630/2006. En la LOE se define como una etapa educativa con identidad propia, que se orienta hacia la consecución del desarrollo de los distintos planos que integran la personalidad infantil: físico y motórico, afectivo, lingüístico, social, cognitivo y a procurar los aprendizajes que contribuyen y hacen posible dicho desarrollo. Una de estas finalidades de Educación Infantil es la de contribuir al desarrollo social de los niños y las niñas; en ambos ciclos deberá atender al desarrollo de las pautas elementales de convivencia y relación social, 
así como al descubrimiento de las características físicas y sociales del medio. Se exponen así las dos finalidades primordiales desde el ámbito de las Ciencias sociales aplicadas a la Educación Infantil. La dimensión social hace referencia a las transformaciones derivadas de la acción humana sobre el medio. Desde el punto de vista educativo, en cuanto a la dimensión social, es necesario poner el acento en las consecuencias que dicha intervención humana ha tenido en la modificación del espacio, y de los problemas medioambientales que todo ello ha generado. Por lo que se deberá intentar favorecer el sentido de responsabilidad, tanto individual como colectiva, para la conservación y protección del Paisaje (Busquets, 2010, p. 9).

Gómez Ortiz (1993) también apunta el tratamiento que desde el ámbito educativo ha de darse al Paisaje. En Educación Infantil y en Primaria debe ser globalizado; el Paisaje es una realidad tangible vivenciada por los alumnos de esta etapa, por lo que debe ser captado como un todo, tomando como referencia la propia experiencia, y sobre ella elaborar nuevos conocimientos. De este modo no resulta difícil tipificar grandes grupos de Paisajes en función de atributos dominantes (urbano o natural) e incluso llegar a distinguir la acción humana sobre el medio.

En el currículo de Educación Infantil de LOE no aparecen competencias básicas, a diferencia del de Educación Primaria. El enfoque metodológico en Infantil que promueve el currículo de esta ley deja patente el carácter procedimental y actitudinal de la etapa. Para asegurar esos aprendizajes es necesario trabajar el desarrollo de habilidades y competencias específicas básicas ajustadas a las edades y formas de aprender del alumnado de El.

Las áreas del currículo son las siguientes: Conocimiento de sí mismo y Autonomía Personal, Conocimiento del Entorno, Lenguajes: comunicación y representación. Las tres se definen como áreas de conocimiento y experiencia, sus contenidos adquieren sentido desde la complementariedad, y contienen tanto aspectos relativos al saber, como al saber hacer y al ser. Por eso todas han de ser tenidas en cuenta desde el punto de vista de las Ciencias Sociales. Sin embargo, serán con los contenidos del área de Conocimiento del Entorno los que favorecen el proceso de descubrimiento y representación de los diferentes contextos que componen el entorno infantil, así como facilitar su inserción en ellos, de manera reflexiva y participativa. Desde esta área se concibe el medio como la realidad en la que se aprende y sobre la que se aprende. A lo largo de esta etapa, los niños y las niñas descubren su pertenencia al medio social. El entorno Infantil debe ser entendido, consecuentemente, como el espacio de vida que rodea a la infancia (familia, amigos, escuela o barrio). Así, las niñas y los niños 
reconocerán en ellos las dimensiones física, natural, social y cultural que componen el medio en que vivimos.

Los contenidos del área del Conocimiento del Entorno integran

- El conocimiento del medio físico, que se relaciona con contenidos de las Ciencias naturales, experimentales y matemáticas

- El conocimiento del medio social y cultural que se relaciona con contenidos propios de las Ciencias Sociales

Las referencias específicas al concepto Paisaje en las enseñanzas mínimas establecidas por el Ministerio de Educación no son muchas, aunque éste está indirectamente presente en muchos de los contenidos. El concepto es utilizado en los criterios de evaluación del Área de Conocimiento del Entorno:

Se valorará también si son capaces de establecer algunas relaciones entre medio físico y social, identificando cambios naturales que afectan a la vida cotidiana de las personas (cambios de estaciones, temperatura...) y cambios en el Paisaje por intervenciones humanas. Se mostrarán actitudes de cuidado y respeto hacia la naturaleza participando en actividades para conservarla. Se estimará, así mismo, el interés que manifiestan por el conocimiento del medio, las observaciones que hacen, así como las conjeturas que sobre sus causas y consecuencias formula (BOE 2007).

Como observamos se hace referencia al Paisaje, a su cuidado y conservación sólo en los criterios de evaluación, y es el entorno, el escenario privilegiado que rodea a los discentes, dónde se produce los aprendizajes más diversos.

Martínez Medina y García Morís (2013) señalan que el alumnado debe descubrir los cambios en el medio en sus dos vertientes: física y social. Para ello deben percibir las transformaciones naturales, pero también las que son producto de la acción humana. Asimismo, el Paisaje se muestra también útil para el fomento de la Educación Ambiental, ya que con el estudio del Paisaje o del entorno, se fomenta su cuidado y conservación. Estos autores también hacen un análisis del desarrollo de las enseñanzas mínimas de los currículos de Educación Infantil en las distintas comunidades autónomas, llegando a la conclusión, que la enseñanza y aprendizaje del Paisaje está presente en varios de los objetivos, contenidos y criterios de evaluación del segundo ciclo de Ed. Infantil, especialmente en el área de Conocimiento del Entorno, pero las referencias al concepto Paisaje varían de unos textos normativos a otros. Así, unos se centran en los aspectos naturales del mismo, otros en el estudio del Paisaje desde el punto de vista del medio físico y en los restantes casos, su enseñanza trabaja los aspectos culturales, haciendo 
hincapié en las distintas formas de organización de las sociedades. En la mayoría de las Autonomías se analiza este concepto desde un enfoque global, teniendo en cuenta tanto los aspectos naturales como los aspectos humanos, y la relación que existe entre ellos, una forma de entender el Paisaje que se enmarca dentro de la ciencia geográfica.

\subsubsection{El área del Conocimiento del Medio Natural, Social y Cultural en el currículum de} Educación Primaria (LOE)

La noción de medio a que se refiere el área, alude no sólo al conjunto de fenómenos que constituyen el escenario de la existencia humana, sino también a la interacción de los seres humanos con ese conjunto de fenómenos. El medio se ha de entender como el conjunto de elementos, sucesos, factores y procesos diversos que tienen lugar en el entorno de las personas y donde, a su vez, su vida y actuación adquieren significado. El entorno se refiere a aquello que el niño o la niña puede conocer mejor porque es fruto de sus experiencias sensoriales, directas o indirectas, porque le es familiar y porque está próximo en el tiempo o en el espacio, si bien el uso de las tecnologías de la información y la comunicación hace que esta proximidad dependa cada vez menos de la distancia física. El currículo de esta área ha de atender al desarrollo evolutivo físico, sensorial y psíquico del alumnado, al pensamiento concreto de los niños y niñas de seis a doce años, a su amplia capacidad e interés por aprender al establecer relaciones afectivas con los elementos de su entorno y, también, a la necesidad de iniciarlo en el pensamiento abstracto al final de la etapa.

El área de conocimiento del medio natural, social y cultural, engloba distintos ámbitos del saber, respeta la coherencia de cada uno de ellos, atiende a sus procesos específicos de aprendizaje, y orienta los distintos saberes hacia un propósito coincidente: contribuir a una mejor comprensión y explicación del conjunto de aspectos y dimensiones que constituyen el entorno humano. Por ello, el currículo del área posee un carácter eminentemente interdisciplinar, que establece relaciones orientadas a conseguir que los aprendizajes se apoyen mutuamente y se favorezca un aprendizaje significativo. Aunque el área tiene un claro peso conceptual, los conceptos, procedimientos y actitudes se presentan plenamente relacionados, de manera que los conceptos aparecen normalmente asociados a los procedimientos que se requieren para su adquisición y a las actitudes que de ellos se derivan. Los procedimientos en los aprendizajes propios de esta área se vinculan a la observación, a la búsqueda, recogida y organización de la información, a la elaboración y comunicación de dicha información y a la reflexión sobre el proceso de aprendizaje, como base del método científico. Por 
su parte, las actitudes se vertebran en torno a la identidad personal, la socialización y la convivencia, la salud y el medio ambiente.

Los contenidos se han agrupado en bloques que permiten una identificación de los principales ámbitos que componen el área. Su organización no obedece a ningún tipo de orden ni jerárquico ni en el tratamiento de los contenidos

\subsubsection{El «Paisaje» en los distintos bloques de contenidos}

En la Ley Orgánica de Educación (LOE), a diferencia de la LOGSE, en el currículum del Área del Conocimiento del Medio Natural, Social y Cultural, se utiliza más el concepto "entorno", que "medio" o "Paisaje", de tal forma que el Bloque I de los tres ciclos se denomina: "El entorno y su conservación". El concepto Paisaje está entre los contenidos del Segundo Ciclo en el Bloque I: Observación y descripción de distintos tipos de Paisaje: interacción de naturaleza y seres humanos.

Igualmente se recoge en los Criterios de Evaluación.

Reconocer y explicar, recogiendo datos y utilizando aparatos de medida, las relaciones entre algunos factores del medio físico (relieve, suelo, clima, vegetación...) y las formas de vida y actuaciones de las personas, valorando la adopción de actitudes de respeto por el equilibrio ecológico.

Con este criterio se trata de conocer si son capaces de apreciar relaciones como las que se dan entre tipo de vivienda, cultivos, Paisaje, vestimenta, etc. con el clima, el relieve, la presencia de determinadas especies animales y vegetales, etc., como aproximación al concepto de hábitat. Asimismo se valorará si reconocen la importancia de la sostenibilidad del equilibrio ecológico y la necesidad de adoptar actitudes respetuosas con el medio, la necesidad de conservar estos recursos, especialmente con respecto al uso del agua.

Y en los contenidos del Tercer Ciclo en el Bloque I:

- Características del clima del lugar en que se vive y de los principales climas. Influencia en el Paisaje y en la actividad humana.

- Valoración de la diversidad y riqueza de los Paisajes del territorio español e interés por conocer Paisajes de otros lugares.

Y en los Criterios de evaluación:

Caracterizar los principales Paisajes españoles y analizar algunos agentes físicos y humanos que los conforman, y poner ejemplos del impacto de las 
actividades humanas en el territorio y de la importancia de su conservación (BOE, 2007)

Este criterio pretende medir el conocimiento sobre los principales Paisajes característicos de los diferentes territorios españoles, la capacidad para establecer comparaciones (semejanzas y diferencias) entre Paisajes, distinguir los elementos fundamentales, conocer los principales tipos de asentamiento humano en las regiones españolas y comprender la importancia de la intervención humana en la modificación o en la conservación de los Paisajes naturales.

En el análisis del área, aparece el Paisaje en el segundo y tercer Ciclo de Educación Primaria de una forma explícita, pero son muchos más los contenidos que se recogen en el área, en relación con el aprendizaje del Paisaje, aproximándose así, a la definición que hace El Convenio Europeo del Paisaje:

El paisaje...cualquier parte del territorio tal como lo percibe la población, cuyo carácter sea el resultado de la acción y la interacción de factores naturales y/o humanos.

Una de las claves de este Convenio es que reconoce que todo territorio es Paisaje, y reconoce todas las formas de los Paisajes: naturales, rurales, urbanos, periurbanos, emblemáticos u ordinarios, y que concierne a los componentes naturales, culturales y humanizados y a sus interconexiones. $E$ insiste en la necesidad de desarrollar e incrementar la sensibilización de la sociedad civil, las organizaciones privadas y las autoridades públicas respecto del valor de los Paisajes, su papel y su transformación.

El carácter global del área de Conocimiento del Medio Natural, Social y Cultural hace que contribuya en mayor o menor medida, al desarrollo de la mayoría de las competencias básicas. En especial, el currículo de esta área va más allá de los aspectos conceptuales, para desarrollar destrezas y habilidades y, sobre todo, actitudes. El Conocimiento del Medio, junto con el área de Educación para la Ciudadanía y los derechos humanos, pretende asentar las bases de una futura ciudadanía mundial, solidaria, curiosa e informada, participativa y demócrata. Así mismo, contribuye de forma sustancial a la competencia en el conocimiento y la interacción con el mundo físico ya que muchos de los aprendizajes que integra están totalmente centrados en la interacción del ser humano con el mundo que le rodea, entre ellos el Paisaje. Dice Busquets (1996) que es en Educación Primaria cuando debe iniciarse a los alumnos en la lectura sistemática del Paisaje. Lo que se pretende en esta etapa es que los alumnos sean capaces de reconocer los diferentes elementos que lo constituyen y establecer relaciones sencillas entre ellos y que adquieran los procedimientos necesarios para la 
lectura y representación del Paisaje. Con ello se pretende que al finalizar la Educación Primaria los alumnos cuenten con las capacidades y herramientas necesarias para realizar el análisis geográfico del Paisaje en profundidad, cuestión ésta que se acometerá a lo largo de la Educación Secundaria.

\subsection{LEY ORGÁNICA PARA LA MEJORA DE LA CALIDAD EDUCATIVA}

Ley Orgánica para la Mejora de la Calidad Educativa entró en vigor en diciembre del año 2013. Durante el curso 2014-2015 se ha iniciado en la mitad de los cursos de Educación Primaria la implantación de la última reforma educativa en España. Una ley controvertida que cuenta con un amplio rechazo no sólo de la mayoría de las fuerzas políticas, sino también de la inmensa mayoría de las organizaciones profesionales y sindicales del profesorado. Con LOMCE, las Ciencias Sociales han adquirido una relevancia especial en el currículo de Educación Primaria, al desaparecer el área del Conocimiento del Medio Natural, Social y Cultural por las materias de Ciencias Sociales y Ciencias Naturales. Esto supone un cambio en la organización de los contenidos y de las finalidades socioeducativas.

\subsubsection{Las Ciencias Sociales en el Currículum de Educación Infantil}

El Currículo de Educación Infantil está regulado por el Real Decreto 1630/2006, ya que en LOMCE aún no se han fijado las enseñanzas mínimas de Educación Infantil. La ley prevé la inclusión en ellas de las competencias básicas. Esta ley ha mantenido los principios generales de la educación Infantil establecidos en LOE. Parra, Colomer y Sáiz (2015) afirman que se ignora que la educación Infantil es una fase fundamental en la socialización del alumnado y por tanto, en la construcción de su identidad. De ahí, la importancia de las ciencias sociales para la consecución de estos objetivos.

\subsubsection{Las Ciencias Sociales en el Currículum de Educación Primaria}

En el Real Decreto 126/2014, de 28 de febrero, se estableció el currículo básico de Educación Primaria. El currículo aparece organizado, para cada una de las áreas, partiendo de los objetivos propios de la etapa y de las competencias que se van a desarrollar a lo largo de la educación básica. La novedad de esta ley viene dada con la aparición de una nueva asignatura de Ciencias Sociales en el currículum de Educación Primaria. Como hemos comentado anteriormente. Esta medida, que en principio podría ser positiva para profundizar en el carácter cívico y crítico de esta disciplina, y así, conseguir un desarrollo personal y social del alumnado, sin embargo ha supuesto una 
involución hacia las clásicas Ciencias Sociales existentes en EGB (Educación General Básica) de Ley General de Educación de 1970 (Parra, Colomer y Sáiz, 2015, p. 8-14). De acuerdo con estos autores la propuesta final que aparece en la ley, está muy lejos de las finalidades educativas sugeridas por los especialistas en didáctica, y que debería perseguir esta materia en la escuela. Las Ciencias Sociales, durante la etapa de Educación Obligatoria, habrían de servir para fomentar los valores cívicos y democráticos, lo cual implica dotar al alumnado de herramientas que le permitan desarrollar la capacidad de entender y comprender el mundo que les rodea.

LOMCE, en el currículo básico de Educación Primaria, refuerza el carácter conceptual de las Ciencias Sociales. De tal forma, que la materia de geografía es eminentemente descriptiva y tradicional y la de historia está basada en el clásico relato nacional de España, todo ello susceptible de ser memorizado de forma acrítica y sin un análisis reflexivo. Además, se plantea una predominancia de contenidos sociales, históricos y geográficos conceptuales, lo que implica un abandono de los contenidos procedimentales y especialmente de los contenidos actitudinales, siendo considerados fundamentales para la formación y participación activa del futuro ciudadano en la vida económica, social y cultural, favoreciendo una actitud crítica y responsable en el alumnado y así poder adaptarse a las distintas situaciones que se le presenten en la sociedad en la que vive.

\subsubsection{El «Paisaje» en los distintos bloques de contenidos}

El concepto de Paisaje desempeña en el currículo de Educación Primaria de LOMCE una situación casi anecdótica, con unos enunciados muy vagos y difíciles de concretar en la práctica. Por otra parte, el concepto de Paisaje se asocia en el currículo únicamente a elementos de carácter natural: relieve, clima e hidrografía. Sin embargo el cumplimiento del Convenio Europeo del Paisaje, firmado por España en 2000 y ratificado en 2007, debería haber propiciado un mejor tratamiento del concepto y sus derivaciones. Como observamos, no incluye esta interacción de factores naturales y/o humanos en el Paisaje, de la que nos habla el Convenio en su definición de Paisaje Esa definición y la cláusula c) del Convenio debería haber animado a los redactores del currículo (BOE del 1 de Marzo del 2014) de Educación Primaria a adoptar el concepto de Paisaje contemplado en él.

El contenido de Paisaje se recoge en el Decreto de enseñanzas mínimas en la nueva materia de Ciencias Sociales de forma explícita en el Bloque 2. El Mundo en que vivimos en los Contenidos: 
- La diversidad geográfica de los Paisajes de España: relieve e hidrografía.

- La diversidad geográfica de los Paisajes de Europa: relieve, climas, e hidrografía.

En los Criterios de evaluación:

- Explicar que es un Paisaje e identificar los principales elementos que lo componen.

Y en los Estándares de aprendizaje evaluables

- Define Paisaje, identifica sus elementos y explica las características de los principales

Paisajes de España y Europa, valorando su diversidad (p. 19375).

También el Decreto recoge indirectamente en el Bloque 2, en que se trata el Paisaje, contenidos relacionados con él:

Se identificarán los elementos del Paisaje (relieve, clima, hidrografía...) y se describirán y caracterizaran los principales medios naturales y su localización. Por último, se analizarán la influencia humana en el medio y sus consecuencias ambientales.

El Bloque 2 incluye, así, contenidos que van desde el Universo, la representación de la Tierra y la orientación en el espacio, al agua y el consumo responsable, el clima y el cambio climático, el Paisaje y la intervención humana en el medio (BOE 2014, p. 19372)

Como podemos observar la presencia del Paisaje es mucho menor que en los currículos anteriores (LOGSE y LOE), a pesar de que en los últimos años es mayor la preocupación por la conservación de los Paisajes, intentando crear en la población en general, y en los alumnos/as en particular, una mayor sensibilidad y conciencia de protección. Hay autores que señalan que la LOMCE "aleja el estudio de los Paisajes de su repercusión en la concepción ambiental y ciudadana y puntualizan que es importante estudiar el Paisaje desde la representación espacial de problemas sociales" (AA.VV, 2015, p. 34). El Convenio Europeo del Paisaje se propone alcanzar un desarrollo sostenible basado en una relación equilibrada y armoniosa entre las necesidades sociales, la economía y el medio ambiente. El Paisaje desempeña un papel importante y de interés general en los campos cultural, ecológico, medioambiental y social, constituye un recurso favorable para la actividad económica, y su protección gestión y ordenación pueden contribuir a la creación del empleo. La responsabilidad del sistema educativo y de la escuela es enorme para conseguir los fines que se proponen. El objetivo final del proceso de estudio del Paisaje debería ser la comprensión de éste como resultado de la interacción del medio y las sociedades humanas cuya cultura es fruto de la adaptación de éstas a un territorio determinado; el Paisaje contiene testimonios de esta adaptación (tipos de hábitat, cultivos, 
formas de poblamiento, restos históricos, etc...) que constituyen parte del patrimonio colectivo.

Es importante saber que los procedimientos más adecuados para le enseñanza del Paisaje deben comenzar durante la etapa de Infantil y continuar en Primaria y Secundaria, animando a los niños/as a que investiguen y exploren su entorno, con el fin de comprenderlo y desarrollar habilidades y capacidades técnicas que permitan un entendimiento más profundo, todo ello acompañado del desarrollo de la sensibilidad hacia los seres vivos y la responsabilidad hacia el medio ambiente. Para ello será necesario tener en cuenta tanto los aspectos cognitivos, como motóricos y afectivos a la hora de proporcionar una base de calidad en la enseñanza para despertar y mantener en los niños la curiosidad y motivación en el descubrimiento del Paisaje en el que está inmerso. 


\section{CAPÍTULO 4. EL PAISAJE EN EL GRADO DE MAESTRO EN EDUCACIÓN INFANTIL Y EN EDUCACIÓN PRIMARIA}

La creación del Espacio Europeo de Educación Superior ha supuesto para todos los países, incluida España, la reestructuración del ordenamiento de las enseñanzas universitarias oficiales. Desde el curso académico 2010-2011 todas las Universidades españolas tienen adaptados sus planes de estudios a la normativa del EEES. De acuerdo con la nueva ordenación, desaparecen las anteriores diplomaturas y licenciaturas y se establece como titulación universitaria de primer nivel el título de Grado, seguido de los niveles de Máster y Doctorado.

En la formación del profesorado la incorporación de España al EEES supondrá una sustancial mejora en la formación inicial del profesorado de los niveles no universitarios, tanto de los maestros de Educación Infantil como en los maestros de Educación Primaria. La creación de los nuevos Grados en Magisterio, en sustitución de las anteriores diplomaturas, conlleva la ampliación de la carrera a cuatro años en lugar de los tres que tenía antes, lo que permitirá dotar a quienes estudien esta carrera de una formación más amplia; alcanzando así una mayor cualificación profesional, ya que los nuevos planes de estudio inciden más en la adquisición de competencias profesionales

La sociedad actual, caracterizada por un elevado nivel de complejidad, demanda unos profesionales de la docencia altamente cualificados, con una sólida formación en la doble vertiente científica y didáctica, que les capacite para enseñar a sus alumnos a alcanzar aprendizajes significativos y a aprender a aprender a lo largo de toda la vida. En el caso del profesorado de los Grados en Magisterio no basta con que conozca los contenidos (geográficos, entre ellos el Paisaje) que el currículo de cada nivel educativo prescribe trabajar con los estudiantes, sino que es imprescindible, también, saber enseñarlos.

Entre las reformas que afectan a las titulaciones universitarias, un lugar importante lo ocupan las relativas a aquellas que habilitan para el ejercicio de la profesión docente. Las prescripciones que la normativa del EEES hace en relación con la formación del profesorado son múltiples. Sin embargo, de acuerdo con Marrón Gaite (2010) señalamos, las que nos resultan especialmente relevantes:

1. Aumento cualitativo y cuantitativo de la formación exigida para el profesorado de Educación Primaria. De este modo la formación inicial de los maestros contempla el mismo número de créditos ECTS que el del resto de los titulados universitarios. 
2. Regulación de la formación del profesorado de Educación Infantil. Se trata de integrar la formación del profesorado de este nivel en las enseñanzas universitarias, hecho que ya compartían la mayor parte de los países de la Unión Europea, si bien algunos como Alemania o Italia, mantenían esta formación en instituciones ajenas a la Universidad.

3. Nuevas exigencias profesionales al profesorado, debido a la existencia de nuevas dificultades para ejercer la docencia. Las complejas situaciones a las que el profesorado tiene que enfrentarse en el aula, derivadas de múltiples factores, como la ampliación de la escolaridad obligatoria hasta los dieciséis años, la interculturalidad en las aulas derivada del incremento de la inmigración en Europa, la relajación en los hábitos de vida de los muchachos, entre otras causas, hacen especialmente difícil el ejercicio de la docencia, por lo que se hace imprescindible dotar al profesorado de una sólida formación, no sólo científica, sino también didáctica.

La Comisión Europea trabaja con los Estados miembros para ayudarles a desarrollar y modernizar sus políticas de educación y formación, a través del Programa de Trabajo «Educación y Formación 2010». Así mismo incentiva también medidas políticas para mejorar la calidad de la formación del profesorado, de entre las cuales destacan, las relacionadas con la formación inicial. En concreto se indicaba a los Estados miembros la necesidad de:

1. Identificar las competencias que deberían tener los maestros y profesores, en la actual sociedad del conocimiento.

2. Proporcionar al profesorado el apoyo institucional adecuado con el fin de poder enfrentarse a los retos de esa sociedad y

3. Asegurar el nivel adecuado a la profesión, es decir, proporcionar una formación inicial adecuada a las nuevas demandas de la sociedad del siglo XXI. Todo ello ha conducido a la remodelación de las titulaciones que capacitan al profesorado para el ejercicio de su profesión en todos los niveles educativos no universitarios de los países europeos miembros del EEES. En España, que participa de dicha tendencia e inquietudes, la incorporación como Estado miembro en el Espacio Europeo de Educación Superior ha generado un cambio sustancial en la forma de estructurar y concebir la formación del profesorado en estos niveles educativos. A continuación exponemos de forma sintética los principales aspectos relativos a las titulaciones que habilitan para ejercer la profesión de maestro en los correspondientes planes de estudio. 


\subsection{FORMACIÓN DEL PROFESORADO DE EDUCACIÓN INFANTIL Y DE EDUCACIÓN PRIMARIA}

Con la integración de España en el Espacio Europeo de Educación Superior, las titulaciones de Magisterio se reducen a dos modalidades: Educación Infantil y Educación Primaria, desapareciendo el resto de las especialidades establecidas en 1990 por Ley Orgánica de Educación (Educación Especial, Lengua Extranjera, Audición y Lenguaje, Educación Musical y Educación Física). Así mismo, como en todos los países miembros del EEES, la anterior Diplomatura se transforma en Título de Grado, pasando el periodo formativo de tres a cuatro años.

Contemplar la formación de maestros a partir de estas dos únicas titulaciones, Grado de Maestro en Educación Infantil y Grado de Maestro en Educación Primaria, supone, desde nuestro punto de vista, apostar acertadamente por la formación de un maestro generalista, que requiere ser formado en una amplia gama de contenidos científicos y didáctico-pedagógicos, que le capaciten para ejercer con plena cualificación las funciones propias de maestro tutor del grupo de alumnos que el Centro educativo le encomienda. Tanto la especialidad de Educación Infantil como la de Educación Primaria, cuentan con una fuerte tradición en nuestro país y han sido siempre titulaciones muy demandadas. Este interés se está viendo altamente incrementado en la actualidad debido a la confluencia de diversos factores socioeconómicos y culturales y las actuales características de edad del profesorado especialista en estas etapas.

En España, en el nuevo marco normativo, los Títulos de Grado en Educación Infantil y en Educación Primaria están regulados por Orden Ministerial ECI/3854/2007 de 27 de diciembre de 2007, publicada en el Boletín Oficial del Estado $\mathrm{n}^{\circ}$ 312, de 29 de diciembre de 2007, siendo estos Títulos los únicos que capacitan para impartir la docencia.

Uno de los principios fundamentales que inspiran el modelo de educación universitaria del EEES es que la educación superior debe estar centrada en los estudiantes, y no en los profesores. Así mismo, se insiste de forma reiterada en que Universidad ha de capacitar a los estudiantes para aprender a lo largo de toda la vida, dotándoles de las capacidades de aprendizaje que les permitan desarrollar todo su potencial personal de forma progresiva y en función de los acontecimientos y situaciones que hayan de afrontar en cada momento y situación personal. Se trata del proceso que persigue la consecución del desarrollo personal, social y profesional en el transcurso de la vida de los individuos, con el fin de mejorar la calidad de vida tanto de éstos a nivel individual como de la colectividad. 
La educación permanente es una respuesta a las demandas de la sociedad contemporánea, donde el aprendizaje no puede limitarse a los años de formación académica, ya que la capacidad de aprendizaje en el individuo se mantiene a lo largo de toda la vida. De ahí la importancia de enseñar a los estudiantes a aprender a aprender. Los objetivos de la educación permanente son múltiples y hacen referencia a diversos ámbitos del aprendizaje. A través de ella se persigue lograr una sociedad democrática e igualitaria, integrada por ciudadanos libres, responsables y solidarios, que trabajen por alcanzar un mundo mejor. Concede una importancia capital al autoaprendizaje y a la autoevaluación y contempla múltiples estilos o formas de aprendizaje, de modo que cada individuo y cada situación requieren el suyo propio.

Desde esta perspectiva, el EEES ha enfatizado el valor de la enseñanza activa, sustentada en el aprendizaje significativo, en la que el alumno es considerado como el auténtico protagonista del proceso educativo y en la que se concede una importancia capital al trabajo personalizado del mismo y al desarrollo de la capacidad de aprender a aprender. Ha puesto de manifiesto la necesidad que existe de innovar didácticamente en las enseñanzas universitarias, indicando que sobre las clases teóricas o magistrales deben dominar las clases de carácter práctico, en las que los estudiantes participen activamente en los procesos de enseñanza-aprendizaje, interactuando entre sí y con el profesor, el cual desempeñará el papel de orientador y dinamizador de los aprendizajes de sus alumnos.

\subsection{EL GRADO DE MAESTRO EN EDUCACIÓN INFANTIL Y PRIMARIA EN LA UNIVERSIDAD DE SALAMANCA}

\subsubsection{Antecedentes de los estudios de Magisterio en la Universidad de Salamanca}

Los Grados de Maestro en la Universidad de Salamanca se adecuan a esos principios y asumen las medidas políticas para mejorar la calidad de la formación del profesorado de la Unión Europea, y en consecuencia proponen planes exigentes en cuanto a la formación, y vinculados activamente a la profesión. Antes de explicar la situación actual, debemos hacer referencia al inicio de los estudios de Maestro en las Escuelas Normales, anterior a la entrada de dichos estudios en la Universidad.

Salamanca tuvo desde 1842 una Escuela Normal para la formación de maestros, que se fue amoldando a las circunstancias de cada momento histórico. Era una formación que carecía de estatus universitario. 
(...) Salamanca cifra su existencia en su antigua y venerable Universidad, y es un deber de todos los que la profesan cariño y se interesan en su ventura y en sus glorias no omitir ningún medio para conservarla y mejorarla. Nuevas instituciones deben nacer en derredor suyo para fortalecerla y completar la larga serie de estudios que necesita el hombre en el curso de su vida. La Escuela Normal y la Universidad deben estar íntimamente ligadas porque la una principia lo que debe terminar la otra. La una educa al hombre niño, la otra al hombre joven; la primera prepara a la niñez para recibir nuevas y más profundas lecciones en la segunda, y ésta dispone a la juventud para servir útilmente a su país y a su familia. Me lisongea la esperanza de que entrambas unirán sus esfuerzos para aumentar las glorias de esta población ilustre" (Hernández, 1986).

La Escuela Normal de Salamanca es una más de las instituciones que el sistema liberal pone en marcha para generalizar la educación a todos los ciudadanos. La Ley Moyano en 1857 dota de más autonomía a las Normales de maestros al cambiar su tutela del Instituto al Rectorado; se crean también las Escuelas Normales de Maestras, y la de Salamanca en 1858. El prestigio que, desde sus orígenes, tiene La Escuela Normal de Maestros de Salamanca, se debe a la talla científica de algunos de los profesores de esta primera época, profesores universitarios, escritores y políticos de enorme relevancia en la vida política y universitaria salmantina y española del tercio central del XIX. Destacan Santiago Diego Madrazo catedrático y político, que tuvo a su cargo la enseñanza de la Geografía y la Historia, y Lázaro Ralero, primer director de la Normal entre 1842 y 1849, y entre 1856-57, activo político y escritor además de docente, y autor entre otras obras de «Elementos de Geografía, cronología e Historia para el uso de las escuelas de instrucción Primaria» (Salamanca, 1856).

La Universidad de Salamanca solo ha impartido los títulos para la formación de Maestros desde que ésta se incorporó al sistema universitario, con la Ley General de Educación de 1970. Se han desarrollado así los planes de estudios de 1971, de 1992 y el de 2000 antes de los Grados actuales. La larga tradición y la experiencia acumulada con que contaba la Universidad de Salamanca justificaron su continuidad y la necesidad de su adaptación e implantación de los nuevos Grados. La necesidad social de contar con maestros suficientes que impulsó la existencia de Escuelas Normales en todas las provincias españolas, pervive en nuestro tiempo. La percepción social de esta necesidad se traslada al creciente número de estudiantes matriculados en los últimos años para todas las titulaciones de maestro.

Los Grados de Maestro de la USAL se adecuan pues a contextos de escalas diversas. Se han concebido para el ámbito europeo, se han elaborado con la legislación española, y por tanto se pueden ofrecer a estudiantes europeos y españoles. $Y$ por último se han 
adecuado a su ámbito socioeconómico más próximo especialmente en aquellos aspectos que redundan en aspectos organizativos. Los estudios de Grado, que en estas fechas están culminando la formación de sus primeras promociones, han ampliado un año académico con respecto a las anteriores diplomaturas, así como una homogeneización en la duración de los estudios en relación con titulaciones que anteriormente eran de cinco cursos. Esto no ha supuesto una disminución del interés por estos estudios; no obstante en la USAL, al igual que en otras universidades, las limitaciones de plazas impuestas a los Grados de Maestro, han impedido que el número de matrículas aumente.

\subsubsection{El Plan de Estudios del grado de Maestro en Educación Infantil y Primaria}

El Plan de Estudios de Grado de maestro en educación Infantil y Primaria se imparte en la Facultad de Educación de la Universidad de Salamanca desde el curso académico 2010-2011. Su estructura y planificación corresponde a la ORDEN ECI/3854/2007, de 27 de diciembre, por la que se establecen los requisitos para la consecución de los títulos universitarios oficiales que habilitan para el ejercicio de la profesión de Maestro en Educación Infantil y Primaria.

En el Plan de Estudios se incluyen, por la propia naturaleza del título y su función social, enseñanzas relacionadas con los derechos fundamentales y de igualdad de oportunidades entre hombres y mujeres, con los principios de accesibilidad universal de las personas con discapacidad y con los valores propios de una cultura de la paz y de valores democráticos.

Los Módulos del Plan de Estudios de Grado de Maestro de Educación Infantil y Educación Primaria en la Facultad de Educación de la Universidad de Salamanca son cuatro y entre ellos está el Módulo Didáctico Disciplinar, dónde están incluidas las asignaturas pertenecientes al área de Ciencias Sociales:

- $\quad$ Aprendizaje de las Ciencias Sociales en Educación Infantil (6 créditos ECTS) impartida en el $2^{\circ}$ curso del Grado de Maestro en Educación Infantil.

En relación con el Grado de Maestro en Educación Primaria, las asignaturas son:

- Fundamentos Geográficos e Históricos, impartida en el $2^{\circ}$ curso y

- Didáctica de las Ciencias Sociales impartida en $3^{\circ}$ curso, ambas de (6 créditos ECTS). 
En dicho plan también se ofertan las asignaturas optativas:

- $\quad$ Historia de España para $4^{\circ}$ curso de Maestro en Educación Primaria y

- $\quad$ Unión Europea en $4^{\circ}$ curso para ambos grados de Maestro en Educación Infantil y Educación Primaria

Podemos resumirlo en el cuadro 4:

Cuadro 4. Asignaturas del área de Didáctica de las Ciencias Sociales en el Grado de Maestro

\begin{tabular}{|l|l|l|l|}
\hline Curso & Titulación & Asignatura & Tipología asignatura \\
\hline $2^{\circ}$ & Grado EI & $\begin{array}{l}\text { Aprendizaje de las Ciencias Sociales en } \\
\text { Educación Infantil }\end{array}$ & Obligatoria \\
\hline $2^{\circ}$ & Grado EP & Fundamentos Geográficos e Históricos & Obligatoria \\
\hline $3^{\circ}$ & Grado EP & Didáctica de las Ciencias Sociales & Obligatoria \\
\hline $4^{\circ}$ & Grado EP & Historia de España & Optativa \\
\hline $4^{\circ}$ & Grado EP & La Unión Europea & Optativa \\
\hline $4^{\circ}$ & Grado El & La Unión Europea & Optativa \\
\hline
\end{tabular}

La situación actual de los planes de estudio de la formación de maestros, como puntualizaba Pagés (2000) ha cambiado mucho, pero aún no está en consonancia con las importantes aportaciones teórico-prácticas que han realizado muchos profesores e investigadores en el campo de la didáctica de las ciencias sociales en los últimos años. La formación inicial del profesorado en maestro de educación Infantil y Primaria presenta limitaciones a la hora de trabajar los conocimientos del Medio Social y cultural, y más concretamente la educación en Paisaje.

Autoras como Martínez \& Sauleda (2004) son muy críticas con la actual formación inicial del profesorado, sobre todo en educación infantil. Hernández Cervantes (2013) considera que para conseguir que los futuros profesores desarrollen un aprendizaje óptimo en el aprendizaje de las ciencias sociales, habría que tener una mayor relación y coordinación entre los conocimientos de distintas asignaturas que componen la formación inicial en maestro. No sólo en relación con las asignaturas troncales, sino también con las optativas. Tonda (2001) señala que es importante una mayor especialización en la formación generalista de los futuros maestros en educación Primaria e infantil. La formación inicial en maestro en Infantil y Primaria debe potenciar, entre otros conocimientos, la educación en Paisaje. 
Creemos que la escuela es el marco social en el que se desarrolla una parte fundamental de la educación de nuestros jóvenes, ya que entre sus finalidades está la transmisión de conocimiento, fomentar valores y generar actitudes. Es sin duda ninguna, el lugar idóneo para promover y desarrollar la educación en Paisaje, como recoge el CEP a través de sus diferentes programas y, más en concreto, en la guía "La sensibilización del Paisaje. Un reto para el S.XXI. Busquets i Fábregas señalan "el Paisaje siempre está cerca, alrededor, se está inmerso, es una experiencia directa y cotidiana" (2011, p. 36)

Como hemos podido comprobar a lo largo de esta investigación, el Paisaje no debe entenderse como algo ajeno, sino como algo vivido, del cual somos integrantes y responsables. La educación en Paisaje, en el marco de la educación formal, debe responder a un proyecto progresivo en todas las etapas y ciclos, transversal con la integración de contenidos de diversas áreas y cívico promoviendo pautas éticas con el medio y con otros ciudadanos. Para conseguirlo se deben actualizar, los contenidos sobre el Paisaje en la escuela e introducir el paradigma de Paisaje del CEP a la enseñanza. Es decir, educar a las nuevas generaciones transmitiendo interés y estima por el Paisaje. Esto no será posible sin una buena formación del profesorado en general y más concretamente, del profesorado de formación inicial especialista en didáctica de las Ciencias Sociales; ya que en ellos recae parte de la responsabilidad de conseguir la educación en Paisaje de los futuros maestros en educación Infantil y Primaria. 
PARTE II: ESTUDIO EMPÍRICO 


\section{INTRODUCCIÓN}

La presente tesis tiene como objetivo principal conocer la percepción y conocimientos que tiene el alumnado de Educación Infantil y Primaria del Paisaje. En este capítulo se revisan los modelos y métodos que hemos seguido en la investigación, una de cuyas intenciones es indagar las representaciones sociales que tienen los alumnos sobre el Paisaje.

Delimitar y seleccionar un modelo de investigación educativa es necesario para elaborar una propuesta que plantee la mejora y transformación de la práctica educativa. Gimeno y Pérez (1992) hablan de dos grandes modelos o paradigmas de investigación educativa: el paradigma positivista, racionalista o cuantitativo y el paradigma interpretativo, heurístico o cualitativo. Otros autores como Carr y Kemmis (1988), Arnal y otros (1992), distinguen tres paradigmas característicos de la investigación en educación: el paradigma positivista, el interpretativo y el crítico

La metodología elegida en esta investigación, que está en el marco de la Didáctica de las Ciencias Sociales, se encuadra por una parte dentro del paradigma crítico basado en la Investigación-acción ( Corey, 1953; Escudero, 1987; Carr y Kemmis, 1988 y Souto (2011) donde el propio investigador es el principal instrumento de investigación, a través de su sensibilidad, juicio y competencia profesional, sobre una realidad educativa concreta (en este caso, la formación inicial) por medio del proceso de indagación y reflexión y contraste entre sus propias hipótesis y datos obtenidos Travé (1998). Este mismo autor afirma que las investigaciones centradas en el profesor se basan en la consideración del profesor como un auténtico guía y orientador del proceso educativo. Ese referente ha propiciado una corriente de investigación basada en la formación inicial y permanente del profesorado. Entre las investigaciones sobre la formación del profesorado destaca, el trabajo de Benejam (1986) o el estudio de Plata (1990/91) sobre la formación inicial y permanente del profesorado en Canarias. Puesto que el propósito de la investigación es proporcionar información sobre las condiciones de enseñanza y aprendizaje para mejorarlas, su abordaje desde esta metodología supone un impulso al pensamiento crítico y transformador Por otra parte se ajusta al paradigma interpretativo, ya que la población objeto de estudio son las concepciones o representaciones que manifiesta el alumnado del Grado en Maestro en Educación Infantil y Primaria sobre el Paisaje. Según este paradigma, en este estudio el investigador trabaja con las representaciones sobre el Paisaje para entender el mundo subjetivo del alumnado para así, lograr conocer lo que piensan y sienten, llegando a elaborar sus teorías a través de la reflexión. Las teorías y los resultados de las investigaciones desarrolladas con el 
paradigma interpretativo no se establecen como leyes universales, sino circunscritas al entorno en las que se realiza dicho estudio

La investigación se ha hecho en el aula, por medio de un estudio de caso (Barton, et al., 2007). El estudio de caso nos permite indagar las representaciones que tiene el alumnado sobre el Paisaje. Además, nos ofrece la oportunidad de conocer las ideas, conocimientos, percepciones e incluso los sentimientos de los estudiantes en relación con el Paisaje y su enseñanza.

Siguiendo esta línea, Prats (1997) propone que las investigaciones en Didáctica de las Ciencias Sociales deben abarcar 5 campos posibles de estudio, siendo uno el referido a las concepciones de los alumnos sobre las ciencias sociales, sus actitudes y funcionalidad. La finalidad de este campo de estudio es:

"La preocupación por el Paisaje y el patrimonio es una vía eficaz para el diseño de un futuro sustentable, pues juega un papel esencial en la asunción de identidades colectivas e incide de forma determinante en las construcciones culturales" Blanco Pérez y López Facal (2015, p. 110).

La metodología utilizada para esta investigación, especialmente en su vertiente empírica ha utilizado tanto técnicas cuantitativas como cualitativas para poder complementar aspectos que sólo se analizan de forma integral si utilizamos ambas. Consideramos que la combinación de ambas es más enriquecedora y completa y potencia el desarrollo del conocimiento, la construcción de teorías y la resolución de problemas.

En los últimos años han aumentado de forma importante las investigaciones en el campo de la didáctica de las ciencias sociales. Esto ha hecho que se consolide un modelo que pretende mejorar la formación del profesorado, compartiendo reflexiones teóricas, diseño de materiales y análisis crítico de la experimentación de la práctica.

Santisteban, González y Pagès (2010) afirman que investigadores en didáctica de las ciencias sociales están produciendo un cuerpo de evidencia empírica que puede usarse para tomar decisiones sobre la docencia y el aprendizaje. Este modelo genera conocimiento desde las indagaciones en las representaciones sociales del alumnado y trabaja en la formación de maestros y maestras de Primaria a partir de problemas reales en una línea muy parecida a la que propone Johnston cuando afirma: "Los educadores de maestros y los maestros de aula que trabajan con estudiantes de maestros demostrarán directamente el valor de la indagación para el desarrollo profesional haciendo investigación. Si queremos futuros maestros que sean críticamente prácticos reflexivos, entonces nosotros debemos modelar aquello que se le parece en nuestros 
propios programas de educación de maestros y en la enseñanza en las aulas" (2006, p. 75). Señalan también que en los últimos años, la investigación "de" y "sobre" la didáctica de las ciencias sociales, requiere una reflexión profunda sobre los métodos de investigación, que generen modelos útiles para la mejora de la enseñanza y de la formación del profesorado, además de ayudar a construir la propia disciplina.

Las finalidades de la investigación en estudios sociales son contribuir al conocimiento de la enseñanza y el aprendizaje, es decir saber: 1) cómo los estudiantes piensan y aprenden, y en qué contextos lo hacen; 2) cómo el profesorado toma decisiones en la práctica y por qué, y 3) cómo las fuerzas sociales, políticas y culturales influyen en el currículo escolar y en los contenidos de enseñanza (Barton, 2006)

Los instrumentos por los que optamos para conocer el Paisaje como recurso fueron el cuestionario personal y el análisis de fotografías como más fiables para acercarnos a conocer qué percepción tiene el alumnado de Educación Infantil y Primaria sobre la realidad objeto de estudio. La utilización de las técnicas cuantitativas y cualitativas nos ha servido para conocer las fortalezas y minimizar las debilidades sobre esta temática. Todo ello nos ayudará a establecer las conclusiones y las proyecciones de la investigación.

\section{PARADIGMAS DE LA INVESTIGACIÓN}

\subsection{EL PARADIGMA CRÍTICO}

A nivel ontológico, la perspectiva crítica supone que la realidad se materializa a lo largo del tiempo en una serie de estructuras que se consideran reales, naturales e inmutables, pero susceptibles de ser comprendidas y construidas por las personas involucradas en la situación que se estudia. A nivel epistemológico, sostiene que el investigador y el objeto de estudio están vinculados interactivamente, y que los valores del investigador inevitablemente influencian la investigación. Por último, a nivel metodológico mantiene que la naturaleza negociada de la investigación requiere de un diálogo de carácter dialéctico entre el investigador y lo investigado con el propósito de superar la ignorancia y los conceptos erróneos en una conciencia más informada (el conocimiento como comprensión de las acciones necesarias para efectuar el cambio.

La investigación crítica puede tratar los sistemas culturales que inciden en la práctica educativa. El profesor plantea y trabaja con problemas e intenta una transformación reflexiva y crítica de la sociedad, y al mismo tiempo una mayor autonomía profesional y 
personal para planificar una intervención de mejora. Este tipo de investigación permite un mejor conocimiento del entorno y producir interpretaciones que sirvan para entender cómo se configura y se transforman las representaciones sociales (Pagés y Santisteban, 2010).

\subsection{EL PARADIGMA INTERPRETATIVO}

El paradigma interpretativo se basa en la etnografía como modelo de investigación social. Lo que se persigue es entender el mundo subjetivo de la experiencia humana (Cohen y Manion, 1989).

Según el paradigma interpretativo, el investigador trabaja con la experiencia, para a través de la reflexión de ésta llegar a elaborar sus teorías. El investigador analiza los grupos y los procesos, tanto en los aspectos generales como particulares, con la finalidad de dar validez a su descripción. Las teorías y los resultados de las investigaciones desarrolladas bajo el alero del paradigma interpretativo no se establecen como leyes universales aplicables a todas las realidades, sino más bien como experiencias obtenidas en un momento y un contexto determinado, que pueden ser comparadas con investigaciones desarrolladas en otros momentos y lugares. Como señala Armento (1991), el paradigma interpretativo nos permite utilizar las ciencias sociales como una herramienta para poder entender como los seres humanos construyen la realidad. Para lograr comprender y explicar esta construcción es necesario tomar en cuenta los contextos en los cuales se encuentran insertas las personas que están siendo estudiadas, sus creencias, experiencias y representaciones.

Nuestra investigación se sitúa en una perspectiva interpretativa los sujetos investigados son alumnos de Grado de Maestro en Primaria e Infantil y por tanto, la representación puede ser considerada, en sentido amplio, como un modo de organizar su conocimiento de la realidad, es decir del Paisaje, que está construida socialmente. Este conocimiento se elabora a partir de sus propios códigos de interpretación, culturalmente marcados, y en este sentido constituye en sí un fenómeno social. Por ello, las representaciones sociales designan una forma de conocimiento específico, que es el saber de sentido común, en el que los contenidos remiten a procesos generativos y funcionales, y designan una forma de pensamiento social (Vala, 1986; citado por Elejabarrieta, 1991).

\subsubsection{Las representaciones sociales}

El concepto de representaciones sociales designa una forma de pensamiento social. Son modalidades de pensamiento práctico orientadas hacia la comunicación, la comprensión y el dominio del ambiente social, material e ideal. La representación social 
es una teoría que integra los conceptos de actitud, opinión, estereotipos, imagen, etc., logrando llegar a un todo que es más que la suma de las partes; son una forma particular de conocimiento.

Desde la psicología social (Moscovici, 1961, 1976, 1986) y de acuerdo con la interpretación que hace Denise Jodelet (1991) se define la representación social a partir de:

imágenes que condensan un conjunto de significados: sistemas de referencias que nos permiten interpretar lo que sucede, dar sentido a lo inesperado; como categorías que sirven para clasificar las circunstancias, los fenómenos, a los individuos y a las teorías que permiten establecer hechos sobre ellos (p. 472).

Por tanto, las representaciones sociales nos sitúan en el punto donde se relacionan lo psicológico y lo social. En lo psicológico, las personas y los grupos realizan una actividad mental para posicionarse en relación con lo social. Lo social interviene: "a través del contexto concreto donde se sitúan los individuos y los grupos; a través de la comunicación que se establece entre ellos; a través de los marcos de aprehensión que proporciona su bagaje cultural; a través de los códigos, valores e ideologías relacionadas con las posiciones y pertenencias sociales específicas" (Jodelet, 1986, p. 473). El estudio de las representaciones sociales nos ayuda a entender la manera en la cual los seres humanos tratan de aprehender y entender las cosas que los rodean. Pueden distinguirse distintos campos de investigación en representaciones sociales. Uno de ellos es el que caracteriza la perspectiva original de las representaciones como conocimiento vulgar, o conocimiento popular, de ideas científicas popularizadas.

Originalmente la idea de las representaciones sociales fue desarrollada por Sergei Moscovici (1976). Lo familiar, lo conocido, nos sirve como base para comparar y entender lo que sucede alrededor de nosotros, por lo que el principio de la representación es convertir en familiar algo que hasta entonces nos resultaba extraño. Las representaciones sociales, en el sentido de conocimiento científico vulgarizado, tienen funciones declarativas, instrumentales y explicativas. El aspecto declarativo describe y da significado al fenómeno social por el que la Ciencia popularizada aparece relevante, y el aspecto explicativo proporciona una comprensión cotidiana de sus razones subyacentes.

Jodelet (1993); considera que la noción de representación social involucra lo psicológico o cognitivo y lo social, fundamentando que el conocimiento se constituye a partir de las 
experiencias propias de cada persona y de las informaciones y modelos de pensamiento que recibimos a través de la sociedad. Además señala dos aspectos básicos para su definición, por un lado las representaciones sociales son una forma de conocimiento y por otro lado son, una forma de reconstrucción mental de la realidad. Es decir, son un producto social $\mathrm{y}$, por lo tanto, el conocimiento generado es compartido colectivamente. La realidad social es una realidad construida y en permanente proceso de construcción y reconstrucción. En un proceso, que podría decirse que es a la vez cultural, cognitivo y afectivo.

Las representaciones sociales surgen como un proceso de elaboración mental e individual en el que se toma en cuenta la historia de la persona, su experiencia y construcciones personales propiamente cognitivas (Banch, 1991). Alvarez (1995), señala que las representaciones sociales articulan campos de significaciones múltiples, y que son heterogéneas. Son una forma de conocimiento que tiene un carácter colectivo e individual, esto coloca a las representaciones en dos universos teóricos relacionados con las determinaciones sociales y con la conceptualización. Fisher (1990), propone la siguiente definición:

La representación social, es un proceso de elaboración perceptiva y mental de la realidad que transforma los objetos sociales (personas, contextos, situaciones) en categorías simbólicas (valores, creencias, ideologías) y les confiere un estatuto cognitivo que permite captar los aspectos de la vida ordinaria mediante un remarque de nuestras propias conductas en el interior de las interacciones sociales (Fisher, 1990)

Las representaciones sociales son una forma de conocimiento práctico, que conduce a preguntarse por los marcos sociales, su génesis y por su función social en la relación con los otros en la vida cotidiana. Tiene un carácter constructivo, autónomo y creativo. Es importante aclarar que la representación social no es una reproducción de algo o alguien, sino una construcción, esto sucede porque siempre aparece el carácter significante de quien la representa.

Las investigaciones en el área de didáctica también hacen referencia al concepto de representaciones sociales de Moscovici (1979) y Jodelet (1986). Según Dalongeville (2003) el concepto de representaciones sociales fue exportado al área de la didáctica de las ciencias sociales por Giordan y De Vecchi desde la didáctica de las ciencias experimentales.

Tomando en cuenta la definición del concepto de representaciones sociales pensamos que la visión que presenta Evans (1988) de las concepciones es equiparable a las 
propuestas de Moscovici (1979) y Jodelet (1986). En esta investigación haremos referencia de manera indistinta a concepciones, percepciones, ideas y representaciones. Si bien reconocemos que provienen de tradiciones diferentes, las consideramos como teorías cercanas ya que nos permiten alcanzar los objetivos de nuestra investigación.

Para recabar información se utilizó un cuestionario enfocado hacia las concepciones del Paisaje de los alumnos de Grado, y algunos datos personales de estos que podían influir en la conformación de esas concepciones. La información obtenida a través de este cuestionario fue utilizada, además, para establecer tipologías.

También hemos tomado en cuenta los aportes metodológicos de Guimerá, (1991) para desarrollar nuestra investigación. Esta autora centró su investigación doctoral en reconocer las concepciones de los profesores de secundaria sobre la historia. En nuestro caso hemos adaptado algunas de sus ideas al Paisaje.

Al igual que en el caso de la investigación de Evans (1988) y Guimerá (1991) hemos recogido a través del cuestionario información relacionada con la formación disciplinar, y las ideas y conocimientos sobre el Paisaje, de los futuros docentes. Tanto en nuestra investigación, como en la de los autores citados, se persiguió establecer las relaciones existentes entre la formación disciplinar y las creencias y concepciones de los futuros profesores de Primaria e Infantil.

El trabajo de González (1993) se inscribe en la línea de análisis de las concepciones, visiones y representaciones que los estudiantes tienen de la historia. El objetivo de su investigación era "acercarse a la imagen que los estudiantes tenían de la historia y su enseñanza después de años de escolarización" (González, 1993, p. 267). Para lograr este objetivo, González diseñó un cuestionario de 41 preguntas abiertas, semi-abiertas y cerradas que fue aplicado a estudiantes de tercero de BUP de distintas Comunidades Autónomas.

En nuestra investigación se trata de analizar las concepciones y conocimientos que los estudiantes tienen del Paisaje. También hemos diseñado un cuestionario de 40 preguntas abiertas y cerradas aplicadas a los cuatro cursos del alumnado del Grado de Primaria e Infantil y un análisis de cuatro fotografías.

Así mismo, Barton (2010) constató que los estudiantes consideran la historia como una herramienta que les puede servir para sacar lecciones sobre cómo actuar. En nuestro caso, los alumnos consideran fundamental el Paisaje como un recurso importante que 
deben enseñar a sus futuros alumnos; Barton expresa que las ideas de los estudiantes están muy condicionadas por la naturaleza de su formación escolar. 


\section{METODOLOGÍA DE LA INVESTIGACIÓN}

\subsection{OBJETIVOS E HIPÓTESIS}

\subsubsection{Objetivos}

\section{Objetivo general}

Identificar y analizar las ideas, conocimientos, percepciones y valoración sobre el Paisaje de los alumnos del Grado de Maestro en Educación Primaria e Infantil en la Facultad de Educación de la Universidad de Salamanca, a fin de conocer sus representaciones, detectar posibles deficiencias, y proponer la construcción del conocimiento profesional favoreciendo la Educación en Paisaje, para mejorar la enseñanza y el aprendizaje de las Ciencias Sociales en la formación de los futuros docentes.

\section{Objetivos específicos}

- Analizar las características individuales y grupales de los alumnos de los Grados de Maestro de Educación Infantil y Primaria, en sus representaciones sobre el Paisaje

- Interpretar qué papel juegan los contextos culturales y sociales en el aprendizaje del Paisaje

- Determinar si existen diferencias significativas en la percepción del Paisaje en función de distintas variables sociodemográficas

- Distinguir qué procesos y estrategias de Enseñanza-Aprendizaje serán los más adecuados para la formación de los futuros profesores en la enseñanza de los Grados de Infantil y Primaria, en concreto el abordaje del Paisaje con calidad

- Formular orientaciones que mejoren la práctica docente de los alumnos del Grado en Maestro en Educación Infantil y Primaria

\subsubsection{Hipótesis}

La hipótesis principal de esta investigación es que los estudiantes de los Grados de Maestro poseen conocimientos disciplinares suficientes aunque incorrectos acerca del Paisaje para abordar un modelo alternativo en su formación en Ciencias Sociales.

No se pone en duda la formación disciplinar previa en Historia y Geografía. La hipótesis, por el contrario, solo trata de contrastar las condiciones de partida para la formación de 
maestros de los Grados en Educación Infantil y Primaria con un programa en el que la Educación en Paisaje ofrece una alternativa a los modelos disciplinares más habituales, con la introducción del Paisaje en los contenidos y con unas competencias específicas adecuadas en ambos grados, que basa su oportunidad en el interés social de la Educación en Paisaje, que se viene apoyando en las acciones derivadas del Convenio Europeo del Paisaje.

La hipótesis se confronta con el análisis y la descripción de las concepciones y la construcción del conocimiento del Paisaje en los alumnos del Grado de Maestro, y no conduce a una verificación universal, sino metodológica, que se va adaptando al proceso de enseñanza-aprendizaje en el currículo que se implemente.

\subsection{MÉTODOS CUANTITATIVOS Y CUALITATIVOS EN LA INVESTIGACIÓN}

El paradigma positivista surge en el S. XIX representado por Comte (1798-1857) quien distingue las ciencias de la sociedad y las ciencias naturales con relación al objeto de estudio, sin embargo no plantea una distinción en el método. Va a ser en la obra de Durkeim (1858-1917), discípulo de Comte, donde se encuentra enunciada en forma sistemática una propuesta metodológica para las Ciencia Sociales (la Sociología) que dará origen en el siglo XX al método cuantitativo. La finalidad del método cuantitativo es descubrir las leyes que regulan los procesos educativos al objeto de ofrecer y elaborar normas que mejoren la práctica escolar.

Esta investigación está basada en métodos cuantitativos porque como señala Travé (1998), es necesario que los conocimientos que tienen los alumnos sobre el Paisaje tengan una contrastación empírica, a través de unos resultados estadísticos que nos permitan conseguir unas características de fiabilidad y validez. Todo ello, con el fin de mejorar nuestra práctica educativa.

En el ámbito didáctico general hay un movimiento de crítica a los enfoques de investigación estadístico-cuantitativos y a los modelos simplificadores que consideran que la enseñanza causa el aprendizaje, modelo proceso-producto (Guba, 1981; Pérez Gómez, 1983; Porlán, 1989; Contreras, 1991). Se resaltan, por contraposición, los enfoques holísticos y situacionales, se proponen metodologías cualitativas y de estudio de casos y se comienzan a valorar los significados construidos por profesores y alumnos como variables mediadoras en el proceso de enseñanza-aprendizaje (Shavelson y Stern, 1981; Shulman, 1981; Yinger y Clark, 1982; San Martín, 1984; Clark, 1985; Pérez Gómez y Gimeno, 1988; Porlán, 1989). 
Desde el Historicismo, que constituye uno de los antecedentes de los que se denominarán métodos cualitativos se propone una práctica científica orientada a la comprensión de los fenómenos sociales en su especificidad histórica y contextualizada. Entendiendo la comprensión como la búsqueda de los significados socialmente situados.

Según Pérez (2000) una investigación cualitativa se define en contraposición a una de tipo cuantitativo, siendo una de las diferencias más importantes entre ambas la metodología utilizada para llevar a cabo el estudio. La cuantitativa recurre a los métodos positivistas propios de las ciencias naturales, busca las causas de los fenómenos de una manera independiente de los estados subjetivos de las personas. En contraposición, la investigación cualitativa trata de entender la realidad social según la percepción que tienen de ella los individuos, "se interesa por la comprensión personal, los motivos, valores y circunstancias que subyacen en las acciones humanas" (Pérez, 2000 , p. 28). Autores como Straus y Corbin señalan que hay varias razones que se pueden enumerar para explicar por qué un investigador opta por este tipo de metodología. Pueden ser la misma preferencia del investigador; la disciplina desde la que está investigando; la orientación filosófica; por la naturaleza del problema que se estudia; y, porque permite obtener detalles complejos de algunos fenómenos (2002).

Bajo el paradigma cualitativo se enmarca la investigación acción que nos permite compaginar la docencia y la investigación. El objetivo de la investigación cualitativa es estudiar y comprender fenómenos sociales complejos que contienen múltiples variables explicativas. El investigador en la metodología cualitativa, es el instrumento principal de interpretación de los datos obtenidos, lo que nos permite una mayor comprensión del fenómeno a medida que se avanza en la interpretación. Además, debe ser un buen observador y saber hacer buenas preguntas. Merrian indica que: "el diseño de un estudio cualitativo es flexible al no conocerse con antelación variables relevantes" (2009, p. 17).

Al trabajar las representaciones, concepciones, percepciones e ideas de profesores y estudiantes, una investigación cualitativa interpretativa era la que nos podía aportar más elementos para el análisis y la interpretación, lo cual justifica nuestra elección. En el ámbito de la investigación en Educación, el enfoque cualitativo tiene como principal objetivo interpretar la acción social y explicar su significado. Este tipo de investigaciones parte del supuesto de que para poder cambiar la realidad se debe conocer primero como la viven y perciben sus implicados, ya que solamente esto generará que ellos se sientan como un elemento constitutivo de ella y quieran participar en su transformación. 
Desde el punto de vista metodológico, los instrumentos más útiles para el desarrollo de una investigación cualitativa son varios como las entrevistas, los estudios de caso, el análisis de material biográfico y la observación. Nosotros hemos elegido el estudio del caso y la observación a través de fotografías.

El estudio de caso nos permite indagar en profundidad las representaciones sociales de una estudiante. Esto nos ofrece la oportunidad de conocer las creencias, las ideas, los conocimientos, pero también los sentimientos y la experiencia del alumnado en relación con un tema concreto, la enseñanza y el aprendizaje del Paisaje. Además permite un acercamiento a la vida personal y académica de los futuros maestros. Uno de los objetivos del estudio de caso es que ofrece la posibilidad de analizar e interpretar la información, no sólo desde una mirada externa y aislada, como investigadora, sino como una acompañante durante el tiempo que dura el proceso de investigación.

\subsection{FASES DEL TRABAJO DE CAMPO}

a) Primer periodo: octubre de 2014 a enero de 2015

Durante el primer periodo se obtuvo la mayor parte de los datos. En octubre se diseñó el cuestionario (anexo 1) y en noviembre, diciembre y enero se aplicó al alumnado de los cursos de primero a cuarto del Grado de Maestro en Educación Primaria e Infantil. A continuación hicimos el análisis cuantitativo de los cuestionarios que consistió en la elaboración de gráficos, tanto de las preguntas cerradas como de las abiertas. En estos gráficos incluimos los porcentajes, frases cortas o palabras que describieran de forma general las representaciones sociales con respecto al Paisaje.

Para el análisis cualitativo, me apoyé de la metodología utilizada en el estudio de Goodman \& Adler (1985). El análisis de los resultados que se presentan en esta investigación se basa en lo que sugieren Glaser \& Strauss (1997). Los resultados se presentan de forma narrativa, es decir, usando ejemplos de los participantes para aclarar los conceptos y las categorías que se formaron. Esta forma de presentación de acuerdo con Goodman \& Adler tiene el objetivo de demostrar la relación que existe entre el análisis y la realidad social. La finalidad de ello es ilustrar los conceptos y por lo tanto, proveer de una base que puede generar discusiones y debates en un futuro.

Las propuestas de Aranda (2003) y Tonda (2001) fueron utilizadas para explicar los objetivos y las finalidades que tienen el conocimiento del medio social en la educación preescolar. Los artículos de Pagès $(1994,1997,2010,2011)$ y Pagès \& Santisteban 
(2011) en relación con la formación del profesorado y la didáctica de las ciencias sociales fueron utilizados para comprender los procesos de enseñanza y aprendizaje de los conocimientos sociales

b) Segundo periodo: febrero de 2015 a abril de 2015

El segundo periodo de trabajo de campo coincidió con el segundo cuatrimestre del curso académico (2014-2015). Se pidió a los alumnos de primero y tercero de ambas especialidades que describieran los Paisajes de las 4 imágenes elegidas y que aparecen en el anexo 2.

\subsection{LA MUESTRA}

La matrícula del curso 2014-15 del Grado de Educación Primaria y Educación Infantil de la Facultad de Educación de la Universidad de Salamanca fue de 954 alumnos. De ellos se seleccionó una muestra, el tamaño total de la ha sido de 554 estudiantes, 267 del Grado de Infantil y 287 del Grado de Primaria.

El trabajo de campo se realizó en las aulas de la Facultad de Educación y el tiempo fue en el primer trimestre del curso, de octubre del 2014 a enero del 2015.

El nivel de confianza utilizado ha sido 2 sigmas, equivalente al 95,5\% de probabilidad y un margen de error de $+/-4 \%$, siendo la varianza poblacional: $p=q=0,5$.

\section{Ficha técnica:}

- Universo: Alumnado del Grado de Educación Infantil y Primaria.

- Población: Alumnos y alumnas del Grado de Educación Infantil y Primaria en el curso 2014-15, era de 554.

- Error global de estimación: $\pm 4 \%$

- Nivel de confianza: $95,5 \%$

$$
\mathbf{p} / \mathbf{q}=0,5 / 0,5
$$


La finalidad de los instrumentos fue indagar las representaciones sociales generales sobre la enseñanza de las ciencias sociales y profundizar en el análisis de las representaciones sociales sobre el Paisaje.

Los instrumentos de medida utilizados como base de este trabajo, han consistido en la aplicación de un cuestionario estandarizado sobre "EL CONOCIMIENTO DEL PAISAJE EN EL ALUMNADO DEL GRADO DE EDUCACIÓN INFANTIL Y PRIMARIA" y el análisis de fotografías sobre el Paisaje.

\subsection{INSTRUMENTO CUANTITATIVO: EL CUESTIONARIO}

Es el instrumento formalizado para recopilar la información de los futuros profesores, que contiene las preguntas a realizar y los espacios destinados a las respuestas; es decir, es la traducción de los objetivos informativos de la investigación en preguntas específicas (Fraile y Maya, 2015).

La elección de esta herramienta ha venido motivada por algunas de sus ventajas: su costo relativamente bajo, su capacidad para proporcionar información sobre un mayor número de personas en un período bastante breve y la facilidad de obtener, cuantificar, analizar e interpretar los datos.

En el diseño de este cuestionario destinado al alumnado optamos por una estructura mixta de preguntas abiertas y cerradas, que responden a los siguientes objetivos:

- Valorar las expectativas y los conocimientos del alumnado respecto al concepto de Paisaje.

- Disponer de información para poder diseñar alguna estrategia de trabajo con relación al Paisaje como recurso educativo.

- Valorar la opinión que tiene el alumnado sobre la formación en educación Infantil y Primaria sobre el Paisaje.

Preparamos un cuestionario estandarizado de preguntas abiertas, cerradas y otras en las que se aplicó la escala Likert (anexo 1), todas ellas relacionadas con nuestro objeto de estudio. Se han seleccionado aquellas variables que a nuestro juicio, podían darnos mayor información en relación al conocimiento que el alumnado tiene sobre la realidad del Paisaje. 
La intencionalidad del cuestionario era la de recoger todos los aspectos que integran el concepto de Paisaje, así como acercarnos al conocimiento, valoraciones, opiniones y percepciones de los alumnos y alumnas del Grado de Maestro, de la Facultad de Educación.

Por ello, dividimos el cuestionario en los siguientes apartados:

a) Información socio-demográfica: edad y sexo, titulación, curso, centro de estudios y si se disponía de alguna titulación previa.

b) Información acerca de la opinión de los encuestados: se expresa en una serie de ítems de carácter continuo.

Las preguntas de investigación se han obtenido tras la formulación de hipótesis sobre el tema objeto de investigación, de las cuales se han sacado las variables correspondientes para confeccionar el cuestionario. Su análisis se ha realizado con el programa estadístico SPSS, versión 22, del que hemos obtenido numerosas tablas, que nos han permitido contrastar las hipótesis y cumplir algunos de nuestros objetivos.

El cuestionario se aplicó previamente a un pequeño grupo de alumnos y alumnas (estudio piloto) con el objeto de poder mejorar algunos aspectos, tales como el cambio de redacción de algunas preguntas, eliminar alguna reiteración etc. formulando preguntas abiertas para obtener las respuestas correspondientes a cada una de dichas preguntas y de esta forma confeccionar el cuestionario definitivo de aquellas variables con preguntas cerradas. Finalmente, el cuestionario quedó estructurado del siguiente modo: 40 ítems en total, de los cuales 6 son de tipo Likert. Además hay 11 preguntas abiertas, denominadas de opinión.

Una vez elaborado el cuestionario definitivo, fue aplicado al alumnado del Grado de Infantil y Primaria en la Facultad de Educación de la Universidad de Salamanca.

El cuestionario recoge datos que creemos fundamentales para profundizar en nuestro objeto de estudio. Con dichos datos pretendemos precisar la opinión sobre el conocimiento del Paisaje de los futuros profesionales en Maestro de Educación Infantil y Primaria.

\subsection{INSTRUMENTO CUALITATIVO: ANÁLISIS DE FOTOGRAFÍAS}

Dado el objeto de estudio que nos ocupa nos parecía fundamental optar dentro de las herramientas metodológicas por realizar un análisis de las fotografías sobre diferentes 
Paisajes para conocer el grado de conocimientos y las percepciones que tiene el alumnado de Educación Infantil y Primaria sobre estas imágenes propuestas

Las técnicas cualitativas de investigación enfatizan la obtención de información referida básicamente a percepciones, actitudes, opiniones, significados y conductas. Por lo que analiza e interpreta el lenguaje para encontrar el sentido oculto del fenómeno social que se está investigando.

Ibáñez (1992) ha destacado que lo central de la investigación cualitativa es la utilización del lenguaje como representación simbólica de la comunicación social, del mundo subjetivo de las creencias, valores, motivaciones, deseos y significados que caracteriza a los hechos sociales. Se considera que el verdadero dato es el significado, que su magnitud está conformada por su nivel de significación y que el dato sólo tiene significación en una estructura de relaciones.

Las representaciones de la realidad captadas a partir de instrumentos y técnicas gráficas de diferentes tipos constituyen una fuente de información y una forma de comunicación utilizada en educación y más concretamente en geografía. Entre las fuentes utilizadas destacan las fotografías terrestres y aéreas que representan Paisajes.

A los documentos se les puede "entrevistar" mediante preguntas implícitas y se les puede "observar" con la misma intensidad y emoción con la que se observa un rito nupcial, una pelea callejera o una manifestación popular. En este caso la lectura es una mezcla de entrevista/observación y puede desarrollarse como cualquiera de ellas (Ruiz Olabuénaga e Ispizua, 1989, p. 69).

Hemos utilizado la imagen fotográfica como recurso con el alumnado de $1^{\circ}$ y $3^{\circ}$ del Grado de Maestro en Educación Infantil y Primaria, porque puede ser introducida en el proceso de enseñanza-aprendizaje dado su interés y conocimiento por los estudiantes y su accesibilidad técnica, con el objetivo de saber qué conocimientos y percepciones tiene nuestro alumnado sobre el Paisaje.

En las últimas décadas ha sido frecuente el empleo de las fotografías en las investigaciones llevadas a cabo en el ámbito de la educación y de las ciencias sociales. El empleo de las fotografías permite a los investigadores obtener un punto de vista de la realidad social, en este caso concreto del Paisaje, que investigan desde la perspectiva de los informantes, es decir del alumnado.

Las fotografías son recursos adecuados para trabajar en distintos niveles de la enseñanza, ya que sirven para que el investigador pueda conocer un mundo de 
experiencias que de otra manera sería muy difícil, como por ejemplo, a través de una entrevista convencional. Además, las fotografías son un método fundamental cuando la investigación es especialmente sensible o pueda afectar emocionalmente a los encuestados y suponen la forma de representación que más directamente enlaza el aula con la realidad.

La utilización de la fotografía en la enseñanza es importante porque un saber no se aprende si no se entiende y se interpreta lo visualizado, si no se cuestiona el mismo conocimiento, si no se discute, si no se verbaliza en las palabras de uno mismo, en lo que los expertos han llamado transposición didáctica, y sobre todo, si no se practica (Gavaldà, 2007) ${ }^{5}$.

Son muchas las temáticas, en este caso concreto es el Paisaje, a considerar para utilizar adecuadamente la fotografía en el aula, en el que se encuadraría el uso de la fotografía y valorar su papel en la construcción del conocimiento. Ante esta situación, el profesorado debe ser competente en la interpretación y valoración de las imágenes para poder evaluar la intencionalidad del autor, su significado como lenguaje y forma de comunicación y su interés en la construcción del conocimiento Álvarez Orellana (2006). Esta misma autora señala que el profesorado precisa de un conocimiento práctico sobre la fotografía. Necesita saber para qué sirve y el conocimiento procedimental del saber "leer e interpretar" y reflexionar sobre las competencias intelectuales y sociales que se activan al poner en marcha su lectura e interpretación y reconocer las características internas de los tipos de actividades utilizadas en dicha lectura.

La interpretación de la fotografía en general y de la fotografía del Paisaje en particular, no ha sido siempre igual. Ha ido evolucionando en función del enfoque metodológico dado en cada etapa. Resumiendo, puede decirse que metodológicamente hablando, ha ido desde la observación y el análisis descriptivo de los elementos de la Geografía Clásica, hacia una interpretación más compleja, en la que adquiere protagonismo la percepción individual, los significados personales y sociales, el análisis sistémico, la interpretación y el planteamiento de hipótesis y la reflexión sobre la evolución del territorio representado para elaborar propuestas, en relación con las distintas interpretaciones llegadas desde la Geografía de la Percepción, la Teoría de Sistemas, la Geografía Radical y la Geografía Humanística. Es importante el cambio metodológico que se ha producido en los últimos años para el estudio del Paisaje, pero sobre todo a partir del Convenio Europeo del Paisaje del año 2000.

\footnotetext{
${ }^{5}$ Traducción propia de la versión original escrita en catalán por el autor Antoni Gavaldà, 2007.
} 
El uso de la fotografía en el contexto docente necesita además del conocimiento teórico y práctico, conocimientos didácticos relativos al valor que tiene o adquiere la fotografía como recurso didáctico, en relación con las características del alumnado y a las estrategias didácticas utilizadas.

Arqué Bertrán (1996) explica que:

en didáctica de las Ciencias Sociales, hay diversos procedimientos necesarios y complementarios para el estudio del Paisaje. Entre ellos la fotografía es un recurso de gran utilidad en las aulas porque facilita, la observación y adquisición potencial de conceptos. La fotografía de Paisaje es considerada como un género dentro de la fotografía documental, dada su fuerza para documentar con realismo lugares y hechos, pero su característica más importante es el protagonismo que tienen los escenarios de la acción humana más que por los mismos grupos humanos. En todo Paisaje, la organización espacial, los cambios estacionales, las transformaciones a lo largo del tiempo son aspectos clave en la observación y en la interpretación ${ }^{6}$ (1996, p. 125).

Esta investigadora elaboró una propuesta metodológica para trabajar con fotografías en el aula. Es más, debido a su experiencia con los alumnos universitarios de Magisterio comenta que las imágenes de las fotografías pueden ser susceptibles de un análisis cuantitativo y cualitativo de la misma manera que un texto escrito, ya que éstas nos muestran un mundo más complejo del que aparentemente aparece en la vida real.

Teniendo en cuenta todas estas consideraciones y estando de acuerdo con la importancia de la imagen visual en el proceso de enseñanza-aprendizaje en la didáctica de las ciencias sociales y en concreto del Paisaje, elegimos 50 fotografías para la investigación, las analizamos de acuerdo a nuestros propósitos, y al final seleccionamos 4 que nos parecieron las más significativas.

Para seleccionar las fotografías nos apoyamos en aquellas que las imágenes abarcaban vistas panorámicas con gran riqueza de elementos y temáticas muy diferentes. Todas las imágenes requieren un tiempo mínimo de observación y de análisis para que permita al alumnado obtener una información suficiente para la reflexión.

Sobre el número de fotografías más adecuado para desarrollar en una sesión hemos barajado diversas cifras. De acuerdo con Álvarez Orellana (2006), el n ${ }^{\circ}$ puede ser muy variable y depende del uso que se haga de las mismas. Finalmente optamos por 4 para evitar la pérdida de interés de los encuestados.

\footnotetext{
${ }^{6}$ Traducción propia de la versión original escrita en catalán de la autora Arqué Bertrán.
} 
Las fotografías seleccionadas se le han pasado al alumnado del Grado de Educación Infantil y Primaria, en los cursos de $1^{\circ}$ y $3^{\circ}$. Nos interesaba conocer la diferencia que había en el alumnado de los dos cursos sobre la representación del Paisaje que visualizan en cada una de las fotografías.
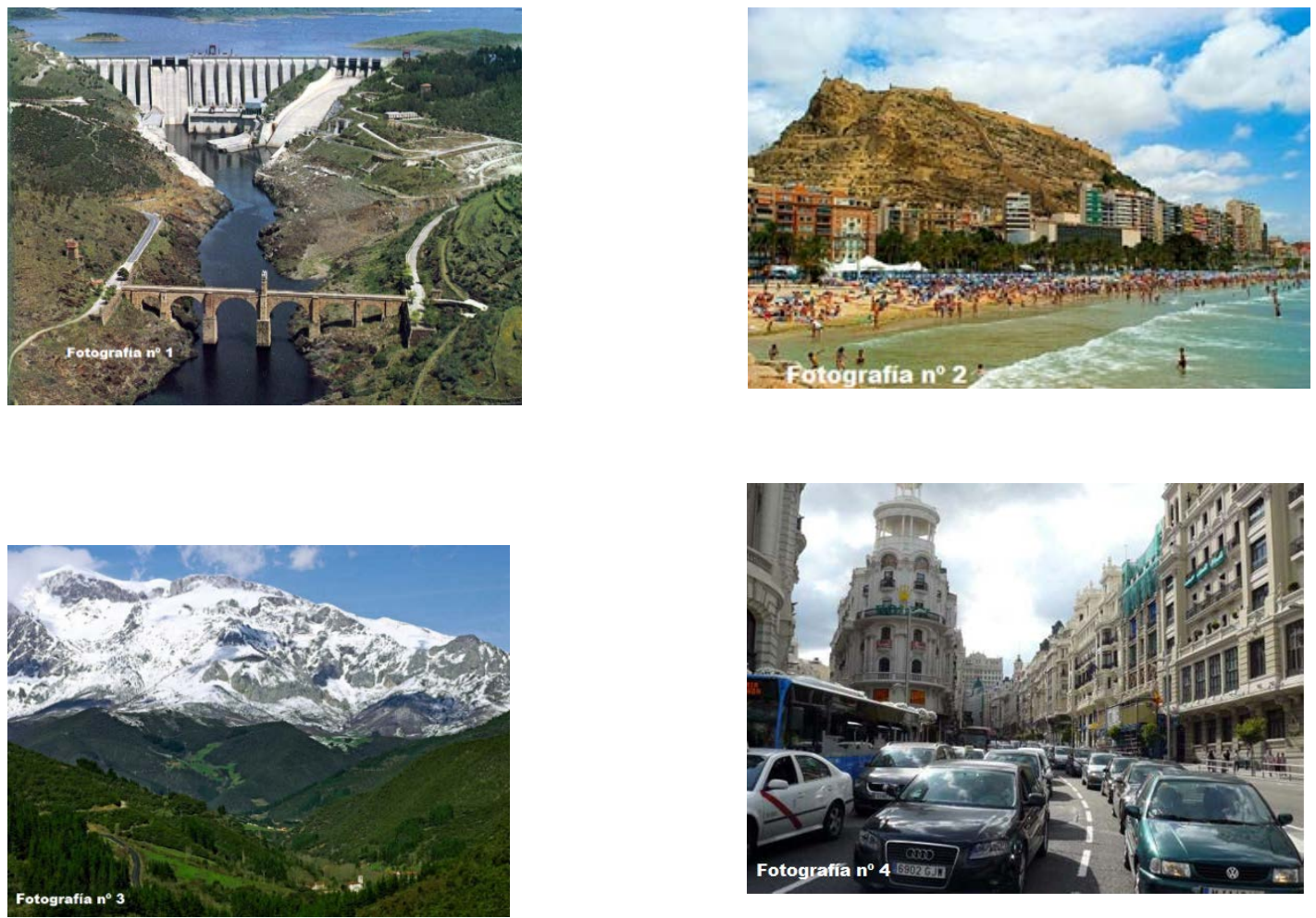


\section{ANÁLISIS DE RESULTADOS}

En el siguiente capítulo se expone el análisis de los resultados obtenidos tras la aplicación del cuestionario que constituye el instrumento central del trabajo de campo de esta tesis (anexo 1).

Las respuestas a los ítems del cuestionario de los alumnos de Grado de Maestro de Educación Infantil y de Educación Primaria participantes, nos han proporcionado los datos que posteriormente hemos cuantificado, analizado, ordenado e interpretado, obteniendo un perfil del tipo de alumnos que han colaborado en la investigación, para presentar así a los protagonistas del estudio.

La cuantificación de las respuestas nos ha permitido ordenarlas cruzando las variables dependientes e independientes, y realizar el análisis descriptivo y explicativo de las mismas. Las variables independientes elegidas fueron las siguientes:
a) Por especialidades
b) Por fases o etapas del Grado
c) Por ámbito donde cursó los estudios anteriores.
d) Por lugar de nacimiento

Una parte de la información proporcionada por los alumnos se recogió de las respuestas a un conjunto de preguntas abiertas, cuyo objeto era obtener información lo más precisa y clara posible sobre el conocimiento, la percepción y la valoración que los alumnos tienen sobre al Paisaje, indagando sobre los siguientes aspectos:

- $\quad$ La labor de los maestros en la formación de los alumnos sobre el Paisaje

- Definiciones e ideas de los alumnos sobre el Paisaje

- $\quad$ Percepciones y valoraciones sobre el Paisaje

- $\quad$ La utilidad del conocimiento del Paisaje en la formación de los maestros

- $\quad$ Los fines que los futuros docentes asignan a la enseñanza del Paisaje

Con ese propósito hemos transcrito también textualmente algunos de los párrafos que el propio alumnado nos ha transmitido en las preguntas abiertas, situándolos en los apartados correspondientes relacionados con los temas tratados.

Finalmente, para acometer el análisis de las preguntas abiertas del cuestionario, se procedió a clasificar las respuestas emitidas por los participantes en categorías y 
subcategorías, Se crearon variables dicotómicas (si/no) para cada una de estas categorías y sub-categorías, y se registraron las respuestas de los sujetos en cada una de las preguntas abiertas asignándolas a todas las categorías y sub-categorías a las que los términos expresados en la respuesta hacían referencia.

\subsection{DATOS SOCIODEMOGRÁFICOS DE LOSIAS ESTUDIANTES DEL GRADO DE MAESTROIA DE EDUCACIÓN INFANTIL Y PRIMARIA}

En la encuesta han participado 554 estudiantes: 267 (un 48\%) de la especialidad de Infantil y 287 (un 52\%) de la de Primaria estando por tanto equilibradas ambas especialidades. Por otro lado podemos observar que por cursos hay cerca de un $30 \%$ del $1^{\circ}$ curso, frente al $24 \%$ y el $27 \%$ de los de $2^{\circ}$ y $3^{\circ}$ y desciende hasta poco más del 18\% en los alumnos/as del último año (fig. 1).

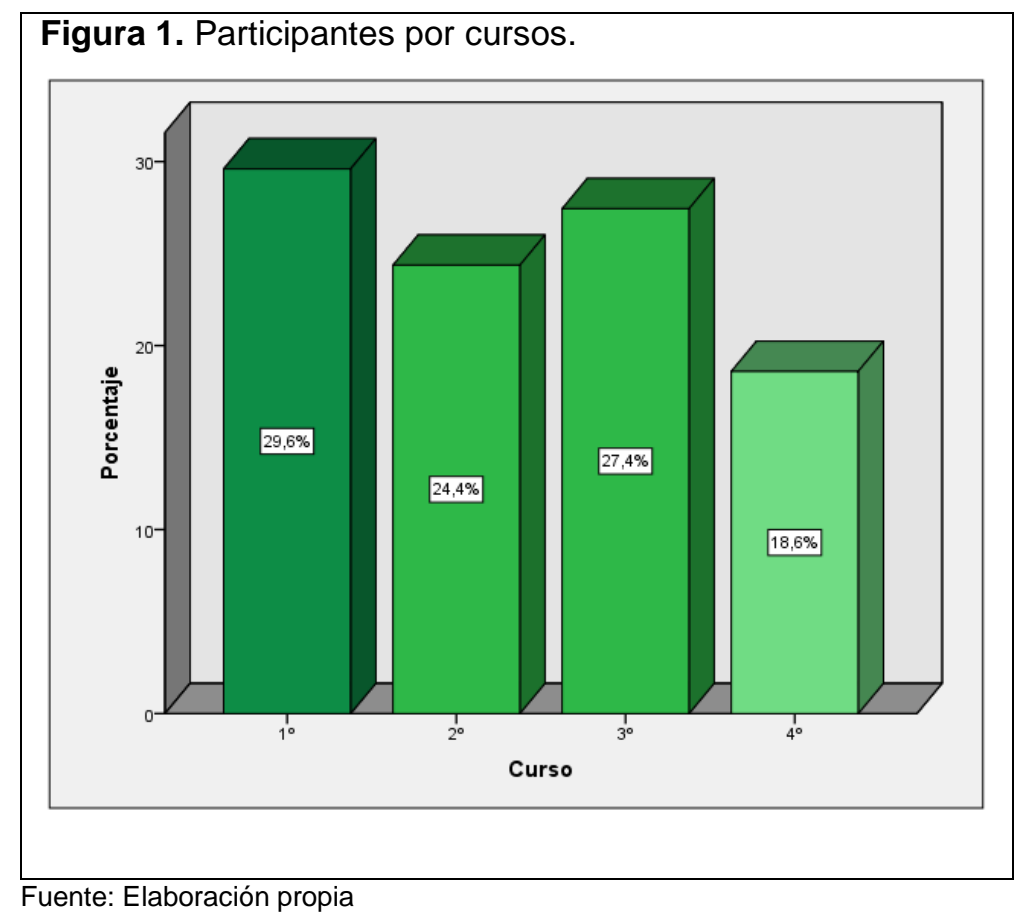

\subsubsection{Sexo, edad y procedencia de los alumnos encuestados}

En la figura 2 podemos observar que en Infantil, los 4 cursos están representados de manera homogénea variando entre el $28 \%$ de $1^{\circ}$ y $21 \%$ de $2^{\circ}$; En Primaria la homogeneidad es aún mayor en los tres primeros cursos, con solo tres puntos de diferencia, sin embargo se aprecia de forma clara el descenso que se produce entre estos y hasta el $12 \%$ del $4^{\circ}$ curso. La inasistencia en las fechas en que se pasó el cuestionario hace que tengamos que trabajar con resultados incompletos, aunque la división que 
haremos, a efectos del análisis, en las dos fases o etapas de los estudios, reste importancia a estas cifras.

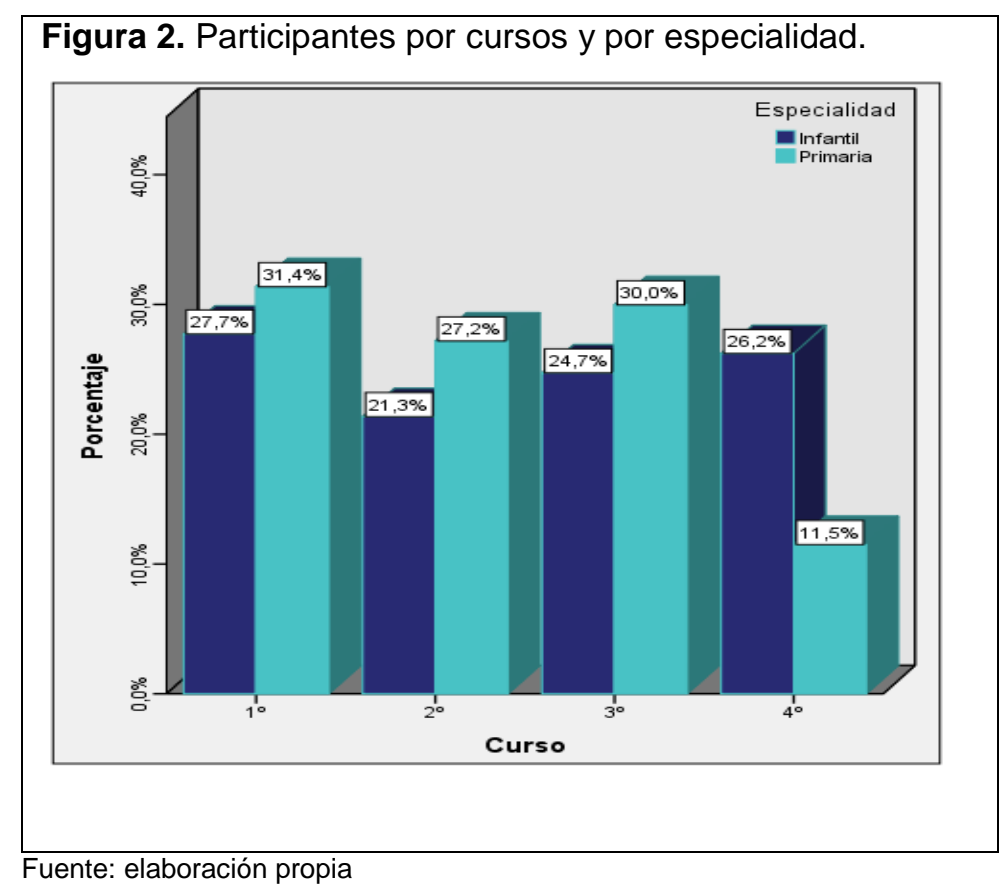

De todo el alumnado encuestado, podemos observar en la tabla 1 que casi un $83 \%$ son mujeres (459) que son una clara mayoría frente al 17\% de varones (95), cifra casi proporcional a las de la matrícula en ambos grados (28\% de alumnos y $72 \%$ de alumnas). Estas cifras reflejan la realidad, de que a pesar de estar en el siglo XXI, las mujeres se siguen decantando por esta profesión. Esta composición refleja el papel subalterno, tanto de la mujer como de la profesión docente, en el imaginario social; a pesar de los cambios que se han producido en nuestra sociedad, todavía queda mucho por alcanzar.

En cuanto a la edad, se ha detectado la participación de algunos casos aparentemente fuera del rango habitual para un universitario de grado (de 18 a 22 años). En concreto hay cerca de un $30 \%$ de casos que tienen 23 o más años y si extendemos la edad habitual para permanecer en la universidad haciendo un grado hasta los 26 años, aún hay casi un 5\% que supera la edad. La edad media de los participantes es de 21 años. La media de edad de los hombres (21.4) y de las mujeres (21.2) como se puede ver son similares. La presencia del alumnado de mayor edad puede ser debido a que ha coincido con los años de la crisis económica y encontrándose sin trabajo han decidido seguir formándose. El análisis del cuestionario nos dirá el grado de influencia que esto pudiera tener en los resultados. 


\begin{tabular}{lllll}
\hline \multicolumn{2}{l}{ Tabla 1. Características sociodemográficas por especialidad. } & & \\
\hline \multirow{2}{*}{ Variables } & Categorías & Totales & Infantil & Primaria \\
& & $(\mathrm{N}=554)$ & $(\mathrm{N}=267)$ & $(\mathrm{N}=287)$ \\
\hline \multirow{2}{*}{ Género } & Mujer & $82.9 \%$ & $\mathbf{9 7 . 4 \%}$ & $69.3 \%$ \\
& Hombre & $17.1 \%$ & $2.6 \%$ & $\mathbf{3 0 . 7 \%}$ \\
Edad & -- & 21.2 & 21.5 & 20.9 \\
\multirow{2}{*}{ Autonomía origen } & Castilla y León & $67.0 \%$ & $\mathbf{7 2 . 3 \%}$ & $62.1 \%$ \\
& Extremadura & $13.7 \%$ & $10.6 \%$ & $\mathbf{1 6 . 5 \%}$ \\
& Aut. mitad norte & $8.9 \%$ & $6.1 \%$ & $\mathbf{1 1 . 6 \%}$ \\
& Aut. mitad sur & $7.8 \%$ & $9.1 \%$ & $6.7 \%$ \\
Autonomía residencia & Extranjero & $2.6 \%$ & $1.9 \%$ & $3.2 \%$ \\
& Castilla y León & $90.3 \%$ & $92.5 \%$ & $88.3 \%$ \\
& Extremadura & $6.4 \%$ & $5.7 \%$ & $7.1 \%$ \\
& Aut. mitad norte & $1.8 \%$ & $1.1 \%$ & $2.5 \%$ \\
& Aut. mitad sur & $1.5 \%$ & $0.8 \%$ & $2.1 \%$ \\
\hline
\end{tabular}

Fuente: elaboración propia

En relación con las características sociodemográficas, cuyos resultados se resumen en la tabla 1, aunque las mujeres son mayoría en la muestra, están mucho más presentes en la especialidad de Infantil (97\%) que en la de Primaria (69\%) donde están casi todos los varones participantes. En la edad se aprecia una leve diferencia de medio año, siendo mayores los sujetos de Infantil.

El factor lugar de nacimiento, ha presentado un número de respuestas muy diferentes. En primer lugar se decidió categorizarlo por comunidad autónoma. Aunque evidentemente no están representadas todas, el número sigue siendo elevado y de muchas de ellas hay muy pocos participantes. De manera que se decidió reagruparlas en los 4 niveles que se citan en la tabla 1.

La Autonomía más representada es Castilla y León con un $67 \%$ de casos, aunque hay más en Infantil (72\%) que en Primaria (62\%), seguida de Extremadura con un 14\% que está más representada en Primaria (17\%) que en Infantil (11\%). Las demás autonomías no llegan a estar presentes en más de un 3\% (País Vasco). Si tenemos en cuenta el mapa español, podemos agruparlas en la mitad norte (casi un 9\%) y la mitad sur (8\%). Además, hay la misma representación del alumnado que viene del País Vasco con el de procedencia extranjera (3\%), este número de alumnos son los que vienen con el programa Erasmus. En cuanto al alumnado de Castilla y León se aprecia una diferencia de 10 puntos entre la especialidad de Infantil y Primaria (72 y 62\%). En cuanto a las Autonomías de residencia, el 90\% lo hace en Castilla y León, con una diferencia de 4 puntos en ambas especialidades, siendo a favor de infantil, y en concreto, residen en Salamanca el $83 \%$ de los participantes (84\% en Infantil y $82 \%$ en Primaria). 


\subsubsection{Estudios anteriores del alumnado participante en la encuesta}

El 87\% del alumnado que llega a la Universidad de Salamanca ha cursado el bachillerato como estudios anteriores, aunque este porcentaje es mayor en Primaria que en Infantil (90 y 84\%). En FP se produce el fenómeno contrario debido a la existencia de un módulo específico de FP, un 15\% estudian Infantil frente al $8 \%$ que lo hacen en Primaria (tabla 2). En cuanto al tipo de bachillerato, casi un $80 \%$ realizó el bachillerato por CC. Sociales y Humanidades, le sigue el bachillerato Científico-Tecnológico con un 11\%.

\begin{tabular}{lllll}
\hline \multicolumn{2}{l}{ Tabla 2. Estudios previos del alumnado por especialidad. } \\
\hline \multirow{2}{*}{ Variables } & Categorías & $\begin{array}{c}\text { Totales } \\
(\mathrm{N}=554)\end{array}$ & $\begin{array}{c}\text { Infantil } \\
(\mathrm{N}=267)\end{array}$ & $\begin{array}{l}\text { Primaria } \\
(\mathrm{N}=287)\end{array}$ \\
\hline Estudios anteriores & Bachillerato & $87.0 \%$ & $83.5 \%$ & $\mathbf{9 0 . 2 \%}$ \\
& Formación Prof. & $11.0 \%$ & $\mathbf{1 4 . 7 \%}$ & $7.7 \%$ \\
& Otros & $2.0 \%$ & $1.9 \%$ & $2.1 \%$ \\
Tipo Bachillerato & CC. Sociales y & $52.6 \%$ & $51.8 \%$ & $53.3 \%$ \\
& Humanidades & $79.7 \%$ & $82.9 \%$ & $77 \%$ \\
& Cientif-Tecnolog. & $10.6 \%$ & $7.7 \%$ & $13.2 \%$ \\
& CC. de la Salud & $6.5 \%$ & $5.9 \%$ & $7.0 \%$ \\
& Artes & $1.9 \%$ & $2.3 \%$ & $1.6 \%$ \\
Ámbito del centro & CC. Naturales & $1.3 \%$ & $1.4 \%$ & $1.2 \%$ \\
& Urbano & $69.9 \%$ & $76.0 \%$ & $64.3 \%$ \\
Gestión del centro & Rural & $30.1 \%$ & $24.0 \%$ & $\mathbf{3 5 . 7 \%}$ \\
& Público & $77.6 \%$ & $75.2 \%$ & $79.7 \%$ \\
& Concertado & $20.1 \%$ & $22.1 \%$ & $18.2 \%$ \\
& Privado & $2.4 \%$ & $2.7 \%$ & $2.1 \%$ \\
\hline
\end{tabular}

Fuente: elaboración propia

El ámbito del centro donde cursaron sus estudios anteriores fue principalmente urbano (70\%), aunque con mayor presencia en los de Infantil (76\%) que en los de Primaria (64\%). Tres de cada cuatro encuestados realizó sus estudios en un centro público, un $20 \%$ lo hizo en un centro concertado, mientras que apenas los privados tienen representación. No hay diferencias significativas entre las dos especialidades.

Este dato nos confirma que el nivel económico de nuestro alumnado es medio, ya que un 58\% del alumnado de los alumnos de Grado de la Facultad disfruta de una beca, aunque son más los alumnos de la especialidad de Infantil (64\%) que entre los alumnos de Primaria (52\%) quienes tienen ese privilegio. Hoy con los nuevos planes de estudio es muy importante salir a hacer algún curso en otra universidad dentro o fuera de España, aunque en Educación Infantil y Primaria son escasas estas salidas, como nos lo reflejan los datos que nos ha dado el alumnado encuestado. La estancia en el extranjero con becas Erasmus, apenas un 2.2\% (12 casos) sí la han realizado: 8 de Primaria (un 2.8\%) y 4 de Infantil (1.5\%). Como queda reflejado (tabla 3). 


\begin{tabular}{lllll}
\hline \multicolumn{3}{l}{ Tabla 3. Característica personales del alumnado por especialidad. } & & \\
\hline \multirow{2}{*}{ Variables } & Categorías & $\begin{array}{c}\text { Totales } \\
(\mathrm{N}=554)\end{array}$ & $\begin{array}{c}\text { Infantil } \\
(\mathrm{N}=267)\end{array}$ & $\begin{array}{c}\text { Primaria } \\
(\mathrm{N}=287)\end{array}$ \\
\hline Vive en ... & Hogar fam. padres & $54.7 \%$ & $\mathbf{6 1 . 4 \%}$ & $48.4 \%$ \\
& Piso compartido & $33.8 \%$ & $28.1 \%$ & $\mathbf{3 9 . 0 \%}$ \\
& Hogar fam. propio & $5.8 \%$ & $6.4 \%$ & $5.2 \%$ \\
& Residencia & $3.8 \%$ & $2.6 \%$ & $4.9 \%$ \\
Ordenador propio & Otro & $2.0 \%$ & $1.5 \%$ & $2.4 \%$ \\
Teléfono móvil & Sí & $98.0 \%$ & $98.1 \%$ & $97.9 \%$ \\
Conexión internet & Sí & $99.8 \%$ & $99.6 \%$ & $100 \%$ \\
Ha trabajado & Sí & $96.7 \%$ & $\mathbf{9 8 . 5 \%}$ & $95.1 \%$ \\
Becario & Sí & $44.9 \%$ & $42.2 \%$ & $47.4 \%$ \\
\hline Fuente: elaboración propia & Sí & $57.5 \%$ & $\mathbf{6 3 . 5 \%}$ & $51.9 \%$ \\
\hline
\end{tabular}

Fuente: elaboración propia

Prácticamente el total de los encuestados hacen uso de las nuevas tecnologías, observando que todos tienen ordenador propio y teléfono móvil, sin que sea posible detectar diferencias entre especialidades. En cambio, aunque es muy alta la tasa de participantes que tienen conexión a internet (casi el 97\%), es más alta entre los de Infantil (99\%) que entre los de Primaria (95\%).

Es necesario resaltar que nuestro alumnado compagina estudios y trabajo, casi la mitad de la muestra ha tenido un trabajado remunerado (45\%), no habiendo diferencias entre especialidades.

Una de cada tres personas de la muestra encuestada lee la prensa a diario, si bien son más los del grupo de la especialidad de Primaria (37\%) que los de Infantil (27\%) quienes se decantan por la lectura. La relación de periódicos citados es también muy elevada, por lo que se puede decir que destacan los diarios digitales y los regionales asociados al lugar de origen de los encuestados.

Cuando elaboramos la encuesta, nos pareció interesante y significativo conocer si dentro de sus aficiones, o gustos estaba "el viajar". Si era así, se les preguntó cuáles eran los motivos para viajar, ya que esta afición les permitía entrar en contacto y valorar nuevos Paisajes. Los resultados fueron que dos de cada tres manifestaron que lo hacían por ocio, un $40 \%$ por descanso y un $38 \%$ por motivos culturales. Hay un $16 \%$ que respondieron que esos viajes lo realizan por ver naturaleza, siendo tres puntos superior en el alumnado de Primaria que en el de Infantil. No podemos obviar el $6 \%$ de la muestra dicen que esos viajes lo hacen porque son voluntarios de alguna ONG, aunque no hay diferencia entre especialidades (tabla 4). 


\begin{tabular}{llcc}
\hline \multicolumn{1}{l}{ Tabla 4. Motivos para viajar por especialidad. } & & \\
\hline Variables & $\begin{array}{l}\text { Totales } \\
(\mathrm{N}=554)\end{array}$ & $\begin{array}{c}\text { Infantil } \\
(\mathrm{N}=267)\end{array}$ & $\begin{array}{c}\text { Primaria } \\
(\mathrm{N}=287)\end{array}$ \\
\hline Ocio & $66.8 \%$ & $67.0 \%$ & $66.6 \%$ \\
Descanso & $40.4 \%$ & $44.6 \%$ & $36.6 \%$ \\
Cultura & $37.7 \%$ & $34.5 \%$ & $40.8 \%$ \\
Naturaleza & $15.5 \%$ & $14.2 \%$ & $16.7 \%$ \\
Voluntariado & $6.1 \%$ & $6.7 \%$ & $5.6 \%$ \\
Otros & $2.5 \%$ & $1.5 \%$ & $3.5 \%$ \\
\hline Fuente: elaboración propia & & &
\end{tabular}

\subsubsection{El entorno familiar y el lugar de residencia de los alumnos encuestados}

Cuando les preguntamos por el lugar en el que viven, algo más de la mitad de la muestra, un 55\%, afirma que vive en la casa de sus padres, siendo mayor la tasa en el caso de Infantil (61\%) que en el de Primaria (48\%). Un 34\% vive en un piso compartido con compañeros o compañeras, siendo en Educación Primaria mayor el porcentaje (39\%) que en Infantil (28\%). También tenemos que reseñar que hay casi un $6 \%$ que tienen su propia vivienda o un $4 \%$ que viven en alguna residencia universitaria (tabla 5).

En lo que se refiere a la familia, el número de hermanos en la muestra es ligeramente superior a 1,2 tanto en la muestra total como en los grupos de cada especialidad.

El 45\% de los padres del alumnado entrevistado tienen estudios primarios, seguido del nivel de secundaria con un $33 \%$ y un $20 \%$ que dicen tener estudios universitarios. Sin embargo, se han encontrado diferencias entre las especialidades: en Infantil, la mitad de los entrevistados dicen que su padre tiene estudios primarios y solo un $16 \%$ llegan a ser universitarios. En cambio, en la muestra encuestada en Primaria, hay más padres universitarios (23\%) pero también hay un $5 \%$ que no tienen estudios y un $2 \%$ en Educación Infantil (tabla 5).

En cuanto a los estudios de la madre, los niveles de Primaria y secundaria tiene casi la misma tasa (37\% y $38 \%$ ) sin que haya diferencias notables entre especialidades. Sin embargo, tenemos que hacer referencia a que las madres con estudios universitarios son casi tres puntos superiores que los estudios de los padres. 


\begin{tabular}{lllll}
\hline \multicolumn{2}{l}{ Tabla 5. Características familiares del alumnado por especialidad } & & \\
\hline \multirow{2}{*}{ Variables } & Categorías & $\begin{array}{l}\text { Totales } \\
(\mathrm{N}=554)\end{array}$ & $\begin{array}{c}\text { Infantil } \\
(\mathrm{N}=267)\end{array}$ & $\begin{array}{l}\text { Primaria } \\
(\mathrm{N}=287)\end{array}$ \\
\hline Número de hermanos & -- & 1.24 & 1.26 & 1.23 \\
Estudios del padre & Sin estudios & $3.1 \%$ & $1.5 \%$ & $4.6 \%$ \\
& Primarios & $44.6 \%$ & $\mathbf{5 1 . 2} \%$ & $38.7 \%$ \\
& Secundarios & $32.7 \%$ & $31.5 \%$ & $33.7 \%$ \\
& Universitarios & $19.6 \%$ & $15.8 \%$ & $\mathbf{2 3 . 0 \%}$ \\
\multirow{2}{*}{ Estudios de la madre } & Sin estudios & $2.0 \%$ & $2.3 \%$ & $1.8 \%$ \\
& Primarios & $37.3 \%$ & $40.2 \%$ & $34.7 \%$ \\
& Secundarios & $37.9 \%$ & $38.6 \%$ & $37.2 \%$ \\
& Universitarios & $22.8 \%$ & $18.9 \%$ & $26.3 \%$ \\
\hline
\end{tabular}

Fuente: elaboración propia

El análisis de las profesiones es especialmente difícil, pues al ser pregunta abierta la variedad de las respuestas es enorme. Aunque se trató de categorizar por semejanzas solo se han encontrado las siguientes categorías que están presentes en tasas superiores al 5\%: Los padres de la muestra trabajan en el sector de la construcción (15\%), autónomos (10\%), sector administración (8\%), funcionario (7\%), transportes (6\%) y un $6.3 \%$ se encuentra en el paro. Mientras que las madres la actividad que realizan es: ama de casa (38\%), sector salud (12\%), servicios (8\%), educación (8\%), administración (7\%) y hostelería (7\%); donde las opciones son menos numerosas, debido sobre todo a la presencia de mujeres que solo se ocupan de las actividades domésticas.

Concluimos este apartado confiando en que mediante el análisis de los datos sociodemográficos del alumnado encuestado, según Armento (1991) y a la luz del paradigma interpretativo, que nos permite utilizar las ciencias sociales como una herramienta para poder entender cómo los seres humanos construyen la realidad lleguemos a comprender y explicar mejor la construcción del concepto del Paisaje, para el cual es necesario tener en cuenta los contextos en los cuales se encuentran insertas las personas que están siendo estudiadas, sus creencias, experiencias y representaciones. 


\subsection{REPRESENTACIONES Y CONOCIMIENTOS DEL ALUMNADO DE INFANTIL $Y$ PRIMARIA SOBRE EL PAISAJE}

\subsubsection{Categorización de las respuestas}

La elección de las categorías por la que hemos optado para clasificar los contenidos de las respuestas: conocimiento, concienciación, comportamiento y recursos, se debe a que es análoga a la que se han venido aplicando a los temas del medio ambiente, y por la concordancia y la proximidad entre éstos y las creencias, actitudes, normas y valores sobre el Paisaje que pone de manifiesto el Convenio Europeo del Paisaje, cuando lo vincula a los campos cultural, ecológico, medioambiental y social. Cuando el mencionado Convenio, compromete a los países firmantes a incrementar la sensibilización de la sociedad civil respecto del valor de los Paisajes, su papel y su transformación, está impulsando la profundización en el conocimiento de sus Paisajes, y lo hace por medio de programas para concienciar, conocer, valorar y actuar de una manera responsable. Así pues, es preciso detectar el grado de conocimiento del Paisaje que tiene el alumnado, su grado de concienciación sobre el valor social de los Paisajes y su disposición para actuar en pro de la educación en Paisaje.

Para hacer esta categorización, también hemos tomado como referencia las variables y valores paisajísticos que sirvieron para delimitar las unidades del Paisaje en Cataluña (Nogué, 2010) y los indicadores del Paisaje que definió el Observatorio del Paisaje de Cataluña. Los indicadores pueden servir para categorizar un Paisaje pero también son una herramienta para transmitir los valores éticos y morales.

De acuerdo con Sala "los indicadores surgen con la nueva cultura del Paisaje y del territorio que emerge en toda Europa y a escala internacional, donde cada vez se da más importancia a las dimensiones perceptivas y sociales del concepto indicador de Paisaje" (2009, p. 339).

La cantidad y variedad de variables paisajísticas que pueden utilizarse para la caracterización del Paisaje, constituye una seria dificultad metodológica. En el estudio sobre la ordenación del territorio de Cataluña, Nogué (2010) utiliza seis variables paisajísticas que sirven para delimitar las unidades del Paisaje. Además, atendiendo a la riqueza y diversidad de Paisajes culturales de Cataluña analiza una serie de valores como son: los valores estéticos, naturales y ecológicos, productivos, históricos, de uso social, religiosos y espirituales y los simbólicos e identitarios que le ayudan a identificar y caracterizar esos Paisajes. Es decir, los Paisajes estimulan muchos tipos de valores unos patentes y otros latentes. 
El desarrollo de la dimensión perceptiva es una oportunidad para el desarrollo de la personalidad del alumno y ayuda a promover la conciencia y la complejidad del conocimiento (Busquets, 2010). Incluso este autor puntualiza "el gran reto de la educación en Paisaje es conseguir que el Paisaje sea algo vivido y experimentado por los alumnos/as, algo que sientan como suyo y que comprometa su actitud como ciudadanos" (p. 9).

Según Luginbühl "el concepto de Paisaje está vinculado a diversas consideraciones de tipo cualitativo relacionadas con el entorno vital y los valores estéticos, simbólicos, ecológicos y sociales de un espacio" (2009, p. 336).

Al hilo de esta opinión, Liceras señala que "el Paisaje es también una vivencia, una representación, una forma de ver y de imaginar el mundo capaz de suscitar sentimientos y valoraciones estéticas y éticas" (2013, p. 89). Para conseguirlo, afirma este autor, que es fundamental tener una percepción estética del mundo, es decir, partir de la educación de los sentidos, ya que cuánto más se educados estén los sentidos, mejor se perciben las dimensiones estéticas del mundo. Todo ello nos posibilita para tomar conciencia de los valores de la naturaleza, de respeto y finalmente reafirmarnos en una ética ecológica. Para este autor materialidad y espiritualidad son dimensiones inseparables del Paisaje.

Conviene reseñar también que el Paisaje como recurso forma parte de nuestro patrimonio y por tanto debemos conservarlo para el disfrute de las nuevas generaciones.

"El Paisaje es un concepto que cada vez se entiende más como recurso que forma parte del patrimonio de los individuos y de las sociedades. Un bien de carácter natural, histórico, social y cultural que requiere una atención no solo por parte de los científicos sino también de las administraciones porque el Paisaje en sí mismo, como legado cultural, debe ser un bien común. Todo Paisaje es resultado de una evolución tanto natural como cultural" (Bajo, 2001, p. 52).

También debemos vincular la preservación del Paisaje con la subsistencia económica. Por un lado el mantenimiento de actividades tradicionales permite la conservación del Paisaje y por otro lado, el Paisaje puede ser un capital que propicie un mayor desarrollo económico asociado a actividades de ocio y turismo (Durán, 2009).

La mayoría de la personas, incluido nuestro alumnado, identifican el Paisaje con los elementos naturales. Hay un conjunto de ideas preconcebidas que dominan el imaginario colectivo sobre el Paisaje e incluso con el medio ambiente en general que son incompletas o erróneas. Debemos tener en cuenta una visión amplia del Paisaje y de su valor. Señala Durán 
"es necesario introducir los valores del Paisaje (estéticos, ecológicos, sociales, económicos, simbólicos, espirituales y mitológicos) en los medios de comunicación y sean conocidos por la mayor parte de la población. Aunque muchos de estos valores son difíciles de medir, ya que son fruto de la percepción de cada persona" (2009, p. 347)

Para hacer el análisis de las preguntas abiertas del cuestionario relacionadas con el conocimiento, percepción y valoración del Paisaje, como las respuestas dadas por el alumnado encuestado eran tan variadas, creímos conveniente clasificar las respuestas en las siguientes categorías:

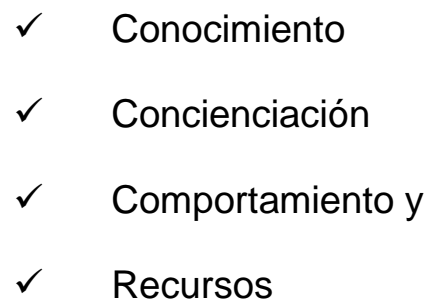

Algunas de las categorías se dividieron en sub-categorías, así:

* La categoría de conocimientos incluye a: medio físico, medio ambiente, naturaleza, rural y urbano, características y tipos de Paisaje, ecosistema y biodiversidad, historia y práctica.

* La categoría de concienciación contiene a: valores y sensibilidad, valores estéticos y estados de ánimo.

* La categoría de comportamiento: conservación y mejora

* La categoría de recursos consta de: necesario/ importante para la vida, aprender más para transmitir a los alumnos y ocio y turismo

\subsubsection{Análisis de los datos obtenidos}

El análisis sigue el mismo orden de las preguntas del cuestionario (Anexo 1), ya que esta tiene un carácter progresivo para facilitar tanto las respuestas de los entrevistados como el análisis del investigador.

Al preguntar al alumnado de Educación Infantil y Primaria sobre la "Valoración de la importancia que tiene el Paisaje", hemos tomado como medida una escala de 6 puntos (0-5), la mayor parte de las respuestas se concentran en los valores 4 (47\%) y 5 (38\%) de modo que la media es 4 ; no hubo ninguna respuesta en el valor 0 . La media en Infantil es 4, muy similar a la de Primaria: 4. 
Al contrastar por ámbito rural-urbano la diferencia de valores medios de la importancia asignada al Paisaje, cuyos resultados se resumen en la tabla 6, en el caso de los sujetos de Infantil, la media de los que estudiaron en el medio rural es algo mayor que la de los de urbano, mientras que en el caso de los que están en Primaria, ambas medias son casi iguales En el análisis y comparación entre dos fases o etapas del Grado los valores medios de la importancia asignada al Paisaje nos dan una media de 4.18 para la $1^{\mathrm{a}}$ etapa y una media de 4.21 para la $2^{\mathrm{a}}$ etapa, una diferencia escasa de décimas entre ambas que aquí redondeamos.

Tabla 6. Importancia del Paisaje según procedencia

\begin{tabular}{llll}
\hline \multicolumn{2}{l}{ Especialidad Medio } & $\mathrm{N}$ & Media \\
\hline \multirow{2}{*}{ Infantil } & Rural & 63 & 4.32 \\
& Urbano & 197 & 4.20 \\
\multirow{2}{*}{ Primaria } & Rural & 100 & 4.14 \\
& Urbano & 183 & 4.16 \\
\hline Fuente: elaboración propia & &
\end{tabular}

La diferencia entre las medias de la importancia asignada al Paisaje en función del lugar de nacimiento no tiene trascendencia en los sujetos de Primaria, pero sí que la tiene en el caso de los alumnos de Infantil. En ellos, se ha encontrado que los nacidos en Castilla y León puntúan menos (tabla 7).

Tabla 7. Importancia del Paisaje según el lugar de nacimiento.

\begin{tabular}{llll}
\hline Especialidad & Nacimiento & N & Media \\
\hline \multirow{2}{*}{ Infantil } & En Castilla y León & 190 & 4.17 \\
& En otras Autonomías & 71 & 4.39 \\
\multirow{2}{*}{ Primaria } & En Castilla y León & 176 & 4.13 \\
& En otras Autonomías & 99 & 4.20 \\
\hline Fuente: elaboración propia &
\end{tabular}

En el análisis de la pregunta formulada a los entrevistados que "dónde habían adquirido los conocimientos que tienen sobre el Paisaje“, la respuesta más señalada es que los conocimientos que tienen sobre el Paisaje, los adquirieron en educación secundaria (17\%) seguido de cerca por Primaria (15\%), hay un 14\% que lo conocieron en la familia y un $13 \%$ en los viajes. En el rango más bajo destaca que los han adquirido en la Lectura a periódicos, Publicaciones especializadas, junto a FP son las fuentes de conocimiento menos indicadas. La tabla 8, muestra que apenas existen diferencias entre las dos especialidades, con excepciones: en la opción de la familia, que ha sido marcada por casi el $60 \%$ de Infantil frente al $48 \%$ de Primaria, en el Bachillerato, donde Educación 
Infantil (47\%) difiere de Primaria (50\%) en más de 8 puntos, así como en Viajes, donde la diferencia (55\% en Educación Infantil frente al 46\% en Educación Primaria) incluso la supera.

Tabla 8. Adquisición de conocimientos sobre el Paisaje por especialidad

\begin{tabular}{llcc}
\hline & $\begin{array}{l}\text { Totales } \\
(\mathrm{N}=554)\end{array}$ & $\begin{array}{c}\text { Infantil } \\
(\mathrm{N}=267)\end{array}$ & $\begin{array}{c}\text { Primaria } \\
(\mathrm{N}=287)\end{array}$ \\
\hline Familia & $53.8 \%$ & $\mathbf{5 9 . 6 \%}$ & $48.4 \%$ \\
\hline Primaria & $58.5 \%$ & $59.9 \%$ & $57.1 \%$ \\
\hline Secundaria & $64.4 \%$ & $65.9 \%$ & $63.1 \%$ \\
Bachillerato & $45.8 \%$ & $41.6 \%$ & $49.8 \%$ \\
\hline FP & $2.7 \%$ & $3.4 \%$ & $2.1 \%$ \\
Lectura de periódicos & $7.0 \%$ & $6.4 \%$ & $7.7 \%$ \\
\hline Publicaciones especializadas & $6.3 \%$ & $6.7 \%$ & $5.9 \%$ \\
Viajes & $50.5 \%$ & $54.7 \%$ & $46.3 \%$ \\
\hline Películas y documentales TV & $43.7 \%$ & $42.7 \%$ & $44.6 \%$ \\
Internet & $36.5 \%$ & $34.8 \%$ & $38.0 \%$ \\
\hline Amigos & $18.1 \%$ & $19.9 \%$ & $16.4 \%$ \\
\hline
\end{tabular}

Fuente: elaboración propia

También podemos observar que en la tabla 9, en relación con "la adquisición de conocimientos, en la respuesta "en la familia" hay diferencias entre las especialidades de Infantil y Primaria; en el resto de las respuestas, apenas existen diferencias ${ }^{7}$ entre ellas en ambas especialidades.

Se han encontrado diferencias en la opción de "en la familia" dentro de la especialidad de Infantil y en la opción de "en Primaria" en la muestra total, los casos de la $1^{\text {a }}$ Etapa aparecen en tasas mayores (por encima del 62\%) que en los sujetos de la $2^{\mathrm{a}}$ Etapa (sobre un 54\%). ${ }^{8}$ Aparte de esas diferencias, los resultados de ambas muestran en la segunda fase una tendencia a valorar más los aspectos relacionados con la formación secundaria y las experiencias propias de la vida adulta, lo que supondría reconocer, con el transcurrir de los estudios, la preeminencia de éstos sobre los del conocimiento escolar y familiar. Así, en la opción "lectura de periódicos" al contrario, son los sujetos de la $2^{\mathrm{a}}$ etapa los que la señalan en mayor medida. En el resto de las variables no se han encontrado diferencias que se pueden juzgar como estadísticamente significativas.

\footnotetext{
7 En aquellos casos, donde previamente se hayan encontrado diferencias entre las especialidades de Infantil y Primaria, se tratarán por separado. En las que no, se tratarán de forma conjunta.

${ }^{8}$ Esta división en dos mitades del Grado, reduciéndolo a dos fases o etapas, obedece a la posibilidad de que la maduración académica y personal de los alumnos haya influido en los resultados de las encuestas. Por esa razón se realiza la comparación de los resultados anteriores, en función de si el participante está estudiando uno de los cursos $1^{\circ}$ y $2^{\circ}$ o primera etapa $\left(1^{\mathrm{a}} \mathrm{E}\right)$, o bien en $3^{\circ}$ y $4^{\circ}$ o segunda etapa $\left(2^{\mathrm{a}} \mathrm{E}\right)$. El número de participantes de cada etapa está bastante equilibrado, aunque hay un cierto predominio de la $1^{a}$ E: 299 casos (un 54\%) frente a 255 (un 46\%) de la $2^{\mathrm{a}} \mathrm{E}$, debido al menor número de casos de $4^{\circ}$ de Primaria ya comentado.
} 


\begin{tabular}{|c|c|c|c|}
\hline Especialidad & & $1^{\circ}$ y $2^{\circ}\left(1^{a} E\right)$ & $3^{o}$ y $4^{o}\left(2^{a} E\right)$ \\
\hline Infantil & Familia & $65.5 \%$ & $53.7 \%$ \\
\hline Primaria & Familia & $51.8 \%$ & $43.7 \%$ \\
\hline Ambas & Primaria & $62.5 \%$ & $53.7 \%$ \\
\hline Ambas & Secundaria & $63.5 \%$ & $65.5 \%$ \\
\hline Ambas & Bachillerato & $44.8 \%$ & $47.1 \%$ \\
\hline Ambas & FP & $2.3 \%$ & $3.1 \%$ \\
\hline Ambas & Lectura de periódicos & $5.0 \%$ & $9.4 \%$ \\
\hline Ambas & $\begin{array}{l}\text { Publicaciones } \\
\text { especializadas }\end{array}$ & $5.4 \%$ & $7.5 \%$ \\
\hline Ambas & Viajes & $49.5 \%$ & $51.8 \%$ \\
\hline Ambas & $\begin{array}{l}\text { Películas y documentales } \\
\text { TV }\end{array}$ & $42.5 \%$ & $45.1 \%$ \\
\hline Ambas & Internet & $33.8 \%$ & $39.6 \%$ \\
\hline Ambas & Amigos & $17,7 \%$ & $18.4 \%$ \\
\hline
\end{tabular}

Fuente: elaboración propia

Cuando hacemos un cruce entre la variable de "Dónde ha adquirido los conocimientos del Paisaje" en relación "con la procedencia del alumnado", no se han encontrado diferencias suficientemente importantes entre los sujetos que provienen de Castilla y León y los que lo hacen de otras autonomías (tabla 10), en ninguna de las variables en Primaria, y ligeras en Infantil, donde los alumnos de Castilla y León valoran más los conocimientos adquiridos en Secundaria y Bachillerato, y los restantes en Internet.

\begin{tabular}{lllll}
\hline \multicolumn{3}{c}{ Tabla 10. Adquisición de conocimientos sobre el Paisaje y lugar de nacimiento } \\
\hline & \multicolumn{3}{c}{ Infantil } & \multicolumn{2}{c}{ Primaria } \\
\hline C y L & $\begin{array}{l}\text { Otras } \\
\text { autonomías }\end{array}$ & C y L & $\begin{array}{l}\text { Otras } \\
\text { autonomías }\end{array}$ \\
\hline Familia & $58.1 \%$ & $63.4 \%$ & $49.7 \%$ & $46.5 \%$ \\
\hline Primaria & $61.3 \%$ & $59.2 \%$ & $58.8 \%$ & $54.5 \%$ \\
\hline Secundaria & $\mathbf{6 8 . 6} \%$ & $59.2 \%$ & $65.0 \%$ & $59.4 \%$ \\
\hline Bachillerato & $\mathbf{4 4 . 5 \%}$ & $36.6 \%$ & $52.0 \%$ & $49.5 \%$ \\
\hline FP & $2.1 \%$ & $7.0 \%$ & $1.1 \%$ & $4.0 \%$ \\
\hline Lectura de periódicos & $4.7 \%$ & $9.9 \%$ & $6.2 \%$ & $7.9 \%$ \\
\hline Publicaciones & $5.2 \%$ & $9.9 \%$ & $7.3 \%$ & $4.0 \%$ \\
especializadas & $53.4 \%$ & $56.3 \%$ & $49.7 \%$ & $42.6 \%$ \\
Viajes & $40.8 \%$ & $46.5 \%$ & $43.5 \%$ & $43.6 \%$ \\
\hline Películas y documentales TV & $31.9 \%$ & $39.4 \%$ & $39.0 \%$ & $34.7 \%$ \\
\hline Internet & $18.8 \%$ & $22.5 \%$ & $18.1 \%$ & $11.9 \%$ \\
\hline Amigos & & & &
\end{tabular}

Fuente: elaboración propia

Cuando les preguntamos ¿Qué recuerda de lo que le enseñaron sobre el Paisaje? , la primera de las preguntas abiertas, sin ninguna duda, la categoría en la que se encuadran 
la mayor parte de las respuestas es la de Conocimientos. Un 53\% del total de la muestra han dado una respuesta que se ha clasificado en esta categoría. En segundo lugar encontramos respuestas del grupo de Comportamiento (conservación y mejora), un $23 \%$ de la tasa total de participantes que se han expresado en esta línea. A continuación, se encuentra un $11 \%$ de sujetos que dan respuestas dentro de la categoría de Concienciación. Y finalmente encontramos las respuestas sobre Recursos, dadas solamente por un $3 \%$ de participantes (tabla 11).

Por especialidades no se aprecian diferencias entre Infantil y Primaria, con porcentajes muy similares entre sí, incluso idénticos en Concienciación.

Tabla 11. Recuerdos de los conocimientos del Paisaje por especialidades.

\begin{tabular}{lrrr}
\hline & \multicolumn{1}{c}{ Totales } & \multicolumn{1}{c}{ Infantil } & \multicolumn{1}{c}{ Primaria } \\
\hline Conocimientos & $53.1 \%$ & $53.6 \%$ & $52.6 \%$ \\
Concienciación & $10.5 \%$ & $10.5 \%$ & $10.5 \%$ \\
$\begin{array}{l}\text { Comportam.: conservación y } \\
\text { mejora }\end{array}$ & $23.3 \%$ & $24.7 \%$ & $22.0 \%$ \\
Recursos & $3.1 \%$ & $3.0 \%$ & $3.1 \%$ \\
\hline Fuente: elaboración propia & & &
\end{tabular}

Fuente: elaboración propia

Al estudiar las respuestas por sub-categorías (tabla 12) se ha comprobado que dentro de la categoría de Conocimientos las respuestas más comunes pertenecen a la subcategoría de Características y tipos de Paisaje (32\%) sin que se aprecien diferencias entre especialidades. Medio físico, Naturaleza y Medio ambiente son las que siguen a la anterior, estando cada una ellas sobre un 8-9\%, y solamente en el caso de las respuestas de Naturaleza hay diferencias, pues son más habituales en Infantil (12\%) que en Primaria (6\%).

Dentro de Concienciación las respuestas son casi todas del tipo Valores y sensibilidad (10\%) y en cuanto a las respuestas de Recursos, dentro de lo poco frecuentes que son, se relacionan casi todas ellas con la Importancia/necesidad del Paisaje para la vida. No hay diferencias entre especialidades en estas dos subcategorías. 
Tabla 12. Recuerdos de la enseñanza del Paisaje por especialidades

\begin{tabular}{lrrr}
\hline & \multicolumn{1}{l}{ Totales } & \multicolumn{1}{c}{ Infantil } & \multicolumn{1}{c}{ Primaria } \\
\hline \multicolumn{1}{c}{ CONOCIMIENTOS } & & & \\
Medio físico & $9.0 \%$ & $11.3 \%$ & $6.7 \%$ \\
Medio ambiente & $7.8 \%$ & $8.3 \%$ & $7.3 \%$ \\
Naturaleza & $8.7 \%$ & $11.6 \%$ & $5.9 \%$ \\
Rural y urbano & $4.0 \%$ & $3.0 \%$ & $4.9 \%$ \\
Característica y tipos de Paisaje & $32.1 \%$ & $30.3 \%$ & $33.8 \%$ \\
Ecosistema y biodiversidad & $3.6 \%$ & $3.7 \%$ & $3.5 \%$ \\
Historia & $0.2 \%$ & $0 \%$ & $0.3 \%$ \\
Práctica & $0.2 \%$ & $0 \%$ & $0.3 \%$ \\
\multicolumn{1}{c}{ CONCIENCIACIÓN } & & & \\
Valores y sensibilidad & $9.6 \%$ & $9.0 \%$ & $10.1 \%$ \\
Valores estéticos & $0.5 \%$ & $0.7 \%$ & $0.3 \%$ \\
Estados de ánimo & $0.4 \%$ & $0.7 \%$ & 0 \\
\multicolumn{1}{c}{ RECURSOS } & & & \\
Necesario/importante para la vida & $2.7 \%$ & $3.0 \%$ & $2.4 \%$ \\
Aprender para transmitir & $0.2 \%$ & $0.4 \%$ & $0 \%$ \\
Ocio y turismo & $0.4 \%$ & $0 \%$ & $0.7 \%$ \\
\hline Fuente: elaboración propia & & &
\end{tabular}

Fuente: elaboración propia

Al contrastar las respuestas a esta pregunta en función de dos etapas de los estudios, con ambas especialidades unidas debido a la ausencia de diferencias entre ellas, se ha observado (tabla 13) que solo existen pequeñas diferencias entre tres de las cuatro categorías establecidas, excepto en la que se define como Concienciación: estas respuestas han resultado ser más habituales en la $2^{\mathrm{a}}$ etapa (16\%) que en los alumnos de la $1^{\mathrm{a}}$ etapa $(6 \%)$.

Tabla 13. Recuerdos de la enseñanza del Paisaje por etapas

\begin{tabular}{llrr}
\hline Especialidad & Categorías & $1^{\circ}$ y $2^{\circ}\left(1^{\mathrm{a}} \mathrm{E}\right)$ & $3^{\circ}$ y $4^{\circ}\left(2^{\mathrm{a}} \mathrm{E}\right)$ \\
\hline Ambas & Conocimientos & $55.7 \%$ & $50.8 \%$ \\
Ambas & Concienciación & $5.7 \%$ & $\mathbf{1 6 . 1 \%}$ \\
Ambas & $\begin{array}{l}\text { Comportam.: conservación y } \\
\text { mejora }\end{array}$ & $26.4 \%$ & $19.6 \%$ \\
Ambas & Recursos & $4.0 \%$ & $2.0 \%$ \\
\hline Fuente: elaboración propia
\end{tabular}

Por subcategorías (tabla 14) se ha comprobado que entre las respuestas de Conocimientos, las más frecuentes, de forma destacada, son del grupo de Características y tipos de Paisajes en la que además se han encontrado diferencias: estas respuestas son más habituales en los alumnos de $2^{a}$ etapa (37\%) que en los de $1^{\mathrm{a}}$ etapa (28\%). También se han encontrado diferencias en la subcategoría de Ecosistema y biodiversidad siendo de nuevo más repetida en la $2^{\mathrm{a}}$ etapa (6\%) que en la $1^{\mathrm{a}}(1 \%)$. 
Dentro del grupo de Concienciación, también se han encontrado diferencias en Valores y sensibilidad que tiene claramente más presencia en los alumnos de la $2^{\mathrm{a}}$ etapa (16\%) que en los de la $1^{\mathrm{a}}(4 \%)$ siendo además la subcategoría más frecuente dentro de este grupo.

En todas las demás categorías no se aprecian diferencias entre ciclos.

Tabla 14. Recuerdos de la enseñanza del Paisaje por etapas. Subcategorías

\begin{tabular}{|c|c|c|c|}
\hline Especialidad & Sub-Categorías & $1^{\circ}$ y $2^{\circ}\left(1^{a} E\right)$ & $3^{\circ}$ y $4^{o}\left(2^{a} E\right)$ \\
\hline \multicolumn{4}{|c|}{ CONOCIMIENTOS } \\
\hline Ambas & Medio físico & $11.2 \%$ & $6.1 \%$ \\
\hline Ambas & Medio ambiente & $5.7 \%$ & $10.2 \%$ \\
\hline Infantil & Naturaleza & $9.2 \%$ & $14.0 \%$ \\
\hline Primaria & Naturaleza & $7.7 \%$ & $3.4 \%$ \\
\hline Ambas & Rural y urbano & $5.0 \%$ & $2.7 \%$ \\
\hline Ambas & Característica y tipos de Paisaje & $28.1 \%$ & $36.9 \%$ \\
\hline Ambas & Ecosistema y biodiversidad & $1.3 \%$ & $6.3 \%$ \\
\hline Ambas & $\begin{array}{l}\text { CONCIENCIACIÓN } \\
\text { Valores y sensibilidad }\end{array}$ & $4.3 \%$ & $15.7 \%$ \\
\hline \multicolumn{3}{|c|}{ RECURSOS } & $2.0 \%$ \\
\hline
\end{tabular}

Las respuestas a esta pregunta en función del ámbito del centro donde estudiaron comparadas por categorías (tabla 15) no han arrojado grandes diferencias entre los que se formaron en el medio rural y los que lo hicieron en el urbano.

Tabla 15. Recuerdos de la enseñanza del Paisaje por medio ruralurbano

\begin{tabular}{llrr}
\hline Especialidad & Categorías & \multicolumn{1}{c}{ Rural } & \multicolumn{1}{c}{ Urbano } \\
\hline Ambas & Conocimientos & $54.5 \%$ & $52.5 \%$ \\
Ambas & Concienciación & $9.1 \%$ & $11.2 \%$ \\
Ambas & $\begin{array}{l}\text { Comportam.: } \\
\text { conservación y mejora }\end{array}$ & $24.2 \%$ & $22.7 \%$ \\
Ambas & Recursos & $1.2 \%$ & $3.9 \%$ \\
\hline Fuente: elaboración propia & &
\end{tabular}


Y tampoco aparecen cuando se contrastan las subcategorías (tabla 16).

Tabla 16. Recuerdos de la enseñanza del Paisaje por medio rural-urbano. Subcategorías

\begin{tabular}{llrr}
\hline Especialidad & SubCategorías & \multicolumn{1}{c}{ Rural } & Urbano \\
\hline \multirow{2}{*}{ Ambas } & \multicolumn{1}{c}{ CONOCIMIENTOS } & \\
Ambas & Medio físico & $6.4 \%$ & $9.9 \%$ \\
Infantil & Medio ambiente & $5.5 \%$ & $8.6 \%$ \\
Primaria & Naturaleza & $12.7 \%$ & $11.1 \%$ \\
Ambas & Rural y urbano & $4.9 \%$ & $6.5 \%$ \\
Ambas & Característica y tipos de Paisaje & $4.8 \%$ & $3.7 \%$ \\
Ambas & Ecosistema y biodiversidad & $33.9 \%$ & $31.6 \%$ \\
& $\quad$ CONCIENCIACIÓN & $3.6 \%$ & $3.7 \%$ \\
Ambas & Valores y sensibilidad & & \\
\multicolumn{2}{c}{ RECURSOS } & $9.1 \%$ & $9.9 \%$ \\
Ambas & Necesario/importante para la vida & $1.2 \%$ & $3.4 \%$ \\
\hline Fuente: elaboración propia & &
\end{tabular}

Por último, las respuestas tampoco varían sustancialmente en función del lugar de nacimiento en ninguna de las 4 categorías, entre los nacidos en Castilla y León y los nacidos en otras Autonomías (tabla 17).

Tabla 17. Recuerdos de la enseñanza del Paisaje y lugar de nacimiento

\begin{tabular}{llrr}
\hline Especialidad & Categorías & Castilla y León & Otras Autonomías \\
\hline Ambas & Conocimientos & $54.3 \%$ & $50.0 \%$ \\
Ambas & Concienciación & $9.2 \%$ & $14.0 \%$ \\
\multirow{2}{*}{ Ambas } & $\begin{array}{l}\text { Comportam.: conservación y } \\
\text { mejora }\end{array}$ & $23.9 \%$ & $23.3 \%$ \\
\hline Ambas & Recursos & $3.3 \%$ & $2.9 \%$ \\
\hline Fuente: elaboración propia
\end{tabular}

Tampoco aparecen cuando se contrastan las subcategorías (tabla 18), excepto en la de Naturaleza en Educación Infantil de Castilla y León. 
Tabla 18. Recuerdos de la enseñanza del Paisaje y lugar de nacimiento. Subcategorías

\begin{tabular}{|c|c|c|c|}
\hline Especialidad & Subcategorías & C y L & Otras autonomías \\
\hline \multicolumn{4}{|c|}{ CONOCIMIENTOS } \\
\hline Ambas & Medio físico & $9.3 \%$ & $8.1 \%$ \\
\hline Ambas & Medio ambiente & $7.1 \%$ & $7.6 \%$ \\
\hline Infantil & Naturaleza & $14.1 \%$ & $5.6 \%$ \\
\hline Primaria & Naturaleza & $6.2 \%$ & $5.9 \%$ \\
\hline Ambas & Rural y urbano & $4.6 \%$ & $2.3 \%$ \\
\hline Ambas & Característica y tipos de Paisaje & $32.6 \%$ & $31.4 \%$ \\
\hline Ambas & Ecosistema y biodiversidad & $3.8 \%$ & $3.5 \%$ \\
\hline \multicolumn{4}{|c|}{ CONCIENCIACIÓN } \\
\hline Ambas & Valores y sensibilidad & $8.7 \%$ & $12.2 \%$ \\
\hline \multicolumn{4}{|c|}{ RECURSOS } \\
\hline Ambas & Necesario/importante para la vida & $3.0 \%$ & $2.3 \%$ \\
\hline
\end{tabular}

Observamos que la mayoría de las veces, las respuestas son cortas y se limitan a conceptos que se corresponden con los conocimientos y con las sub-categorías, sobre todo mencionan los distintos tipos de Paisajes, sus características y sus elementos. En algunos casos se mencionan a los de factores naturales y factores humanos, desastres naturales, contaminación, explotación, etc. También hacen alusión a la categoría relacionada con la concienciación y la conservación del Paisaje, sobre todo en lo que hemos llamado $2^{\circ}$ etapa, que se corresponde con los cursos de $3^{\circ}$ y $4^{\circ}$. Este alumnado tiene una mayor madurez y es más consciente de nuestra responsabilidad con el Paisaje.

Veamos algunas respuestas de los alumnos/as como ejemplo de lo que hemos comentado:

"En ciencias sociales y en el Conocimiento del Medio me enseñaron los tipos de Paisajes, sus características, campo montaña, playa, ciudad... Con mi familia aprendí el Paisaje rural de nuestra zona y pueblo" (Alumno $1^{\circ}$ Primaria).

La importancia que tiene el respeto al medio ambiente porque es fuente de vida. Debemos concienciarnos y actuar correctamente para que las nuevas generaciones puedan disfrutar de la belleza que posee la naturaleza (Alumna $2^{\circ}$ infantil).

Tipos de Paisajes y sus características. Gran influencia humana (alumna $2^{\circ}$ Primaria.

Todo lo relacionado con su importancia. Con los tipos de Paisajes que existen, las zonas geográficas principales, como se distribuyen en España y la relación fauna y flora según la zona (Alumna $3^{\circ}$ infantil).

El Paisaje es el medio que nos rodea compuesto de biotopo y biocenesis. Hay Paisajes urbanos y rurales (alumno $3^{\circ}$ Primaria).

La capacidad de valorar y apreciar el entorno próximo (alumno $4^{\circ}$ Primaria). 
Que es muy importante para los seres vivos. Se debe cuidar para mejorar la calidad de vida de los personas hay que protegerlo y cuidarlo (alumna $4^{\circ}$ Infantil).

La pregunta sobre la "...forma en que sus maestros les enseñaron sus conocimientos sobre el Paisaje" hay que puntualizar que es de respuesta múltiple, donde se pueden marcar todas las opciones que se deseen. Por ello, el total de datos recogidos es de 1135. Lo hicieron a través de los libros en un $38 \%$ y en un $32 \%$ mediante los materiales cartográficos, que son de forma muy destacada las más elegidas. Es reseñable que las nuevas tecnologías como las TIC apenas han sido utilizadas (fig. 3).

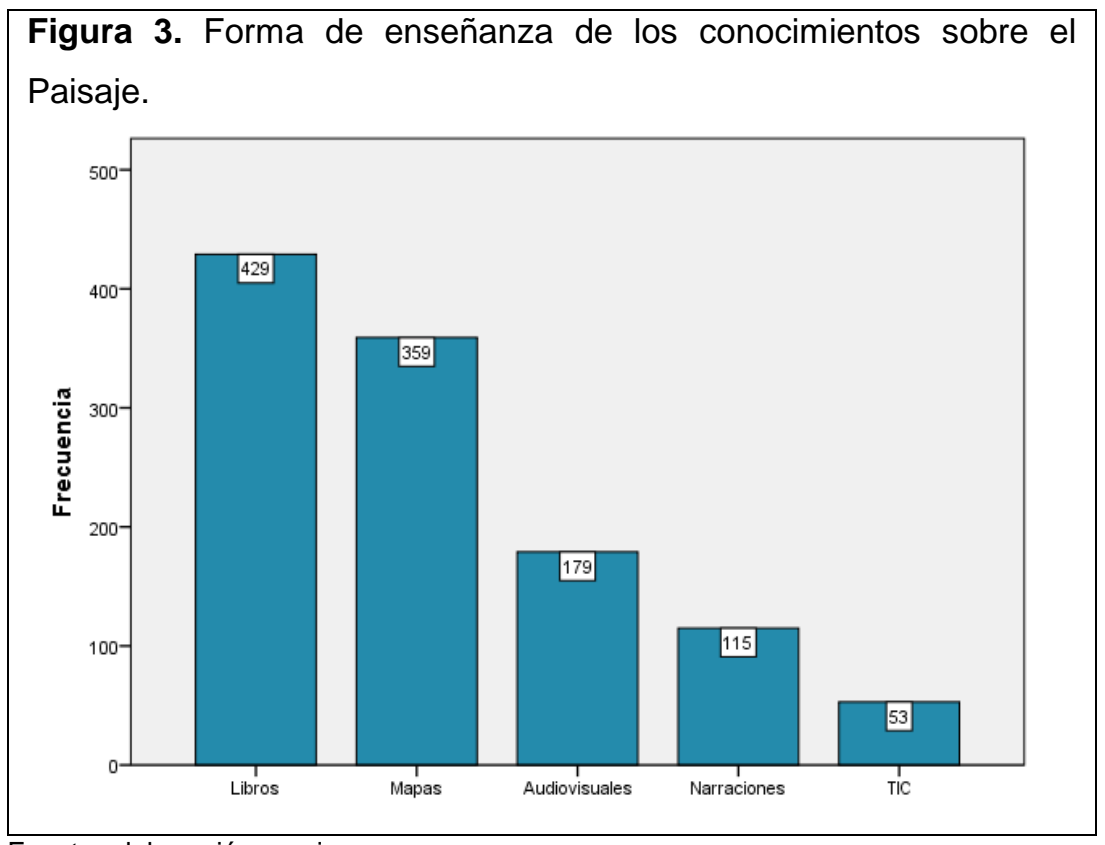

Fuente: elaboración propia

Las diferencias que se han observado entre una y otra especialidad (tabla 19) no llegan a ser importantes en el caso de narraciones, libros y audiovisuales, pero sí en las TIC, que son más citadas por los que ahora estudian Primaria y en materiales cartográficos que lo fue por los que actualmente cursan Infantil.

Tabla 19. Forma de enseñanza de conocimientos sobre el Paisaje por especialidad

\begin{tabular}{lllc}
\hline & Totales & Infantil & Primaria \\
\hline Narraciones & $20.8 \%$ & $21.0 \%$ & $20.6 \%$ \\
Libros & $77.4 \%$ & $\mathbf{7 8 . 3} \%$ & $76.7 \%$ \\
Mapas & $64.8 \%$ & $\mathbf{7 0 . 4 \%}$ & $59.6 \%$ \\
Audiovisuales & $32.3 \%$ & $31.8 \%$ & $32.8 \%$ \\
TIC & $9.6 \%$ & $6.4 \%$ & $\mathbf{1 2 . 5 \%}$ \\
\hline
\end{tabular}

Fuente: Elaboración propia 
No debemos olvidar que nuestro alumnado tiene entre 18 y 22 años, hace más de 10 años en nuestras escuelas aún se utilizaban poco las nuevas tecnologías. Los maestros trabajaban de forma mayoritaria con libros y material cartográfico. El salto cualitativo en la utilización de las TIC se ha producido en los últimos años. Hoy prácticamente todos los colegios disponen de las nuevas tecnologías para trabajar con el alumnado, aunque disponer de ellas no quiere decir que se utilicen habitualmente. En todo caso, las respuestas reflejan solo un recuerdo, no un hecho cierto.

Si hacemos el análisis de cómo recibieron la enseñanza del Paisaje con la variable "lugar de nacimiento", podemos observar en la tabla 20 que no se ha encontrado ninguna diferencia que se pueda considerar importante, excepto ligeras diferencias en narraciones.

Tabla 20. Forma de enseñanza de conocimientos sobre el Paisaje, lugar de nacimiento y especialidad

\begin{tabular}{llll}
\hline Especialidad & & Castilla y León & Otras autonomías \\
\hline Infantil & Narraciones & $18.8 \%$ & $28.2 \%$ \\
& Libros & $76.4 \%$ & $81.7 \%$ \\
& Mapas & $71.2 \%$ & $70.4 \%$ \\
& Audiovisuales & $33.0 \%$ & $26.8 \%$ \\
& TIC & $7.9 \%$ & $2.8 \%$ \\
\hline \multirow{2}{*}{ Primaria } & Narraciones & $22.0 \%$ & $16.8 \%$ \\
& Libros & $76.8 \%$ & $76.2 \%$ \\
& Mapas & $58.8 \%$ & $60.4 \%$ \\
& Audiovisuales & $33.3 \%$ & 31.7 \\
& TIC & $11.9 \%$ & $13.9 \%$ \\
\hline Fuente: Elaboración propia & &
\end{tabular}

En la forma en que le enseñaron sus maestros se contrastan dos respuestas separadas por especialidad, y las demás sin separar: en la tabla 21 podemos ver que no se han encontrado diferencias significativas en la mayoría de las respuestas, salvo en el caso de la opción "Audiovisuales" donde la incidencia es mayor en el alumnado de la primera etapa que para los de la $2^{\mathrm{a}}$ etapa ( $38 \%$ vs $26 \%$ ), aunque también se aprecia ligeramente en el uso de las TIC por parte de los alumnos de Primaria, en los que aparece una mayor tasa en los de la $2^{\mathrm{a}}$ etapa. Sorprendentemente los recuerdos de los alumnos más maduros -y al mismo tiempo los más mayores- desmienten la poca utilización de las TIC. 
Tabla 21. Forma de enseñanza de conocimientos sobre el Paisaje en las etapas

\begin{tabular}{llll}
\hline Especialidad & Opciones & $1^{\mathrm{o}}$ y $2^{\circ}\left(1^{\mathrm{a}} \mathrm{E}\right)$ & $3^{\mathrm{o}}$ y $4^{\circ}\left(2^{\mathrm{a}} \mathrm{E}\right)$ \\
\hline Ambas & Narraciones & $19.4 \%$ & $22.4 \%$ \\
Ambas & Libros & $76.6 \%$ & $78.4 \%$ \\
Infantil & Mapas & $71.8 \%$ & $69.1 \%$ \\
Primaria & Mapas & $60.7 \%$ & $58.0 \%$ \\
Ambas & Audiovisuales & $\mathbf{3 7 . 5} \%$ & $26.3 \%$ \\
Infantil & TIC & $5.3 \%$ & $7.4 \%$ \\
Primaria & TIC & $9.5 \%$ & $16.8 \%$ \\
\hline Fuente: Elaboración propia & &
\end{tabular}

En la tabla 22 podemos observar que la forma de enseñanza de conocimientos sobre el Paisaje no se ve muy influida por el medio dónde han adquirido los conocimientos pues no se han encontrado diferencias importantes entre los que estudiaron en centros rurales y los que lo hicieron en urbanos, con una sola excepción con la lectura de periódicos de los sujetos de Primaria que fue mayor en los que vienen de centros urbanos que los del medio rural.

Tabla 22. Forma de enseñanza de conocimientos sobre el Paisaje según el medio rural-urbano

\begin{tabular}{llll}
\hline Especialidad & Opciones & Rural & Urbano \\
\hline Infantil & Narraciones & $19.0 \%$ & $22.1 \%$ \\
& Libros & $65.1 \%$ & $\mathbf{8 1 . 9 \%}$ \\
& Mapas & $66.7 \%$ & $71.4 \%$ \\
& Audiovisuales & $34.9 \%$ & $30.2 \%$ \\
Primaria & TIC & $11.1 \%$ & $5.0 \%$ \\
& Narraciones & $21.6 \%$ & $20.1 \%$ \\
& Libros & $77.5 \%$ & $76.6 \%$ \\
& Mapas & $60.8 \%$ & $592 . \%$ \\
& Audiovisuales & $\mathbf{4 1 . 2} \%$ & $27.7 \%$ \\
& TIC & $13.7 \%$ & $12.0 \%$ \\
\hline
\end{tabular}

Fuente: Elaboración propia

Respecto de la forma en que le enseñaron sus maestros el Paisaje, la tabla 23 presenta los resultados de la comparación entre los ámbitos rural y urbano. Solamente se han encontrado diferencias significativas en dos de las respuestas, en la utilización de libros en la especialidad de Infantil, que es más frecuente en los centros de medio urbano (82\% vs 65\%) y en el uso de audiovisuales en la especialidad de Primaria que por el contrario es mayor en el medio rural (41\% vs $28 \%)$. 


\begin{tabular}{|c|c|c|c|}
\hline Especialidad & Opciones & Cy L & Otras Autonomías \\
\hline \multirow[t]{5}{*}{ Infantil } & Narraciones & $18.8 \%$ & $28.2 \%$ \\
\hline & Libros & $76.4 \%$ & $81.7 \%$ \\
\hline & Mapas & $71.2 \%$ & $70.4 \%$ \\
\hline & Audiovisuales & $33.0 \%$ & $26.8 \%$ \\
\hline & TIC & $7.9 \%$ & $2.8 \%$ \\
\hline \multirow[t]{5}{*}{ Primaria } & Narraciones & $22.0 \%$ & $16.8 \%$ \\
\hline & Libros & $76.8 \%$ & $76.2 \%$ \\
\hline & Mapas & $58.8 \%$ & $60.4 \%$ \\
\hline & Audiovisuales & $33.3 \%$ & 31.7 \\
\hline & TIC & $11.9 \%$ & $13.9 \%$ \\
\hline
\end{tabular}

Fuente: Elaboración propia

Cuando se les pregunta ¿Cómo definiría el Paisaje? -los resultados del análisis se resumen en la tabla 24, donde además se comparan por especialidades- la gran mayoría de las respuestas que definen al Paisaje hacen referencia a elementos de la categoría de Conocimientos (61\%) en tanto que para el resto de categorías apenas se han registrado respuestas (menos del $5 \%$ en la que más). Por otro lado las diferencias que se aprecian entre Infantil y Primaria son mínimas, de modo que se concluye que el contenido de las respuestas es similar en ambas especialidades.

Tabla 24. Definición del Paisaje por especialidades.

\begin{tabular}{lccc}
\hline Categorías & \multicolumn{1}{c}{ Totales } & \multicolumn{1}{c}{ Infantil } & \multicolumn{1}{c}{ Primaria } \\
\hline Conocimientos & $60.5 \%$ & $63.3 \%$ & $57.8 \%$ \\
Concienciación & $4.7 \%$ & $6.0 \%$ & $3.5 \%$ \\
$\begin{array}{l}\text { Comportam.: conservación y } \\
\text { mejora }\end{array}$ & $1.6 \%$ & $2.2 \%$ & $1.0 \%$ \\
Recursos & $0.3 \%$ & $0.7 \%$ & $.03 \%$ \\
\hline Fuente: Elaboración propia & & &
\end{tabular}

En los contrastes del desglose de categorías en sus correspondientes sub-categorías (tabla 25), se ha encontrado que dentro de Conocimientos, la mayor parte de las respuestas se concentran en el grupo de Naturaleza (casi el 33\%) donde además se aprecia diferencia entre especialidades: es más frecuente en los alumnos de Infantil (42\%) que en los de Primaria (24\%). En segundo lugar aparecen las respuestas relacionadas con Medio ambiente (16\%) sin que haya diferencias entre especialidades; las respuestas que ocupan el tercer lugar son las que hacen referencia al Medio físico (10\%), donde vuelven a aparecer diferencias pero en sentido contrario a las anteriores ya que son ahora los de Primaria quienes más hacen uso de estos términos, 16\%, frente a un $5 \%$ en los estudiantes de la especialidad de Infantil. 
Tabla 25. Definición del Paisaje por especialidades. Subcategorías

\begin{tabular}{lccc}
\hline Subcategorías & \multicolumn{1}{l}{ Totales } & Infantil & Primaria \\
\hline \multicolumn{1}{c}{ CONOCIMIENTOS } & & & \\
Medio físico & $10.2 \%$ & $4.7 \%$ & $16.2 \%$ \\
Medio ambiente & $15.7 \%$ & $14.6 \%$ & $16.7 \%$ \\
Naturaleza & $32.9 \%$ & $41.9 \%$ & $24.4 \%$ \\
Rural y urbano & $6.5 \%$ & $8.2 \%$ & $4.9 \%$ \\
Característica y tipos de Paisaje & $2.9 \%$ & $1.5 \%$ & $4.2 \%$ \\
Ecosistema y biodiversidad & $1.6 \%$ & $1.5 \%$ & $1.7 \%$ \\
Historia & $0.5 \%$ & $0.7 \%$ & $0.3 \%$ \\
Práctica & $0 \%$ & $0 \%$ & $0 \%$ \\
\multicolumn{1}{c}{ CONCIENCIACIÓN } & & & \\
Valores y sensibilidad & $0.9 \%$ & $1.1 \%$ & $0.7 \%$ \\
Valores estéticos & $2.9 \%$ & $3.7 \%$ & $2.1 \%$ \\
Estados de ánimo & $1.8 \%$ & $2.6 \%$ & $1.0 \%$ \\
\hline \multicolumn{1}{c}{ RECURSOS } & & & $0.3 \%$ \\
Necesario/importante para la vida & $0.5 \%$ & $0.7 \%$ & $0 \%$ \\
Aprender para transmitir & $0 \%$ & $0 \%$ & $0 \%$ \\
\hline Fucio y turismo & $0 \%$ Elaborán propia & & \\
\hline
\end{tabular}

Fuente: Elaboración propia

En el resto de subcategorías, tanto de este grupo como de los otros, además de que las tasas de respuesta son muy bajas, no hay apenas diferencias entre las especialidades. Incluso algunas de estas sub-categorías no han sido citadas por nadie de modo que se prescinde de ellas para los análisis que siguen cuando se haga el estudio por subgrupos.

Como hemos señalado en el marco teórico, el Paisaje es un concepto de uso extendido y coloquial. Es usado con distintos significados y muchas veces se confunde con otros conceptos próximos, como medio físico, territorio, medio ambiente, naturaleza y entorno como se refleja en las respuestas del alumnado tanto de Infantil como de Primaria.

Perez, Ezkurdia y Bilbao haciendo referencia a esta confusión, intentan aclarar estos términos.

Así Entorno está relacionado con el Paisaje y hace referencia a diferentes ámbitos, desde medio ambiente hasta otro tipo de significados relacionados con el entorno matemático, con el contexto, con el entorno social, cultural y empresarial. El Medio se refiere tanto al medio ambiente como al medio social y cultural. El medio ambiente define el conjunto de valores naturales existentes en un lugar y en un momento determinados, que influyen en los seres vivos. El medio social, sin embargo, está definido por determinadas condiciones de vida, de trabajo, del nivel de ingresos, de nivel educativo. El medio cultural es el que define una sociedad, junto con sus productos culturales e históricos determinados. El Territorio es un término polisémico muy usado en geografía así como en ciencias natural El territorio se asocia al espacio físico de un estado mucho más claramente que otros conceptos como son Paisaje, región, espacio geográfico (2015, p. 230). 
Busquets i Fábregas intentan establecer diferencias entre el concepto de territorio, medio ambiente y Paisaje.

El concepto de territorio se refiere al conjunto de elementos, tanto estáticos como dinámicos, que forman el marco físico en el que se desarrollan las actividades humanas. El concepto medio ambiente se refiere al sistema de elementos naturales e interrelacionados y modificados por la acción humana. $\mathrm{Y}$ por último el concepto de Paisaje se refiere a la fisonomía que muestra un territorio determinado, como resultado de las interacciones que se producen entre sus componentes y dela forma en que es percibido por la población. La diferencia entre estos tres conceptos es que cuando se menciona Paisaje, se está haciendo referencia a la percepción del entorno con los sentidos, a cómo se interpreta con los conocimientos y cómo se vive bajo la influencia de las emociones personales y de la cultura que está inmerso (2011, p. 24-25).

Esta variedad de términos se recoge en las respuestas dadas por los estudiantes de esta investigación, aunque no queda muy claro si son conscientes de las diferencias que hay en estos conceptos; sobre todo cuando se habla de valores y de emociones personales, que apenas quedan recogidas en el análisis.

A continuación se mostrarán algunas definiciones que han sido recogidas en relación con esta pregunta. Algunas definiciones son muy escuetas, como por ejemplo:

"Distintas formas de territorio" "Lugar habitable lleno de flora y fauna" "Todo aquello que nos rodea" "el entorno en el que vivimos" "el Paisaje es la ciudad y el campo" "Medio o espacio que rodea al hombre" La imagen que obtenemos de nuestro entorno".

"El Paisaje es todo lo que vemos a nuestro alrededor. Es importante mantener limpia la naturaleza".

"El Paisaje es el medio o espacio físico con determinados características humanas y ambientales de cierta belleza natural"

En las siguientes definiciones, aunque los estudiantes hacen referencia a los conocimientos que ellos tienen, sin embargo, aparecen otras categorías como concienciación y comportamiento. Esta diferenciación se aprecia entre el alumnado de los cursos superiores.

"El Paisaje es el conjunto de medios naturales y humanos que nos rodean y con los que cualquier persona puede interactuar a lo largo de su vida" (Alumno de $1^{\circ}$ Primaria).

"El Paisaje es todo aquello que nos rodea y que tiene unas características determinadas que incluyen el terreno, clima, relieve, etc. Hay diversos tipos de 
Paisajes que pueden clasificarse según la intervención antrópica (natural, rural y urbano)" (Alumno de $1^{\circ}$ de infantil).

"El Paisaje es un terreno visto desde un lugar alto. Formado por las características del entorno y por la influencia humana. No puede haber 2 tipos de Paisajes iguales, ya que no sólo dependen del clima sino también de la latitud, altitud" (2 Primaria).

"El Paisaje es nuestro patrimonio natural y en consecuencia debe ser protegido y preservado para nuevas generaciones. También hay que destacar los tipos de Paisajes: natural, rural, urbano" (2 ${ }^{\circ}$ Primaria).

"Un lugar donde se despeja la mente, rodeado de naturaleza con mucha tranquilidad y un sitio ideal para relajarse" ( $2^{\circ}$ Primaria).

"El Paisaje es el conjunto formado por los seres vivos (plantas y animales) que rodean nuestro entorno, dotándolo de una belleza y una sensación de calma natural" ( $2^{\circ}$ infantil).

"El Paisaje es un conjunto de elementos que se dan en el medio, importantísimo para la convivencia diaria de diferentes especies en múltiples ecosistemas ( $3^{\circ}$ Primaria).

"El Paisaje es el medio natural con el que convivimos y dónde suceden ciertos fenómenos físicos que afectan a la vida de todos los seres vivos" (4 Primaria).

"El Paisaje es un entorno físico que requiere del cuidado y mantenimiento por parte de los seres humanos. Es necesario tener en conciencia de los Paisajes porque determinan la calidad de vida de las personas" (4º Primaria).

"El Paisaje es lo que percibimos con la vista y está compuesto por elementos naturales y racionales del entorno. Es decir, el Paisaje se puede considerar todos los elementos tangibles que están o componen la sociedad" (4ºinfantil).

"Paisaje es la percepción del hombre a través de los sentidos, de un entorno natural concreto".

En el estudio comparativo realizado en función de dos etapas del grado, con ambas especialidades unidas puesto que no hubo diferencias entre ellas en las categorías, como se acaba de concluir, se ha encontrado ahora una diferencia muy significativa en el grupo de respuestas que tienen que ver con la Concienciación, ya que este tipo de respuestas es más frecuente en los alumnos de la $1^{\mathrm{a}}$ etapa (7\%) que en los de la $2^{\mathrm{a}}$ (2\%). En los demás grupos (tabla 26) no existen apenas diferencias.

Tabla 26. Definición del Paisaje por etapas

\begin{tabular}{llrr}
\hline Especialidad & Categorías & $1^{\circ}$ y $2^{\circ}\left(1^{\mathrm{a}} \mathrm{E}\right)$ & $3^{\circ}$ y $4^{\circ}\left(2^{\mathrm{a}} \mathrm{E}\right)$ \\
\hline Ambas & Conocimientos & $61.9 \%$ & $58.8 \%$ \\
Ambas & Concienciación & $7.4 \%$ & $1.6 \%$ \\
\multirow{2}{*}{ Ambas } & Comportam.: conservación y & $1.7 \%$ & $1.6 \%$ \\
Ambas & mejora & $0.7 \%$ & $0.4 \%$ \\
\hline Fuente: Elaboración propia & &
\end{tabular}


El análisis desglosado en sub-categorías se resume en la tabla 27. Dentro del grupo de Conocimientos, las respuestas más habituales son las que hacen referencia a: Medio físico y Medio ambiente. Además, en la primera de estas sub-categorías, Medio físico, donde se ha hecho el análisis separando entre especialidades ya que se habían encontrado antes diferencias entre ellas, ahora también se puede afirmar que entre los estudiantes de Primaria las respuestas que usan estos conceptos son más habituales en la $1^{\mathrm{a}}$ etapa que en la $2^{\mathrm{a}}(10 \%$ vs $2 \%)$.

También, dentro del grupo de Conocimientos, se ha encontrado una diferencia en la sub-categoría de Característica y tipos de Paisaje, según la cual este tipo de respuestas es más común entre los que estudian en $1^{\mathrm{a}}$ etapa (4.7\%) que en los de la $2^{\mathrm{a}}(0.8 \%)$.

En la categoría de Concienciación, dentro de lo poco frecuente que ha sido este tipo de respuesta, las más frecuentes hablan de Valores estéticos y las de Estados de ánimo, siendo más habitual en los de la $1^{\mathrm{a}}$ etapa En ninguna otra sub-categoría se aprecian diferencias destacables.

Tabla 27. Definición del Paisaje por etapas. Subcategorías

\begin{tabular}{llrr}
\hline Especialidad & Subcategorías & $1^{\circ}$ y $2^{\circ}\left(1^{\mathrm{a}} \mathrm{E}\right)$ & $3^{\circ}$ y $4^{\circ}\left(2^{\mathrm{a}} \mathrm{E}\right)$ \\
\hline \multirow{2}{*}{ Infantil } & Medio físico & & \\
Primaria & Medio físico & $12.8 \%$ & $9.6 \%$ \\
Ambas & Medio ambiente & $9.8 \%$ & $2.3 \%$ \\
Infantil & Naturaleza & $13.4 \%$ & $18.4 \%$ \\
Primaria & Naturaleza & $9.2 \%$ & $14.0 \%$ \\
Ambas & Rural y urbano & $7.7 \%$ & $3.4 \%$ \\
Ambas & Característica y tipos de Paisaje & $5.7 \%$ & $7.5 \%$ \\
Ambas & Ecosistema y biodiversidad & $4.7 \%$ & $0.8 \%$ \\
Ambas & Historia & $1.7 \%$ & $1.6 \%$ \\
& $\quad$ CONCIENCIACIÓN & $0.3 \%$ & $0.8 \%$ \\
Ambas & Valores y sensibilidad & & \\
Ambas & Valores estéticos & $1.0 \%$ & $0.8 \%$ \\
Ambas & Estados de ánimo & $4.3 \%$ & $1.2 \%$ \\
\multicolumn{2}{c}{ RECURSOS } & $3.3 \%$ & $0 \%$ \\
Ambas & Necesario/importante para la vida & $0.7 \%$ & $0.4 \%$ \\
\hline Fuente: Elaboración propia
\end{tabular}

Fuente: Elaboración propia

A continuación se examinan las posibles diferencias en las respuestas dadas a esta pregunta, con la variable en función del Medio del centro dónde cursaron sus estudios (tabla 28). No se han hallado apenas diferencias en ellas. 
Tabla 28. Definición del Paisaje y medio rural-urbano

\begin{tabular}{llcc}
\hline Especialidad & Categorías & Rural & Urbano \\
\hline Ambas & Conocimientos & $57.6 \%$ & $61.9 \%$ \\
Ambas & Concienciación & $4.2 \%$ & $5.0 \%$ \\
Ambas & $\begin{array}{l}\text { Comportam.: conservación y } \\
\text { mejora }\end{array}$ & $0 \%$ & $2.3 \%$ \\
Ambas & Recursos & $0 \%$ & $0.8 \%$ \\
\hline
\end{tabular}

Fuente: Elaboración propia

Y en el estudio de cada una de las sub-categorías (tabla 29) tampoco se han encontrado diferencias significativas.

Tabla 29. Definición de Paisaje y medio rural-urbano. Subcategorías

\begin{tabular}{|c|c|c|c|}
\hline Especialidad & Subcategorías & Rural & Urbano \\
\hline \multicolumn{4}{|c|}{ CONOCIMIENTOS } \\
\hline Infantil & Medio físico & $6.4 \%$ & $12.5 \%$ \\
\hline Primaria & Medio físico & $6.4 \%$ & $6.9 \%$ \\
\hline Ambas & Medio ambiente & $15.2 \%$ & $16.2 \%$ \\
\hline Infantil & Naturaleza & $12.7 \%$ & $11.1 \%$ \\
\hline Primaria & Naturaleza & $4.9 \%$ & $6.5 \%$ \\
\hline Ambas & Rural y urbano & $3.6 \%$ & $7.8 \%$ \\
\hline Ambas & Característica y tipos de Paisaje & $3.0 \%$ & $2.9 \%$ \\
\hline Ambas & Ecosistema y biodiversidad & $1.8 \%$ & $1.6 \%$ \\
\hline Ambas & Historia & $0 \%$ & $0.8 \%$ \\
\hline \multicolumn{4}{|c|}{ CONCIENCIACIÓN } \\
\hline Ambas & Valores y sensibilidad & $1.2 \%$ & $0.8 \%$ \\
\hline Ambas & Valores estéticos & $1.8 \%$ & $3.4 \%$ \\
\hline Ambas & Estados de ánimo & $1.8 \%$ & $1.8 \%$ \\
\hline \multicolumn{4}{|c|}{ RECURSOS } \\
\hline
\end{tabular}

La última comparación que se realiza con cada pregunta corresponde al contraste con la variable del lugar de nacimiento; la tabla 30 muestra los resultados por categorías.

Se ha encontrado cierta diferencia, aunque por escaso margen en Conocimientos, ya que este tipo de respuestas es más común entre los nacidos en Castilla y León (64\%) que entre los que proceden de otras autonomías (55\%). En el resto de las categorías no se aprecian diferencias. 
Tabla 30. Definición del Paisaje y lugar de nacimiento

\begin{tabular}{llrc}
\hline Especialidad & Categorías & Castilla y León & Otras Autonomías \\
\hline Ambas & Conocimientos & $63.6 \%$ & $54.7 \%$ \\
Ambas & Concienciación & $4.1 \%$ & $6.4 \%$ \\
Ambas & $\begin{array}{l}\text { Comportam.: conservación y } \\
\text { mejora }\end{array}$ & $1.9 \%$ & $1.2 \%$ \\
Ambas & Recursos & $0.5 \%$ & $0.6 \%$ \\
\hline
\end{tabular}

Fuente: Elaboración propia

En los análisis de las sub-categorías (tabla 31) tampoco se han encontrado diferencias aunque es cierto que en el caso de las respuestas del subgrupo de Naturaleza, en los alumnos de Infantil, podría verse una posible tendencia al ser esta respuesta más frecuente en los sujetos de Castilla y León.

Tabla 31: ¿Cómo definiría el Paisaje? por el lugar de nacimiento y especialidad. Subcategorías

\begin{tabular}{llrr}
\hline Especialidad & Sub-Categorías & Castilla y León & Otras Autonomías \\
\hline \multirow{2}{*}{ Infantil } & \multicolumn{1}{c}{ CONOCIMIENTOS } & & \\
Primaria & Medio físico & $12.6 \%$ & $8.8 \%$ \\
Ambas & Medio físico & $5.8 \%$ & $7.6 \%$ \\
Infantil & Medio ambiente & $14.9 \%$ & $18.0 \%$ \\
Primaria & Naturaleza & $14.1 \%$ & $5.6 \%$ \\
Ambas & Naturaleza & $6.2 \%$ & $5.9 \%$ \\
Ambas & Caral y urbano & $6.3 \%$ & $7.6 \%$ \\
Ambas & Ecosistema y biodiversidad & $3.3 \%$ & $1.7 \%$ \\
Ambas & Historia & $1.6 \%$ & $1.7 \%$ \\
& $\quad$ CONCIENCIACIÓN & $0.8 \%$ & $0 \%$ \\
Ambas & Valores y sensibilidad & & $1.2 \%$ \\
Ambas & Valores estéticos & $0.8 \%$ & $3.5 \%$ \\
Ambas & Estados de ánimo & $2.7 \%$ & $1.7 \%$ \\
Ambas & Recesario/importante para la vida & $1.9 \%$ & \\
\hline Fuente: Elaboración propia & & $0.6 \%$ \\
\hline
\end{tabular}

Cuando se les preguntó "Indique qué ideas le sugiere la palabra Paisaje" el análisis descriptivo de las respuestas categorizadas (tabla 32) nos indica que el grupo más habitual es de nuevo el que tiene contenidos de Conocimientos (74\%) seguido del que hace referencia a la Concienciación (41\%). Las otras dos categorías apenas registran respuestas. En el contraste entre especialidades, no se han registrado apenas diferencias. 
Tabla 32. Qué le sugiere la palabra Paisaje por especialidades

\begin{tabular}{lccc}
\hline Categorías & Totales & Infantil & Primaria \\
\hline Conocimientos & $73.8 \%$ & $73.8 \%$ & $73.9 \%$ \\
Concienciación & $41.2 \%$ & $43.4 \%$ & $39.0 \%$ \\
Comportam.: conservación y mejora & $2.9 \%$ & $3.7 \%$ & $2.1 \%$ \\
Recursos & $2.3 \%$ & $3.4 \%$ & $1.4 \%$ \\
\hline Fuente: Elaboración propia & &
\end{tabular}

En la descripción de las sub-categorías (tabla 33) en Conocimientos, el contenido más frecuente es el que hace referencia a la Naturaleza (54\%) seguido de los contenidos de Medio físico (20\%) y de Medio ambiente (18\%), con exiguas diferencias entre las especialidades.

Dentro del grupo de Concienciación, predominan las respuestas que se relacionan con Estados de ánimo $(20,4 \%)$ y con Valores estéticos (23.5\%) que se distribuyen por igual en las dos especialidades. Finalmente las respuestas sobre Recursos apenas tienen aparición como se sabe y sin diferencias entre especialidades.

Tabla 33. Qué le sugiere la palabra Paisaje por especialidades

\begin{tabular}{|c|c|c|c|}
\hline Subcategorías & Totales & Infantil & Primaria \\
\hline \multicolumn{4}{|l|}{ CONOCIMIENTOS } \\
\hline Medio físico & $20.4 \%$ & $23.3 \%$ & $17.7 \%$ \\
\hline Medio ambiente & $17.7 \%$ & $17.2 \%$ & $18.1 \%$ \\
\hline Naturaleza & $54.3 \%$ & $55.4 \%$ & $53.3 \%$ \\
\hline Rural y urbano & $4.3 \%$ & $3.4 \%$ & $5.2 \%$ \\
\hline Característica y tipos de Paisaje & $2.5 \%$ & $1.5 \%$ & $3.5 \%$ \\
\hline Ecosistema y biodiversidad & $4.5 \%$ & $4.1 \%$ & $4.9 \%$ \\
\hline Historia & $2.5 \%$ & $3.4 \%$ & $1.7 \%$ \\
\hline Práctica & $0.2 \%$ & $0.4 \%$ & $0 \%$ \\
\hline \multicolumn{4}{|l|}{ CONCIENCIACIÓN } \\
\hline Valores y sensibilidad & $4.3 \%$ & $5.6 \%$ & $3.1 \%$ \\
\hline Valores estéticos & $23.5 \%$ & $24.0 \%$ & $23.0 \%$ \\
\hline Estados de ánimo & $24.0 \%$ & $25.5 \%$ & $22.6 \%$ \\
\hline \multicolumn{4}{|l|}{ RECURSOS } \\
\hline Necesario/importante para la vida & $0.2 \%$ & $0.4 \%$ & $0 \%$ \\
\hline Aprender para transmitir & $0.7 \%$ & $0.4 \%$ & $1.0 \%$ \\
\hline Ocio y turismo & $1.4 \%$ & $2.6 \%$ & $0.3 \%$ \\
\hline
\end{tabular}

Fuente: Elaboración propia

Aunque los conceptos más repetidos son naturaleza, medio físico, medio ambiente, biodiversidad, también se mencionaron términos como espacios naturales, contaminación, flora, fauna, montañas, ríos, cascadas, agua, edificios, vegetación, campo, bosque, etc. todos están relacionados con la categoría de conocimientos. 
Sin embargo, es necesario destacar conceptos como: tranquilidad, placer, alegría, vida, libertad, relajación, admiración, belleza, lugar de disfrute, que muestran todo tipo de sensaciones, la mayoría positivas, incluso estados de ánimo.

Hay determinados Paisajes que transmiten serenidad y calma, mientras que otros transmiten inquietud y tristeza, porque están ligados a determinados momentos y situaciones de la vida. Incluso aparecen conceptos de respeto, cuidado y concienciación ciudadana.

Los contrastes que siguen se realizan sin separar las especialidades, dada la ausencia de divergencias que se acaba de encontrar. La comparación de las categorías entre las dos fases de los estudios se resume en la tabla 34. Como se puede ver en ella, en tres de las cuatro no existen diferencias, pero en Concienciación sí que las hay, con una tasa de respuestas más elevada en $1^{\mathrm{a}}$ etapa (45\%) que en $2^{\mathrm{a}}(37 \%)$.

Tabla 34. Qué le sugiere la palabra Paisaje por etapas

\begin{tabular}{llrr}
\hline Especialidad & Categorías & $1^{\circ}$ y $2^{\circ}\left(1^{\mathrm{a}} \mathrm{E}\right)$ & $3^{\circ}$ y $4^{\circ}\left(2^{\mathrm{a}} \mathrm{E}\right)$ \\
\hline Ambas & Conocimientos & $74.6 \%$ & $72.9 \%$ \\
Ambas & Concienciación & $45.2 \%$ & $36.5 \%$ \\
\multirow{2}{*}{ Ambas } & $\begin{array}{l}\text { Comportam.: conservación y } \\
\text { mejora }\end{array}$ & $2.7 \%$ & $3.1 \%$ \\
Ambas & Recursos & $1.7 \%$ & $3.1 \%$ \\
\hline Fuente: Elaboración propia
\end{tabular}

Fuente: Elaboración propia

En el estudio detallado por subcategorías (tabla 35) y dentro del grupo de Conocimientos, solo se han encontrado diferencias en una de las respuestas menos habituales, en Historia, donde la tasa observada es más alta en la $2^{\mathrm{a}}$ etapa (5\%) que en la $1^{\mathrm{a}}(0.3 \%)$. El tipo de respuesta más frecuente dentro de este grupo es de la Naturaleza (más del $53 \%$ en cada ciclo) y le siguen a bastante distancia las de Medio físico, sin diferencias entre ciclos, y Medio ambiente, con una ligera diferencia en la $2^{\mathrm{a}}$ etapa.

Dentro de Concienciación, las respuestas sobre Estado de ánimo y Valores estéticos son, de nuevo, las más frecuentes con pequeñas diferencias entre ciclos. En cambio son más visibles en la otra sub-categoría, la de Valores y sensibilidad, que es más habitual en los cursos avanzados (7\%) que en los principiantes (2\%).

Las respuestas de las subcategorías de Recursos, aparte de ser muy poco frecuentes, se distribuyen por igual en ambos ciclos. 
Tabla 35. Qué le sugiere la palabra Paisaje por etapas. Subcategorías

\begin{tabular}{llrr} 
Especialidad & Sub-Categorías & $1^{\circ}$ y $2^{\circ}\left(1^{\mathrm{a}} \mathrm{E}\right)$ & $3^{\circ}$ y $4^{\circ}\left(2^{\mathrm{a}} \mathrm{E}\right)$ \\
\hline \multirow{2}{*}{ Ambas } & CONOCIMIENTOS & & \\
Ambas & Medio físico & $21.6 \%$ & $18.9 \%$ \\
Ambas & Naturaleza & $15.7 \%$ & $\mathbf{2 0 . 0 \%}$ \\
Ambas & Rural y urbano & $53.8 \%$ & $54.9 \%$ \\
Ambas & Característica y tipos de Paisaje & $4.3 \%$ & $4.3 \%$ \\
Ambas & Ecosistema y biodiversidad & $1.7 \%$ & $3.5 \%$ \\
Ambas & Historia & $3.0 \%$ & $6.3 \%$ \\
& $\quad$ CONCIENCIACIÓN & $0.3 \%$ & $5.1 \%$ \\
Ambas & Valores y sensibilidad & & \\
Ambas & Valores estéticos & $2.0 \%$ & $\mathbf{7 . 1 \%}$ \\
Ambas & Estados de ánimo & $\mathbf{2 5 . 1} \%$ & $21.6 \%$ \\
& $\quad$ RECURSOS & $\mathbf{2 6 . 4} \%$ & $21.2 \%$ \\
Ambas & Aprender para transmitir & & \\
Ambas & Ocio y turismo & $0.3 \%$ & $1.2 \%$ \\
\hline Fuente: Elaborión propia & $1.3 \%$ & $1.6 \%$ \\
\hline
\end{tabular}

Fuente: Elaboración propia

En cuanto a las diferencias en función del Medio (tabla 36) son poco importantes en las cuatro categorías definidas para clasificar a las respuestas, excepto en Conocimientos.

Tabla 36. Qué le sugiere la palabra Paisaje y medio rural y urbano

\begin{tabular}{llcc}
\hline Especialidad & Categorías & \multicolumn{1}{l}{ Rural } & Urbano \\
\hline Ambas & Conocimientos & $\mathbf{7 8 . 8 \%}$ & $72.1 \%$ \\
Ambas & Concienciación & $39.4 \%$ & $41.8 \%$ \\
Ambas & $\begin{array}{l}\text { Comportam.: conservación y } \\
\text { mejora }\end{array}$ & $1.2 \%$ & $3.7 \%$ \\
Ambas & Recursos & $1.8 \%$ & $2.6 \%$ \\
\hline Fuente: Elaboración propia & &
\end{tabular}

Al comparar las subcategorías (tabla 37) no se han detectado diferencias importantes entre el medio rural y el urbano, salvo las de Naturaleza y Estado de ánimo, más altas en el medio rural. 
Tabla 37. Qué le sugiere la palabra Paisaje y medio rural y urbano. Subcategorías

\begin{tabular}{|c|c|c|c|}
\hline Especialidad & Sub-Categorías & Rural & Urbano \\
\hline \multicolumn{4}{|c|}{ CONOCIMIENTOS } \\
\hline Ambas & Medio físico & $18.4 \%$ & $21.3 \%$ \\
\hline Ambas & Medio ambiente & $17.6 \%$ & $18.0 \%$ \\
\hline Ambas & Naturaleza & $58.2 \%$ & $53.0 \%$ \\
\hline Ambas & Rural y urbano & $3.0 \%$ & $4.7 \%$ \\
\hline Ambas & Característica y tipos de Paisaje & $4.8 \%$ & $1.6 \%$ \\
\hline Ambas & Ecosistema y biodiversidad & $4.8 \%$ & $4.4 \%$ \\
\hline Ambas & Historia & $1.8 \%$ & $2.9 \%$ \\
\hline \multicolumn{4}{|c|}{ CONCIENCIACIÓN } \\
\hline Ambas & Valores y sensibilidad & $4.8 \%$ & $4.2 \%$ \\
\hline Ambas & Valores estéticos & $21.1 \%$ & $24.0 \%$ \\
\hline Ambas & Estados de ánimo & $27.9 \%$ & $22.2 \%$ \\
\hline \multicolumn{4}{|c|}{ RECURSOS } \\
\hline Ambas & Aprender para transmitir & $0.6 \%$ & $0.8 \%$ \\
\hline Ambas & Ocio y turismo & $1.2 \%$ & $1.6 \%$ \\
\hline
\end{tabular}

Fuente: Elaboración propia

En los contrastes de las categorías en función del Lugar de nacimiento tampoco se han encontrado grandes diferencias, aunque es cierto que la de Conocimientos podría estar indicando una posible tendencia hacia una mayor presencia de este tipo de respuestas en los sujetos nacidos en Castilla y León (tabla 38).

Tabla 38. Qué le sugiere la palabra Paisaje y lugar de nacimiento

\begin{tabular}{llrr}
\hline Especialidad & Categorías & Castilla y León & $\begin{array}{c}\text { Otras } \\
\text { Autonomías }\end{array}$ \\
\hline Ambas & Conocimientos & $76.9 \%$ & $69.2 \%$ \\
Ambas & Concienciación & $40.8 \%$ & $43.0 \%$ \\
Ambas & $\begin{array}{l}\text { Comportam.: conservación y } \\
\text { mejora }\end{array}$ & $3.0 \%$ & $2.9 \%$ \\
Ambas & Recursos & $1.9 \%$ & $3.5 \%$ \\
\hline
\end{tabular}

Fuente: Elaboración propia

En el estudio de las sub-categorías (tabla 39) dentro del grupo de Conocimientos, se han encontrado diferencias apreciables en las respuestas de Medio ambiente que son algo más habituales en los sujetos de Castilla y León (19.8\%) que en los que han nacido en otras autonomías (12.8\%). En el resto de subcategorías no se han apreciado diferencias. 
Tabla 39. Qué le sugiere la palabra Paisaje y lugar de nacimiento. Subcategorías

\begin{tabular}{llcc}
\hline Especialidad & Subcategorías & Castilla y León & $\begin{array}{c}\text { Otras } \\
\text { Autonomías }\end{array}$ \\
\hline Ambas & \multicolumn{1}{c}{ CONOCIMIENTOS } & \\
Ambas & Medio físico & $20.7 \%$ & $19.0 \%$ \\
Ambas & Naturaleza & $19.8 \%$ & $12.8 \%$ \\
Ambas & Rural y urbano & $56.8 \%$ & $51.7 \%$ \\
Ambas & Característica y tipos de Paisaje & $4.9 \%$ & $2.9 \%$ \\
Ambas & Ecosistema y biodiversidad & $3.3 \%$ & $1.2 \%$ \\
Ambas & Historia & $4.9 \%$ & $3.5 \%$ \\
Ambas & $\quad$ CONCIENCIACIÓN & $2.7 \%$ & $2.3 \%$ \\
Ambas & Valores y sensibilidad & & \\
Ambas & Estados de ánimo & $4.6 \%$ & $27.3 \%$ \\
Ambas & $\quad$ Aprender para transmitir & $21.5 \%$ & $22.7 \%$ \\
Ambas & Ocio y turismo & $25.3 \%$ & \\
\hline Fuente: Elaboración propia & & $1.7 \%$ \\
& $\quad 0.3 \%$ & $1.7 \%$ \\
\hline
\end{tabular}

En la siguiente pregunta se les pidió a los encuestados que señalaran qué importancia le concede a los valores paisajísticos. En esta cuestión se presentaron 11 elementos que debían ser puntuados en una escala de 6 puntos de 0 a 5, de nada a máxima importancia. Por ello, los análisis estadísticos que se realizan evalúan los valores medios de las respuestas emitidas hacia cada una de esas 11 variables. La fig. 4 presenta dichos valores medios para la muestra total. El más valorado (4.42) es el medioambiental, seguido por el geográfico (4.24) siendo además el grado de acuerdo elevado. Por encima de los 4 puntos también están el valor turístico y el histórico (tabla 40). Los valores: económico y político, han sido los menos puntuados. 


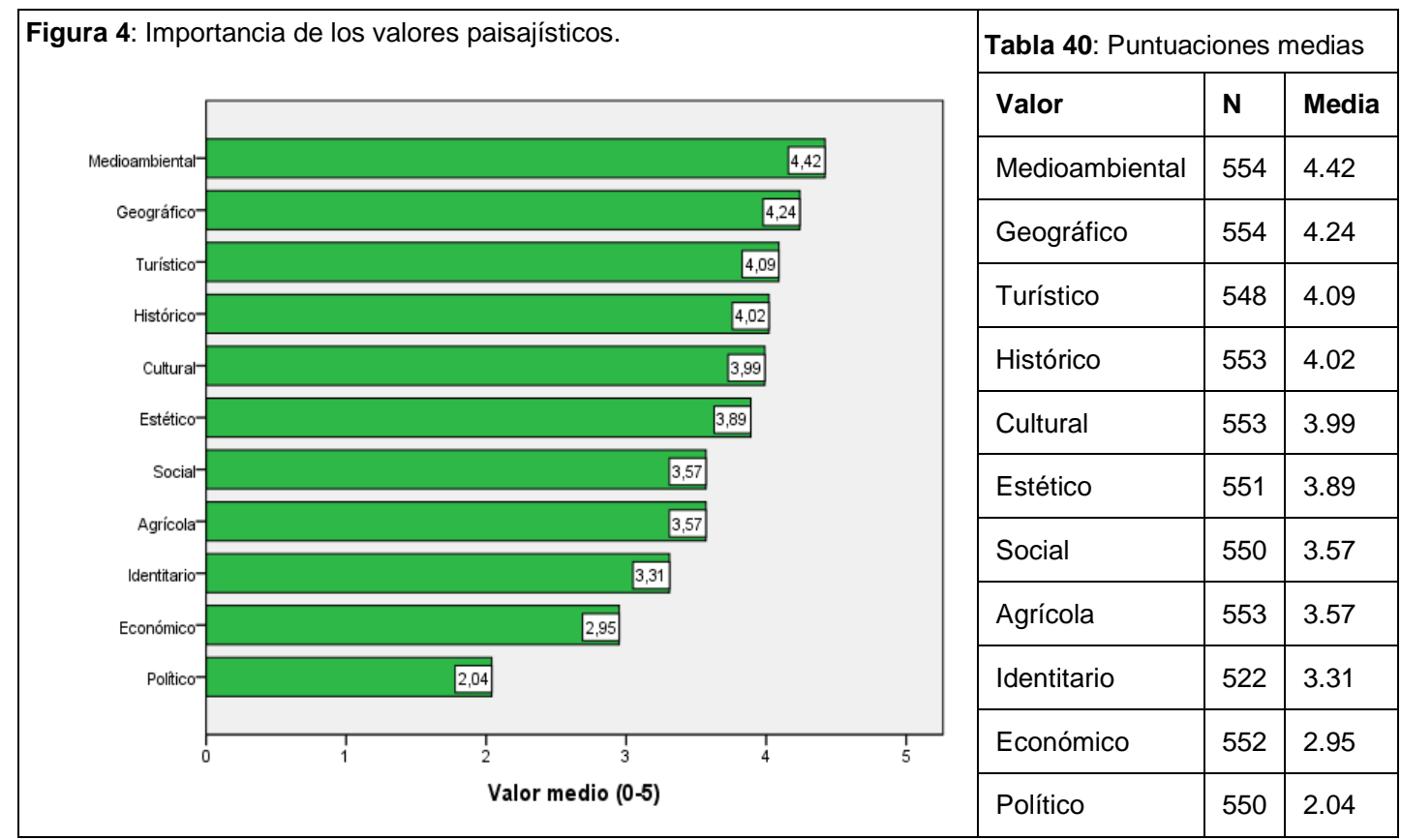

Fuente: Elaboración propia

Para contrastar la posible existencia de diferencias entre las dos especialidades encuestadas, se resumen sus resultados en la tabla 41. En todos los casos, salvo una excepción (el valor político), los alumnos de Infantil han puntuado por encima a cada una de las variables aunque las diferencias son escasas salvo en el caso del valor turístico (4.16 vs 4.02).

Tabla 41. Valores paisajísticos por especialidad

\begin{tabular}{lll}
\hline Variables & Media Infantil & Media Primaria \\
\hline Medioambiental & 4.47 & 4.38 \\
\hline Geográfico & 4.27 & 4.22 \\
\hline Turístico & 4.16 & 4.02 \\
\hline Histórico & 4.09 & 3.96 \\
\hline Cultural & 4.01 & 3.97 \\
\hline Estético & 3.96 & 3.83 \\
\hline Social & 3.61 & 3.53 \\
\hline Agrícola & 3.62 & 3.52 \\
\hline Identitario & 3.34 & 3.27 \\
\hline Económico & 2.99 & 2.91 \\
\hline Político & 2.01 & 2.07 \\
\hline Fuente: Elaborán & & \\
\hline
\end{tabular}

Fuente: Elaboración propia 
Por etapas en los estudios y para el contraste de las medias de las variables asociadas a la pregunta sobre la importancia que se le concede a los valores paisajísticos no es necesario separar a los participantes según su especialidad (tabla 42). En todas las variables, los sujetos de la $1^{\mathrm{a}}$ etapa han puntuado menos que los participantes de la $2^{\mathrm{a}}$ etapa; son en general diferencias no significativas, aunque donde más se aprecian es en los valores: histórico y estético por una parte, y algo menos en cultural, Identitario, económico y político.

Tabla 42. Valores paisajísticos por etapas

\begin{tabular}{|c|c|c|c|}
\hline Variables Etapas & & $\mathrm{N}$ & Media \\
\hline \multirow[t]{2}{*}{ Medioambiental } & $1^{\mathrm{a}}$ etapa & 299 & 4.38 \\
\hline & $2^{\mathrm{a}}$ etapa & 255 & 4.47 \\
\hline \multirow[t]{2}{*}{ Geográfico } & $1^{\mathrm{a}}$ etapa & 299 & 4.22 \\
\hline & $2^{\mathrm{a}}$ etapa & 255 & 4.26 \\
\hline \multirow[t]{2}{*}{ Turístico } & $1^{\mathrm{a}}$ etapa & 294 & 4.07 \\
\hline & $2^{\mathrm{a}}$ etapa & 254 & 4.11 \\
\hline \multirow[t]{2}{*}{ Histórico } & $1^{\mathrm{a}}$ etapa & 298 & 3.94 \\
\hline & $2^{a}$ etapa & 255 & 4.12 \\
\hline \multirow[t]{2}{*}{ Cultural } & $1^{\mathrm{a}}$ etapa & 298 & 3.88 \\
\hline & $2^{a}$ etapa & 255 & 4.12 \\
\hline \multirow[t]{2}{*}{ Estético } & $1^{\mathrm{a}}$ etapa & 296 & 3.80 \\
\hline & $2^{\mathrm{a}}$ etapa & 255 & 4.00 \\
\hline \multirow[t]{2}{*}{ Social } & $1^{\mathrm{a}}$ etapa & 298 & 3.52 \\
\hline & $2^{a}$ etapa & 252 & 3.63 \\
\hline \multirow[t]{2}{*}{ Agrícola } & $1^{\mathrm{a}}$ etapa & 298 & 3.54 \\
\hline & $2^{\mathrm{a}}$ etapa & 255 & 3.60 \\
\hline \multirow[t]{2}{*}{ Identitario } & $1^{\mathrm{a}}$ etapa & 280 & 3.13 \\
\hline & $2^{\mathrm{a}}$ etapa & 242 & 3.51 \\
\hline \multirow[t]{2}{*}{ Económico } & $1^{\mathrm{a}}$ etapa & 298 & 2.80 \\
\hline & $2^{\mathrm{a}}$ etapa & 254 & 3.12 \\
\hline \multirow[t]{2}{*}{ Político } & $1^{\mathrm{a}}$ etapa & 297 & 1.88 \\
\hline & $2^{\mathrm{a}}$ etapa & 253 & 2.23 \\
\hline
\end{tabular}

El medio en que cursaron los estudios anteriores a la Universidad, en el contraste de las medias de las variables de la pregunta sobre la importancia de los valores paisajísticos entre los niveles del medio del centro escolar (tabla 43) no se han encontrado diferencias que puedan ser consideradas como estadísticamente significativas con excepción de una sola, se trata del valor estético en la muestra de Infantil, en la que los que estudiaron en centro rural puntúan significativamente por encima de los del medio urbano. En el 
resto además de no haber apenas diferencias, no se ha encontrado un determinado patrón por el que siempre puntúan más alto unos u otros.

Tabla 43. Valores paisajísticos por especialidad y medio rural-urbano

\begin{tabular}{|c|c|c|c|c|c|c|}
\hline Variable & Especialidad & Medio & Media & Especialidad & Medio & Media \\
\hline \multirow{2}{*}{ Medioambiental } & \multirow{2}{*}{ Infantil } & Rural & 4.56 & \multirow{2}{*}{ Primaria } & Rural & 4.51 \\
\hline & & Urbano & 4.43 & & Urbano & 4.30 \\
\hline \multirow{2}{*}{ Geográfico } & & Rural & 4.14 & & Rural & 4.33 \\
\hline & & Urbano & 4.29 & & Urbano & 4.17 \\
\hline \multirow{2}{*}{ Turístico } & & Rural & 4.16 & & Rural & 4.06 \\
\hline & & Urbano & 4.16 & & Urbano & 3.99 \\
\hline \multirow{2}{*}{ Histórico } & & Rural & 4.08 & & Rural & 4.02 \\
\hline & & Urbano & 4.08 & & Urbano & 3.95 \\
\hline \multirow{2}{*}{ Cultural } & & Rural & 3.95 & & Rural & 4.00 \\
\hline & & Urbano & 4.04 & & Urbano & 3.96 \\
\hline \multirow{2}{*}{ Estético } & & Rural & 4.30 & & Rural & 3.73 \\
\hline & & Urbano & 3.87 & & Urbano & 3.88 \\
\hline \multirow{2}{*}{ Social } & & Rural & 3.48 & & Rural & 3.46 \\
\hline & & Urbano & 3.64 & & Urbano & 3.57 \\
\hline \multirow{2}{*}{ Agrícola } & & Rural & 3.57 & & Rural & 3.61 \\
\hline & & Urbano & 3.63 & & Urbano & 3.48 \\
\hline \multirow{2}{*}{ Identitario } & & Rural & 3.27 & & Rural & 3.29 \\
\hline & & Urbano & 3.38 & & Urbano & 3.26 \\
\hline \multirow{2}{*}{ Económico } & & Rural & 2.89 & & Rural & 2.93 \\
\hline & & Urbano & 3.03 & & Urbano & 2.91 \\
\hline \multirow{2}{*}{ Político } & & Rural & 1.74 & & Rural & 2.09 \\
\hline & & Urbano & 2.09 & & Urbano & 2.05 \\
\hline
\end{tabular}

Fuente: Elaboración propia

Por el lugar de nacimiento la tabla 44 resume los contrastes de medias de las variables de la pregunta acerca de la importancia de los valores paisajísticos; no hay diferencias notables. 


\begin{tabular}{|c|c|c|c|c|c|c|}
\hline Variables & Especialidad & Nacimiento & Media & Especialidad & Nacimiento & Media \\
\hline \multirow{2}{*}{ Medioambiental } & \multirow{2}{*}{ Infantil } & Cy L & 4.47 & \multirow{2}{*}{ Primaria } & Cy L & 4.41 \\
\hline & & Otras & 4.46 & & Otras & 4.34 \\
\hline \multirow{2}{*}{ Geográfico } & & Cy L & 4.25 & & Cy L & 4.20 \\
\hline & & Otras & 4.35 & & Otras & 4.26 \\
\hline \multirow{2}{*}{ Turístico } & & Cy L & 4.17 & & Cy L & 4.11 \\
\hline & & Otras & 4.11 & & Otras & 3.89 \\
\hline \multirow{2}{*}{ Histórico } & & Cy L & 4.08 & & Cy L & 4.02 \\
\hline & & Otras & 4.14 & & Otras & 3.87 \\
\hline \multirow{2}{*}{ Cultural } & & Cy L & 3.99 & & Cy L & 4.02 \\
\hline & & Otras & 4.03 & & Otras & 3.88 \\
\hline \multirow{2}{*}{ Estético } & & Cy L & 4.03 & & Cy L & 3.86 \\
\hline & & Otras & 3.73 & & Otras & 3.85 \\
\hline \multirow{2}{*}{ Social } & & Cy L & 3.55 & & Cy L & 3.55 \\
\hline & & Otras & 3.77 & & Otras & 3.44 \\
\hline \multirow{2}{*}{ Agrícola } & & C y L & 3.57 & & Cy L & 3.52 \\
\hline & & Otras & 3.76 & & Otras & 3.49 \\
\hline \multirow{2}{*}{ Identitario } & & Cy L & 3.32 & & Cy L & 3.31 \\
\hline & & Otras & 3.34 & & Otras & 3.24 \\
\hline \multirow{2}{*}{ Económico } & & Cy L & 2.99 & & Cy L & 2.92 \\
\hline & & Otras & 2.99 & & Otras & 2.85 \\
\hline \multirow{2}{*}{ Político } & & Cy L & 2.03 & & C y L & 2.11 \\
\hline & & Otras & 1.91 & & Otras & 1.91 \\
\hline
\end{tabular}

Fuente: Elaboración propia

Seguidamente se les preguntó sobre la importancia que tienen los elementos de una lista de temas relacionados con el Paisaje, las repuestas quedan reflejadas en la figura 5 que los muestra ordenados de mayor a menor relevancia asignada por los encuestados. Biodiversidad (4.58) y los espacios naturales (4.51) se destacan del resto y con gran homogeneidad en las respuestas. Le sigue la contaminación (4.33) aunque con algo más de variabilidad. Por abajo, descolgados se quedan: la urbanización (3.25) y la ordenación territorial (3.16) (tabla 45). 


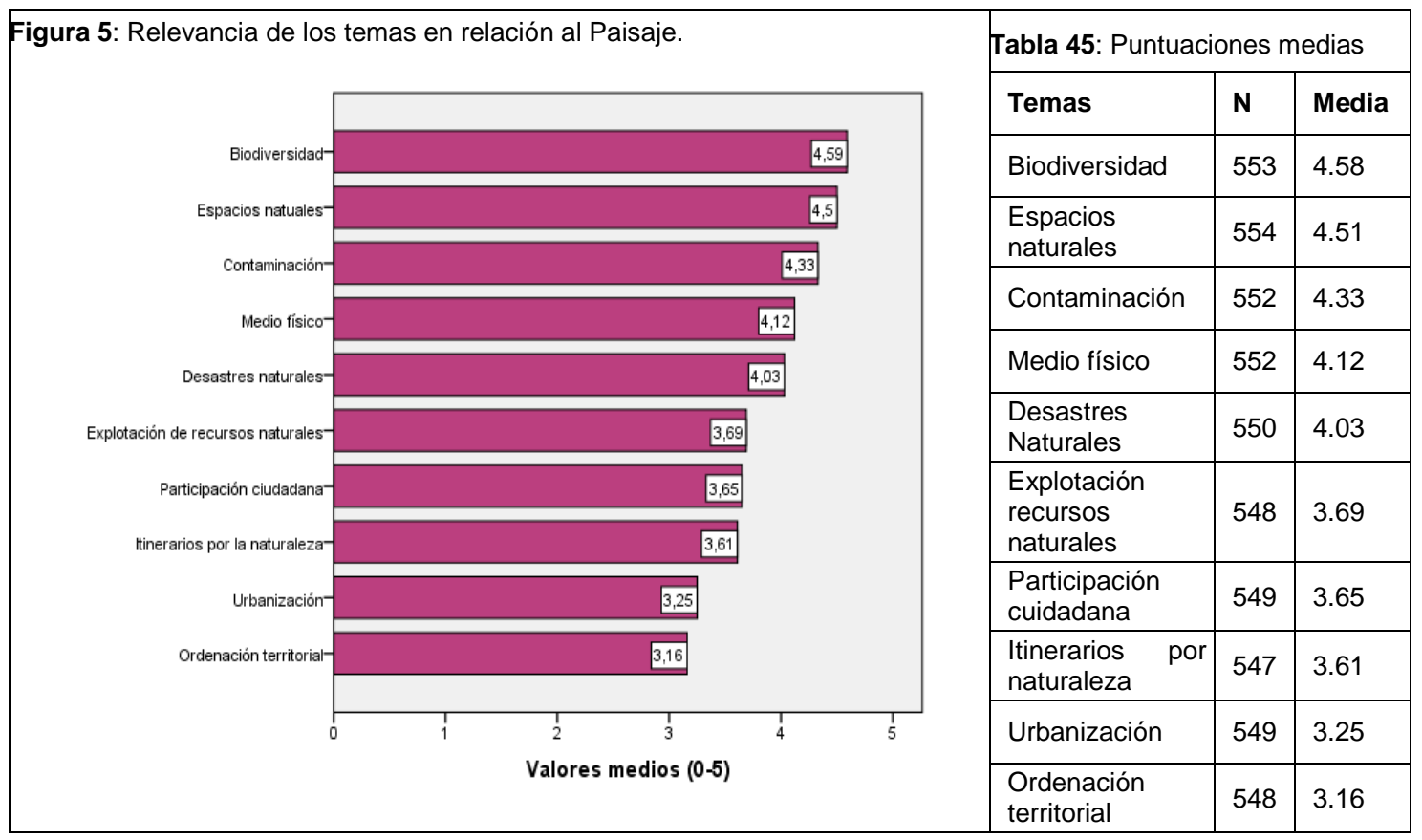

Fuente: Elaboración propia

Si la valoración de estos temas lo comparamos entre ambas especialidades (tabla 46) no se han encontrado diferencias apenas en 7 de los 10 temas en cuestión, aunque siempre los participantes de Infantil han puntuado por encima de los de Primaria. Existe una diferencia en los sujetos de Infantil que puntúan como más relevante a la biodiversidad, a la participación ciudadana y a los espacios naturales más que los de Primaria.

Tabla 46. Relevancia de los términos relacionados con el Paisaje por especialidad

\begin{tabular}{lll}
\hline Variables & Media Infantil & Media Primaria \\
\hline Biodiversidad & 4.66 & 4.51 \\
\hline Contaminación & 4.32 & 4.33 \\
\hline Desastres naturales & 4.09 & 3.98 \\
\hline Medio físico (clima...) & 4.12 & 4.12 \\
\hline Itinerarios por naturaleza & 3.66 & 3.56 \\
\hline Urbanización & 3.27 & 3.24 \\
\hline Explotac. recursos naturales & 3.73 & 3.66 \\
\hline Ordenación territorial & 3.10 & 3.21 \\
\hline Participación ciudadana & 3.81 & 3.51 \\
\hline Espacios naturales & 4.64 & 4.39 \\
\hline Fuente: Elaboración propia & &
\end{tabular}

Fuente: Elaboración propia 
La tabla 47 muestra los resultados de los contrastes de las diferencias entre las medias de las valoraciones que se han dado respecto de la relevancia de los temas propuestos. Se ha separado a los sujetos en función de su especialidad solamente en tres de ellas. No aparecen diferencias significativas en la mayoría de las respuestas analizadas, excepto en desastres naturales y en urbanización, en las que la muestra de la $2^{\mathrm{a}}$ etapa ha asignado valores más alto que la de los de la $1^{\mathrm{a}}$ etapa, en ambas especialidades, así como en la respuesta explotación de recursos naturales, con ambas especialidades unidas, donde de nuevo los sujetos la $2^{\mathrm{a}}$ etapa puntúan más alto.

Tabla 47. Relevancia de los términos relacionados con el Paisaje por etapas

\begin{tabular}{|c|c|c|c|c|}
\hline Especialidad & Variables Ciclo & & $\mathrm{N}$ & Media \\
\hline Infantil & Biodiversidad & $\begin{array}{l}\text { Primero } \\
\text { Segundo }\end{array}$ & $\begin{array}{l}131 \\
136\end{array}$ & $\begin{array}{l}4.72 \\
4.60\end{array}$ \\
\hline Primaria & Biodiversidad & $\begin{array}{l}\text { Primero } \\
\text { Segundo }\end{array}$ & $\begin{array}{l}167 \\
119\end{array}$ & $\begin{array}{l}4.50 \\
4.51\end{array}$ \\
\hline Ambas & Contaminación & $\begin{array}{l}\text { Primero } \\
\text { Segundo }\end{array}$ & $\begin{array}{l}297 \\
255\end{array}$ & $\begin{array}{l}4.25 \\
4.41\end{array}$ \\
\hline Ambas & Desastres naturales & $\begin{array}{l}\text { Primero } \\
\text { Segundo }\end{array}$ & $\begin{array}{l}296 \\
254\end{array}$ & $\begin{array}{l}3.94 \\
4.13\end{array}$ \\
\hline Ambas & Medio físico (clima...) & $\begin{array}{l}\text { Primero } \\
\text { Segundo }\end{array}$ & $\begin{array}{l}297 \\
255\end{array}$ & $\begin{array}{l}4.08 \\
4.16\end{array}$ \\
\hline Ambas & Itinerarios por naturaleza & $\begin{array}{l}\text { Primero } \\
\text { Segundo }\end{array}$ & $\begin{array}{l}295 \\
252\end{array}$ & $\begin{array}{l}3.53 \\
3.69\end{array}$ \\
\hline Ambas & Urbanización & $\begin{array}{l}\text { Primero } \\
\text { Segundo }\end{array}$ & $\begin{array}{l}296 \\
253\end{array}$ & $\begin{array}{l}3.13 \\
3.40\end{array}$ \\
\hline Ambas & $\begin{array}{l}\text { Explotación recursos } \\
\text { naturales }\end{array}$ & $\begin{array}{l}\text { Primero } \\
\text { Segundo }\end{array}$ & $\begin{array}{l}297 \\
251\end{array}$ & $\begin{array}{l}3.56 \\
3.84\end{array}$ \\
\hline Ambas & Ordenación territorial & $\begin{array}{l}\text { Primero } \\
\text { Segundo }\end{array}$ & $\begin{array}{l}297 \\
251\end{array}$ & $\begin{array}{l}3.08 \\
3.25\end{array}$ \\
\hline Infantil & Participación ciudadana & $\begin{array}{l}\text { Primero } \\
\text { Segundo }\end{array}$ & $\begin{array}{l}130 \\
134\end{array}$ & $\begin{array}{l}3.89 \\
3.74\end{array}$ \\
\hline Primaria & Participación ciudadana & $\begin{array}{l}\text { Primero } \\
\text { Segundo }\end{array}$ & $\begin{array}{l}166 \\
119\end{array}$ & $\begin{array}{l}3.42 \\
3.62\end{array}$ \\
\hline Infantil & Espacios naturales & $\begin{array}{l}\text { Primero } \\
\text { Segundo }\end{array}$ & $\begin{array}{l}131 \\
136\end{array}$ & $\begin{array}{l}4.60 \\
4.67\end{array}$ \\
\hline Primaria & Espacios naturales & $\begin{array}{l}\text { Primero } \\
\text { Segundo }\end{array}$ & $\begin{array}{l}168 \\
119\end{array}$ & $\begin{array}{l}4.35 \\
4.44\end{array}$ \\
\hline
\end{tabular}

Fuente: Elaboración propia

Por medio rural-urbano, en el que realizaron sus estudios anteriores, en la comparación entre las medias de las valoraciones sobre la relevancia de los temas propuestos (tabla 48) no se han encontrado diferencias apreciables excepto en una variable, la contaminación según la valoración de los alumnos de Infantil donde aquellos que estudiaron en centros rurales lo valoran más alto que los del urbano. 
Tabla 48. Relevancia de los términos relacionados con el Paisaje por medio rural-urbano y especialidad

\begin{tabular}{|c|c|c|c|c|}
\hline & Variable Medio & & $\mathrm{N}$ & Media \\
\hline \multirow[t]{20}{*}{ Infantil } & \multirow[t]{2}{*}{ Biodiversidad } & Rural & 63 & 4.68 \\
\hline & & Urbano & 199 & 4.65 \\
\hline & \multirow[t]{2}{*}{ Contaminación } & Rural & 63 & 4.54 \\
\hline & & Urbano & 199 & 4.25 \\
\hline & \multirow[t]{2}{*}{ Desastres naturales } & Rural & 63 & 4.21 \\
\hline & & Urbano & 199 & 4.04 \\
\hline & \multirow[t]{2}{*}{ Medio físico (clima...) } & Rural & 63 & 4.06 \\
\hline & & Urbano & 199 & 4.13 \\
\hline & \multirow[t]{2}{*}{ Itinerarios por naturaleza } & Rural & 61 & 3.52 \\
\hline & & Urbano & 198 & 3.69 \\
\hline & \multirow[t]{2}{*}{ Urbanización } & Rural & 60 & 3.25 \\
\hline & & Urbano & 199 & 3.25 \\
\hline & \multirow[t]{2}{*}{ Explotac. recursos naturales } & Rural & 62 & 3.73 \\
\hline & & Urbano & 197 & 3.71 \\
\hline & \multirow[t]{2}{*}{ Ordenación territorial } & Rural & 61 & 3.02 \\
\hline & & Urbano & 196 & 3.10 \\
\hline & \multirow[t]{2}{*}{ Participación ciudadana } & Rural & 62 & 3.76 \\
\hline & & Urbano & 197 & 3.82 \\
\hline & \multirow[t]{2}{*}{ Espacios naturales } & Rural & 63 & 4.59 \\
\hline & & Urbano & 199 & 4.65 \\
\hline \multirow[t]{20}{*}{ Primaria } & \multirow[t]{2}{*}{ Biodiversidad } & Rural & 101 & 4.56 \\
\hline & & Urbano & 184 & 4.50 \\
\hline & \multirow[t]{2}{*}{ Contaminación } & Rural & 101 & 4.33 \\
\hline & & Urbano & 183 & 4.36 \\
\hline & \multirow[t]{2}{*}{ Desastres naturales } & Rural & 102 & 3.91 \\
\hline & & Urbano & 181 & 4.02 \\
\hline & \multirow[t]{2}{*}{ Medio físico (clima...) } & Rural & 101 & 4.15 \\
\hline & & Urbano & 183 & 4.13 \\
\hline & \multirow[t]{2}{*}{ Itinerarios por naturaleza } & Rural & 100 & 3.55 \\
\hline & & Urbano & 182 & 3.58 \\
\hline & \multirow[t]{2}{*}{ Urbanización } & Rural & 101 & 3.20 \\
\hline & & Urbano & 183 & 3.26 \\
\hline & \multirow[t]{2}{*}{ Explotac. recursos naturales } & Rural & 102 & 3.73 \\
\hline & & Urbano & 182 & 3.63 \\
\hline & \multirow[t]{2}{*}{ Ordenación territorial } & Rural & 102 & 3.21 \\
\hline & & Urbano & 183 & 3.22 \\
\hline & \multirow[t]{2}{*}{ Participación ciudadana } & Rural & 102 & 3.40 \\
\hline & & Urbano & 182 & 3.56 \\
\hline & \multirow[t]{2}{*}{ Espacios naturales } & Rural & 102 & 4.39 \\
\hline & & Urbano & 184 & 4.41 \\
\hline
\end{tabular}

Fuente: Elaboración propia

Por lugar de nacimiento la tabla 49 resume la comparación entre medias de las valoraciones sobre de la relevancia de los temas propuestos entre los lugares de nacimiento considerados. No se han encontrado diferencias que sean destacables en ninguna de las variables con una sola excepción: se trata del Medio físico en los participantes que estudian Infantil, donde se ha encontrado que los sujetos nacidos en Castilla y León puntúan por encima de los de otras comunidades autónomas. 
Tabla 49. Relevancia de los términos relacionados con el Paisaje por lugar de nacimiento y especialidad

\begin{tabular}{|c|c|c|c|c|}
\hline & & Infantil & & imaria \\
\hline Variables & Ámbito & Media & Ámbito & Media \\
\hline \multirow{2}{*}{ Biodiversidad } & Cy L & 4.66 & Cy L & 4.52 \\
\hline & Otras & 4.62 & Otras & 4.47 \\
\hline \multirow{2}{*}{ Contaminación } & Cy L & 4.40 & Cy L & 4.40 \\
\hline & Otras & 4.14 & Otras & 4.22 \\
\hline \multirow{2}{*}{ Desastres naturales } & Cy L & 4.16 & Cy L & 3.97 \\
\hline & Otras & 3.97 & Otras & 3.95 \\
\hline \multirow{2}{*}{ Medio físico (clima...) } & Cy L & 4.24 & Cy L & 4.06 \\
\hline & Otras & 3.86 & Otras & 4.20 \\
\hline \multirow{2}{*}{$\begin{array}{l}\text { Itinerarios } \\
\text { naturaleza }\end{array}$} & Cy L & 3.70 & Cy L & 3.49 \\
\hline & Otras & 3.53 & Otras & 3.70 \\
\hline \multirow{2}{*}{ Urbanización } & C y L & 3.30 & C y L & 3.23 \\
\hline & Otras & 3.15 & Otras & 3.24 \\
\hline \multirow{2}{*}{$\begin{array}{l}\text { Explotac. } \\
\text { naturales }\end{array}$} & Cy L & 3.84 & Cy L & 3.65 \\
\hline & Otras & 3.48 & Otras & 3.63 \\
\hline \multirow{2}{*}{ Ordenación territorial } & Cy L & 3.17 & Cy L & 3.18 \\
\hline & Otras & 2.94 & Otras & 3.20 \\
\hline \multirow{2}{*}{$\begin{array}{l}\text { Participación } \\
\text { ciudadana }\end{array}$} & C y L & 3.83 & C y L & 3.53 \\
\hline & Otras & 3.77 & Otras & 3.37 \\
\hline \multirow{2}{*}{ Espacios naturales } & Cy L & 4.65 & Cy L & 4.35 \\
\hline & Otras & 4.58 & Otras & 4.47 \\
\hline
\end{tabular}

Fuente: Elaboración propia

A la pregunta ¿Con qué proposiciones está más de acuerdo? Señale 3 como máximo y ordénalas de $1^{a}$ a $3^{a}$ según su orden de importancia (siendo la 1 más importante y la 3 menos) se les pedía a los participantes que de un listado señalasen 3 proposiciones como máximo, por lo que algunos señalaron menos, y que les asignaran un orden de $1^{\circ}$ a $3^{\circ}$ en función de la importancia de mayor a menor. Para el tratamiento de estas variables, se presenta a continuación una tabla que indica el \% y el número de veces que cada una de ellas fue señalada y en qué orden se le asignó, así como la media de esos rangos, para la cual un menor valor medio implica más importancia, pues significa que ha estado más veces en el $1^{\circ}$ lugar. Pero la interpretación no debe atender solo a ello sino también al número de sujetos que la han elegido: puesto que la proposición con menos media (1.70), que sería la más importante, ha sido señalada solamente por 20 participantes (el 3.6\%; de hecho es la menos elegida), se deduce que al restante $96 \%$ de los participantes no les parece que debe estar entre los tres primeros (tabla 50 ). 
Tabla 50. Orden de importancia de proposiciones acerca del Paisaje

\begin{tabular}{|c|c|c|c|c|c|}
\hline Proposición & N (\%) & $1^{0}$ & $2^{\circ}$ & $3^{\circ}$ & Media \\
\hline $\begin{array}{l}\text { El Paisaje tiene que estar dotado de cualidades estéticas } \\
\text { positivas. }\end{array}$ & $71(12.8 \%)$ & $26.8 \%$ & $18.3 \%$ & $53.5 \%$ & 2.31 \\
\hline $\begin{array}{l}\text { El Paisaje proporciona información sobre el territorio visible, } \\
\text { es una fuente de conocimiento geográfico. }\end{array}$ & $244(44.0 \%)$ & $39.8 \%$ & $29.9 \%$ & $30.3 \%$ & 1.91 \\
\hline $\begin{array}{l}\text { El Paisaje proporciona información sobre el transcurso del } \\
\text { tiempo, está dotado de significado histórico. }\end{array}$ & $268(48.4 \%)$ & $31.0 \%$ & $41.8 \%$ & $27.2 \%$ & 1.96 \\
\hline $\begin{array}{l}\text { El Paisaje revela el grado de conservación o transformación } \\
\text { del medio ambiente }\end{array}$ & $231(41.7 \%)$ & $34.6 \%$ & $34.2 \%$ & $31.2 \%$ & 1.97 \\
\hline $\begin{array}{l}\text { Las políticas sobre el Paisaje deben ser un objetivo de los } \\
\text { gobiernos nacionales y supranacionales. }\end{array}$ & $100(18.1 \%)$ & $38.0 \%$ & $29.0 \%$ & $33.0 \%$ & 1.95 \\
\hline $\begin{array}{l}\text { La conservación y preservación del Paisaje debe ser un } \\
\text { empeño de instituciones privadas. }\end{array}$ & $29(5.2 \%)$ & $41.4 \%$ & $31.0 \%$ & $27.6 \%$ & 1.86 \\
\hline $\begin{array}{l}\text { Las necesidades de los grupos humanos deben estar por } \\
\text { encima de la preservación del Paisaje. }\end{array}$ & $20(3.6 \%)$ & $40.0 \%$ & $50.0 \%$ & $10.0 \%$ & 1.70 \\
\hline $\begin{array}{l}\text { El Paisaje es el resultante de la interacción entre diversos } \\
\text { factores bióticos, abióticos y antrópicos }\end{array}$ & $172(31.0 \%)$ & $42.4 \%$ & $25.6 \%$ & $32.0 \%$ & 1.90 \\
\hline El Paisaje es un recurso turístico, cultural y económico. & $230(41.5 \%)$ & $21.3 \%$ & $37.8 \%$ & $40.9 \%$ & 2.20 \\
\hline $\begin{array}{l}\text { Las políticas económicas deben estar supeditadas a la } \\
\text { conservación del Paisaje. }\end{array}$ & $85(15.3 \%)$ & $34.1 \%$ & $28.2 \%$ & $37.6 \%$ & 2.04 \\
\hline
\end{tabular}

De entre las 7 proposiciones que tienen una media entre 1 y 2 , que quiere decir que han estado casi siempre situadas en el $1^{\mathrm{er}}$ y $2^{\circ}$ lugar, la más señalada (por el $48.4 \%$ de la muestra) ha sido que "El Paisaje proporciona información sobre el transcurso del tiempo, está dotado de significado histórico" por tanto se debe considerar que es la más valorada (gráfico 6). Le sigue de cerca la que dice que "El Paisaje proporciona información sobre el territorio visible, es una fuente de conocimiento geográfico" casi con la misma media que la anterior y marcada por el $44 \%$ de la muestra. Para el tercer lugar hay dos proposiciones casi empatadas en cuanto al porcentaje de elección (41.7\% y 41.5\%) pero una con media menor (1.97) que la otra (2.20) por lo que este $3^{\text {er }}$ lugar se le adjudica a la que dice que "El Paisaje revela el grado de conservación o transformación del medio ambiente“. Como consecuencia, las tres primeras están relacionadas con la información que aporta el Paisaje (tabla 50).

A la vista de los problemas de interpretación que se encontraron en esta cuestión y ante las escasas diferencias en cuanto a los valores medios calculados (1.70 a 2.31) desde los rangos asignados $\left(1^{\circ}\right.$ al $\left.3^{\circ}\right)$ se decide que para los análisis comparativos que siguen, se van a considerar estas variables como dicotómicas, teniendo en cuenta solamente los \% de casos que las señala, prescindiendo del orden. Es decir que se cambia la interpretación de "orden" de importancia por la de "tiene / no tiene" importancia cada proposición. Los resultados se resumen en la tabla 51.

Por especialidades solo se ha encontrado diferencias que se puedan considerar destacables entre 4 de ellas, en el resto no los son, por lo que la tasa de elección es 
similar en ambas especialidades. Las diferencias han aparecido en "El Paisaje tiene que estar dotado de cualidades estéticas positivas", "...es un recurso turístico, cultural y económico" y en "...proporciona información sobre el territorio visible, es una fuente de conocimiento geográfico" que han sido señaladas por más participantes de la muestra de Infantil. Y también es significativa la diferencia en "Las políticas sobre el Paisaje deben ser un objetivo de los gobiernos nacionales y supranacionales" donde por el contrario se observa mayor tasa de elección en los sujetos de la especialidad de Primaria.

Tabla 51. Grado de acuerdo con las proposiciones por especialidad

\begin{tabular}{|c|c|c|c|}
\hline Proposición ( $\mathrm{P}$ = Paisaje) & Totales & Infantil & Primaria \\
\hline El Paisaje tiene que estar dotado de cualidades estéticas positivas. & $48.4 \%(268)$ & $53.6 \%$ & $43.6 \%$ \\
\hline $\begin{array}{l}\text { El Paisaje proporciona información sobre el territorio visible, es una } \\
\text { fuente de conocimiento geográfico. }\end{array}$ & $44.0 \%(244)$ & $47.2 \%$ & $41.1 \%$ \\
\hline $\begin{array}{l}\text { El Paisaje proporciona información sobre el transcurso del tiempo, está } \\
\text { dotado de significado histórico. }\end{array}$ & $41.7 \%(231)$ & $41.6 \%$ & $41.8 \%$ \\
\hline $\begin{array}{l}\text { El Paisaje revela el grado de conservación o transformación del medio } \\
\text { ambiente }\end{array}$ & $41.5 \%(230)$ & $46.4 \%$ & $36.9 \%$ \\
\hline $\begin{array}{l}\text { Las políticas sobre el Paisaje deben ser un objetivo de los gobiernos } \\
\text { nacionales y supranacionales. }\end{array}$ & $31.0 \%(172)$ & $24.7 \%$ & $36.9 \%$ \\
\hline $\begin{array}{l}\text { La conservación y preservación del Paisaje debe ser un empeño de } \\
\text { instituciones privadas. }\end{array}$ & $18.1 \%(52)$ & $18.0 \%$ & $18,1 \%$ \\
\hline $\begin{array}{l}\text { Las necesidades de los grupos humanos deben estar por encima de la } \\
\text { preservación del Paisaje. }\end{array}$ & $15.3 \%(85)$ & $14.2 \%$ & $16.4 \%$ \\
\hline $\begin{array}{l}\text { El Paisaje es el resultante de la interacción entre diversos factores } \\
\text { bióticos, abióticos y antrópicos }\end{array}$ & $12.8 \%(71)$ & $15.4 \%$ & $10.5 \%$ \\
\hline El Paisaje es un recurso turístico, cultural y económico. & $5.2 \%(29)$ & $4.1 \%$ & $6.3 \%$ \\
\hline $\begin{array}{l}\text { Las políticas económicas deben estar supeditadas a la conservación del } \\
\text { Paisaje. }\end{array}$ & $3.6 \%(20)$ & $3.4 \%$ & $3.8 \%$ \\
\hline
\end{tabular}

Fuente: Elaboración propia

Por etapas de los estudios de Grado, para los análisis en esta pregunta, tras la reconversión de las respuestas anteriormente explicada, se va a segmentar por etapa a los participantes en tres de las proposiciones, manteniendo juntos a los sujetos en las restantes. Los resultados se resumen en la tabla 52. No aparecen diferencias importantes en bastantes de las variables, pero sí para en dos de ellas: que "el Paisaje proporciona información sobre el paso del tiempo" en la especialidad de Primaria y en "Paisaje revela el grado de conservación/transformación del medio ambiente" con ambas especialidades unidas. En las dos variables, los participantes de la $1^{\mathrm{a}}$ etapa han manifestado su acuerdo en mayor tasa que los de la $2^{\mathrm{a}}$ etapa; también la hay en "el Paisaje es el resultado de la interacción de factores..." donde los sujetos de la $2^{\mathrm{a}}$ etapa la han señalado más que los de la $1^{\mathrm{a}}$ etapa, y en "el Paisaje tiene que estar dotado de cualidades estéticas...", también con los sujetos de ambas especialidades, y en el que ahora son los de la $1^{\mathrm{a}}$ etapa los que han manifestado un mayor grado de acuerdo. 
Tabla 52. Grado de acuerdo con las proposiciones por etapas

\begin{tabular}{|c|c|c|c|}
\hline Especialidad & Proposición & $1^{\circ}$ y $2^{\circ}\left(1^{a} E\right)$ & $3^{\circ}$ y $4^{\circ}\left(2^{a} E\right)$ \\
\hline Infantil & $\begin{array}{l}\text { El Paisaje proporciona información sobre el } \\
\text { transcurso del tiempo, está dotado de significado } \\
\text { histórico. }\end{array}$ & $53.4 \%$ & $53.7 \%$ \\
\hline Primaria & $\begin{array}{l}\text { El Paisaje proporciona información sobre el } \\
\text { transcurso del tiempo, está dotado de significado } \\
\text { histórico. }\end{array}$ & $49.4 \%$ & $35.3 \%$ \\
\hline Ambas & $\begin{array}{l}\text { El Paisaje proporciona información sobre el territorio } \\
\text { visible, es una fuente de conocimiento geográfico. }\end{array}$ & $45.8 \%$ & $42.0 \%$ \\
\hline Ambas & $\begin{array}{l}\text { El Paisaje revela el grado de conservación o } \\
\text { transformación del medio ambiente }\end{array}$ & $45.8 \%$ & $36.9 \%$ \\
\hline Infantil & $\begin{array}{l}\text { El Paisaje es un recurso turístico, cultural y } \\
\text { económico. }\end{array}$ & $51.1 \%$ & $41.9 \%$ \\
\hline Primaria & $\begin{array}{l}\text { El Paisaje es un recurso turístico, cultural y } \\
\text { económico. }\end{array}$ & $37.5 \%$ & $36.1 \%$ \\
\hline Ambas & $\begin{array}{l}\text { El Paisaje es el resultante de la interacción entre } \\
\text { diversos factores bióticos, abióticos y antrópicos }\end{array}$ & $25.8 \%$ & $37.3 \%$ \\
\hline Ambas & $\begin{array}{l}\text { Las políticas sobre el Paisaje deben ser un objetivo } \\
\text { de los gobiernos nacionales y supranacionales. }\end{array}$ & $18.7 \%$ & $17.3 \%$ \\
\hline Infantil & $\begin{array}{l}\text { Las políticas económicas deben estar supeditadas a } \\
\text { la conservación del Paisaje. }\end{array}$ & $17.6 \%$ & $11.0 \%$ \\
\hline Primaria & $\begin{array}{l}\text { Las políticas económicas deben estar supeditadas a } \\
\text { la conservación del Paisaje. }\end{array}$ & $16.1 \%$ & $16.8 \%$ \\
\hline Ambas & $\begin{array}{l}\text { El Paisaje tiene que estar dotado de cualidades } \\
\text { estéticas positivas. }\end{array}$ & $17.4 \%$ & $7.5 \%$ \\
\hline Ambas & $\begin{array}{l}\text { La conservación y preservación del Paisaje debe ser } \\
\text { un empeño de instituciones privadas. }\end{array}$ & $5.7 \%$ & $4.7 \%$ \\
\hline Ambas & $\begin{array}{l}\text { Las necesidades de los grupos humanos deben } \\
\text { estar por encima de la preservación del Paisaje. }\end{array}$ & $2.7 \%$ & $4.7 \%$ \\
\hline
\end{tabular}

Fuente: Elaboración propia

Por ámbito de realización de estudios anteriores en la tabla 53 se resumen los contrastes realizados con la pregunta después de su reconversión a dicotómica entre los medios rural y urbano. Como se puede ver fácilmente, no se han encontrado diferencias que merezcan comentario en ninguna de las variables. 
Tabla 53. Grado de acuerdo con las proposiciones según procedencia rural-urbana

\begin{tabular}{|c|c|c|c|c|}
\hline \multirow[b]{2}{*}{ Proposición (P = Paisaje) } & \multicolumn{2}{|c|}{ Infantil } & \multicolumn{2}{|c|}{ Primaria } \\
\hline & Rural & Urbano & Rural & Urbano \\
\hline $\begin{array}{l}\text { El Paisaje proporciona información sobre el transcurso del tiempo, está } \\
\text { dotado de significado histórico. }\end{array}$ & $60.3 \%$ & $52.3 \%$ & $46.1 \%$ & $41.8 \%$ \\
\hline $\begin{array}{l}\text { El Paisaje proporciona información sobre el territorio visible, es una } \\
\text { fuente de conocimiento geográfico. }\end{array}$ & $50.8 \%$ & $45.7 \%$ & $43.1 \%$ & $40.2 \%$ \\
\hline $\begin{array}{l}\text { El Paisaje revela el grado de conservación o transformación del medio } \\
\text { ambiente }\end{array}$ & $47.6 \%$ & $40.2 \%$ & $43.1 \%$ & $41.3 \%$ \\
\hline El Paisaje es un recurso turístico, cultural y económico. & $41.3 \%$ & $47.2 \%$ & $33.3 \%$ & $39.1 \%$ \\
\hline $\begin{array}{l}\text { El Paisaje es el resultante de la interacción entre diversos factores } \\
\text { bióticos, abióticos y antrópicos }\end{array}$ & $17.5 \%$ & $27.1 \%$ & $39.2 \%$ & $35.3 \%$ \\
\hline $\begin{array}{l}\text { Las políticas sobre el Paisaje deben ser un objetivo de los gobiernos } \\
\text { nacionales y supranacionales. }\end{array}$ & $23.8 \%$ & $16.6 \%$ & $14.7 \%$ & $20.1 \%$ \\
\hline $\begin{array}{l}\text { Las políticas económicas deben estar supeditadas a la conservación } \\
\text { del Paisaje. }\end{array}$ & $7.9 \%$ & $16.1 \%$ & $11.8 \%$ & $18.5 \%$ \\
\hline El Paisaje tiene que estar dotado de cualidades estéticas positivas. & $15.9 \%$ & $14.6 \%$ & $11.8 \%$ & $9.8 \%$ \\
\hline $\begin{array}{l}\text { La conservación y preservación del Paisaje debe ser un empeño de } \\
\text { instituciones privadas. }\end{array}$ & $3.2 \%$ & $4.0 \%$ & $7.8 \%$ & $5.4 \%$ \\
\hline $\begin{array}{l}\text { Las necesidades de los grupos humanos deben estar por encima de } \\
\text { la preservación del Paisaje. }\end{array}$ & $1.6 \%$ & $3.5 \%$ & $4.9 \%$ & $3.3 \%$ \\
\hline
\end{tabular}

Fuente: Elaboración propia

Por lugar de nacimiento los contrastes se exponen en la tabla 54. Hay algunas diferencias remarcables en El Paisaje proporciona información sobre el territorio visible, es una fuente de conocimiento geográfico donde puntúan más las otras Autonomías y en El Paisaje es el resultante de la interacción entre diversos factores bióticos, abióticos y antrópicos donde puntúan más los estudiantes de Castilla y León, pero esas diferencias no proporcionan información interesante.

Tabla 54. Grado de acuerdo con las proposiciones según lugar de nacimiento y especialidad

\begin{tabular}{|c|c|c|c|c|}
\hline \multirow[b]{2}{*}{ Proposición } & \multicolumn{2}{|c|}{ Infantil } & \multicolumn{2}{|c|}{ Primaria } \\
\hline & C y L & $\begin{array}{l}\text { Otras } \\
\text { auton. }\end{array}$ & Cy L & $\begin{array}{l}\text { Otras } \\
\text { auton. }\end{array}$ \\
\hline $\begin{array}{l}\text { El Paisaje proporciona información sobre el transcurso del tiempo, está } \\
\text { dotado de significado histórico. }\end{array}$ & $\begin{array}{l}55.0 \\
\%\end{array}$ & $50.7 \%$ & $46.9 \%$ & $39.6 \%$ \\
\hline $\begin{array}{l}\text { El Paisaje proporciona información sobre el territorio visible, es una } \\
\text { fuente de conocimiento geográfico. }\end{array}$ & $\begin{array}{l}45.5 \\
\%\end{array}$ & $52.1 \%$ & $37.3 \%$ & $47.5 \%$ \\
\hline $\begin{array}{l}\text { El Paisaje revela el grado de conservación o transformación del medio } \\
\text { ambiente }\end{array}$ & $\begin{array}{l}42.4 \\
\%\end{array}$ & $42.3 \%$ & $45.8 \%$ & $34.7 \%$ \\
\hline El Paisaje es un recurso turístico, cultural y económico. & $\begin{array}{l}46.1 \\
\%\end{array}$ & $46.5 \%$ & $33.9 \%$ & $40.6 \%$ \\
\hline $\begin{array}{l}\text { El Paisaje es el resultante de la interacción entre diversos factores } \\
\text { bióticos, abióticos y antrópicos }\end{array}$ & $\begin{array}{l}27.2 \\
\%\end{array}$ & $19.7 \%$ & $40.7 \%$ & $29.7 \%$ \\
\hline $\begin{array}{l}\text { Las políticas sobre el Paisaje deben ser un objetivo de los gobiernos } \\
\text { nacionales y supranacionales. }\end{array}$ & $\begin{array}{l}18.3 \\
\%\end{array}$ & $16.9 \%$ & $17.5 \%$ & $17.8 \%$ \\
\hline $\begin{array}{l}\text { Las políticas económicas deben estar supeditadas a la conservación del } \\
\text { Paisaje. }\end{array}$ & $\begin{array}{l}12.0 \\
\%\end{array}$ & $21.1 \%$ & $15.3 \%$ & $18.8 \%$ \\
\hline El Paisaje tiene que estar dotado de cualidades estéticas positivas. & $\begin{array}{l}14.7 \\
\%\end{array}$ & $16.9 \%$ & $9.0 \%$ & $13.9 \%$ \\
\hline $\begin{array}{l}\text { La conservación y preservación del Paisaje debe ser un empeño de } \\
\text { instituciones privadas. }\end{array}$ & $5.2 \%$ & $1.4 \%$ & $5.6 \%$ & $7.9 \%$ \\
\hline $\begin{array}{l}\text { Las necesidades de los grupos humanos deben estar por encima de la } \\
\text { preservación del Paisaje. }\end{array}$ & $4.7 \%$ & $0 \%$ & $4.5 \%$ & $2.0 \%$ \\
\hline
\end{tabular}

Fuente: Elaboración propia 
La pregunta siguiente, sobre la "valoración sobre la utilidad de los conocimientos que han adquirido sobre el Paisaje" se realizó, de nuevo, en la ya empleada escala de 0 a 5 puntos. Por tanto se describe y contrasta con sus valores medios. En la muestra total, han aparecido valores desde el 0 (5 casos, 0.9\%) hasta el 5 (58 casos, 11\%) con una media de 3.34 siendo los valores más frecuentes, el 3 (41\%) y el 4 (33\%).

Al contrastar las dos especialidades se encontraron medias casi idénticas: Infantil 3.32 vs Primaria 3.35, por lo que la diferencia no se puede considerar significativa.

La valoración de en qué grado se consideran útiles los conocimientos que se han adquirido sobre el Paisaje a lo largo de su escolaridad Primaria y secundaria alcanza el valor de media 3.38 en los sujetos de la $1^{a}$ etapa, ligeramente superior a la media de los de la $2^{\mathrm{a}}$ etapa: 3.29 .

La valoración sobre en qué grado se considera que han sido útiles los conocimientos adquiridos sobre el Paisaje a lo largo de su escolaridad comparada con la variable del medio de hábitat de los centros escolares (tabla 55) no registra diferencias importantes.

\begin{tabular}{|c|c|c|c|}
\hline \multicolumn{2}{|c|}{ Especialidad Ámbito } & $\mathrm{N}$ & Media \\
\hline \multirow{2}{*}{ Infantil } & Rural & 63 & 3.46 \\
\hline & Urbano & 199 & 3.28 \\
\hline \multirow{2}{*}{ Primaria } & Rural & 102 & 3.37 \\
\hline & Urbano & 183 & 3.33 \\
\hline
\end{tabular}

Fuente: Elaboración propia

En la valoración sobre la utilidad de los conocimientos con la variable del lugar de nacimiento (tabla 56) no se han encontrado diferencias estadísticamente significativas.

Tabla 56. Utilidad de los conocimientos según el lugar de nacimiento y especialidad

\begin{tabular}{llll}
\hline Especialidad & Ámbito & N & Media \\
\hline \multirow{2}{*}{ Infantil } & En Castilla y León & 191 & 3.34 \\
& En otras & 71 & 3.27 \\
\multirow{2}{*}{ Primaria } & En Castilla y León & 176 & 3.38 \\
& En otras & 101 & 3.27 \\
\hline Fuente: Elaboración propia & &
\end{tabular}

Fuente: Elaboración propia

Al preguntar ¿Por qué han sido útiles los conocimientos adquiridos sobre el Paisaje en su escolarización en Primaria y secundaria? hay que señalar que en la pregunta cerrada anterior, en que se pedía una valoración de la utilidad de los conocimientos adquiridos, 
se obtuvo una cifra media en torno a 3,3 sin grandes diferencias por grupos analizados, y un alto índice de respuesta. Sin embargo, en las respuestas ya categorizadas de esta pregunta (tabla 57) lo primero que se observa es que la cantidad de respuestas es mucho menor que en las anteriores preguntas, con tasas que no llegan al 30\%. Entre las emitidas, encontramos una vez más que el grupo más frecuente es el de Conocimientos (29\%) pero esta vez seguido de los otros tres que tienen tasas muy similares entre sí, siendo el que ocupa el segundo lugar es del Comportamiento para la conservación y mejora (16\%).

Por especialidades los contrastes no presentan diferencias importantes, la distribución de respuestas es similar en ambas.

Tabla 57. ¿Por qué han sido útiles los conocimientos sobre el Paisaje? por especialidades.

\begin{tabular}{lccc}
\hline & \multicolumn{1}{c}{ Totales } & \multicolumn{1}{c}{ Infantil } & Primaria \\
\hline Conocimientos & $28.5 \%$ & $31.1 \%$ & $26.1 \%$ \\
Concienciación & $14.3 \%$ & $14.6 \%$ & $13.9 \%$ \\
$\begin{array}{l}\text { Comportamiento.: conservación y } \\
\text { mejora }\end{array}$ & $16.2 \%$ & $15.0 \%$ & $17,4 \%$ \\
Recursos & $11.2 \%$ & $12.7 \%$ & $9.8 \%$ \\
\hline Fuente: Elaboración propia & & &
\end{tabular}

En la descripción de las subcategorías y puesto que ésta ha sido una pregunta poco contestada, en 4 grupos no es analizable estadísticamente. Dentro de la categoría de Conocimientos, las respuestas más frecuentes están relacionadas con Característica y tipos de Paisaje (19\%) casi sin diferencias entre las especialidades. El resto apenas llega al 5\%. Una de ellas, Medio ambiente, parece indicar que este tipo de respuestas es más frecuente en los sujetos de Infantil; aunque al ser el número de casos tan reducido es un resultado que se debe de tomar con precaución. En el resto de las subcategorías no se han encontrado diferencias reseñables. 
Tabla 58. ¿Por qué han sido útiles los conocimientos sobre el Paisaje? por especialidades.

\begin{tabular}{lrrr}
\hline Subcategorías & \multicolumn{1}{c}{ Totales } & Infantil & Primaria \\
\hline \multicolumn{1}{c}{ CONOCIMIENTOS } & & & \\
Medio físico & $4.9 \%$ & $2.6 \%$ & $7.1 \%$ \\
Medio ambiente & $2.5 \%$ & $4.1 \%$ & $1.0 \%$ \\
Naturaleza & $1.4 \%$ & $1.9 \%$ & $1.0 \%$ \\
Rural y urbano & $0.4 \%$ & $0.4 \%$ & $0.3 \%$ \\
Característica y tipos de Paisaje & $19.1 \%$ & $19.5 \%$ & $18.8 \%$ \\
Ecosistema y biodiversidad & $0.5 \%$ & $0.7 \%$ & $0.3 \%$ \\
Historia & $1.6 \%$ & $2.2 \%$ & $1.0 \%$ \\
Práctica & $1.8 \%$ & $2.2 \%$ & $1.4 \%$ \\
\multicolumn{1}{c}{ CONCIENCIACIÓN } & & & \\
Valores y sensibilidad & $13.0 \%$ & $13.1 \%$ & $12.9 \%$ \\
Valores estéticos & $1.3 \%$ & $1.9 \%$ & $0.7 \%$ \\
Estados de ánimo & $1.3 \%$ & $1.9 \%$ & $0.7 \%$ \\
$\quad$ RECURSOS & & & \\
Necesario/importante para la vida & $11.0 \%$ & $12.4 \%$ & $9.8 \%$ \\
Aprender para transmitir & $0.4 \%$ & $0.4 \%$ & $0.3 \%$ \\
Ocio y turismo & $0.2 \%$ & $0.4 \%$ & $0 \%$ \\
\hline Fuente: Elaboración propia & & &
\end{tabular}

Por etapas los resultados de la comparación de las categorías se resumen en la tabla 59. Como se puede observar en ella, se han encontrado diferencias muy importantes tanto en Conocimientos como en Recursos. De la primera de ellas son más habituales entre los sujetos de la $2^{\mathrm{a}}$ etapa ( $35 \%$ vs $23 \%$ ) en tanto que de las segundas hay más entre los alumnos que están en la $1^{a}$ etapa ( $17 \%$ vs $\left.4 \%\right)$. En las otras categorías, no aparece más que una posible tendencia por la cual, las respuestas de Concienciación serían más comunes en la $2^{\mathrm{a}}$ etapa y las de Comportamiento entre los de la primera.

Tabla 59. ¿Por qué han sido útiles los conocimientos sobre el Paisaje? por etapas

\begin{tabular}{llrr}
\hline Especialidad & Categorías & $1^{\circ}$ y $2^{\circ}\left(1^{\mathrm{a}} \mathrm{E}\right)$ & $3^{\circ}$ y $4^{\circ}\left(2^{\mathrm{a}} \mathrm{E}\right)$ \\
\hline Ambas & Conocimientos & $23.1 \%$ & $\mathbf{3 4 . 9 \%}$ \\
Ambas & Concienciación & $11.7 \%$ & $17.3 \%$ \\
\multirow{2}{*}{ Ambas } & $\begin{array}{l}\text { Comportamiento.: conservación y } \\
\text { mejora }\end{array}$ & $18.7 \%$ & $13.3 \%$ \\
Ambas & Recursos & $\mathbf{1 7 . 4 \%}$ & $3.9 \%$ \\
\hline Fuente: Elaboración propia
\end{tabular}

En el estudio por subcategorías (tabla 60) en el grupo de Conocimientos, en Medio físico es donde esta respuesta es más común en los alumnos que están en la $1^{\text {a }}$ etapa (8\% vs $0 \%$ y en Característica y tipos de Paisaje por el contrario la respuestas son más habituales en los de la segunda (28\%). 
También se han encontrado diferencias en Valores y sensibilidad dentro de la categoría de Concienciación, siendo algo mayor la tasa de participantes que dan estas respuestas entre los que cursan la $2^{\mathrm{a}}$ etapa (16\% va $\left.10 \%\right)$.

Y por último, entre los Recursos, hay diferencias visibles en las respuestas del subgrupo Importante/necesario para la vida, que han sido dadas en mayor medida por los que estudian la $1^{\text {a }}$ etapa ( $17 \%$ vs $\left.4 \%\right)$

Tabla 60. ¿Por qué han sido útiles los conocimientos sobre el Paisaje? por etapas

\begin{tabular}{|c|c|c|c|}
\hline Especialidad & Subcategorías & $1^{\circ}$ y $2^{\circ}\left(1^{a} E\right)$ & $3^{\circ}$ y $4^{\circ}\left(2^{a} E\right)$ \\
\hline \multicolumn{4}{|c|}{ CONOCIMIENTOS } \\
\hline Ambas & Medio físico & $8.3 \%$ & $0 \%$ \\
\hline Ambas & Medio ambiente & $3.0 \%$ & $2.0 \%$ \\
\hline Ambas & Naturaleza & $1.7 \%$ & $1.2 \%$ \\
\hline Ambas & Característica y tipos de Paisaje & $11.4 \%$ & $28.2 \%$ \\
\hline Ambas & Historia & $1.0 \%$ & $2.4 \%$ \\
\hline Ambas & Práctica & $2.0 \%$ & $1.6 \%$ \\
\hline \multicolumn{4}{|c|}{ CONCIENCIACIÓN } \\
\hline Ambas & Valores y sensibilidad & $10.4 \%$ & $16.1 \%$ \\
\hline Ambas & Valores estéticos & $0.7 \%$ & $2.0 \%$ \\
\hline Ambas & Estados de ánimo & $1.0 \%$ & $1.6 \%$ \\
\hline \multicolumn{4}{|c|}{ RECURSOS } \\
\hline Ambas & Necesario/importante para la vida & $17.1 \%$ & $3.9 \%$ \\
\hline
\end{tabular}

Por medio rural-urbano (tabla 61) no se han encontrado diferencias apreciables en ninguna de las categorías de clasificación de las respuestas.

Tabla 61. ¿Por qué han sido útiles los conocimientos sobre el Paisaje? y medio rural-urbano

\begin{tabular}{llcc}
\hline Especialidad & Categorías & Rural & Urbano \\
\hline Ambas & Conocimientos & $29.1 \%$ & $28.5 \%$ \\
Ambas & Concienciación & $17.0 \%$ & $13.3 \%$ \\
Ambas & $\begin{array}{l}\text { Comportamiento.: } \\
\text { conservación y mejora }\end{array}$ & $17.0 \%$ & $15.9 \%$ \\
Ambas & Recursos & $9.7 \%$ & $11.7 \%$ \\
\hline Fuente: Elaboración propia & &
\end{tabular}

En el contraste de las subcategorías (tabla 62) apenas hay diferencias entre el medio rural y el urbano. 
Tabla 62. ¿Por qué han sido útiles los conocimientos sobre el Paisaje? y medio rural-urbano. Subcategorías

\begin{tabular}{llrl}
\hline Especialidad & Subcategorías & Rural & Urbano \\
\hline \multirow{2}{*}{ Ambas } & \multicolumn{1}{c}{ CONOCIMIENTOS } & & $5.2 \%$ \\
Ambas & Medio físico & $4.3 \%$ & $2.9 \%$ \\
Ambas & Medio ambiente & $1.8 \%$ & $1.3 \%$ \\
Ambas & Naturaleza & $1.8 \%$ & $18.8 \%$ \\
Ambas & Característica y tipos de Paisaje & $20.0 \%$ & $2.1 \%$ \\
Ambas & Historia & $0.6 \%$ & $1.3 \%$ \\
Ambas & Práctica & $3.0 \%$ & $11.5 \%$ \\
Ambas & CONCIENCIACIÓN & $17.0 \%$ & $1.3 \%$ \\
Ambas & Valores y sensibilidad & $1.2 \%$ & $1.6 \%$ \\
Ambas & Estados de ánimo & $0.6 \%$ & $11.7 \%$
\end{tabular}

Fuente: Elaboración propia

Por Lugar de nacimiento (tabla 63) no se han encontrado grandes diferencias aunque es cierto que de nuevo en la de Conocimientos se podría hablar de una cierta preferencia.

Tabla 63. ¿Por qué han sido útiles los conocimientos sobre el Paisaje? y lugar de nacimiento

\begin{tabular}{llcc}
\hline Especialidad & Categorías & Castilla y León & Otras Autonomías \\
\hline Ambas & Conocimientos & $31.3 \%$ & $23.8 \%$ \\
Ambas & Concienciación & $14.7 \%$ & $12.8 \%$ \\
\multirow{2}{*}{ Ambas } & Comportamiento.: conservación y & $16.6 \%$ & $15.1 \%$ \\
Ambas & mejora & $11.4 \%$ & $11.0 \%$ \\
\hline
\end{tabular}

Fuente: Elaboración propia

En el estudio de las sub-categorías (tabla 64) tampoco se han apreciado diferencias entre los nacidos en Castilla y León los que han nacido en otras Autonomías. 
Tabla 64. ¿Por qué han sido útiles los conocimientos sobre el Paisaje? y lugar de nacimiento. Subcategorías

\begin{tabular}{|c|c|c|c|}
\hline Especialidad & Subcategorías & Castilla y León & Otras Autonomías \\
\hline \multicolumn{4}{|c|}{ CONOCIMIENTOS } \\
\hline Ambas & Medio físico & $4.7 \%(10)$ & $5.7 \%(5)$ \\
\hline Ambas & Medio ambiente & $3.3 \%(12)$ & $1.2 \%(2)$ \\
\hline Ambas & Naturaleza & $1.6 \%(6)$ & $1.2 \%(2)$ \\
\hline Ambas & Característica y tipos de Paisaje & $20.4 \%(75)$ & $16.9 \%(29)$ \\
\hline Ambas & Historia & $1.4 \%(5)$ & $2.3 \%(4)$ \\
\hline Ambas & Práctica & $2.2 \%(8)$ & $1.2 \%(2)$ \\
\hline \multicolumn{4}{|c|}{ CONCIENCIACIÓN } \\
\hline Ambas & Valores y sensibilidad & $13.9 \%(51)$ & $10.5 \%(18)$ \\
\hline Ambas & Valores estéticos & $1.4 \%(5)$ & $1.2 \%(2)$ \\
\hline Ambas & Estados de ánimo & $1.1 \%(4)$ & $1.7 \%(3)$ \\
\hline \multicolumn{4}{|c|}{ RECURSOS } \\
\hline
\end{tabular}

En la siguiente pregunta “¿qué contenidos te gustaría que te hubieran enseñado sobre el Paisaje?" Los encuestados se decantaron por la categoría de Conocimientos (55\%) y las que ocupan el segundo lugar son las de Comportamiento (23\%), (tabla 65). Por especialidades no aparecen diferencias significantes en ninguna de las cuatro categorías.

Tabla 65. ¿Qué conocimientos le gustaría que le hubiesen enseñado sobre el Paisaje? por especialidades

\begin{tabular}{lrcc}
\hline & \multicolumn{1}{c}{ Totales } & \multicolumn{1}{c}{ Infantil } & Primaria \\
\hline Conocimientos & $55.1 \%$ & $54.7 \%$ & $55.4 \%$ \\
Concienciación & $9.9 \%$ & $10.5 \%$ & $9.4 \%$ \\
$\begin{array}{l}\text { Comportamiento.: conservación y } \\
\text { mejora }\end{array}$ & $22.7 \%$ & $21.7 \%$ & $23.7 \%$ \\
Recursos & $4.7 \%$ & $6.0 \%$ & $3.5 \%$ \\
\hline Fuente: Elaboración propia & & &
\end{tabular}

En las subcategorías (tabla 66) dentro del grupo de Conocimientos las respuestas más habituales son las que hacen referencias a Característica y tipos de Paisaje (29\%) sin diferencias entre especialidades. El resto de sub-categorías tienen bastante menos presencia, pero en una de ellas, en Naturaleza (7\%) sí que se encuentran diferencias importantes: estas respuestas se encuentran mucho más entre estudiantes de Infantil (11\%) que entre los de Primaria (2\%). En el resto de sub-categorías no se han encontrado diferencias de interés.

Algunos ejemplos de respuestas del alumnado, demandando conocimientos como:

"Explotación de los recursos por parte del ser humano" 
"Características del Paisaje y factores positivos y negativos"

"Las transformaciones del Paisaje a lo largo del tiempo"

"Historia de los Paisajes de un pueblo o de una ciudad"

"La acción del ser humano en el Paisaje"

Incluso algunos alumnos/as pedían tener más conocimientos prácticos en el aula e incluso salidas para conocer mejor los Paisajes y sus características.

Tabla 66. ¿Qué conocimientos le gustaría que le hubiesen enseñado sobre el Paisaje? por especialidades. Subcategorías

\begin{tabular}{|c|c|c|c|}
\hline Sub-Categorías & Totales & Infantil & Primaria \\
\hline \multicolumn{4}{|l|}{ CONOCIMIENTOS } \\
\hline Medio físico & $7.1 \%$ & $4.6 \%$ & $9.5 \%$ \\
\hline Medio ambiente & $6.9 \%$ & $6.7 \%$ & $7.0 \%$ \\
\hline Naturaleza & $6.7 \%$ & $11.2 \%$ & $2.4 \%$ \\
\hline Rural y urbano & $1.8 \%$ & $1.5 \%$ & $2.1 \%$ \\
\hline Característica y tipos de Paisaje & $28.9 \%$ & $29.2 \%$ & $28.6 \%$ \\
\hline Ecosistema y biodiversidad & $5.8 \%$ & $4.9 \%$ & $6.6 \%$ \\
\hline Historia & $4.2 \%$ & $5.6 \%$ & $2.8 \%$ \\
\hline Práctica & $6.9 \%$ & $6.4 \%$ & $7.3 \%$ \\
\hline \multicolumn{4}{|l|}{ CONCIENCIACIÓN } \\
\hline Valores y sensibilidad & $9.0 \%$ & $9.7 \%$ & $8.4 \%$ \\
\hline Valores estéticos & $1.4 \%$ & $1.9 \%$ & $1.0 \%$ \\
\hline Estados de ánimo & $0 \%$ & - & - \\
\hline \multicolumn{4}{|l|}{ RECURSOS } \\
\hline Necesario/importante para la vida & $3.1 \%$ & $3.4 \%$ & $2.8 \%$ \\
\hline Aprender para transmitir & $0.4 \%$ & $0.4 \%$ & $0.3 \%$ \\
\hline Ocio y turismo & $1.3 \%$ & $2.2 \%$ & $0.3 \%$ \\
\hline
\end{tabular}

Los conocimientos que les hubiera gustado que les enseñaran sobre el Paisaje, si hacemos el cruce por etapas, lo podemos observar en la tabla 67, en que las diferencias más significativas son en dos de las respuestas: en Concienciación en los alumnos que cursan la $2^{\mathrm{a}}$ etapa (15\% vs $5 \%$ ) mientras que en la respuesta de Comportamiento para la conservación y mejora son los alumnos de la $1^{\text {a }}$ etapa se decantan por esta opción. (26\% vs $19 \%)$.

“Cuidado del Medio Ambiente" (4 Primaria)

"La participación ciudadana en los espacios naturales para una mayor protección" (10 Primaria)

"Planes sobre la conservación de la naturaleza" (2Infantil)

"Respeto a la naturaleza" (3० infantil)

"La importancia de la conservación y el cuidado de los Paisajes" (2 Primaria) 
Tabla 67. ¿Qué conocimientos le gustaría que le hubiesen enseñado sobre el Paisaje? por etapas

\begin{tabular}{llrr}
\hline Especialidad & Categorías & $1^{\circ}$ y $2^{\circ}\left(1^{\mathrm{a}} \mathrm{E}\right)$ & $3^{\circ}$ y $4^{\circ}\left(2^{\mathrm{a}} \mathrm{E}\right)$ \\
\hline Ambas & Conocimientos & $54.8 \%$ & $55,3 \%$ \\
Ambas & Concienciación & $5.4 \%$ & $\mathbf{1 5 . 3 \%}$ \\
Ambas & $\begin{array}{l}\text { Comportamiento.: conservación y } \\
\text { mejora }\end{array}$ & $\mathbf{2 6 . 1 \%}$ & $18.8 \%$ \\
Ambas & Recursos & $4.0 \%$ & $5.5 \%$ \\
\hline Fuente: Elaboración propia
\end{tabular}

Fuente: Elaboración propia

En los contrastes de las subcategorías (tabla 68) se han encontrado diferencias notables en la respuesta del Medio físico, más presente en los sujetos de la $1^{\text {a }}$ etapa (9\%) que en los de la $2^{\mathrm{a}}(4 \%)$. También son significativas las respuestas que dan sobre el conocimiento en Naturaleza, siendo este tipo de respuestas más común entre los participantes que están en la $2^{\mathrm{a}}$ etapa (37\%) que entre los que están en la $1^{\mathrm{a}}(22 \%)$. Asimismo, se ha observado que en Valores y sensibilidad dentro del grupo de Concienciación, son los alumnos de la $2^{\mathrm{a}}$ etapa (14\%) quienes dan mayor porcentaje de respuestas que los de la primera etapa.

Tabla 68. ¿Qué conocimientos le gustaría que le hubiesen enseñado sobre el Paisaje? por etapas. Subcategorías

\begin{tabular}{llrr}
\hline Especialidad & Subcategorías & $1^{\circ}$ y $2^{\circ}\left(1^{\mathrm{a}} \mathrm{E}\right)$ & $3^{\circ}$ y $4^{\circ}\left(2^{\mathrm{a}} \mathrm{E}\right)$ \\
\hline \multirow{2}{*}{ Ambas } & CONOCIMIENTOS & \\
Ambas & Medio ambico & $9.4 \%$ & $4.0 \%$ \\
Infantil & Naturaleza & $8.0 \%$ & $5.5 \%$ \\
Primaria & Naturaleza & $14.5 \%$ & $8.1 \%$ \\
Ambas & Rural y urbano & $3.6 \%$ & $0.8 \%$ \\
Ambas & Característica y tipos de Paisaje & $2.7 \%$ & $0.8 \%$ \\
Ambas & Ecosistema y biodiversidad & $22.4 \%$ & $36.5 \%$ \\
Ambas & Historia & $6.0 \%$ & $5.5 \%$ \\
Ambas & Práctica & $3.3 \%$ & $51 . \%$ \\
& $\quad$ CONCIENCIACIÓN & $6.0 \%$ & $7.8 \%$ \\
Ambas & Valores y sensibilidad & & \\
Ambas & Valores estéticos & $4.7 \%$ & $14.1 \%$ \\
\multicolumn{1}{c}{ RECURSOS } & $0.7 \%$ & $2.4 \%$ \\
Ambas & Necesario/importante para la vida & $2.7 \%$ & $3.5 \%$ \\
Ambas & Ocio y turismo & $1.0 \%$ & $1.6 \%$ \\
\hline Fuente: Elaboración propia & &
\end{tabular}

En relación al medio rural-urbano donde habían adquirido los conocimientos sobre el Paisaje (tabla 69) no se han encontrado diferencias significativas entre ambos medios. 
Tabla 69. ¿Qué conocimientos le gustaría que le hubiesen enseñado sobre el Paisaje? según medio rural-urbano

\begin{tabular}{llrc}
\hline Especialidad & Categorías & Rural & Urbano \\
\hline Ambas & Conocimientos & $56.4 \%$ & $55.1 \%$ \\
Ambas & Concienciación & $7.3 \%$ & $11.2 \%$ \\
Ambas & $\begin{array}{l}\text { Comportam.: conservación y } \\
\text { mejora }\end{array}$ & $23.6 \%$ & $22.2 \%$ \\
Ambas & Recursos & $4.2 \%$ & $5.0 \%$ \\
\hline
\end{tabular}

Fuente: Elaboración propia

En las subcategorías (tabla 70) solamente se ha encontrado una diferencia de dos puntos en la respuesta "naturaleza" en los encuestados de educación Infantil en el medio rural, en donde se ha comprobado que estas respuestas son más frecuentes en los casos del medio Rural (5\%) en educación Primaria frente a los alumnos del medio urbano (1\%) aunque es cierto que el número de casos es muy pequeño y este resultado hay que tomarlo con prudencia.

Tabla 70. ¿Qué conocimientos le gustaría que le hubiesen enseñado sobre el Paisaje? según medio rural-urbano. Subcategorías

\begin{tabular}{llrr}
\hline Especialidad & Sub-Categorías & Rural & Urbano \\
& \multicolumn{1}{c}{ CONOCIMIENTOS } & \\
Ambas & Medio físico & $8.1 \%$ & $6.7 \%$ \\
Ambas & Medio ambiente & $4.8 \%$ & $7.8 \%$ \\
Infantil & Naturaleza & $12.7 \%$ & $10.6 \%$ \\
Primaria & Naturaleza & $4.9 \%$ & $1.1 \%$ \\
Ambas & Rural y urbano & $1.8 \%$ & $1.8 \%$ \\
Ambas & Característica y tipos de Paisaje & $31.5 \%$ & $27.9 \%$ \\
Ambas & Ecosistema y biodiversidad & $7.9 \%$ & $5.0 \%$ \\
Ambas & Historia & $4.2 \%$ & $4.2 \%$ \\
Ambas & Práctica & $7.3 \%$ & $6.8 \%$ \\
& $\quad$ CONCIENCIACIÓN & & \\
Ambas & Valores y sensibilidad & $7.3 \%$ & $9.9 \%$ \\
Ambas & Valores estéticos & $0.6 \%$ & $1.8 \%$ \\
Ambas & Necesario/importante para la vida & $2.4 \%$ & $3.4 \%$ \\
Ambas & Ocio y turismo & $1.2 \%$ & $1.3 \%$ \\
\hline Fuente: Elaboración propia & &
\end{tabular}

Cuando realizamos el cruce de "los conocimientos que le gustaría que le hubiesen enseñado sobre el Paisaje" según "el lugar de nacimiento", el mayor porcentaje lo encontramos en la categoría de conocimientos, con una diferencia de seis puntos entre los que han nacido en la Comunidad de Castilla y León y los que han nacido en otras Comunidades. También el alumnado de Castilla y León son los que más han afirmado en las categorías de conservación y los recursos. Los encuestados que piensan que les 
hubiera gustado que le concienciaran sobre el Paisaje, es el alumnado de otras comunidades quienes se decantan con un $12 \%$ de respuestas (tabla 71 ).

Tabla 71. ¿Qué conocimientos le gustaría que le hubiesen enseñado sobre el Paisaje? según lugar de nacimiento

\begin{tabular}{llrc}
\hline Especialidad & Categorías & Castilla y León & Otras autonomías \\
\hline Ambas & Conocimientos & $52.7 \%$ & $59.3 \%$ \\
Ambas & Concienciación & $9.0 \%$ & $11.6 \%$ \\
Ambas & $\begin{array}{l}\text { Comportamiento.: conservación y } \\
\text { mejora }\end{array}$ & $23.4 \%$ & $20.9 \%$ \\
Ambas & Recursos & $5.2 \%$ & $4.1 \%$ \\
\hline
\end{tabular}

Fuente: Elaboración propia

Finalmente, cuando hacemos el cruce de "los conocimientos que le gustaría que le hubiesen enseñado sobre el Paisaje, la especialidad y el lugar de nacimiento", pero teniendo en cuenta las subcategorías que venimos comentando a lo largo del análisis; podemos observar en la tabla 72 , que la mayor diferencia la encontramos en la subcategoría de conocimientos, en la característica y tipos de Paisaje con un 33\% en otras Comunidades y seis puntos menos en Castilla y León.

Tabla 72. ¿Qué conocimientos le gustaría que le hubiesen enseñado sobre el Paisaje? según lugar de nacimiento. Subcategorías

\begin{tabular}{|c|c|c|c|}
\hline Especialidad & Subcategorías & Castilla y León & Otras autonomías \\
\hline \multicolumn{4}{|c|}{ CONOCIMIENTOS } \\
\hline Ambas & Medio físico & $7.5 \%$ & $7.0 \%$ \\
\hline Ambas & Medio ambiente & $5.7 \%$ & $8.7 \%$ \\
\hline Infantil & Naturaleza & $12.0 \%$ & $8.5 \%$ \\
\hline Primaria & Naturaleza & $2.3 \%$ & $3.0 \%$ \\
\hline Ambas & Rural y urbano & $2.4 \%$ & $0 \%$ \\
\hline Ambas & Característica y tipos de Paisaje & $26.9 \%$ & $33.1 \%$ \\
\hline Ambas & Ecosistema y biodiversidad & $5.4 \%$ & $5.8 \%$ \\
\hline Ambas & Historia & $3.8 \%$ & $4.7 \%$ \\
\hline Ambas & Práctica & $7.1 \%$ & $6.4 \%$ \\
\hline \multicolumn{4}{|c|}{ CONCIENCIACIÓN } \\
\hline Ambas & Valores y sensibilidad & $7.6 \%$ & $11.6 \%$ \\
\hline Ambas & Valores estéticos & $1.9 \%$ & $0.6 \%$ \\
\hline \multicolumn{4}{|c|}{ RECURSOS } \\
\hline Ambas & Necesario/importante para la vida & $3.5 \%$ & $2.3 \%$ \\
\hline Ambas & Ocio y turismo & $1.4 \%$ & $1.2 \%$ \\
\hline
\end{tabular}

A continuación se les preguntó a los alumnos/as por qué consideran interesantes esos conocimientos elegidos; en el análisis por especialidades se ha encontrado (tabla 73) que las respuestas más frecuentemente emitidas pertenecen a la categoría de Recursos (23\%). Las otras tres tienen una clara menor presencia. En ninguna de las 4 categorías se han encontrado diferencias que se puedan considerar notables. 
Tabla 73. ¿Por qué considera interesantes esos conocimientos? por especialidades

\begin{tabular}{llc}
\hline Categorías & Infantil & Primaria \\
\hline Conocimientos & $16.1 \%$ & $13.6 \%$ \\
Concienciación & $7.9 \%$ & $10.1 \%$ \\
$\begin{array}{l}\text { Comportamiento.: conservación y } \\
\text { mejora }\end{array}$ & $10.1 \%$ & $11.1 \%$ \\
Recursos & $23.2 \%$ & $22.0 \%$ \\
\hline Fuente: Elaboración propia
\end{tabular}

Fuente: Elaboración propia

Al cruzar con las subcategorías (tabla 74) no han aparecido tampoco grandes diferencias entre las especialidades. Se puede reseñar que, dentro de la categoría de recursos la más señalada es necesario/importante para la vida.

Tabla 74. ¿Por qué considera interesantes esos conocimientos? Por Especialidades.

\begin{tabular}{lcr}
\hline Subcategorías & Infantil & Primaria \\
\hline \multicolumn{1}{c}{ CONOCIMIENTOS } & & \\
Medio físico & $2.1 \%$ & $2.6 \%$ \\
Medio ambiente & $1.5 \%$ & $0.3 \%$ \\
Naturaleza & $2.6 \%$ & $1.4 \%$ \\
Rural y urbano & $1.1 \%$ & $0.3 \%$ \\
Característica y tipos de Paisaje & $7.5 \%$ & $7.7 \%$ \\
Ecosistema y biodiversidad & $0 \%$ & $1.4 \%$ \\
Historia & $0.7 \%$ & $0 \%$ \\
Práctica & $2.2 \%$ & $0.7 \%$ \\
$\quad$ CONCIENCIACIÓN & & \\
Valores y sensibilidad & $4.9 \%$ & $9.4 \%$ \\
Valores estéticos & $1.9 \%$ & $0.7 \%$ \\
Estados de ánimo & $1.9 \%$ & $0 \%$ \\
$\quad$ RECURSOS & & \\
Necesario/importante para la vida & $21.3 \%$ & $20.6 \%$ \\
Aprender para transmitir & $1.1 \%$ & $1.4 \%$ \\
Ocio y turismo & $0.7 \%$ & $0.3 \%$ \\
\hline Fuente: Elaboración propia & &
\end{tabular}

En el análisis por etapas los contrastes se resumen en la tabla 75. Solamente aparecen diferencias en la categoría de Recursos, de forma tal que este tipo de respuestas es más habitual en los estudiantes de la $1^{\mathrm{a}}$ etapa (32\%) que en los de la $2^{\mathrm{a}}(11 \%)$. 
Tabla 75. ¿Por qué considera interesantes esos conocimientos? Por etapas

\begin{tabular}{llrr}
\hline Especialidad & Categorías & $1^{\circ}$ y $2^{\circ}\left(1^{\mathrm{a}} \mathrm{E}\right)$ & $3^{\circ}$ y $4^{\circ}\left(2^{\mathrm{a}} \mathrm{E}\right)$ \\
\hline Ambas & Conocimientos & $14.0 \%$ & $15.7 \%$ \\
Ambas & Concienciación & $8.7 \%$ & $9.4 \%$ \\
\multirow{2}{*}{ Ambas } & $\begin{array}{l}\text { Comportamiento.: conservación y } \\
\text { mejora }\end{array}$ & $12.4 \%$ & $8.6 \%$ \\
Ambas & Recursos & $\mathbf{3 2 . 1 \%}$ & $11.4 \%$ \\
\hline
\end{tabular}

Fuente: Elaboración propia

Por su parte, los contrastes de las subcategorías (tabla 76) han determinado la existencia de diferencias destacables solamente en una de ellas, en concreto en Importante/necesario para la vida, siendo estas respuestas mucho más frecuentes en los alumnos de 1 er ciclo (31\%) que en los de $2^{\circ}(9 \%)$. En el resto no hay diferencias.

Tabla 76. ¿Por qué considera interesantes esos conocimientos? Por etapas.

\begin{tabular}{llll}
\hline Especialidad & Subcategorías & $1^{\circ}$ y $2^{\circ}\left(1^{\mathrm{a}} \mathrm{E}\right)$ & $3^{\circ}$ y $4^{\circ}\left(2^{\mathrm{a}} \mathrm{E}\right)$ \\
\hline \multirow{2}{*}{ Ambas } & CONOCIMIENTOS & & \\
Ambas & Medio físico & $3.1 \%$ & $1.0 \%$ \\
Ambas & Nedio ambiente & $0.7 \%$ & $1.2 \%$ \\
Ambas & Ruturaleza & $2.7 \%$ & $1.2 \%$ \\
Ambas & Característica y tipos de Paisaje & $0 \%$ & $1.6 \%$ \\
Ambas & Ecosistema y biodiversidad & $1.0 \%$ & $9.8 \%$ \\
Ambas & Práctica & $1.7 \%$ & $0.4 \%$ \\
& CONCIENCIACIÓN & $1.2 \%$ \\
Ambas & Valores y sensibilidad & $6.7 \%$ & $7.8 \%$ \\
Ambas & Valores estéticos & $1.0 \%$ & $1.6 \%$ \\
Ambas & Estados de ánimo & $1.0 \%$ & $0.8 \%$ \\
Ambas & RECURSOS & & \\
Ambas & Necesario/importante para la vida & $30.8 \%$ & $9.4 \%$ \\
\hline
\end{tabular}

Fuente: Elaboración propia

Por ámbito rural-urbano (tabla 77) tampoco se han encontrado diferencias claras aunque es cierto que dos de ellas podrían considerarse interesantes: los 6 puntos de diferencia positiva de Conocimientos en el ámbito urbano, y por el contrario los 4 puntos de diferencia positiva de Comportamientos: conservación y mejora en el ámbito rural.

Tabla 77. ¿Por qué considera interesantes esos conocimientos? por Medio rural-urbano

\begin{tabular}{llrr}
\hline Especialidad & Categorías & Rural & Urbano \\
\hline Ambas & Conocimientos & $10.9 \%$ & $16.7 \%$ \\
Ambas & Concienciación & $7.3 \%$ & $9.9 \%$ \\
Ambas & Comportamiento.: conservación y & $13.9 \%$ & $9.1 \%$ \\
Ambas & Recursos & $27.3 \%$ & $20.6 \%$ \\
\hline Fuente: Elaboración propia & &
\end{tabular}


En las sub-categorías (tabla 78) no se han encontrado tampoco diferencias entre los sujetos de medio rural y los del medio urbano.

Tabla 78: ¿Por qué considera interesantes esos conocimientos? por Medio rural-urbano

\begin{tabular}{llrr}
\hline Especialidad & Subcategorías & Rural & Urbano \\
\hline \multirow{2}{*}{ Ambas } & \multicolumn{1}{c}{ CONOCIMIENTOS } & & $2.0 \%$ \\
Ambas & Medio físico & $3.3 \%$ & $1.3 \%$ \\
Primaria & Naturaleza & $0 \%$ & $2.1 \%$ \\
Ambas & Rural y urbano & $1.8 \%$ & $1.0 \%$ \\
Ambas & Característica y tipos de Paisaje & $0 \%$ & $8.6 \%$ \\
Ambas & Ecosistema y biodiversidad & $5.5 \%$ & $0.5 \%$ \\
Ambas & Práctica & $1.2 \%$ & $2.1 \%$ \\
& $\quad$ CONCIENCIACIÓN & $0 \%$ & \\
Ambas & Valores y sensibilidad & & $7.8 \%$ \\
Ambas & Valores estéticos & $6.1 \%$ & $1.3 \%$ \\
Ambas & Estados de ánimo & $1.2 \%$ & $1.3 \%$ \\
Ambas & $\quad$ RECURSOS & $0 \%$ & \\
Ambas & Necesario/importante para la vida & $26.1 \%$ & $18.8 \%$ \\
\hline
\end{tabular}

Fuente: Elaboración propia

Por el Lugar de nacimiento, no se han encontrado tampoco diferencias destacables en ninguna de las 4 categorías (tabla 79).

Tabla 79: ¿Por qué considera interesantes esos conocimientos? Por lugar de nacimiento

\begin{tabular}{llrr}
\hline Especialidad & Categorías & \multicolumn{1}{c}{ C y L } & Otras Autonomías \\
\hline Ambas & Conocimientos & $13.9 \%$ & $15.1 \%$ \\
Ambas & Concienciación & $9.0 \%$ & $8.1 \%$ \\
\multirow{2}{*}{ Ambas } & $\begin{array}{l}\text { Comportamiento.: conservación y } \\
\text { mejora }\end{array}$ & $10.9 \%$ & $9.9 \%$ \\
\hline Ambas & Recursos & $22.0 \%$ & $23.8 \%$ \\
\hline
\end{tabular}

Por último, tampoco aparecen cuando se comparan las sub-categorías (tabla 80) entre los lugares de nacimiento. 
Tabla 80. ¿Por qué considera interesantes esos conocimientos? Por Lugar de nacimiento.

\begin{tabular}{|c|c|c|c|}
\hline Especialidad & Subcategorías & Cy L & Otras Autonomías \\
\hline \multicolumn{4}{|c|}{ CONOCIMIENTOS } \\
\hline Ambas & Medio físico & $3.7 \%$ & $0 \%$ \\
\hline Ambas & Medio ambiente & $0.5 \%$ & $1.7 \%$ \\
\hline Ambas & Naturaleza & $1.4 \%$ & $2.9 \%$ \\
\hline Ambas & Rural y urbano & $0.5 \%$ & $0.6 \%$ \\
\hline Ambas & Característica y tipos de Paisaje & $7.3 \%$ & $7.0 \%$ \\
\hline Ambas & Ecosistema y biodiversidad & $0.8 \%$ & $0.6 \%$ \\
\hline Ambas & Práctica & $1.4 \%$ & $1.2 \%$ \\
\hline \multicolumn{4}{|c|}{ CONCIENCIACIÓN } \\
\hline Ambas & Valores y sensibilidad & $7.1 \%$ & $6.4 \%$ \\
\hline Ambas & Valores estéticos & $1.4 \%$ & $1.2 \%$ \\
\hline Ambas & Estados de ánimo & $1.1 \%$ & $0.6 \%$ \\
\hline \multicolumn{4}{|c|}{ RECURSOS } \\
\hline Ambas & Necesario/importante para la vida & $20.7 \%$ & $21.5 \%$ \\
\hline Ambas & Aprender para transmitir & $1.4 \%$ & $1.2 \%$ \\
\hline
\end{tabular}

En la pregunta sobre ¿Qué aspectos relacionados con el Paisaje le parece que deberían de enseñarse a los futuros maestros? (tabla 81) las respuestas más frecuentes dadas consideran que deben pertenecer a Conocimientos (55\%) y las que ocupan el segundo lugar son las de Comportamientos (23\%) porque expresan una mayor responsabilidad en la conservación y mejora.

Si analizamos por especialidades en las respuestas del alumnado no aparecen diferencias reseñables en ninguna de las cuatro categorías.

Tabla 81. ¿Qué conocimientos le gustaría que le hubiesen enseñado sobre el Paisaje? según especialidades

\begin{tabular}{lrcr}
\hline Categorías & \multicolumn{1}{c}{ Totales } & Infantil & Primaria \\
\hline Conocimientos & $55.1 \%$ & $54.7 \%$ & $55.4 \%$ \\
Concienciación & $9.9 \%$ & $10.5 \%$ & $9.4 \%$ \\
$\begin{array}{l}\text { Comportamiento.: conservación y } \\
\text { mejora }\end{array}$ & $22.7 \%$ & $21.7 \%$ & $23.7 \%$ \\
Recursos & $4.7 \%$ & $6.0 \%$ & $3.5 \%$ \\
\hline Fuente: Elaboración propia & &
\end{tabular}

En relación con las subcategorías (tabla 82) observamos que dentro del grupo de Conocimientos las respuestas más habituales son las que hacen referencia a Característica y tipos de Paisaje (29\%) sin diferencias entre las dos especialidades. El resto de sub-categorías tienen bastante menos presencia, pero en una de ellas, en Naturaleza (7\%) sí que se encuentran diferencias importantes entre las respuestas de los estudiantes de Infantil (11\%) y los de Primaria (2\%). En el resto de subcategorías no se han encontrado diferencias de interés. 
Tabla 82. ¿Qué conocimientos le gustaría que le hubiesen enseñado sobre el Paisaje? por especialidades. Subcategorías

\begin{tabular}{|c|c|c|c|}
\hline Subcategorías & Totales & Infantil & Primaria \\
\hline \multicolumn{4}{|l|}{ CONOCIMIENTOS } \\
\hline Medio físico & $7.1 \%$ & $4.6 \%$ & $9.5 \%$ \\
\hline Medio ambiente & $6.9 \%$ & $6.7 \%$ & $7.0 \%$ \\
\hline Naturaleza & $6.7 \%$ & $11.2 \%$ & $2.4 \%$ \\
\hline Rural y urbano & $1.8 \%$ & $1.5 \%$ & $2.1 \%$ \\
\hline Característica y tipos de Paisaje & $28.9 \%$ & $29.2 \%$ & $28.6 \%$ \\
\hline Ecosistema y biodiversidad & $5.8 \%$ & $4.9 \%$ & $6.6 \%$ \\
\hline Historia & $4.2 \%$ & $5.6 \%$ & $2.8 \%$ \\
\hline Práctica & $6.9 \%$ & $6.4 \%$ & $7.3 \%$ \\
\hline \multicolumn{4}{|l|}{ CONCIENCIACIÓN } \\
\hline Valores y sensibilidad & $9.0 \%$ & $9.7 \%$ & $8.4 \%$ \\
\hline Valores estéticos & $1.4 \%$ & $1.9 \%$ & $1.0 \%$ \\
\hline Estados de ánimo & $0 \%$ & - & - \\
\hline \multicolumn{4}{|l|}{ RECURSOS } \\
\hline Necesario/importante para la vida & $3.1 \%$ & $3.4 \%$ & $2.8 \%$ \\
\hline Aprender para transmitir & $0.4 \%$ & $0.4 \%$ & $0.3 \%$ \\
\hline Ocio y turismo & $1.3 \%$ & $2.2 \%$ & $0.3 \%$ \\
\hline
\end{tabular}

Si hacemos el cruce por etapas, en la tabla 83 observamos diferencias a destacar en Concienciación con respuestas más numerosas en los alumnos que cursan la $2^{\mathrm{a}}$ etapa (15\% vs 5\%). Y en Comportamiento para la conservación y mejora por el contrario hay mayor porcentaje en la primera etapa que en la segunda (26\% va $19 \%)$.

Tabla 83. ¿Qué conocimientos le gustaría que le hubiesen enseñado sobre el Paisaje por etapas

\begin{tabular}{llrr}
\hline Especialidad & Categorías & $1^{\circ}$ y $2^{\circ}\left(1^{\mathrm{a}} \mathrm{E}\right)$ & $3^{\circ}$ y $4^{\circ}\left(2^{\mathrm{a}} \mathrm{E}\right)$ \\
\hline Ambas & Conocimientos & $54.8 \%$ & $55,3 \%$ \\
Ambas & Concienciación & $5.4 \%$ & $\mathbf{1 5 . 3 \%}$ \\
\multirow{2}{*}{ Ambas } & $\begin{array}{l}\text { Comportamiento.: conservación y } \\
\text { mejora }\end{array}$ & $\mathbf{2 6 . 1 \%}$ & $18.8 \%$ \\
Ambas & Recursos & $4.0 \%$ & $5.5 \%$ \\
\hline Fuente: Elaboración propia
\end{tabular}

Si tenemos en cuenta las sub-categorías (tabla 84) se han encontrado diferencias notables en Medio físico, más presentes en los sujetos de la $1^{\mathrm{a}}$ etapa (9\%) que en los de la $2^{\mathrm{a}}(4 \%)$. También las hay en Naturaleza, siendo este tipo de respuestas más común entre los participantes que están en la $2^{\mathrm{a}}$ etapa (37\%) que entre los que están en la $1^{\text {a }}$ etapa (22\%). Asimismo, se han observado que en Valores y sensibilidad dentro de la subcategoría de Concienciación, las respuestas que ha dado el alumnado es mayor en la $2^{\mathrm{a}}$ etapa (14\%) que en la $1^{\mathrm{a}}(5 \%)$. 
Tabla 84. ¿Qué conocimientos le gustaría que le hubiesen enseñado sobre el Paisaje? por Etapas.

\begin{tabular}{llrr}
\hline Especialidad & Subcategorías & $1^{\circ}$ y $2^{\circ}\left(1^{\mathrm{a}} \mathrm{E}\right)$ & $3^{\circ}$ y $4^{\circ}\left(2^{\mathrm{a}} \mathrm{E}\right)$ \\
\hline \multirow{2}{*}{ Ambas } & CONOCIMIENTOS & & \\
Ambas & Medio ambiente & $9.4 \%$ & $4.0 \%$ \\
Infantil & Naturaleza & $8.0 \%$ & $5.5 \%$ \\
Primaria & Naturaleza & $14.5 \%$ & $8.1 \%$ \\
Ambas & Rural y urbano & $3.6 \%$ & $0.8 \%$ \\
Ambas & Característica y tipos de Paisaje & $2.7 \%$ & $0.8 \%$ \\
Ambas & Ecosistema y biodiversidad & $22.4 \%$ & $\mathbf{3 6 . 5 \%}$ \\
Ambas & Historia & $6.0 \%$ & $5.5 \%$ \\
Ambas & Práctica & $3.3 \%$ & $51 . \%$ \\
& $\quad$ CONCIENCIACIÓN & $6.0 \%$ & $7.8 \%$ \\
Ambas & Valores y sensibilidad & & \\
Ambas & Valores estéticos & $4.7 \%$ & $\mathbf{1 4 . 1} \%$ \\
\multicolumn{1}{c}{ RECURSOS } & $0.7 \%$ & $2.4 \%$ \\
Ambas & Necesario/importante para la vida & $2.7 \%$ & $3.5 \%$ \\
Ambas & Ocio y turismo & $1.0 \%$ & $1.6 \%$ \\
\hline Fuente: Elaboración propia
\end{tabular}

Fuente: Elaboración propia

Por ámbito de los estudios previos (tabla 85) no se han encontrado diferencias significativas entre los que se formaron en el medio rural y los que lo hicieron en el urbano.

Tabla 85. ¿Qué conocimientos le gustaría que le hubiesen enseñado sobre el Paisaje? según medio rural-urbano

\begin{tabular}{llrc}
\hline Especialidad & Categorías & \multicolumn{1}{c}{ Rural } & \multicolumn{1}{c}{ Urbano } \\
\hline Ambas & Conocimientos & $56.4 \%$ & $55.1 \%$ \\
Ambas & Concienciación & $7.3 \%$ & $11.2 \%$ \\
Ambas & Comportamiento.: conservación y & $23.6 \%$ & $22.2 \%$ \\
Ambas & Recursos & $4.2 \%$ & $5.0 \%$ \\
\hline
\end{tabular}

Fuente: Elaboración propia

En las subcategorías (tabla 86) solamente se ha encontrado una diferencia de interés y ha sido en la variable Naturaleza, dentro de los sujetos de Primaria en concreto, en donde se ha comprobado que estas respuestas son más frecuentes en los casos del medio Rural (5\%) que en los del urbano (1\%), aunque es cierto que el número de casos es muy pequeño y este resultado hay que tomarlo con prudencia. 
Tabla 86. ¿Qué conocimientos le gustaría que le hubiesen enseñado sobre el Paisaje? según medio rural-urbano. Subcategorías

\begin{tabular}{llrr}
\hline Especialidad & Subcategorías & \multicolumn{1}{c}{ Rural } & Urbano \\
\hline \multirow{3}{*}{ Ambas } & CONOCIMIENTOS & \\
Ambas & Medio físico & $8.1 \%$ & $6.7 \%$ \\
Infantil & Naturaleza & $4.8 \%$ & $7.8 \%$ \\
Primaria & Naturaleza & $12.7 \%$ & $10.6 \%$ \\
Ambas & Rural y urbano & $4.9 \%$ & $1.1 \%$ \\
Ambas & Característica y tipos de Paisaje & $1.8 \%$ & $1.8 \%$ \\
Ambas & Ecosistema y biodiversidad & $31.5 \%$ & $27.9 \%$ \\
Ambas & Historia & $7.9 \%$ & $5.0 \%$ \\
Ambas & Práctica & $4.2 \%$ & $4.2 \%$ \\
& $\quad$ CONCIENCIACIÓN & $7.3 \%$ & $6.8 \%$ \\
Ambas & Valores y sensibilidad & & \\
Ambas & Valores estéticos & $7.3 \%$ & $9.9 \%$ \\
& $\quad$ RECURSOS & $0.6 \%$ & $1.8 \%$ \\
Ambas & Necesario/importante para la vida & $2.4 \%$ & $3.4 \%$ \\
Ambas & Ocio y turismo & $1.2 \%$ & $1.3 \%$ \\
\hline
\end{tabular}

Fuente: Elaboración propia

Por lugar de nacimiento, no se han encontrado diferencias en ninguna de las 4 categorías (tabla 87).

Tabla 87. ¿Qué conocimientos le gustaría que le hubiesen enseñado sobre el Paisaje? según lugar de nacimiento.

\begin{tabular}{llrc}
\hline Especialidad & Categorías & Castilla y León & Otras autonomías \\
\hline Ambas & Conocimientos & $52.7 \%$ & $59.3 \%$ \\
Ambas & Concienciación & $9.0 \%$ & $11.6 \%$ \\
\multirow{2}{*}{ Ambas } & $\begin{array}{l}\text { Comportamiento.: conservación y } \\
\text { mejora }\end{array}$ & $23.4 \%$ & $20.9 \%$ \\
Ambas & Recursos & $5.2 \%$ & $4.1 \%$ \\
\hline
\end{tabular}

Fuente: Elaboración propia

Tampoco aparecen cuando se comparan las subcategorías (tabla 88) en función del lugar de nacimiento. 
Tabla 88. ¿Qué conocimientos le gustaría que le hubiesen enseñado sobre el Paisaje? según lugar de nacimiento. Subcategorías

\begin{tabular}{llrc}
\hline Especialidad & Subcategorías & Castilla y León & Otras autonomías \\
\hline \multirow{2}{*}{ Ambas } & Medio físico & & \\
Ambas & Medio ambiente & $7.5 \%$ & $7.0 \%$ \\
Infantil & Naturaleza & $5.7 \%$ & $8.7 \%$ \\
Primaria & Naturaleza & $12.0 \%$ & $8.5 \%$ \\
Ambas & Rural y urbano & $2.3 \%$ & $3.0 \%$ \\
Ambas & Característica y tipos de Paisaje & $2.4 \%$ & $0 \%$ \\
Ambas & Ecosistema y biodiversidad & $26.9 \%$ & $33.1 \%$ \\
Ambas & Historia & $5.4 \%$ & $5.8 \%$ \\
Ambas & Práctica & $3.8 \%$ & $4.7 \%$ \\
Ambas & $\quad$ CONCIENCIACIÓN & $7.1 \%$ & $6.4 \%$ \\
Ambas & Valores y sensibilidad & & \\
& $\quad$ RECURSOS & $7.6 \%$ & $11.6 \%$ \\
Ambas & Necesario/importante para la vida & $1.9 \%$ & $0.6 \%$ \\
Ambas & Ocio y turismo & $3.5 \%$ & \\
\hline
\end{tabular}

Fuente: Elaboración propia

Pasamos a las preguntas sobre qué aspectos relacionados con el Paisaje le parece que deberían de enseñarse a los futuros maestros; observando si son de Infantil o Primaria, podemos ver en la tabla 89 que el mayor porcentaje de respuestas que dan los encuestados son las de Conocimientos (41\%), seguidas de las de Comportamiento de conservación y mejora (30\%). No obstante por especialidades en ninguna de las 4 categorías, se han encontrado diferencias importantes.

Tabla 89. ¿Qué aspectos relacionados con el Paisaje le parece que deberían de enseñarse a los futuros maestros? Por especialidades

\begin{tabular}{lccc}
\hline Categorías & \multicolumn{1}{c}{ Totales } & \multicolumn{1}{c}{ Infantil } & \multicolumn{1}{c}{ Primaria } \\
\hline Conocimientos & $40.8 \%$ & $39.7 \%$ & $41.8 \%$ \\
Concienciación & $13.2 \%$ & $14.6 \%$ & $11.8 \%$ \\
$\begin{array}{l}\text { Comportamiento.: conservación y } \\
\text { mejora }\end{array}$ & $28.7 \%$ & $31.8 \%$ & $25.8 \%$ \\
Recursos & $8.7 \%$ & $9.7 \%$ & $7.7 \%$ \\
\hline Fuente: Elaboración propia & & &
\end{tabular}

En cuanto a las subcategorías (tabla 90) dentro de las de Conocimientos, lo que más se ha respondido está en el grupo de Característica y tipos de Paisaje (23\%) con clara diferencia con respecto a las demás y sin que exista apenas diferencias entre las especialidades. Donde sí hay diferencia, es en la sub-categoría de Naturaleza, que es la respuesta más frecuente entre los que estudian Infantil (6\%) frente a los que estudian Primaria (0.7\%). En Concienciación, las respuestas del área de Valores y sensibilidad son las más repetidas (12\%). El resto tiene muy poca presencia. $Y$ en ninguna otra subcategoría hay diferencias reseñables. 
Tabla 90. ¿Qué aspectos relacionados con el Paisaje le parece que deberían de enseñarse a los futuros maestros? por especialidades. Subcategorías.

\begin{tabular}{|c|c|c|c|}
\hline Subcategorías & Totales & Infantil & Primaria \\
\hline \multicolumn{4}{|l|}{ CONOCIMIENTOS } \\
\hline Medio físico & $5.1 \%$ & $4.5 \%$ & $5.7 \%$ \\
\hline Medio ambiente & $5.1 \%$ & $5.6 \%$ & $4.5 \%$ \\
\hline Naturaleza & $3.1 \%$ & $5.6 \%$ & $0.7 \%$ \\
\hline Rural y urbano & $2.0 \%$ & $1.1 \%$ & $2.8 \%$ \\
\hline Característica y tipos de Paisaje & $22.6 \%$ & $20.6 \%$ & $24.4 \%$ \\
\hline Ecosistema y biodiversidad & $3.6 \%$ & $3.7 \%$ & $3.5 \%$ \\
\hline Historia & $1.8 \%$ & $1.9 \%$ & $1.7 \%$ \\
\hline Práctica & $2.0 \%$ & $3.0 \%$ & $1.0 \%$ \\
\hline \multicolumn{4}{|l|}{ CONCIENCIACIÓN } \\
\hline Valores y sensibilidad & $11.9 \%$ & $12.0 \%$ & $11.8 \%$ \\
\hline Valores estéticos & $1.8 \%$ & $2.6 \%$ & $1.0 \%$ \\
\hline Estados de ánimo & $0.9 \%$ & $1.5 \%$ & $0.3 \%$ \\
\hline \multicolumn{4}{|l|}{ RECURSOS } \\
\hline Necesario/importante para la vida & $4.3 \%$ & $5.2 \%$ & $3.5 \%$ \\
\hline Aprender para transmitir & $4.0 \%$ & $4.1 \%$ & $3.8 \%$ \\
\hline Ocio y turismo & $0.4 \%$ & $0.4 \%$ & $0.3 \%$ \\
\hline
\end{tabular}

El alumnado es consciente de la labor fundamental que tienen los maestros a la hora de transmitir y explicar todo tipo de conocimientos, actitudes y valores. Por lo que se debe potenciar la concienciación y sensibilización del alumnado en relación con el Paisaje. Las etapas de la infancia y adolescencia son especialmente críticas porque en ellas se producen la maduración física y psíquica de las personas. Algunas de las respuestas que al respecto nos ha proporcionado el alumnado del Grado de Educación Infantil y Primaria son:

"Teórica y prácticamente deben conocer los tipos de Paisajes, los climas, la fauna y la flora. También la conservación y protección del Paisaje junto con la contaminación" (10 infantil)

"Los tipos de Paisajes, sus características, dónde se encuentran" para enseñarlos en un futuro a sus alumnos" ( $2^{\circ}$ Primaria)

"Conocer todo lo relacionado con los Paisajes para concienciar a los alumnos y así cuidar y preservar dichos Paisajes" ( $3^{\circ}$ infantil)

"Soluciones posibles para los problemas del Medio Ambiente" (4 Infantil)

Si hacemos el cruce de "los aspectos relacionados con el Paisaje que deberían enseñarse a los futuros maestros" con "la primera y segunda etapa", se han encontrado claras diferencias en Conocimientos (tabla 91), las repuestas de los encuestados es mayor entre los estudiantes de la $1^{\mathrm{a}}$ etapa (45\%) que entre los de la $2^{\mathrm{a}}(36 \%)$. Sin embargo, ocurre lo contrario en Concienciación, siendo más frecuente este grupo de 
respuestas en los de la $2^{\mathrm{a}}$ etapa frente a los de la $1^{\mathrm{a}}$ (18\% vs $\left.9 \%\right)$. En las otras dos categorías ocurre igual, el comportamiento, conservación y mejora es cinco puntos mayor en la primera etapa que en la segunda, en cuanto a los recursos ocurre lo contrario, dos puntos mayor en la segunda etapa.

Tabla 91. ¿Qué aspectos relacionados con el Paisaje le parece que deberían de enseñarse a los futuros maestros? por etapas

\begin{tabular}{llcc}
\hline Especialidad & Categorías & $1^{\circ}$ y $2^{\circ}\left(1^{\mathrm{a}} \mathrm{E}\right)$ & $3^{\circ}$ y $4^{\circ}\left(2^{\mathrm{a}} \mathrm{E}\right)$ \\
\hline Ambas & Conocimientos & $\mathbf{4 5 . 2 \%}$ & $35.7 \%$ \\
Ambas & Concienciación & $9.4 \%$ & $\mathbf{1 7 . 6 \%}$ \\
\multirow{2}{*}{ Ambas } & $\begin{array}{l}\text { Comportamiento.: conservación y } \\
\text { mejora }\end{array}$ & $31.4 \%$ & $25.5 \%$ \\
Ambas & Recursos & $7.7 \%$ & $9.8 \%$ \\
\hline Fuente: Elaboración propia
\end{tabular}

Los aspectos relacionados con el Paisaje que se debería enseñar a los futuros maestros en relación con las subcategorías y las distintas etapas se han encontrado diferencias significativas (tabla 92). Dentro del grupo de Conocimientos, en Medio físico, donde se ha observado que estas respuestas se repiten más entre los participantes que están en la $1^{\mathrm{a}}$ etapa que en los de la $2^{\mathrm{a}}$ (8\% vs $1 \%$ ), y dentro del grupo de Concienciación, en Valores y sensibilidad donde ahora por el contrario es en la $2^{\mathrm{a}}$ etapa donde se tiende de forma más elevada a emitir respuestas de esta subcategoría (17\% vs $8 \%$ ). En todas las demás no hay diferencias que resaltar.

Tabla 92. ¿Qué aspectos relacionados con el Paisaje le parece que deberían de enseñarse a los futuros maestros? por etapas. Subcategorías

\begin{tabular}{llrr}
\hline Especialidad & Subcategorías & $1^{\circ}$ y $2^{\circ}\left(1^{\mathrm{a}} \mathrm{E}\right)$ & $3^{\circ}$ y $4^{\circ}\left(2^{\mathrm{a}} \mathrm{E}\right)$ \\
\hline \multirow{2}{*}{ Ambas } & CONOCIMIENTOS & & \\
Ambas & Medio físico & $7.9 \%$ & $1.2 \%$ \\
Infantil & Naturaleza & $5.0 \%$ & $5.1 \%$ \\
Primaria & Naturaleza & $7.6 \%$ & $3.7 \%$ \\
Ambas & Rural y urbano & $0.6 \%$ & $0.8 \%$ \\
Ambas & Característica y tipos de Paisaje & $3.0 \%$ & $0.8 \%$ \\
Ambas & Ecosistema y biodiversidad & $21.1 \%$ & $24.3 \%$ \\
Ambas & Historia & $2.7 \%$ & $4.7 \%$ \\
Ambas & Práctica & $2.0 \%$ & $1.6 \%$ \\
& $\quad$ CONCIENCIACIÓN & $3.0 \%$ & $0.8 \%$ \\
Ambas & Valores y sensibilidad & & $16.5 \%$ \\
Ambas & Valores estéticos & $8.0 \%$ & $2.7 \%$ \\
Ambas & Estados de ánimo & $1.0 \%$ & $1.2 \%$ \\
Ambas & Recesario/importante para la vida & $4.0 \%$ & $4.7 \%$ \\
Ambas & Aprender para transmitir & $3.3 \%$ & $4.7 \%$ \\
\hline
\end{tabular}


Los aspectos relacionados con el Paisaje que se debería enseñar a los futuros maestros por ámbito del centro de estudios anteriores (tabla 93) no se han encontrado diferencias entre el medio rural y urbano, en las categorías de conocimientos y recursos, sin embargo, en la categoría de concienciación, es cuatro puntos superior en el medio rural que en el urbano y comportamiento: conservación y mejora tres puntos más.

Tabla 93. ¿Qué aspectos relacionados con el Paisaje le parece que deberían de enseñarse a los futuros maestros? según medio rural-urbano

\begin{tabular}{llcc}
\hline Especialidad & Categorías & Rural & Urbano \\
\hline Ambas & Conocimientos & $40.0 \%$ & $40.7 \%$ \\
Ambas & Concienciación & $16.4 \%$ & $12.0 \%$ \\
Ambas & $\begin{array}{l}\text { Comportamiento.: conservación y } \\
\text { mejora }\end{array}$ & $30.9 \%$ & $27.7 \%$ \\
Ambas & Recursos & $9.1 \%$ & $8.4 \%$ \\
\hline Fuente: Elaboración propia & &
\end{tabular}

Los aspectos relacionados con el Paisaje que se debería enseñar a los futuros maestros por ámbito del centro rural y urbano, si tenemos en cuenta las subcategorías, podemos ver en la tabla 94, que el mayor porcentaje de respuestas se encuentra en característica y tipos de Paisaje (22 y 23\%). En el medio físico, es tres puntos superior en el medio rural que el urbano, mientras que el medio ambiente el porcentaje se invierte en los dos medios. En cuanto a los valores y sensibilidad las respuestas son superiores en el medio rural cuatro puntos más que en el medio urbano.

Tabla 94. ¿Qué aspectos relacionados con el Paisaje le parece que deberían de enseñarse a los futuros maestros? Según medio rural-urbano. Subcategorías

\begin{tabular}{|c|c|c|c|}
\hline Especialidad & Subcategorías & Rural & Urbano \\
\hline \multicolumn{4}{|c|}{ CONOCIMIENTOS } \\
\hline Primaria & Medio físico & $6.6 \%$ & $4.1 \%$ \\
\hline Ambas & Medio ambiente & $3.0 \%$ & $6.0 \%$ \\
\hline Infantil & Naturaleza & $6.3 \%$ & $5.0 \%$ \\
\hline Primaria & Naturaleza & $1.0 \%$ & $0.5 \%$ \\
\hline Ambas & Rural y urbano & $1.8 \%$ & $1.8 \%$ \\
\hline Ambas & Característica y tipos de Paisaje & $21.8 \%$ & $23.0 \%$ \\
\hline Ambas & Ecosistema y biodiversidad & $4.2 \%$ & $3.4 \%$ \\
\hline Ambas & Historia & $2.4 \%$ & $1.6 \%$ \\
\hline Ambas & Práctica & $1.8 \%$ & $1.8 \%$ \\
\hline \multicolumn{4}{|c|}{ CONCIENCIACIÓN } \\
\hline Ambas & Valores y sensibilidad & $15.2 \%$ & $10.7 \%$ \\
\hline Ambas & Valores estéticos & $2.4 \%$ & $1.6 \%$ \\
\hline Ambas & Estados de ánimo & $1.2 \%$ & $0.8 \%$ \\
\hline \multicolumn{4}{|c|}{ RECURSOS } \\
\hline Ambas & Necesario/importante para la vida & $4.8 \%$ & $3.9 \%$ \\
\hline Ambas & Aprender para transmitir & $3.6 \%$ & $4.2 \%$ \\
\hline
\end{tabular}


En cuanto al lugar de nacimiento, los conocimientos son mayores en Castilla y León (41\%) que en otras Autonomías (38\%), en las otras categorías no se han encontrado diferencias (tabla 95).

Tabla 95. ¿Qué aspectos relacionados con el Paisaje le parece que deberían de enseñarse a los futuros maestros? según lugar de nacimiento

\begin{tabular}{|c|c|c|c|}
\hline Especialidad & Categorías & Castilla y León & Otras Autonomías \\
\hline Ambas & Conocimientos & $41.3 \%$ & $38.4 \%$ \\
\hline Ambas & Concienciación & $13.0 \%$ & $12.8 \%$ \\
\hline Ambas & $\begin{array}{l}\text { Comportamiento.: conservación y } \\
\text { mejora }\end{array}$ & $28.8 \%$ & $28.5 \%$ \\
\hline Ambas & Recursos & $8.4 \%$ & $9.3 \%$ \\
\hline
\end{tabular}

Fuente: Elaboración propia

Si tenemos en cuenta las subcategorías podemos observar en la tabla 96, que en los conocimientos del Medio ambiente donde la tasa de estas respuestas es más elevada entre los sujetos que nacieron en Castilla y León que en los que nacieron en otras Autonomías (7\% vs $2 \%$ ). En el resto de respuestas no se han encontrado diferencias apreciables entre los lugares de nacimiento analizados.

Tabla 96. ¿Qué aspectos relacionados con el Paisaje le parece que deberían de enseñarse a los futuros maestros? según lugar de nacimiento. Subcategorías

\begin{tabular}{llrr}
\hline Especialidad & Subcategorías & Castilla y León & Otras Autonomías \\
\hline \multirow{2}{*}{ Ambas } & \multicolumn{1}{c}{ CONOCIMIENTOS } & & $5.0 \%$ \\
Ambas & Medio físico & $5.0 \%$ & $1.7 \%$ \\
Infantil & Nedio ambiente & $6.5 \%$ & $7.0 \%$ \\
Primaria & Naturaleza & $5.2 \%$ & $0 \%$ \\
Ambas & Rural y urbano & $1.1 \%$ & $0.6 \%$ \\
Ambas & Característica y tipos de Paisaje & $2.2 \%$ & $22.7 \%$ \\
Ambas & Ecosistema y biodiversidad & $22.3 \%$ & $1.7 \%$ \\
Ambas & Historia & $4.6 \%$ & $2.3 \%$ \\
Ambas & Práctica & $1.1 \%$ & $1.7 \%$ \\
Ambas & $\quad$ CONCIENCIACIÓN & $2.2 \%$ & $11.6 \%$ \\
Ambas & Valores y sensibilidad & & $1.2 \%$ \\
Ambas & Valores estéticos & $11.7 \%$ & $1.2 \%$ \\
Ambas & Estados de ánimo & $1.9 \%$ & \\
Ambas & RECURSOS & $0.8 \%$ & $5.2 \%$ \\
\hline Fuente: Elaboración propia & & $3.5 \%$ \\
\hline
\end{tabular}

En esta última pregunta abierta del cuestionario, cuando le preguntamos al alumnado que por qué un futuro maestro debe conocer los aspectos relacionados con el Paisaje que ellos han determinado en la cuestión anterior, el análisis descriptivo indica que la inmensa mayoría de los participantes (71\%) han dado respuestas orientadas hacia la 
categoría de recursos, sin que haya mucha diferencia entre las especialidades (tabla 97). Las demás categorías apenas tienen presencia, todas ellas menores al $9 \%$. Y solamente en una de ellas, en Concienciación (8\%) se han encontrado diferencias importantes entre las especialidades ya que estas respuestas son más comunes entre los alumnos de Primaria que entre los de Infantil (12\% vs 3\%). En comportamiento: conservación y mejora hay una diferencia de casi cuatro puntos entre el alumnado de Educación Primaria y Educación Infantil.

Tabla 97. ¿Por qué un futuro maestro debe conocerlos? por especialidades

\begin{tabular}{lccc}
\hline Categorías & \multicolumn{1}{c}{ Totales } & Infantil & \multicolumn{1}{c}{ Primaria } \\
\hline Conocimientos & $4.3 \%$ & $3.7 \%$ & $4.9 \%$ \\
Concienciación & $7.6 \%$ & $3.0 \%$ & $\mathbf{1 1 . 9 \%}$ \\
$\begin{array}{l}\text { Comportamiento.: conservación y } \\
\text { mejora }\end{array}$ & $8.8 \%$ & $7.1 \%$ & $10.5 \%$ \\
Recursos & $70.6 \%$ & $71.9 \%$ & $69.3 \%$ \\
\hline Fuente: Elaboración propia & &
\end{tabular}

En cuanto a las subcategorías (tabla 98) en ninguna de las preguntas anteriores se había observado una tan alta concentración de respuestas en un mismo sentido. Así en la categoría de Conocimientos, la mayoría se ha centrado en las que se relacionan con Características y tipos de Paisaje (3\%), sin apenas diferencias entre las especialidades. En el grupo de Concienciación, casi todas las respuestas se han enunciado dentro del subgrupo de Valores y sensibilidad (7\%) pero aquí sí que han aparecido diferencias de manera tal que aparece más entre las respuestas que dan los de Educación Primaria (11\%) que entre los de Educación Infantil (3\%). Y dentro del grupo de Recursos -el más presente recuérdese- la mayor parte de las respuestas se han centrado en los temas de Aprender para transmitir (60\%) seguido de Necesario/Importante para la vida (12\%), sin que en ninguna de las dos se aprecien diferencias a reseñar entre especialidades. Algunos ejemplos:

"Son conocimientos que le servirán para conocer mejor su entorno, para desenvolverse en él y cuidarlo mejor" (1º infantil).

"Porque las sociedades deben avanzar con actitudes y valores que contribuyan a la sostenibilidad de la tierra"

"Para que los enseñen a sus alumnos, reconozcan y disfruten los elementos de los Paisajes". 
Tabla 98. ¿Por qué un futuro maestro debe conocerlos? por especialidades. Subcategorías

\begin{tabular}{lrrr}
\hline Subcategorías & \multicolumn{1}{c}{ Totales } & \multicolumn{1}{c}{ Infantil } & \\
\hline \multicolumn{1}{c}{ CONOCIMIENTOS } & & & $0.8 \%$ \\
Medio físico & $0.4 \%$ & $0 \%$ & $0 \%$ \\
Medio ambiente & $0.4 \%$ & $0.7 \%$ & $0.3 \%$ \\
Naturaleza & $0.4 \%$ & $0.4 \%$ & $0 \%$ \\
Rural y urbano & $0.2 \%$ & $0.4 \%$ & $3.5 \%$ \\
Característica y tipos de Paisaje & $2.5 \%$ & $1.5 \%$ & $0 \%$ \\
Ecosistema y biodiversidad & $0 \%$ & $0 \%$ & $0 \%$ \\
Historia & $0.2 \%$ & $0.4 \%$ & $0.3 \%$ \\
Práctica & $0.2 \%$ & $0 \%$ & $11.2 \%$ \\
$\quad$ CONCIENCIACIÓN & & & $0.3 \%$ \\
Valores y sensibilidad & $7.2 \%$ & $3.0 \%$ & $0.3 \%$ \\
Valores estéticos & $0.2 \%$ & $0 \%$ & \\
Estados de ánimo & $0.2 \%$ & $0 \%$ & $13.3 \%$ \\
$\quad$ RECURSOS & & & $58.9 \%$ \\
Necesario/importante para la vida & $11.9 \%$ & $10.5 \%$ & $0 \%$ \\
Aprender para transmitir & $60.3 \%$ & $61.8 \%$ & \\
Ocio y turismo & $0 \%$ & $0 \%$ & \\
\hline Fuente: Elaboraión propia & & &
\end{tabular}

Fuente: Elaboración propia

Al realizar la comparación en función de la etapa no se encuentran diferencias en dos de las categorías, pero sí en las otras dos (tabla 99). En Concienciación estas respuestas son más mayores en la $2^{\mathrm{a}}$ etapa (11\% vs $5 \%$ ). Sin embargo en Recursos, estas respuestas son superiores en la $1^{\mathrm{a}}$ etapa ( $76 \%$ vs $\left.64 \%\right)$.

Tabla 99. ¿Por qué un futuro maestro debe conocerlos? por etapas

\begin{tabular}{llrr}
\hline Especialidad & Categorías & $1^{\circ}$ y $2^{\circ}\left(1^{\mathrm{a}} \mathrm{E}\right)$ & $3^{\circ}$ y $4^{\circ}\left(2^{\mathrm{a}} \mathrm{E}\right)$ \\
\hline Ambas & Conocimientos & $3.0 \%$ & $5.9 \%$ \\
Ambas & Concienciación & $5.0 \%$ & $\mathbf{1 0 . 6 \%}$ \\
Ambas & $\begin{array}{l}\text { Comportamiento.: conservación y } \\
\text { mejora }\end{array}$ & $8.0 \%$ & $9.8 \%$ \\
Ambas & Recursos & $\mathbf{7 5 . 9 \%}$ & $64.3 \%$ \\
\hline
\end{tabular}

Fuente: Elaboración propia

Para el estudio de las subcategorías, se tienen en cuenta solamente aquellas en las que el número de respuestas supera un mínimo de casos. Si tenemos en cuenta la etapa (tabla 100), se han encontrado varias diferencias que merecen comentario. Las respuestas de Característica y tipos de Paisaje dentro del grupo de Conocimientos están más presentes en los alumnos que están en la $2^{\mathrm{a}}$ etapa ( $5 \%$ vs $0.3 \%$ ). Las de Valores y sensibilidad en Educación Primaria, están más representadas por los alumnos de la $2^{\mathrm{a}}$ etapa de nuevo ( $20 \%$ vs $5 \%$ ), en tanto que no hay diferencias en Infantil. Y en Aprender para transmitir se ha encontrado una mayor tasa entre los de la $1^{\mathrm{a}}$ etapa (64\%) que entre los de la $2^{\mathrm{a}}(56 \%)$. 
Tabla 100. ¿Por qué un futuro maestro debe conocerlos? por etapas. Subcategorías

\begin{tabular}{|c|c|c|c|}
\hline Especialidad & Subcategorías & $1^{\circ}$ y $2^{\circ}\left(1^{a} E\right)$ & $3^{\circ}$ y $4^{\circ}\left(2^{a} E\right)$ \\
\hline Ambas & $\begin{array}{c}\text { CONOCIMIENTOS } \\
\text { Característica y tipos de Paisaje }\end{array}$ & $0.3 \%$ & $5.1 \%$ \\
\hline $\begin{array}{c}\text { Infantil } \\
\text { Primaria }\end{array}$ & $\begin{array}{l}\text { CONCIENCIACIÓN } \\
\text { Valores y sensibilidad } \\
\text { Valores y sensibilidad }\end{array}$ & $\begin{array}{l}3.1 \% \\
5.4 \%\end{array}$ & $\begin{array}{r}2.9 \% \\
19.5 \%\end{array}$ \\
\hline $\begin{array}{l}\text { Ambas } \\
\text { Ambas }\end{array}$ & $\begin{array}{l}\text { RECURSOS } \\
\text { Necesario/importante para la vida } \\
\text { Aprender para transmitir }\end{array}$ & $\begin{array}{l}12.4 \% \\
64.2 \%\end{array}$ & $\begin{array}{l}11.4 \% \\
55.7 \%\end{array}$ \\
\hline
\end{tabular}

Fuente: Elaboración propia

En el cruce en función del ámbito del centro en los que estudiaron anteriormente (tabla 101) no se han encontrado diferencias en tres de las cuatro categorías. Sí que aparecen en la de Concienciación donde se aprecia una mayor presencia de estas respuestas en los que estuvieron en colegios del medio rural (12\%) que en los estuvieron en centros urbanos (6\%).

Tabla 101. ¿Por qué un futuro maestro debe conocerlos? Según medio rural-urbano

\begin{tabular}{llrc}
\hline Especialidad & Categorías & \multicolumn{1}{c}{ Rural } & Urbano \\
\hline Ambas & Conocimientos & $3.0 \%$ & $4.7 \%$ \\
Ambas & Concienciación & $\mathbf{1 2 . 2 \%}$ & $5.7 \%$ \\
Ambas & $\begin{array}{l}\text { Comportamiento.: conservación y } \\
\text { mejora }\end{array}$ & $9.7 \%$ & $8.6 \%$ \\
Ambas & Recursos & $73.3 \%$ & $69.5 \%$ \\
\hline
\end{tabular}

Fuente: Elaboración propia

En relación con las subcategorías (tabla 102) se ha encontrado solamente una diferencia en la variable que contiene las respuestas del tipo Valores y sensibilidad en los alumnos de Primaria, donde estas respuestas son más comunes entre los que estudiaron en centros rurales (19\%) que entre los que lo hicieron en centros del medio urbano (7\%). En las demás no se observa ninguna importante.

Tabla 102. ¿Por qué un futuro maestro debe conocerlos? según medio rural-urbano. Subcategorías

\begin{tabular}{|c|c|c|c|}
\hline Especialidad & Subcategorías & Rural & Urbano \\
\hline Ambas & $\begin{array}{c}\text { CONOCIMIENTOS } \\
\text { Característica y tipos de Paisaje }\end{array}$ & $2.4 \%$ & $2.6 \%$ \\
\hline $\begin{array}{l}\text { Infantil } \\
\text { Primaria }\end{array}$ & $\begin{array}{l}\text { CONCIENCIACIÓN } \\
\text { Valores y sensibilidad } \\
\text { Valores y sensibilidad }\end{array}$ & $\begin{array}{r}1.6 \% \\
18.8 \%\end{array}$ & $\begin{array}{l}3.5 \% \\
7.1 \%\end{array}$ \\
\hline $\begin{array}{l}\text { Ambas } \\
\text { Ambas }\end{array}$ & $\begin{array}{l}\text { RECURSOS } \\
\text { Necesario/importante para la vida } \\
\text { Aprender para transmitir }\end{array}$ & $\begin{array}{l}12.2 \% \\
62.4 \%\end{array}$ & $\begin{array}{l}12.0 \% \\
59.3 \%\end{array}$ \\
\hline
\end{tabular}


El cruce con el lugar de nacimiento se ha detectado una diferencia a resaltar en una de las categorías (tabla 103) se trata de la de Conocimientos, donde se aprecia que estas respuestas están más presentes en alumnos que provienen de autonomías de fuera de la de Castilla y León (8\% vs 3\%). En los recursos, sin embargo, son los alumnos que han nacido en Castilla y León quienes dan mayores respuestas con un $73 \%$.

Tabla 103. ¿Por qué un futuro maestro debe conocerlos? Según lugar de nacimiento

\begin{tabular}{llrr}
\hline Especialidad & Categorías & Castilla y León & $\begin{array}{c}\text { Otras } \\
\text { Autonomías }\end{array}$ \\
\hline Ambas & Conocimientos & $3.0 \%$ & $7.6 \%$ \\
Ambas & Concienciación & $6.3 \%$ & $9.9 \%$ \\
Ambas & $\begin{array}{l}\text { Comportamiento.: conservación y } \\
\text { mejora }\end{array}$ & $8.4 \%$ & $9.3 \%$ \\
Ambas & Recursos & $72.8 \%$ & $65.7 \%$ \\
\hline Fuente: Elaboración propia & &
\end{tabular}

En los análisis de las subcategorías (tabla 104) no han aparecido diferencias reseñables en ninguna de ellas. Aunque es cierto que se ha quedado cerca de serlo y se podría hablar de una cierta tendencia en la de Aprender para transmitir.

Tabla 104. ¿Por qué un futuro maestro debe conocerlos? Según lugar de nacimiento. Subcategorías

\begin{tabular}{llcr}
\hline Especialidad & Subcategorías & Castilla y León & Otras Autonomías \\
\hline \multirow{2}{*}{ Ambas } & CONOCIMIENTOS & & \\
& Característica y tipos de Paisaje & $1.9 \%$ & $4.1 \%$ \\
Infantil & CONCIENCIACIÓN & & $5.6 \%$ \\
Primaria & Valores y sensibilidad & $2.1 \%$ & $11.9 \%$ \\
\cline { 2 - 2 } & Valores y sensibilidad & $10.2 \%$ & $11.6 \%$ \\
Ambas & Necesario/importante para la vida & $11.2 \%$ & $54.7 \%$ \\
\hline
\end{tabular}

Fuente: Elaboración propia

La última pregunta del cuestionario trata sobre el Convenio Europeo del Paisaje. Teniendo en cuenta que este favorece las actuaciones educativas que abordan los valores relacionados con los Paisajes, como docente ¿qué harías para promocionar esos valores en tu clase? Se pedía a los participantes que señalasen “...5 actuaciones educativas de entre 10 que se proponían. A pesar de ello no todos los encuestados señalaron las 5, alguno menos, y algunos ninguna. También se observó que algunos procedieron a ordenar todas desde la $1^{\text {a }}$ hasta la $10^{\mathrm{a}}$; en estos casos se tomaron como respuestas válidas solamente las 5 primeras, para no perder esa información (esto ocurrió en un 18\% de los participantes). En total se emitieron 2588 respuestas, desde participantes que marcaron solamente dos opciones hasta los que marcaron las 5 solicitadas, con la salvedad recién comentada. Sobre ellas, las dos más señaladas con 
mucha diferencia sobre el resto, fueron: "Estimular la educación desde los primeros años de escolaridad" y "Promover la participación ciudadana en la gestión y ordenación de los Paisajes" (fig. 10). Las dos menos indicadas, también con mucha diferencia con las demás, ha sido: "Dejar la iniciativa a profesionales especialistas" y "Estimular la educación desde Asociaciones privadas".

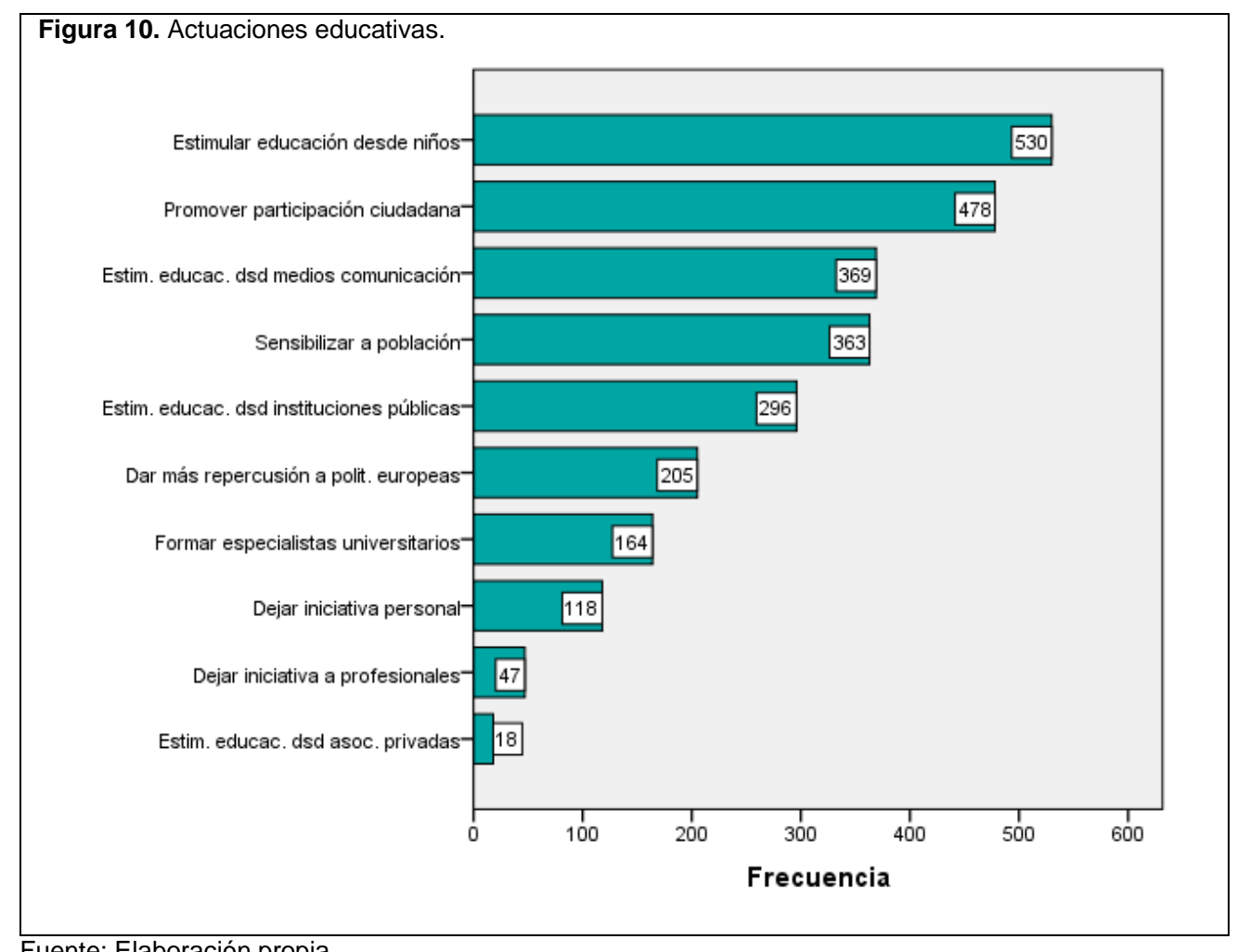

Fuente: Elaboración propia

La tabla 105 presenta el contraste de las escasas diferencias entre las dos especialidades que forman la muestra, que solo aparecen en dos: la segunda en intención "Promover la participación ciudadana en la gestión y ordenación de los Paisajes" que ha sido marcada por más personas de Infantil (90\%) que de Primaria (83\%) y la de "Dar más repercusión a las políticas e iniciativas europeas" que, en cambio, es más señalada por los sujetos de Primaria, con diez puntos de diferencia (42\% vs $32 \%$ ). 
Tabla 105. Acuerdo con las actuaciones educativas de la muestra total y por especialidad.

\begin{tabular}{llll}
\hline Proposición & Totales & Infantil & Primaria \\
\hline $\begin{array}{l}\text { Estimular la educación desde los primeros años de } \\
\text { escolaridad }\end{array}$ & $95.7 \%$ & $97.4 \%$ & $94.1 \%$ \\
\hline $\begin{array}{l}\text { Promover participación ciudadana en gestión y ordenación ... } \\
\text { Estimular educación desde medios de comunicación }\end{array}$ & $86.3 \%$ & $\mathbf{8 9 . 5 \%}$ & $83.3 \%$ \\
\hline Sensibilizar a la población con acciones creadoras de opinión & $65.5 \%$ & $65.2 \%$ & $67.9 \%$ \\
\hline Estimular educación desde otras instituciones públicas & $53.4 \%$ & $67.4 \%$ & $63.8 \%$ \\
\hline Dar más repercusión a las políticas e iniciativas europeas & $37.0 \%$ & $53.6 \%$ & $53.3 \%$ \\
\hline Formar especialistas universitarios & $29.6 \%$ & $31.5 \%$ & $\mathbf{4 2 . 2 \%}$ \\
\hline Dejar la iniciativa al interés personal & $21.3 \%$ & $31.1 \%$ & $28.2 \%$ \\
\hline Dejar la iniciativa a profesionales especialistas & $8.5 \%$ & $21.3 \%$ & $21.3 \%$ \\
\hline Estimular educación desde asociaciones privadas & $3.2 \%$ & $9.0 \%$ & $8.0 \%$ \\
\hline Fuente. Elaboración propia & & $3.0 \%$ & $3.5 \%$ \\
\hline
\end{tabular}

Fuente. Elaboración propia

Por etapas el análisis de la pregunta anterior, se ha realizado segmentando la muestra en función de la especialidad solamente en dos de las respuestas. Los resultados se presentan en la tabla 106. Como se puede comprobar en ella, ninguna de las diferencias analizadas entre las etapas han resultados ser significativas.

Tabla 106. Acuerdo con las actuaciones educativas en la $1^{\circ}$ y la $2^{\circ}$ mitad de los estudios

\begin{tabular}{|c|c|c|c|}
\hline Especialidad & Proposición & $1^{\circ}$ y $2^{\circ}\left(1^{\mathrm{a}} \mathrm{E}\right)$ & $3^{\circ}$ y $4^{\circ}\left(2^{a} E\right)$ \\
\hline Ambas & Estimular la educación desde los primeros años de escolaridad & $96.3 \%$ & $94.9 \%$ \\
\hline Infantil & $\begin{array}{l}\text { Promover participación ciudadana en gestión y ordenación de } \\
\text { los Paisajes }\end{array}$ & $88.5 \%$ & $90.4 \%$ \\
\hline Primaria & $\begin{array}{l}\text { Promover participación ciudadana en gestión y ordenación de } \\
\text { los Paisajes }\end{array}$ & $85.1 \%$ & $80.7 \%$ \\
\hline Ambas & Estimular educación desde medios de comunicación & $67.2 \%$ & $65.9 \%$ \\
\hline Ambas & Sensibilizar a la población con acciones creadoras de opinión & $67.2 \%$ & $63.5 \%$ \\
\hline Ambas & Estimular educación desde otras instituciones públicas & $52.2 \%$ & $54.9 \%$ \\
\hline Infantil & Dar más repercusión a las políticas e iniciativas europeas & $26.0 \%$ & $36.8 \%$ \\
\hline Primaria & Dar más repercusión a las políticas e iniciativas europeas & $42.9 \%$ & $41.2 \%$ \\
\hline Ambas & Formar especialistas universitarios & $28.4 \%$ & $31.0 \%$ \\
\hline Ambas & Dejar la iniciativa al interés personal & $22.1 \%$ & $20.4 \%$ \\
\hline Ambas & Dejar la iniciativa a profesionales especialistas & $9.4 \%$ & $7.5 \%$ \\
\hline Ambas & Estimular educación desde asociaciones privadas & $3.7 \%$ & $2.7 \%$ \\
\hline
\end{tabular}

Fuente: Elaboración propia

Las diferencias entre los medios rural y urbano en cuanto al acuerdo con las actuaciones educativas que se proponen, no tienen diferencias que se puedan considerar como reseñables en ninguna de las variables (tabla 107). 
Tabla 107. Acuerdo con las actuaciones educativas según procedencia rural-urbana.

\begin{tabular}{|c|c|c|c|c|}
\hline \multirow[b]{2}{*}{ Proposición (P = Paisaje) } & \multicolumn{2}{|c|}{ Infantil } & \multicolumn{2}{|c|}{ Primaria } \\
\hline & Rural & Urbano & Rural & Urbano \\
\hline $\begin{array}{l}\text { Estimular la educación desde los primeros } \\
\text { años de escolaridad }\end{array}$ & $96.8 \%$ & $97.5 \%$ & $95.1 \%$ & $93.5 \%$ \\
\hline $\begin{array}{l}\text { Promover participación ciudadana en } \\
\text { gestión y ordenación ... }\end{array}$ & $82.5 \%$ & $91.5 \%$ & $86.3 \%$ & $81.5 \%$ \\
\hline $\begin{array}{l}\text { Estimular educación desde medios de } \\
\text { comunicación }\end{array}$ & $69.8 \%$ & $63.3 \%$ & $63.7 \%$ & $70.1 \%$ \\
\hline $\begin{array}{l}\text { Sensibilizar a la población con acciones } \\
\text { creadoras de opinión }\end{array}$ & $63.5 \%$ & $67.8 \%$ & $67.6 \%$ & $61.4 \%$ \\
\hline $\begin{array}{l}\text { Estimular educación desde otras } \\
\text { instituciones públicas }\end{array}$ & $54.0 \%$ & $54.3 \%$ & $52.9 \%$ & $53.8 \%$ \\
\hline $\begin{array}{l}\text { Dar más repercusión a las políticas e } \\
\text { iniciativas europeas }\end{array}$ & $30.2 \%$ & $32.7 \%$ & $44.1 \%$ & $41.3 \%$ \\
\hline Formar especialistas universitarios & $28.6 \%$ & $31.7 \%$ & $28.4 \%$ & $28.3 \%$ \\
\hline Dejar la iniciativa al interés personal & $22.2 \%$ & $21.1 \%$ & $22.5 \%$ & $20.7 \%$ \\
\hline $\begin{array}{l}\text { Dejar la iniciativa a profesionales } \\
\text { especialistas }\end{array}$ & $11.1 \%$ & $8.5 \%$ & $4.9 \%$ & $9.8 \%$ \\
\hline $\begin{array}{l}\text { Estimular educación desde asociaciones } \\
\text { privadas }\end{array}$ & $3.2 \%$ & $2.5 \%$ & $1.0 \%$ & $4.3 \%$ \\
\hline
\end{tabular}

Finalmente, por lugar de nacimiento, en la tabla 108 están los cruces de las variables de actuaciones educativas. En la submuestra de Infantil no se han encontrado diferencias entre variables y en la Primaria, en la mayoría de las variables tampoco, pero sí que la hay en la más señalada "estimular la educación desde los primeros años de escolaridad" que es más elegida por los nacidos en la Comunidad de Castilla y León que por los de las otras Autonomías. En la segunda "promover participación ciudadana" que también es más marcada por los castellanoleoneses frente a los de las otras Comunidades Autónomas. 
Tabla 108. Acuerdo con las actuaciones educativas según el lugar de nacimiento

\begin{tabular}{|c|c|c|c|c|}
\hline \multirow[b]{2}{*}{ Proposición (P = Paisaje) } & \multicolumn{2}{|c|}{ Infantil } & \multicolumn{2}{|c|}{ Primaria } \\
\hline & Castilla y León & $\begin{array}{l}\text { Otras } \\
\text { autonomías }\end{array}$ & Castilla y León & Otras autonomías \\
\hline $\begin{array}{l}\text { Estimular la educación desde los } \\
\text { primeros años de escolaridad }\end{array}$ & $97.4 \%$ & $97.2 \%$ & $96.6 \%$ & $89.1 \%$ \\
\hline $\begin{array}{l}\text { Promover participación ciudadana en } \\
\text { gestión y ordenación ... }\end{array}$ & $89.0 \%$ & $90.1 \%$ & $87.6 \%$ & $74.3 \%$ \\
\hline $\begin{array}{l}\text { Estimular educación desde medios de } \\
\text { comunicación }\end{array}$ & $63.9 \%$ & $67.6 \%$ & $66.7 \%$ & $68.3 \%$ \\
\hline $\begin{array}{l}\text { Sensibilizar a la población con } \\
\text { acciones creadoras de opinión }\end{array}$ & $69.1 \%$ & $64.8 \%$ & $63.3 \%$ & $64.4 \%$ \\
\hline $\begin{array}{l}\text { Estimular educación desde otras } \\
\text { instituciones públicas }\end{array}$ & $51.8 \%$ & $60.6 \%$ & $52.0 \%$ & $56.4 \%$ \\
\hline $\begin{array}{l}\text { Dar más repercusión a las políticas e } \\
\text { iniciativas europeas }\end{array}$ & $33.5 \%$ & $26.8 \%$ & $44.1 \%$ & $40.6 \%$ \\
\hline Formar especialistas universitarios & $29.3 \%$ & $33.8 \%$ & $31.6 \%$ & $21.8 \%$ \\
\hline Dejar la iniciativa al interés personal & $19.9 \%$ & $23.9 \%$ & $21.5 \%$ & $21.8 \%$ \\
\hline $\begin{array}{l}\text { Dejar la iniciativa a profesionales } \\
\text { especialistas }\end{array}$ & $8.9 \%$ & $8.5 \%$ & $7.9 \%$ & $8.9 \%$ \\
\hline $\begin{array}{l}\text { Estimular educación desde } \\
\text { asociaciones privadas }\end{array}$ & $3.7 \%$ & $1.4 \%$ & $2.3 \%$ & $5.0 \%$ \\
\hline
\end{tabular}




\subsection{PERCEPCIONES DEL PAISAJE A TRAVÉS DE LA IMAGEN}

La imagen fotográfica supone un recurso didáctico y un material documental extraordinario tanto para el geógrafo como para el historiador. La fotografía permite realizar una lectura novedosa de múltiples fenómenos, ya que la fotografía entendida como documento visual registra una serie de elementos que pasan inadvertidos en las fuentes clásicas contemporáneas. Es un recurso, como señala Álvarez Orellana (2006) muy conocido por los estudiantes y de fácil accesibilidad técnica, para poder ser introducido en el proceso de enseñanza de las ciencias sociales.

En nuestra investigación, como hemos comentado en la metodología, optamos por elegir el instrumento cualitativo: Análisis de fotografías, uno de los más fiables para acercarnos a conocer qué percepción tiene el alumnado de Educación Infantil y Primaria sobre el Paisaje. Una fotografía es una representación de parte de la realidad en dos dimensiones, "es intermediaria entre el espacio vivido y el espacio representado" (Flonneau, 1995, p.11) que se convierte en documento geográfico cuando la información que proporciona se refiere a un Paisaje concreto y nos puede ayudar a realizar su interpretación. En este momento hay un reconocimiento unánime entre los investigadores del valor didáctico de la imagen fotográfica. Long y Roberson señalan las amplias posibilidades de comprensión de las imágenes por parte del alumnado, independientemente del nivel formativo e incluso del nivel intelectual. Estos autores afirman que "las fotografías son comprensibles por analfabetos y que existe un amplio horizonte de posibilidades de su utilización para la enseñanza de alumnos/as de baja capacidad intelectual" (1979, p.20). Bailey (1981) reconoce el valor didáctico de la fotografía y afirma que es posible a través de ella conseguir objetivos relacionados con el aprendizaje conceptual (nociones y conceptos) que en su expresión escrita resultan muy abstractos para la comprensión del alumnado. En esta línea Giolitto (1992) reivindica el aprendizaje de procedimientos, ya que la lectura e interpretación de la fotografía favorece el desarrollo de capacidades de observación, análisis, síntesis y reflexión y los relacionados con las actitudes y los valores, como por ejemplo, ayudar a imaginar, desarrollar la sensibilidad (Michaux, 2001).

El conocimiento del Paisaje siempre implica la razón y los sentidos, porque el Paisaje siempre tiene una doble naturaleza: la realidad y la imagen. La educación en Paisaje implica al mismo tiempo dos dimensiones: por una parte es educación de la mirada, es decir, de la sensibilidad, y por otro, es educación de la racionalidad y el pensamiento lógico (Castiglioni, 2011). 
En un primer momento se nos planteó la duda sobre la selección de las imágenes fotográficas ¿cuáles podían tener más interés para el alumnado por un lado, y por otro, cuáles nos ayudarían a conseguir nuestro objeto de estudio de este análisis? Álvarez Orellana puntualiza que las imágenes elegidas tienen que ser significativas, de tal manera que los detalles captados nos conduzcan a la idea principal, sin aportar mucha información que nos distraiga la atención. Es decir, que la imagen posea la información más adecuada para los objetivos propuestos, para las características de los alumnos y relacionado con el tema de estudio. El uso de la fotografía, en geografía no debe limitarse a mirarla y hacer una valoración estética de un Paisaje o territorio, sino que nos ayude a reflexionar sobre competencias intelectuales y sociales que se activan con la lectura e interpretación de la imagen (2006). Los factores generales que pueden condicionar la percepción de las fotografías son esencialmente la edad y las experiencias, sin olvidarnos la cultura, el nivel económico y social, y en ciertas ocasiones el sexo junto con la motivación y las experiencias en el uso de las fotografías.

En el estudio que realizamos sobre el Paisaje, hemos sido conscientes que el profesorado debe conocer cómo percibe el alumnado las fotografías antes de programar su uso en el aula, sin embargo quisimos observar cuales eran las primeras sensaciones de los alumnos/as al ver las fotografías por primera vez. Como hemos reflejado, anteriormente en la metodología, seleccionamos las imágenes fotográficas que abarcaban vistas panorámicas con gran riqueza de elementos y temáticas muy diferentes. Todas las imágenes requieren un tiempo mínimo de observación y de análisis para que permita al alumnado obtener una información suficiente para la reflexión. Con respecto al número de fotografías, en principio elegimos 50 fotografías para la investigación, las analizamos, y al final optamos por 4 que nos parecieron suficientes, y las más significativas. Las fotografías seleccionadas se le han pasado al alumnado del Grado de Educación Infantil y Primaria, en los cursos de $1^{\circ}$ y $3^{\circ}(150)$. Nos interesaba conocer la diferencia que había en el alumnado de los dos cursos sobre la representación del Paisaje que visualizan en cada una de las fotografías.

El análisis de las imágenes fotográficas consistió en pedir a los alumno/as que explicaran el Paisaje de cuatro imágenes respondiendo a las siguientes preguntas:

\footnotetext{
$\checkmark$ ¿Qué representa la imagen?

$\checkmark$ ¿Qué elementos paisajísticos ves?

$\checkmark$ ¿Qué te llama la atención y por qué?
} 
A los alumnos de Educación Primaria e Infantil se les presentó la fotografía 1 para que la interpretasen, el 75\% de las respuestas dadas por ellos tienden a la enumeración de los elementos que se observan en la misma y solamente el $25 \%$ que se corresponde con el alumnado de $3^{\circ}$ curso sintetiza la idea de un Paisaje transformado por la mano de las personas. En estas respuestas no se refleja una expresión clara de la transformación del territorio para el aprovechamiento de los recursos hídricos por las personas, aunque unas pocas respuestas, en concreto de los alumnos de $3^{\circ}$, apuntan a esta idea.

\section{Fotografía 1.}

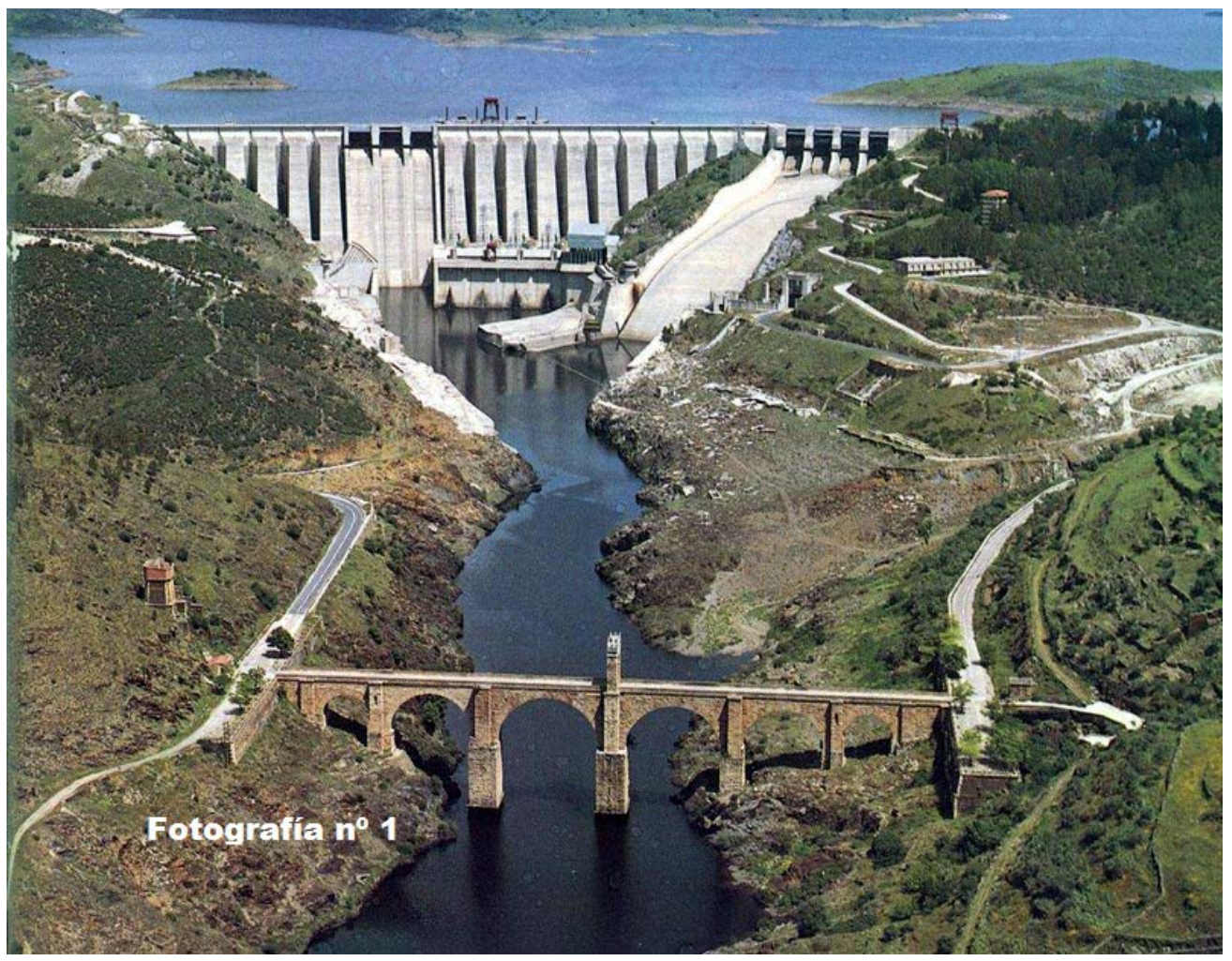

Para hacer la descripción de las imágenes, el alumnado dispuso del tiempo y del espacio suficiente para contestar. Sin embargo, la mayoría de las respuestas fueron tan escuetas que no es posible conocer si aprecian o no los diversos niveles de explotación y planificación territorial existentes en la imagen.

En relación a los aspectos temporales de la imagen, sólo 5 respuestas dadas por los alumnos/as señalan que el puente que aparece en las imágenes es romano, aunque no hay ningún otro comentario al respecto, parece que se debe a que conocen el paraje. Una sola respuesta resalta el contraste entre la construcción antigua y la reciente y otra alude al proceso de transformación. 
El 30\% de las respuestas dadas por el alumnado no menciona la palabra "Paisaje", a pesar de la formulación de la pregunta. Para casi todos los alumnos/as se trata de un Paisaje humanizado. No aparece en ningún caso "Paisaje fluvial". En contados casos se considera que es un Paisaje natural o rural, lo que denota falta de conocimiento o de uso de los posibles tipos de Paisajes.

En cuanto a la valoración que hace el alumnado de la imagen, algunas respuestas, todas del alumnado de $1^{\circ}$ curso, asocian la imagen con "paz o tranquilidad", sin ninguna apreciación adicional. Hay además en este grupo una respuesta que habla de "Paisaje deteriorado", lo cual implica una valoración negativa, y dos de impacto en el Paisaje, sin valorarlo. No se puede concluir que las respuestas restantes contengan valoraciones o matices positivos.

Las respuestas emitidas por el alumnado de $1^{\circ}$ y $3^{\circ}$ tratan de manifestar lo que saben de lo que ven en las imágenes, en algunos casos con errores conceptuales. Por ejemplo: "La separación entre el mar y el río por medio del embalse", "Una presa al final de un río" o "La desembocadura de un río". Y algunas respuestas manifiestan una cierta conciencia de lo que significa la imagen en términos de aprovechamiento económico. Por ejemplo: "Paisaje dónde el agua está controlada por un embalse", o "El cauce de un río controlado por una presa" que en un caso se califica de degradación, sin argumentos adicionales. No hay ninguna referencia a comportamientos deseables.

En cuanto a los elementos paisajísticos que ven, la primera observación que se refleja en las respuestas de los alumnos/as es que han sido identificados y nombrados los elementos más visibles e importantes que aparecen en la imagen 1 por la mayoría de los encuestados sin distinción de curso.

En el gráfico 7 se cuantifican los elementos que aparecen en las respuestas del alumnado. Las seis primeras barras corresponden a elementos naturales (valle, río, agua, montaña, rocas y vegetación) y las ocho restantes a elementos creados por las personas (puente, carretera, camino, transporte, embalse, ce. hidroeléctica y edificios) con la excepción de energía, que no es un elemento directamente visible. En cuanto a los elementos naturales, es patente la presencia del río, que por otra parte se relaciona bien con los elementos "embalse" y "Central Hidroeléctica" entre los no naturales. 
Gráfico 7. Elementos paisajísticos de la fotografía 1

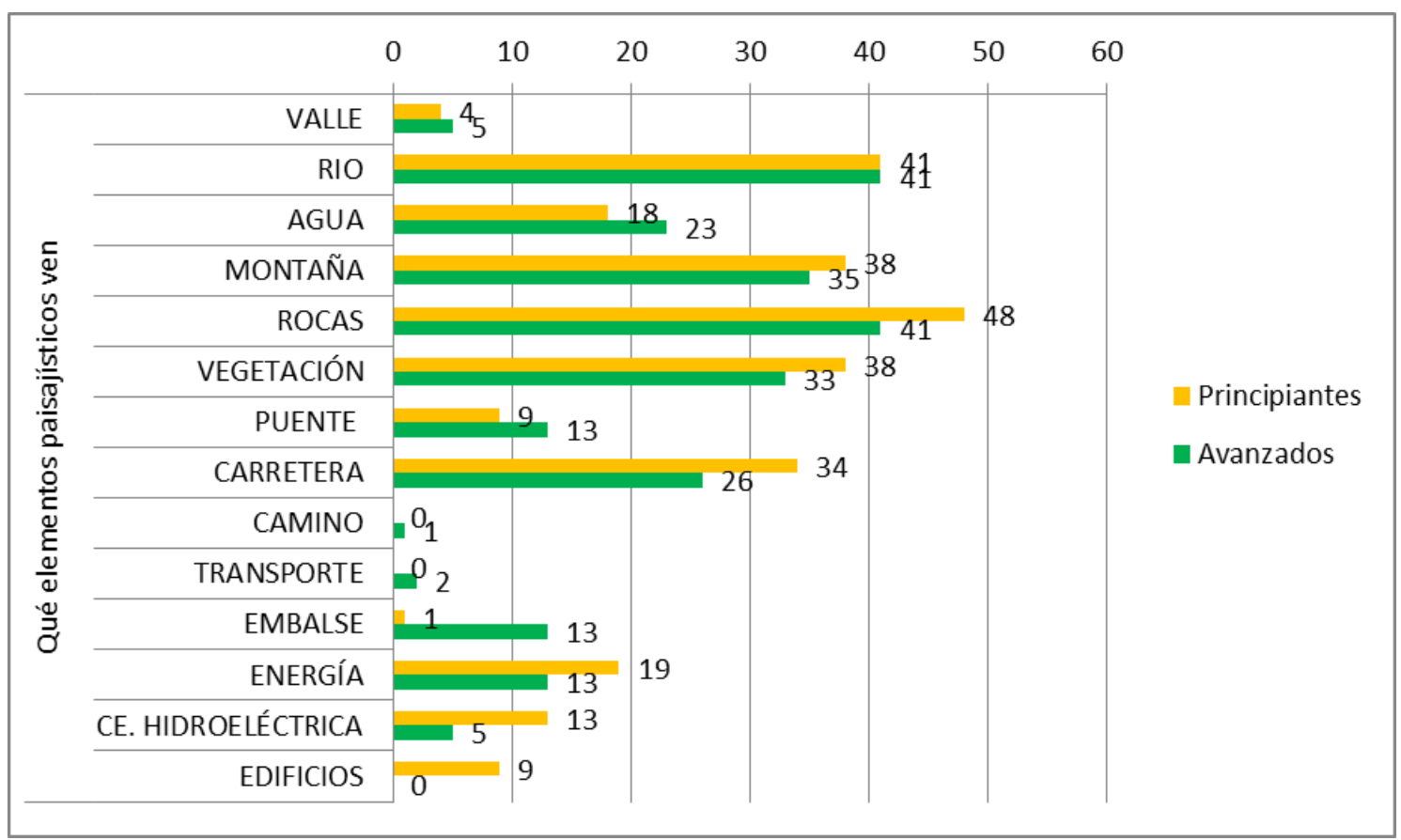

Fuente: elaboración propia

En las respuestas dadas por los estudiantes, es muy llamativo la falta de criterio para identificar el relieve. Solo 9 respuestas ven el valle, menos que los que mencionan las rocas, y también menos que los que dicen que el relieve es montañoso, supuestamente por las vertientes pronunciadas que ven, aunque este extremo no se hace explícito en las respuestas.

En la gráfica 8 observamos el número de elementos descritos en las respuestas de los alumnos/as en relación con el Paisaje de la $1^{\text {a }}$ fotografía. El promedio de elementos reconocidos se aproxima a 4, corresponde a la mayoría de las respuestas del grupo de principiantes del $1^{\circ}$ curso; le siguen las respuestas de 3 elementos en el grupo avanzado, $3^{\circ}$ curso. Estos encuestados han encontrado más fácil contestar a esta pregunta y por regla general se han tomado más interés. Los tres casos de respuestas mínimas son congruentes con la desgana al contestar a la primera cuestión. 
Gráfico 8. Número de elementos paisajísticos

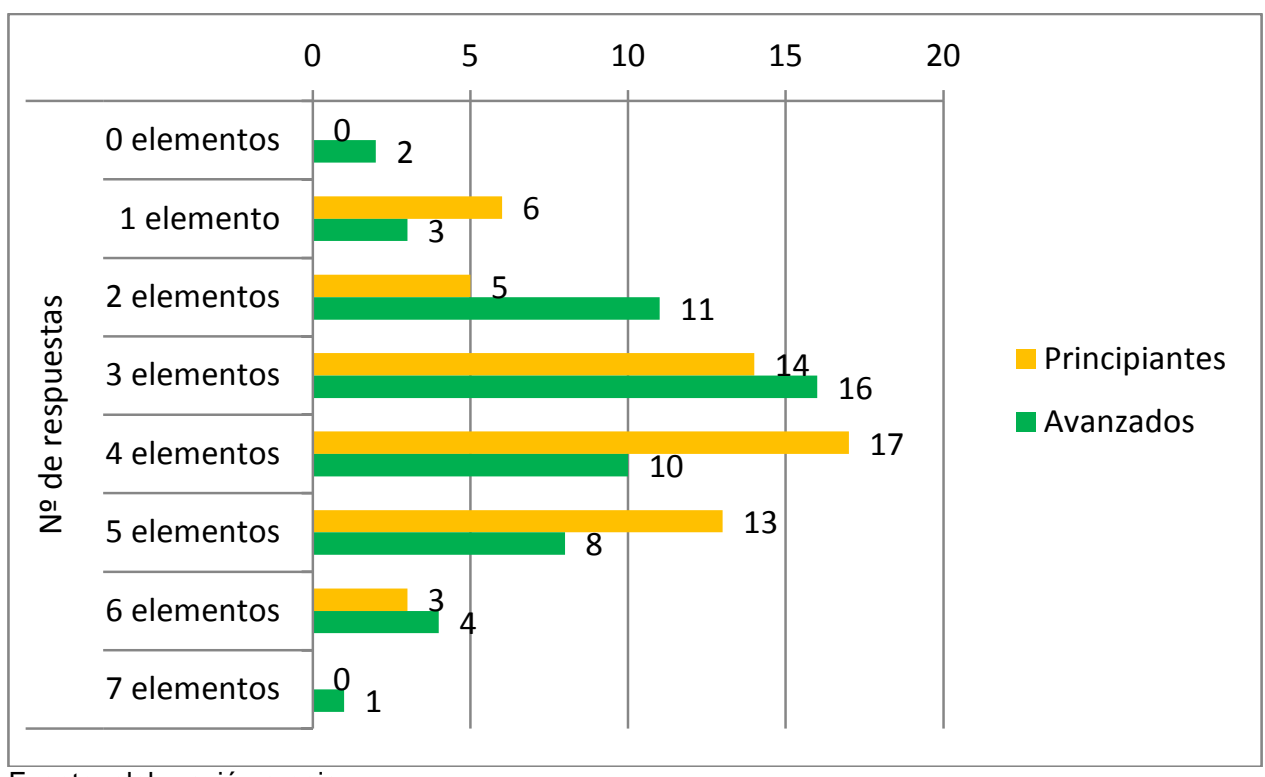

Fuente: elaboración propia

Cuando les preguntamos qué es lo que más le ha llamado la atención y por qué, el conjunto de respuestas emitidas por el alumnado se pueden sintetizar en estos ítems que aparecen en el gráfico 9 y que no se excluyen unos a otros. Los estudiantes del primer curso tienden más a la enumeración de elementos de la imagen, mientras que los del curso avanzado ponen más énfasis en los contrastes, en la intervención espacial. La perspectiva temporal y la valoración en los comentarios son escasamente mencionadas.

Gráfico 9. Que te llama la atención de la fotografía 1

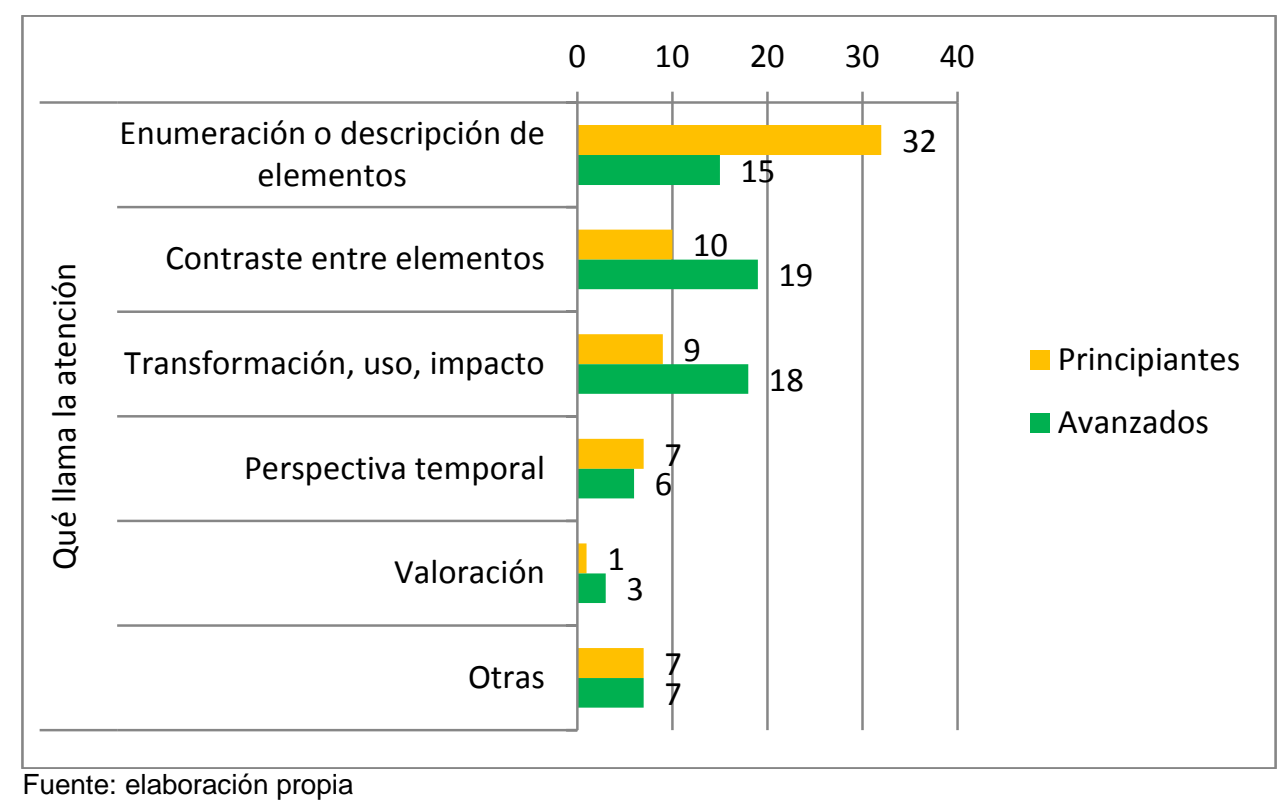


Un número reducido de respuestas emitidas por el alumnado implican valoraciones de carácter negativo y estético, pues consideran que el Paisaje ha perdido su belleza o armonía por las construcciones humanas. Estas valoraciones están presentes en ambos niveles.

Es significativo señalar, como sucede en la pregunta anterior, que hay respuestas dónde se detectan nuevamente errores notables. Por ejemplo, en la respuesta del alumno/a que en su observación describe una "presa construida en la desembocadura de un río", aunque hay otros errores que pueden atribuirse a una deficiente expresión.

\section{Fotografía 2.}

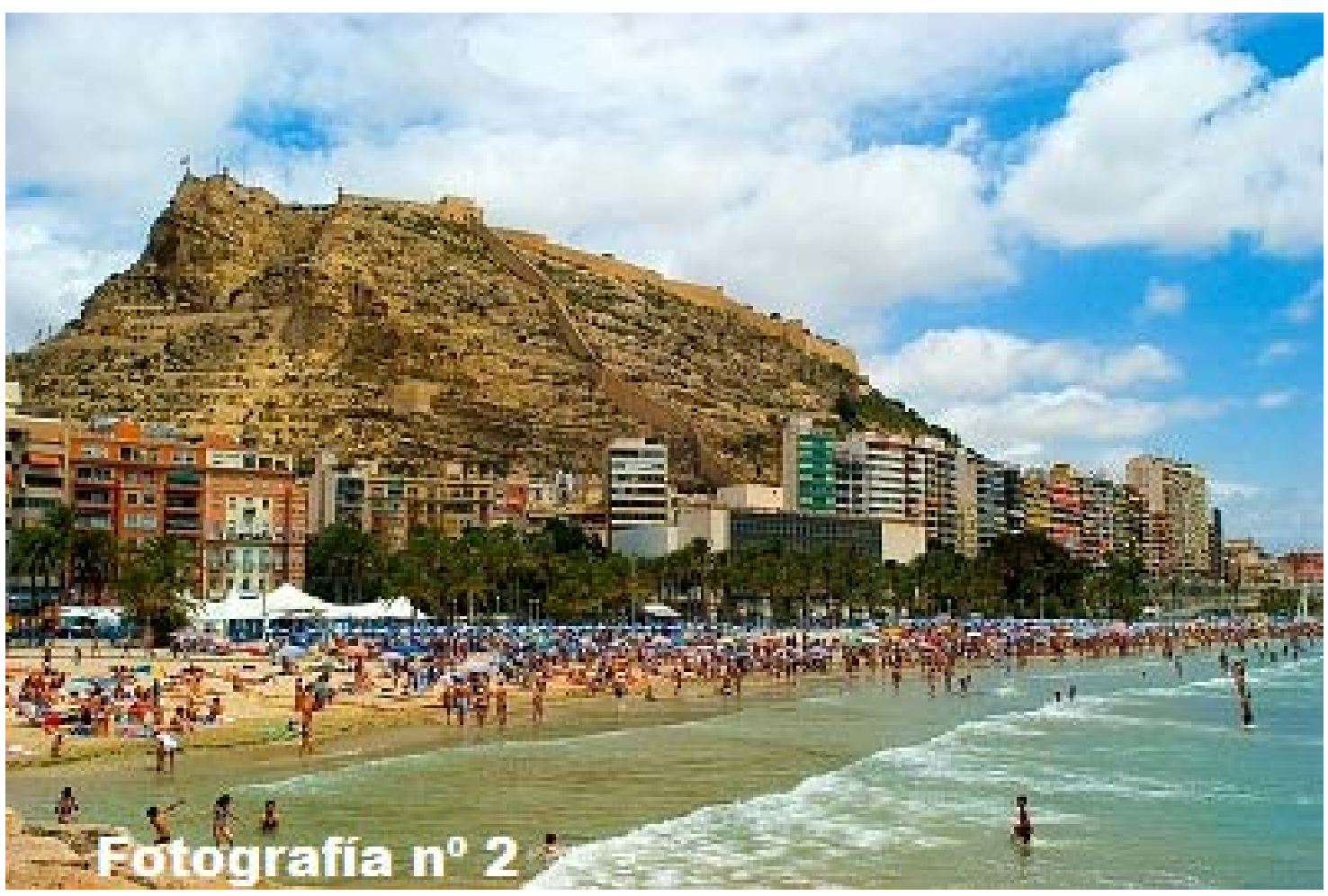

A la pregunta ¿Qué representaría esta imagen? en las respuestas a la fotografía 2, observamos que hay un predominio por parte del alumnado en la identificación del elemento "playa", en un $67 \%$ de las respuestas.

La segunda idea que se recoge en las respuestas, un 25\%, hace mención al concepto de "costa" en diversas variantes. Nos llama nuevamente la atención que los alumnos/as empleen de forma escasa la palabra "Paisaje", apenas un 16\%, aunque se les explicó que las imágenes correspondían a cuatro Paisajes. Eso sí, cuando la utilizan casi siempre es asociada al concepto de costa:" Paisaje costero". 
En las respuestas, se aprecia cierta inseguridad para identificar elementos que conforman un Paisaje urbano, de tal forma que sólo es mencionado por diez encuestados. Sólo seis más de los mencionados anteriormente, hablan de edificios o zona edificada, a pesar de que las edificaciones se encuentran en primera línea de playa. Sin embargo, nos encontramos con que algunos alumnos hacen mención a Paisajes modificados por el hombre, con diversas variantes, como "Acción humana sobre el medio natural", aunque esta es la respuesta que repetidamente dan algunos de los encuestados.

En algunas respuestas, los encuestados hacen referencia al uso y a la valoración de este Paisaje. Con respecto al uso, hay un conjunto de respuestas (30\%) que se refieren a vacaciones, veraneo y turismo. Con respecto a la valoración, hay respuestas de dos tipos: algunos/as alumnos/as que asocian el Paisaje con el bienestar, y otros por el contrario aluden a diversos aspectos negativos que perciben, como la masificación, la especulación y la contaminación.

Cuando se les pregunta ¿qué elementos paisajísticos ves? en general, el alumnado identifica los elementos del Paisaje que ven de forma correcta. Predominan los elementos de montaña, playa, mar, arena, árboles que no se ven en la imagen 2 e incluso edificios, a pesar de que en la anterior pregunta apenas los señalan (gráfico 10).

Gráfico 10. Elementos paisajísticos de la fotografía 2

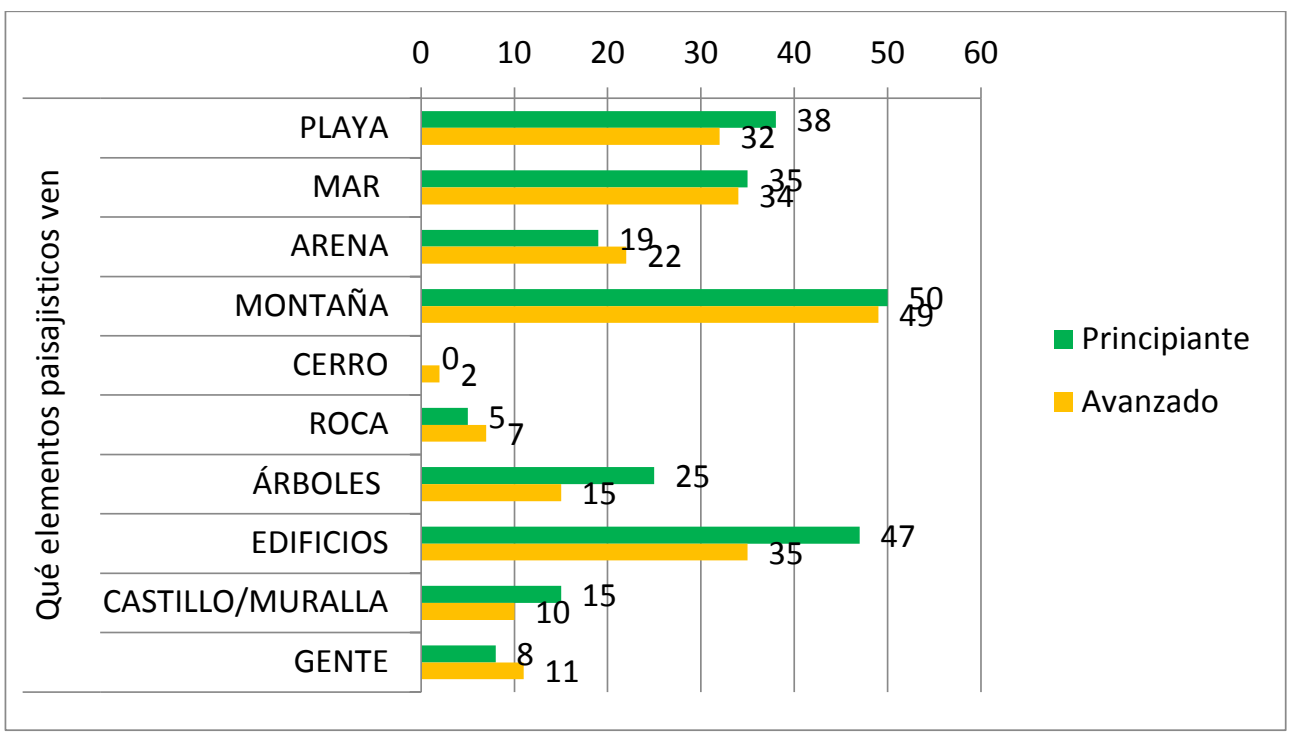

Fuente: Elaboración propia

Llama la atención que hay pocas respuestas que se fijen en el castillo y la muralla. Este análisis nos afianza en la idea de que el alumnado percibe más los elementos naturales que los artificiales. Es interesante la referencia al hombre (gente) como elemento integrante del Paisaje, aunque sólo es recogido por algunos alumnos/as de primero y 
un número más numeroso de tercer curso. Hay dos alumnos que hablan de playa mediterránea y otros dos que identifican la playa de Alicante y el Castillo de Santa Bárbara.

En el gráfico 11 se detalla el número de elementos paisajísticos que han sido identificados por cada alumno/a, al observar la imagen 2 de la playa de Alicante. El resultado más representativo es de tres a cinco elementos identificados por alumno. Parece ser los que consideran suficientes para cumplimentar la encuesta y que coinciden en la mayoría de los casos con elementos naturales.

Gráfico 11. Número de elementos paisajísticos de la fotografía 2

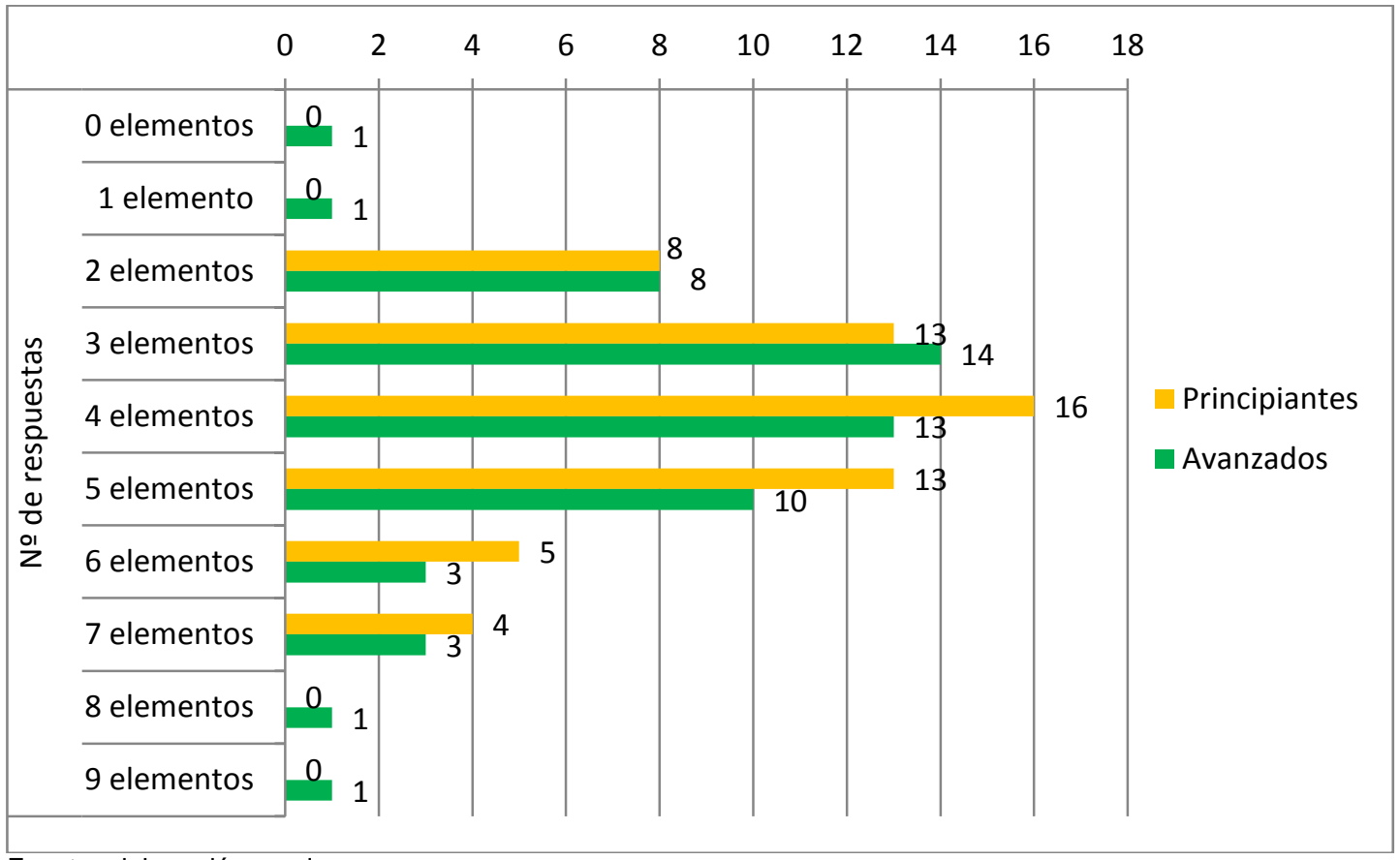

Fuente: elaboración propia

Cuando se le pregunta a los encuestados ¿qué te llama la atención y por qué? las respuestas fueron muy variadas. Hemos intentado sintetizarlas en seis variables (gráfico 12), la primera se refiere a la descripción o enumeración de elementos que se observan en la imagen 2. Es la opción que con más frecuencia eligen los estudiantes de $1^{\circ}$ curso. En cambio, los estudiantes de $3^{\circ}$ perciben más los contrastes paisajísticos y los usos y transformaciones espaciales subsiguientes. Por ejemplo, "cercanía del mar y la montaña" "la montaña por su tamaño" "edificios muy altos que rompen el panorama"; en definitiva, relacionan la segunda y tercera variables. 
Gráfica 12. Que te llama la atención de la fotografía 2

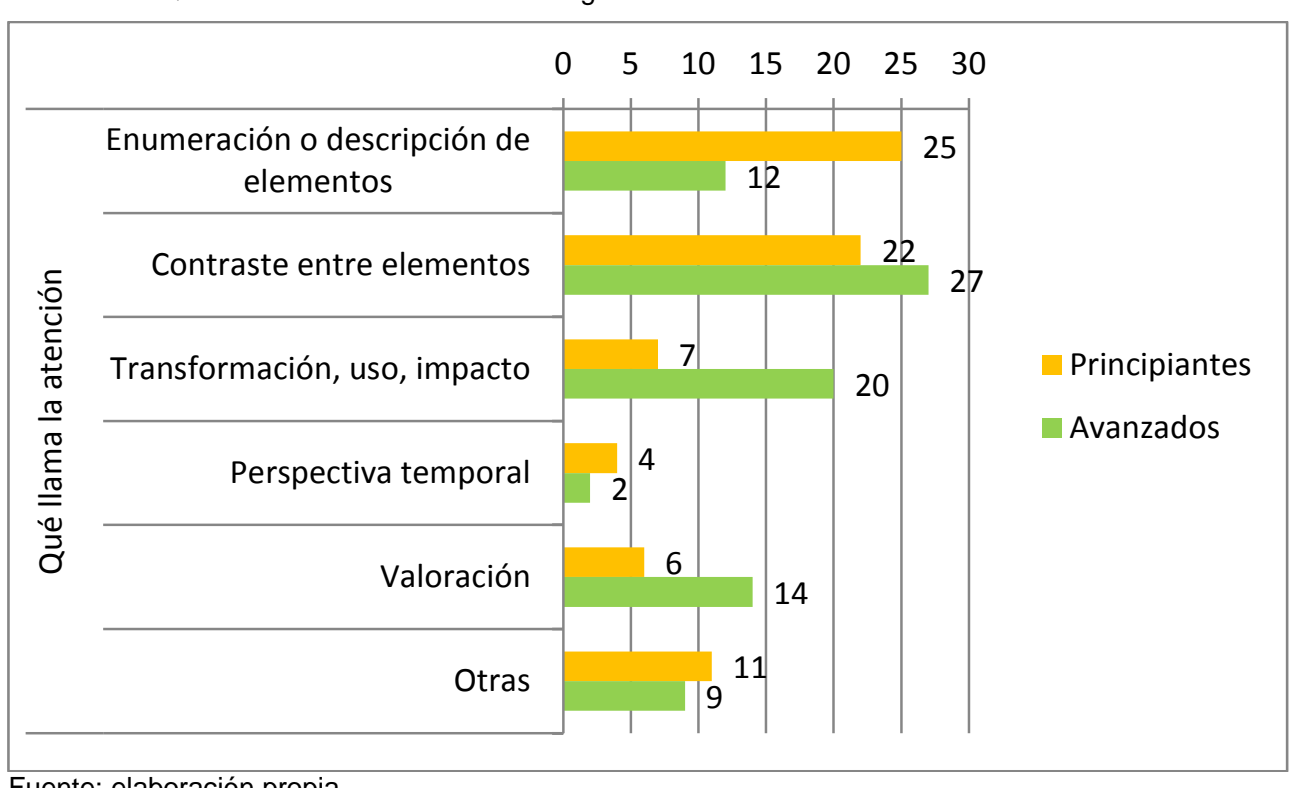

Fuente: elaboración propia

Las valoraciones de los alumnos/as también se aprecian en las respuestas. Señalan el deterioro del Paisaje natural por la intervención humana, así como por la masificación, y son negativos, salvo en un caso que resalta el uso vacacional y gozoso. Ejemplos: "el impacto humano ha moldeado el Paisaje con la construcción de edificios al lado de la playa" "el mar transmite relajación".

Como ya indicamos en la anterior pregunta apenas hay referencias a los elementos (Castillo y muralla) que denotan el paso del tiempo, lo que llama Castiglioni (2011) Paisajes del pasado. Uno de los pocos ejemplos: "Muralla antigua encima de la montaña". La mayoría de los alumnos/as no parece ser consciente de la perspectiva temporal en los Paisajes y por lo que apenas hacen referencia a ellos.

Con respecto a otros elementos que han citado los encuestados, y que se resaltan especialmente, destaca el que se refiere a la cantidad de gente, calificada de masificación, que se ve en la imagen, que ha llamado mucho la atención de los alumnos/as y que queda reflejado en bastantes respuestas. Ejemplo: "mucha gente en la playa" "la gran multitud de gente que se ve en la playa". 


\section{Fotografía 3}

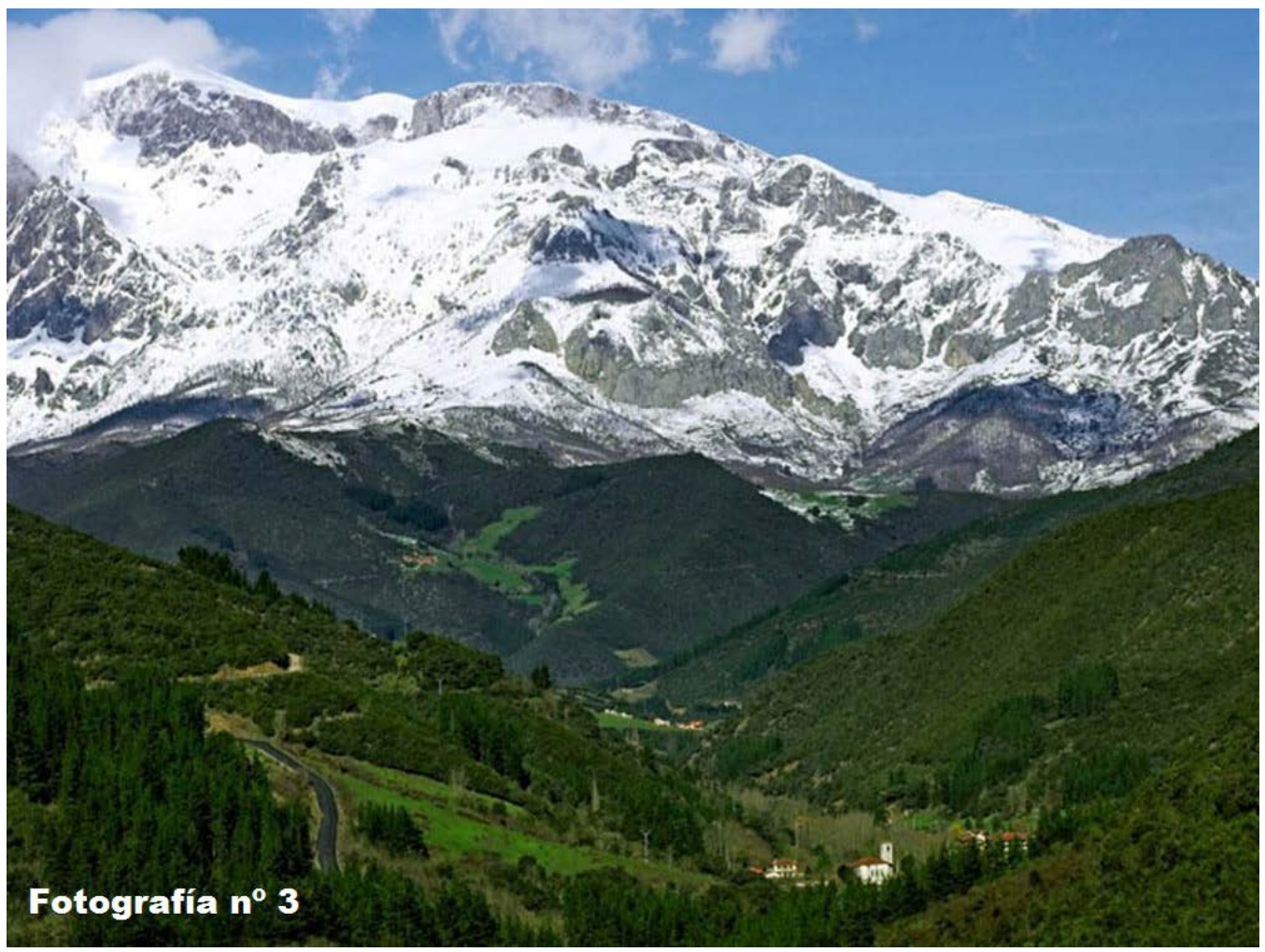

Cuando se hizo la pregunta ¿qué representaría esta imagen de la foto $3^{a}$ ? El análisis de las respuestas emitidas por el alumnado evidencia, que los conceptos más repetidos son: "montañas" o términos similares, acompañadas por descripciones. En ellas, se enumeran los elementos paisajísticos que han observado en la imagen y que sirven para diferenciar a los encuestados.

En las respuestas también se menciona que el relieve es abrupto; pocos alumnos/as, sobre todo los que cursan primer curso hacen alusión a valle, asociándolo sobre todo a la vegetación y al hábitat. Solo hay tres alumnos/as que hablan de clima y el tiempo meteorológico, sin embargo, hay muchas referencias a la nieve. Creemos que es porque esta imagen tiene un gran impacto visual, ya que al observarla se detectan claramente dos tonalidades el blanco en la parte superior que se corresponde con la nieve y el verde de la vegetación.

En estos comentarios que hace el alumnado aparecen errores, como el que dice que es un "Paisaje con una verde pradera y montañas nevadas", confundiendo así la masa forestal con los prados. Otro de los encuestados ve "un glaciar".

La mayoría de los alumnos/as no percibe la ocupación humana, en algunos casos se habla de edificios o el pueblo. Es decir, se pone de manifiesto la dificultad que tiene el alumnado al dividir el Paisaje en sus componentes esenciales: naturales y antrópicos. 
De las 4 imágenes de Paisajes que se les pidió a los alumnos/as que analizaran, fue esta imagen de los Picos de Europa la que suscita más comentarios relativos a la belleza del Paisaje y a la tranquilidad que transmite, pudiendo ser interpretados como una valoración positiva. Castiglioni (2011) señala que la importancia de las cuestiones relacionadas con el Paisaje no proviene de su belleza, sino de sus valores. Normalmente un Paisaje montañoso donde predomina la naturaleza con apenas transformaciones antrópicas resulta más atractivo para el alumnado de maestro que -seguramente- un Paisaje deteriorado. Todos los Paisajes se pueden leer, interpretar y estudiar; todos ellos suscitan emociones, aunque no sean necesariamente positivas. A pesar de ser un Paisaje muy conocido, fueron pocos alumnos/as los que identifican la imagen con los Picos de Europa.

En el análisis realizado a las respuestas de los encuestados tanto a principiantes (10 curso) como a los avanzados ( $3^{\circ}$ curso) en relación a la pregunta ¿qué elementos paisajísticos ves? se llega a la conclusión de que un gran número de alumnos/as son capaces de identificar elementos del Paisaje natural: montañas, nieve, vegetación y bosque, pero sin embargo, no tanto los elementos que se deben a la acción humana y que destacan menos en el Paisaje, como se refleja en la gráfica 13.

Gráfica 13. Elementos paisajísticos de la fotografía 3

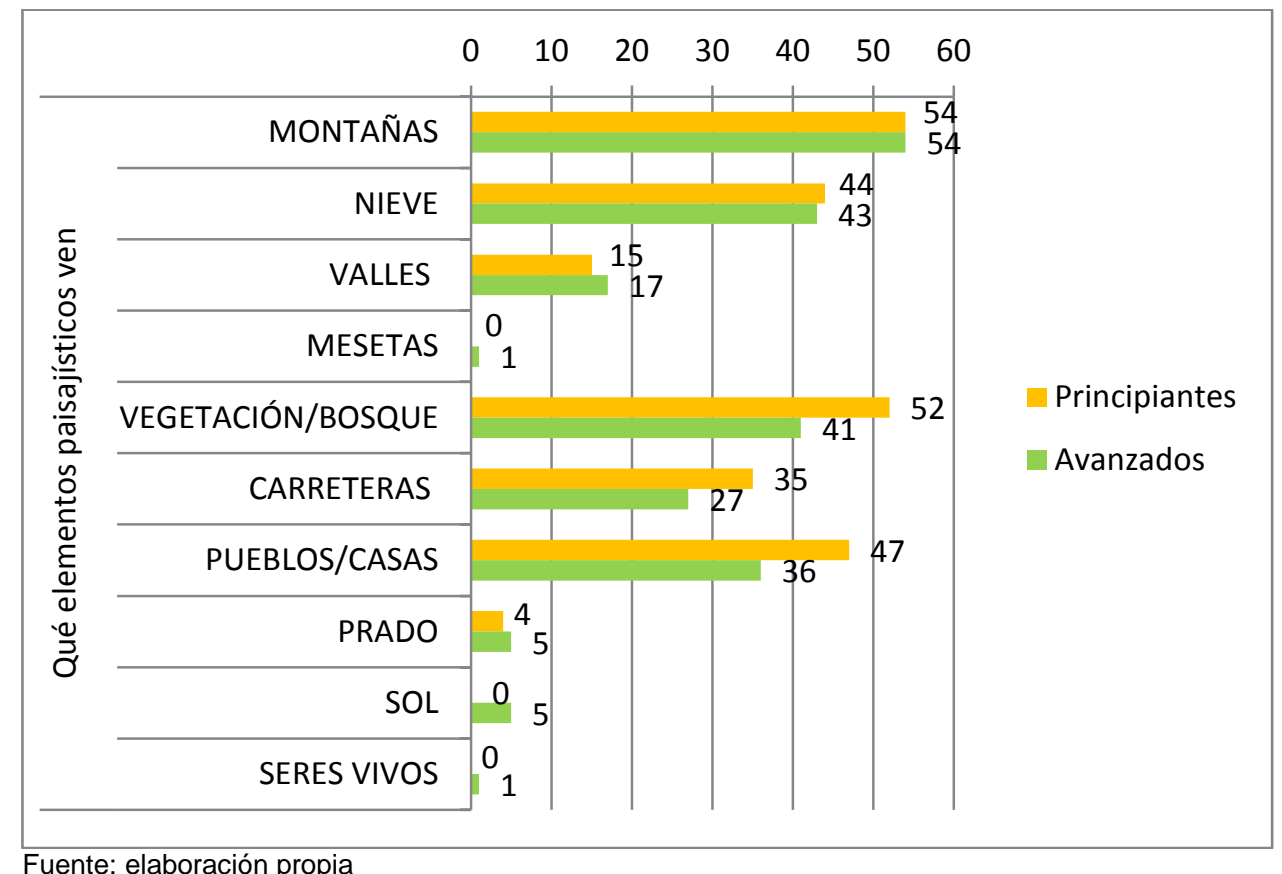

Fuente: elaboración propia 
En la gráfica 14 se representa el número de elementos paisajísticos identificados por el alumnado encuestado al observar la imagen fotográfica de los Picos de Europa. Llama la atención que sea el alumnado del $1^{\circ}$ curso, los que identifiquen un mayor número de elementos paisajísticos ( 6 y 7 ) frente a los alumnos de tercer curso que han recibido una mayor formación. Al hacer el estudio, las respuestas de los encuestados denotan un alto grado de interés por esta imagen.

Gráfica 14. Número de elementos paisajísticos

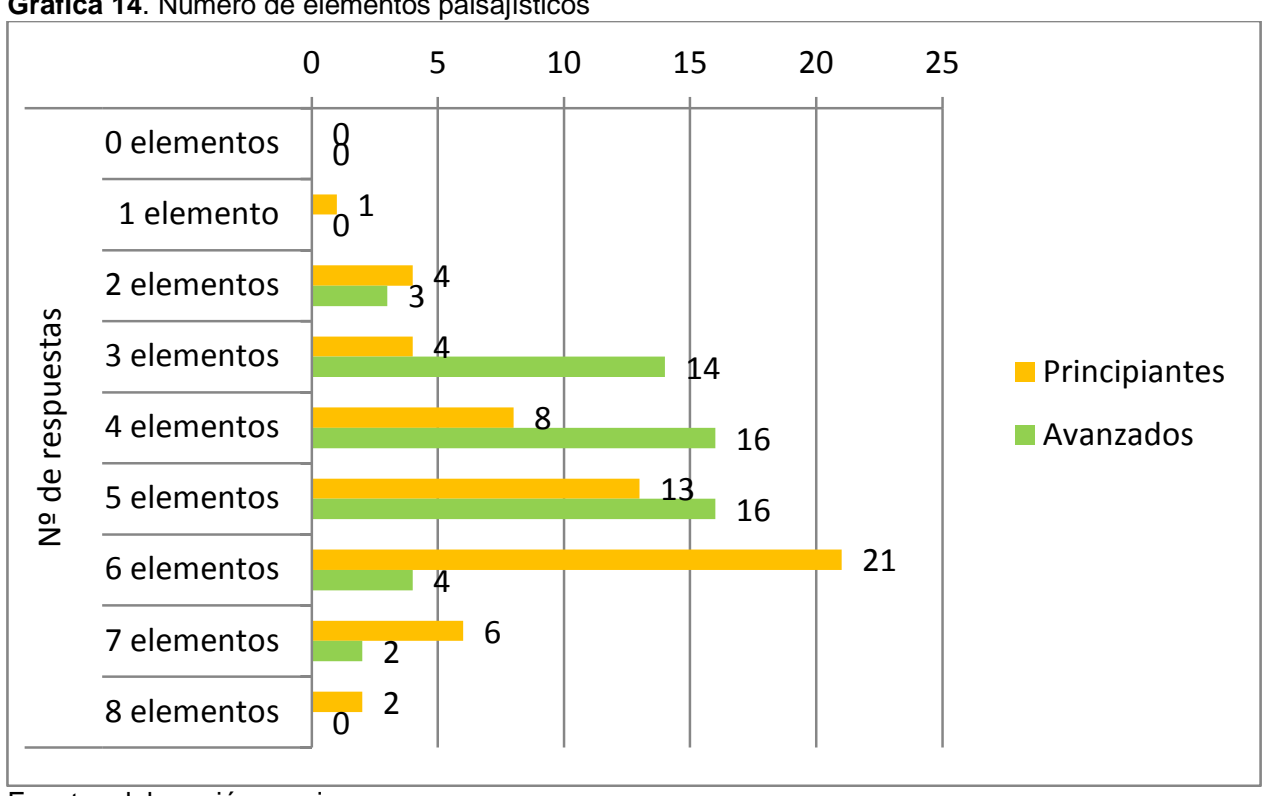

Fuente: elaboración propia

Al plantear la pregunta ¿qué te llama la atención y por qué? se advierte en las respuestas de los alumnos encuestados un mayor entusiasmo al comentar el Paisaje de los Picos de Europa. En ellas (gráfico 15) se observa que la mayoría del alumnado, tanto principiante como avanzado, pone su atención en las dos variables primeras que se corresponden con la enumeración o descripción de elementos paisajísticos y el contraste entre los elementos paisajísticos. Dos encuestados del grupo de $1^{\circ}$ curso escriben "La montaña nevada contrasta con un valle totalmente verde" "Montañas nevadas y montañas verdes", mientras que otro del grupo de $3^{\circ}$ detalla "belleza paisajística, por contraste con una montaña nevada y el verde de los árboles". Sin embargo, hay que resaltar la valoración positiva que aparece sobre todo en el grupo avanzado ( $3^{\circ}$ curso), incluso aquellos relacionados con la transformación del Paisaje resaltan su ausencia como elemento positivo. 
Gráfico 15. Que te llama la atención de la fotografía 3

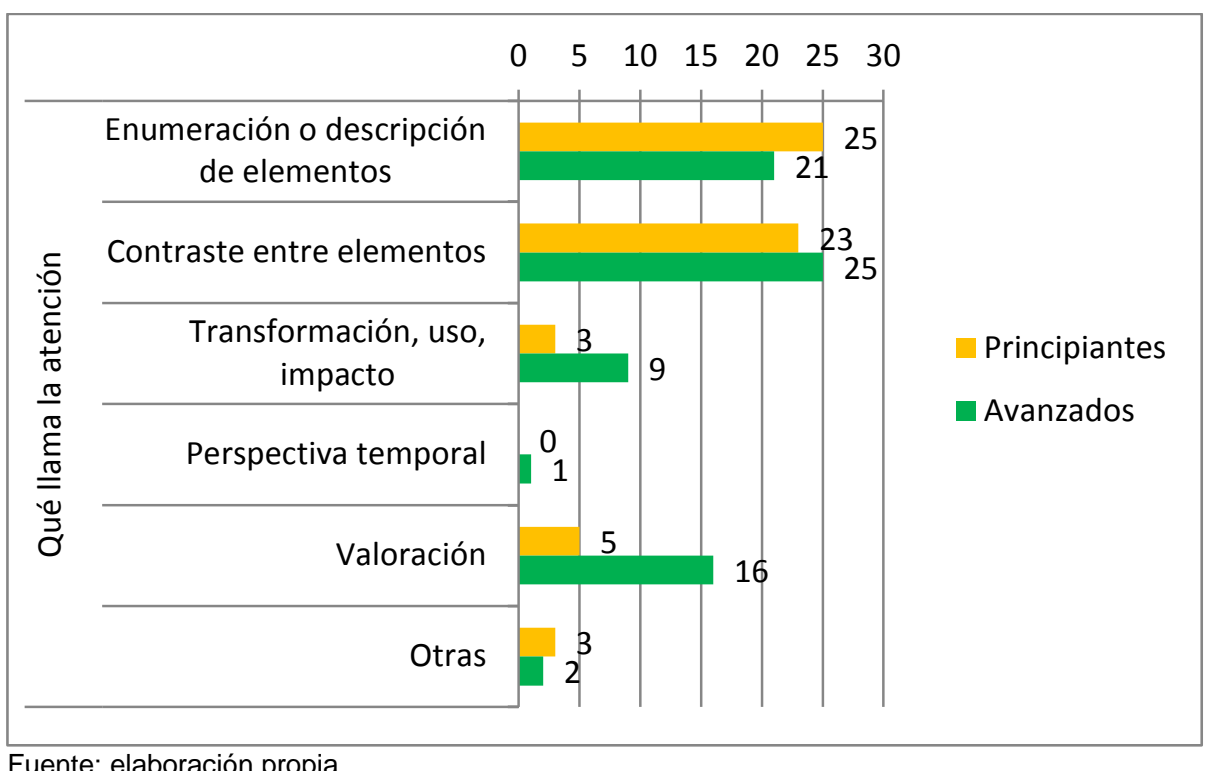

Fuente: elaboración propia

Un número importante del alumnado, encuentran este Paisaje hermoso y lo citan textualmente. Nos parece que con esta expresión muestran el deseo de explicar con palabras bellas la imagen. En relación con la belleza que transmiten ciertos Paisajes, Busquets i Fábregas señala:

"que los Paisajes tanto los más cercanos como los más lejanos, los que se observan directamente como los que se contemplan con la fotografía o las nuevas tecnologías, generan todo tipo de sensaciones: pueden llamar la atención o pasar desapercibidos, complacen o desagradan, estimulan o aburren. Se admira la belleza de ciertos Paisajes y se lamenta la fealdad de otros. Como seres dotados de sentidos, se absorben los estímulos sensoriales que transmite el entorno" (2011, p. 36).

La percepción positiva que tiene el alumnado encuestado puede ser también una muestra de cómo la influencia de los medios convierte al Paisaje en espectáculo que maravilla, en el que la palabra Naturaleza tiene un valor inequívoco. El Paisaje se considera armonioso y bello por sí mismo, por sus formas, colores y contrastes, pero también por estar poco o nada transformado.

Es interesante mencionar que lo que el gráfico 15 no revela es el tono admirativo que domina los comentarios, incluso los puramente descriptivos. Este análisis nos puede llevar a preguntarnos acerca del grado y la naturaleza de la sensibilidad hacia los Paisajes que nuestros alumnos/as muestran.

Solo hay un comentario respecto del tiempo, y se refiere a los cambios estacionales. 
En las respuestas se recogen algunos comentarios curiosos, del tipo de "La presencia de casas en un sitio tan alejado", que aluden a lo remoto que les parece el Paisaje.

\section{Fotografía 4}

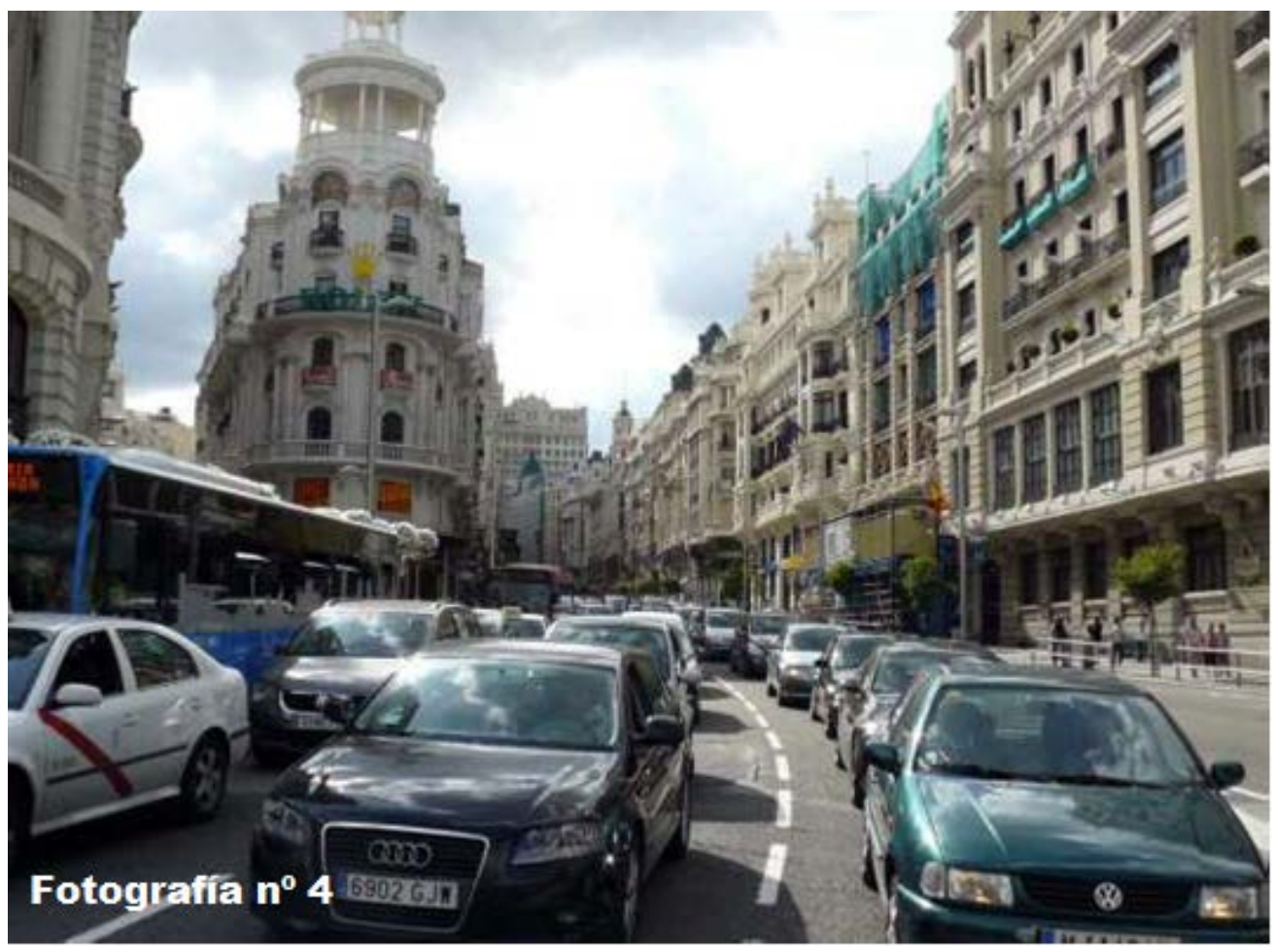

Cuando se le pregunta a los alumnos ¿qué representa esta imagen? la mayoría de los encuestados identifican la Gran Vía de Madrid (fotografía 4) con un Paisaje urbano, expresado de una u otra forma, y los que no, lo hacen de forma indirecta como por ejemplo: "Un día cualquiera en la ciudad", o "Ciudad con contaminación".

Hay un grupo importante de alumnos/as que elude la descripción para centrarse en la percepción y la apreciación que le sugiere la foto de la Gran Vía de Madrid. Así utilizan palabras como: "Caos, contaminación y estrés". La percepción del Paisaje, en el sentido más amplio, no sólo incluye la percepción visual, sino también lo que se percibe a través de los cinco sentidos. Las personas podemos distinguir Paisajes sonoros, olfativos, gustativos y táctiles. Como los Paisajes visuales, estos Paisajes se pueden leer, evaluar según los sentimientos que inspiran (Castiglioni, 2011). El alumnado percibe estas sensaciones porque esta imagen está muy ligada a determinados momentos y situaciones de su vida.

En el análisis, partiendo de la consideración de que los alumnos saben que están ante un Paisaje urbano, hay numerosas referencias en las respuestas del alumnado al tráfico rodado con dos modalidades: una de ellas, la más numerosa se presenta en forma 
neutra "Vía urbana y tráfico" y otra, menos numerosa y más crítica "Un atasco en una gran ciudad".

Hay algunos encuestados que identifican la Gran Vía de Madrid, e incluso uno que repara en los edificios históricos. Otras referencias temporales aluden al paso del tiempo, o a la hora punta.

Al analizar las respuestas del alumnado cuando se le pregunta ¿qué elementos paisajísticos ves? en la fotografía de la Gran Vía de Madrid se observa que los tres elementos paisajísticos más reconocibles para los encuestados han sido los edificios, las calles, expresadas de distintas formas, y el tráfico rodado. Por detrás, aparecen mencionados los árboles, que en la fotografía apenas se ven, y que sin embargo, han sido buscados y mencionados casi tanto como las propias calles. No hay apenas diferencias entre los grupos de principiantes y de avanzados como se puede ver en el (gráfico $\left.n^{\circ} 16\right)$.

Gráfico 16. Elementos paisajísticos de la fotografía 4

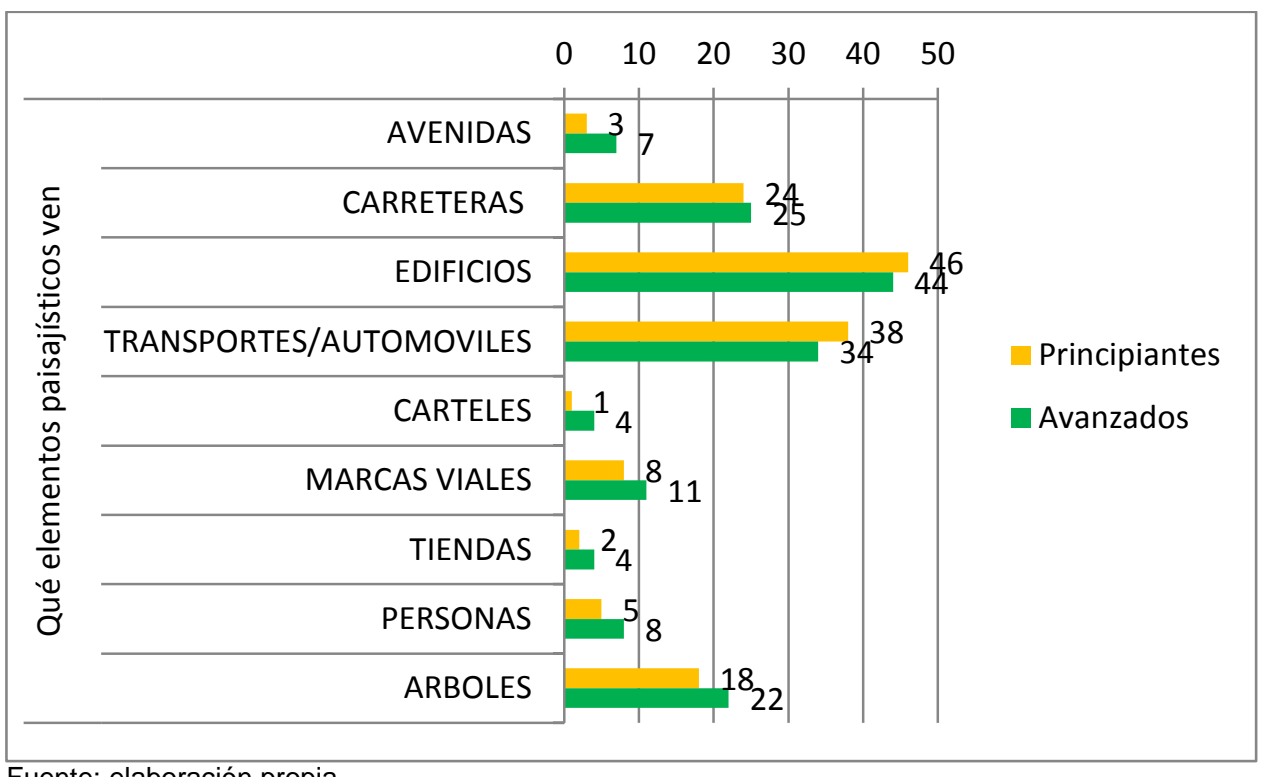

Fuente: elaboración propia

Cuando se examina el número de elementos paisajísticos identificados por los alumnos/as (gráfico 17), llama la atención la gran cantidad de alumnos que manifiesta que no ve ningún elemento paisajístico en la imagen. Esto sin duda corresponde con un concepto de Paisaje que, bien por la distancia del espectador, o bien por su naturaleza, han considerado que no existe. Se vuelve a constatar que el alumnado identifica más Paisaje cuando hay elementos paisajísticos naturales. 
Por lo demás, el número de elementos está en consonancia con los más representativos. El grupo avanzado presenta un promedio superior, y en él están las tres personas que identifican siete elementos en este Paisaje urbano.

Gráfico 17. Número de elementos paisajísticos

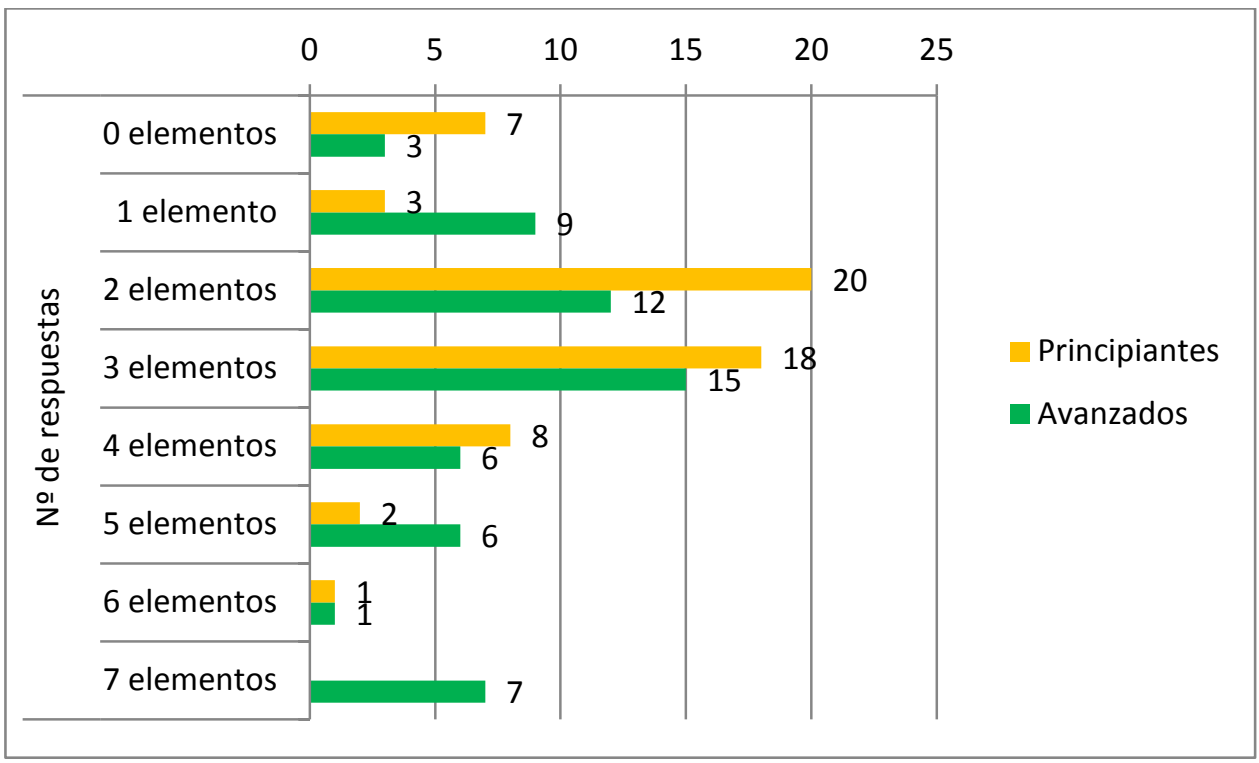

Fuente: elaboración propia

A la pregunta ¿qué le llama la atención y por qué? La mayor parte de los comentarios recogidos en las respuestas se centran en la variable transformación, uso, impacto (gráfico 18). Los alumnos/as resaltan la actuación humana para el tráfico y ocupación de las calles, y destacan sobre la mera enumeración, que suele ser un recurso fácil para responder. No se aprecian apenas contrastes espaciales ni aspectos temporales salvo algunas referencias al carácter histórico de los edificios y a su rehabilitación.

Gráfico 18. Qué te llama la atención de la fotografía 4

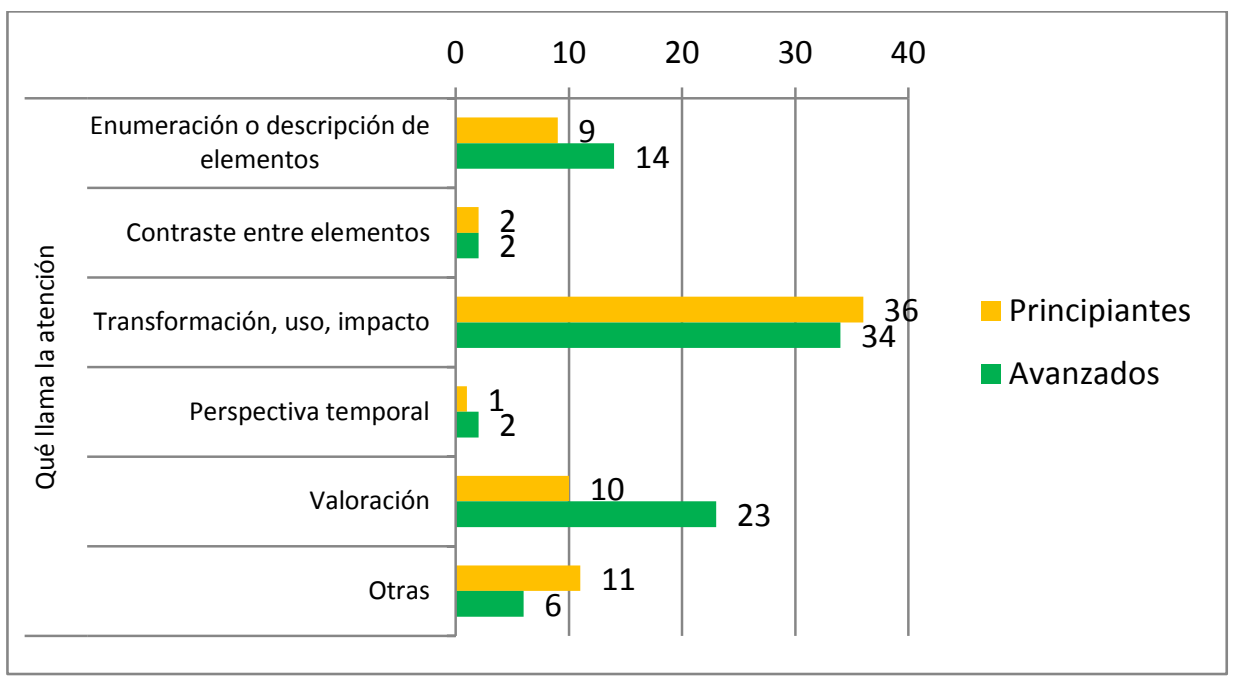

Fuente: elaboración propia 
También son importantes las valoraciones: algunas de las respuestas del alumnado encuestado hacen una valoración positiva de la imagen 4, repartidas por igual entre ambos grupos de principiantes y avanzados, y se relacionan con los edificios y su belleza, como por ejemplo: "edificios muy bonitos de la misma época" "edificios de gran riqueza artística" mientras que las negativas tienen que ver con la "saturación y contaminación ambiental".

El alumnado en sus respuestas muestra en general un fuerte rechazo al intenso tráfico. Hay dos comentarios que no consideran que esto sea un Paisaje, porque hay poca naturaleza y nueve que contestan "nada" o no contestan, todos ellos en el apartado "otros".

En el análisis de las imágenes, no debemos olvidar que las fotografías constituyen sólo una representación de la realidad en un momento dado, seleccionada y registrada a partir de la técnica fotográfica. Esta técnica sólo permite captar ciertos componentes visibles de un Paisaje. Ni las imágenes, ni ninguna otra fuente dan la información. Cada alumno/a obtiene esa información de la fuente, en función de las experiencias y conocimientos que le permiten "ver". Esa mirada es, entonces, una mirada enriquecida y no meramente un registro sensorial: actualiza otras imágenes, situaciones vividas, estudiadas, conocidas que le permiten al observador otorgar significados a lo que representa la imagen (Cappelletti, 2008)

El alumnado de Grado de Maestro en Educación Primaria e Infantil de los cursos $1^{\circ}$ y $3^{\circ}$ se limitan la mayoría en un $75 \%$ a describir los distintos elementos paisajísticos, sobre todo elementos naturales del Paisaje, que observan en las imágenes elegidas. Solo un $25 \%$ son capaces de ver las transformaciones que se han producido por la acción antrópica. Es más, un número elevado del alumnado en la foto del Paisaje urbano (fotografía 4) señala que no hay elementos paisajísticos puesto que los elementos del Paisaje urbano no los consideran elementos del Paisaje. Sin embargo, si perciben y lo reflejan en las respuestas las emociones o estados de ánimo que le provocan dichos paisajes. De tal forma que el Paisaje dónde hay más elementos naturales tiene una valoración positiva, mientras que la foto del Paisaje urbano lo asocian con connotaciones y valoraciones negativas. Es decir, su mirada está enriquecida por situaciones y emociones vividas que le dan un significado a esa imagen.

Como hemos podido comprobar a lo largo de esta investigación, el Paisaje no debe entenderse como algo ajeno, sino como algo vivido, del cual somos integrantes y responsables. 


\section{CONCLUSIONES}

Esta investigación se interesa por conocer las representaciones sociales del Paisaje para el alumnado de maestro en Educación Primaria e Infantil en la Facultad de Educación de la Universidad de Salamanca, como vía para planear la construcción de su conocimiento profesional, favoreciendo la Educación en Paisaje.

Los planteamientos recogidos a continuación son fruto de la confluencia de los aspectos teóricos y prácticos expuestos hasta el momento. En ellos, además de los datos obtenidos en la investigación implementada así como de las fuentes consultadas, se pretende ofrecer una serie de orientaciones específicas que permitan mejorar la práctica docente de la Educación en Paisaje de los alumnos de los Grados de Maestro en Educación Infantil y Primaria. Para dar cabida a todos estos contenidos se ha procedido a estructurar las conclusiones en tres partes. En la primera se reflexiona sobre las implicaciones educativas del Convenio Europeo del Paisaje, así como otros estudios y normativas de referencia que constituyen la base conceptual que debe guiar la Educación en Paisaje. En la segunda se ofrece una visión analítica de las representaciones (en función de distintas variables) sobre el Paisaje de la muestra estudiada. Finalmente se exponen las directrices que, a tenor de lo expuesto en esta tesis, debe seguir cualquier propuesta didáctica que trabaje el Paisaje en los Grados estudiados.

\section{El Convenio Europeo del Paisaje como punto de inflexión}

En sintonía con las perspectivas propuestas por el Convenio Europeo del Paisaje (CEP), y para mejorar la enseñanza y el aprendizaje de las Ciencias Sociales en la formación de los futuros docentes, es necesario tomar en consideración algunos aspectos como:

a) El Convenio Europeo del Paisaje como punto de partida para revisar la importancia de la Educación en Paisaje

El Convenio Europeo del Paisaje, que destaca la importancia del papel de las personas en el Paisaje, reconociendo que tienen tanto derechos como responsabilidades en su protección, gestión y ordenación, propone, entre las medidas específicas que los países firmantes adoptan, las de sensibilización, formación y educación.

El marco del Convenio es muy importante para entender el complejo y rico sentido de la educación en Paisaje, ya que permite contemplarla desde perspectivas nuevas e interesantes. El valor educativo del Paisaje se ha ido reconociendo cada vez con más 
intensidad, a medida que se extendían la preocupación por el medio ambiente y la valoración del patrimonio. Como consecuencia, las experiencias y los enfoques relacionados con el Paisaje en el terreno educativo se han multiplicado y se caracterizan por su gran diversidad.

Para el Convenio Europeo del Paisaje, como ya hemos comentado, el Paisaje es "cualquier parte del territorio tal como lo percibe la población", por tanto el campo de las percepciones como el de las emociones resulta fundamental, igual que el enfoque lógico y científico que nos ayuda a entender los distintos factores naturales y/o humanos que interaccionan en un Paisaje. Así pues, el campo educativo tiene que explorar tanto los sentimientos y las sensaciones como el campo racional, con un enfoque emocional y cognitivo.

Además, el Convenio señala la compleja estructura sistémica del Paisaje, lo que requiere capacidades de síntesis y de análisis al tratarlo, sin olvidar la dimensión social. Esto significa que las actividades educativas no se centren solo en un enfoque personal del Paisaje, sino que es necesario organizar actividades de grupo que subrayen la importancia de compartir percepciones y opiniones diferentes para aprender aceptar la diversidad y mejorar la capacidad de debate, como convirtiendo el Paisaje es una especie de mediador cultura.

b) La Educación en Paisaje, clave del bienestar individual y social.

El Paisaje, como se ha señalado en esta investigación es y ha sido objeto de estudio tradicional en todos los sistemas escolares y etapas educativas, incluida la educación superior y la Universidad. Sin embargo, hay que puntualizar que, en función de los modelos pedagógicos y los enfoques geográficos, ha gozado de un protagonismo desigual y un tratamiento diverso en la escuela como afirma Busquets, quien señala la importancia de la educación en Paisaje (2010). Es a partir de la creación del CEP cuando se produce un mayor interés por el Paisaje, y es cuando se habla del Paisaje en educación. Además, reconoce que el Paisaje es un "elemento importante de calidad de vida de las poblaciones" y que es un "elemento clave del bienestar individual y social" y que para conseguir estos objetivos, la educación de los niños y de los jóvenes en el Paisaje, se convierte en un factor decisivo.

c) Contribución de la Educación en Paisaje a la formación inicial en Didáctica de las Ciencias sociales

Al realizar esta investigación creemos como responsables de la formación inicial en el campo de la didáctica de las Ciencias sociales, que la formación de los futuros maestros 
del Grado de Educación Infantil y Primaria puede experimentar una mejora sustantiva con la introducción del estudio del Paisaje en los contenidos de ambos grados.

Busquets afirma que "El concepto de educación en Paisaje va más allá de la presencia del Paisaje como un componente más del aprendizaje de la geografía y del currículo escolar porque le atribuye una dimensión ciudadana y ética" (2010, p. 378). La educación en Paisaje es educación en todos los niveles: intelectual, emocional y práctico. Implica el conocimiento, los sentimientos y las actividades favorecen el proceso educativo general y mejoran las potencialidades como persona. Además, no requiere de competencias específicas en una determinada asignatura. Lo ideal sería un equipo de profesores que alcancen un buen conocimiento del Paisaje, como concepto y de su valor educativo.

En la formación de profesores, para poner en marcha un proyecto se debe partir del enfoque del Paisaje que hace el Convenio Europeo del Paisaje. La formación de profesores se puede beneficiar profundamente de las experiencias directas con el Paisaje y en el Paisaje porque están implicados personalmente. El informe Education on Landscape for Children sugiere que sería interesante conseguir la implicación de la educación superior y la Universidad, porque son los responsables de la formación de los futuros profesores y porque la capacidad de leer el Paisaje fomenta el desarrollo cultural en los estudios tanto científicos como humanísticos. Uno de los objetivos que pretendemos con este estudio es que los maestros en formación adquieran competencias acordes con sus niveles formativos, en base a la importancia atribuida al Paisaje para aprehenderlo como un componente básico de una sociedad consciente de sus derechos e identidades; para en un futuro transmitirlo a sus alumnos/as de primaria e infantil. El Paisaje puede ser un componente fundamental de una vida de mejor calidad como señalan Domínguez y López Facal, (2014).

d) Contribución a la formación permanente de docentes y ciudadanos

Una finalidad del Convenio Europeo del Paisaje es sensibilizar a la población sobre los aspectos y cuestiones relacionados con el Paisaje. En la actualidad, el hecho de no saber ver el Paisaje causa grandes prejuicios, precisamente porque todo aquello que no es percibido no existe. En este trabajo de sensibilización paisajística se tendría que implicar a toda la ciudadanía, independientemente de su edad. Pero sobre todo es fundamental la educación en ese proceso de sensibilización en el Paisaje, porque sirve para incentivar la adquisición de conocimientos y la adopción de valores y de actitudes. 
En este proceso es necesaria la participación de los educadores que además de dominar los recursos pedagógicos y didácticos, tienen que conocer el concepto de Paisaje promovido por el Convenio Europeo del Paisaje. La escuela es el gran espacio de la educación, por tanto debe serlo del Paisaje. No es posible una sensibilización efectiva del conjunto de la población que no esté fundamentada en la educación formal, porque los aprendizajes y vivencias que se hacen en la escuela dejan una huella efectiva y duradera.

Consideramos que para conseguir este proceso de sensibilización en la escuela es decisiva la labor del profesorado en la formación de los futuros maestros en educación Primaria e Infantil, incluso en Secundaria; puesto que estos profesionales serán los encargados del proceso de enseñanza y aprendizaje a las nuevas generaciones a través del dominio de competencias que permitan lograr un pleno desarrollo de la personalidad y convertirse así en personas responsables, autónomas y capaces.

\section{Representaciones sobre el Paisaje de los alumnos de los Grados de Educación Infantil y Primaria.}

En el desarrollo de esta investigación, hemos intentado conocer las representaciones de los futuros maestros/as de Educación Primaria e Infantil de la Facultad de Educación de la Universidad de Salamanca sobre el Paisaje, identificando y analizando sus ideas, conocimientos, percepciones y valoraciones.

Las conclusiones que se exponen a continuación son el resultado de los diversos análisis realizados a lo largo de esta investigación al alumnado de maestro en educación Primaria e Infantil y que nos permiten reflexionar sobre los cuatro elementos nucleares detectados en la investigación: qué conocimientos tienen los encuestados del Paisaje, cuál es su valoración del mismo, qué utilidad le reconocen y cuál es su importancia como recurso educativo. Teniendo en cuenta qué diferencias y características individuales y en grupo presentan los alumnos de los Grados de Maestro, en sus representaciones sobre el Paisaje, así como qué papel juegan los aspectos y contextos culturales y sociales en el aprendizaje del Paisaje.

A partir de los datos recogidos mediante los instrumentos diseñados en la investigación permiten destacar las siguientes conclusiones:

a) Qué, cómo y dónde aprendieron qué es el Paisaje

La valoración del Paisaje que hace el alumnado encuestado es elevada, ya que tienen una media próxima a 4,2 siendo 5 la máxima puntuación. Esta valoración puede deberse 
a varios motivos: una que se vean influidos por la reciente percepción social positiva de los Paisajes y otra por el interés que le ha suscitado este estudio. No se aprecian diferencias entre los alumnos/as de la especialidad de Primaria e Infantil ni tampoco entre el alumnado de la primera Etapa ( $1^{\circ}$ y $2^{\circ}$ curso) y los de la segunda Etapa ( $3^{\circ}$ y $4^{\circ}$ curso). La valoración del Paisaje es mayor en los alumnos de procedencia rural, tanto por ser el lugar de nacimiento como por ser el ámbito dónde han cursado sus estudios anteriores; también es mayor en los procedentes de otras comunidades.

Los conocimientos que tiene el alumnado sobre el Paisaje al llegar a la Facultad de Educación han sido adquiridos por diversas procedencias. En casi todos los casos la obtención de esos conocimientos fue durante la etapa de la Educación Secundaria Obligatoria, a excepción del alumnado de la especialidad de Infantil que han cursado sus estudios en el ámbito rural, quiénes afirman haberlos adquirido durante su etapa de Primaria. El principal motivo puede ser que al vivir en el ámbito rural, estos alumnos/as han estado más en contacto con los Paisajes. Es llamativa la escasísima elección de la Formación Profesional, aunque hay un número elevado del alumnado que ha cursado esos estudios. Es también notable la importancia que el alumnado le concede a la familia, sobre todo reflejado en los alumnos/as de primero y del ámbito rural. De esta manera constatamos la idea de que los ámbitos donde han adquirido de una forma importante los conocimientos se corresponden con el familiar y el escolar. Los viajes también son considerados por la mayoría de participantes una fuente importante de conocimiento del Paisaje, sobre todo en el alumnado de los cursos superiores y del ámbito urbano. Después de estos, son las películas y documentales, seguidos de lejos por internet, las principales fuentes de conocimiento del Paisaje.

Los recuerdos que mencionan sobre el Paisaje se decantan mayoritariamente por los conocimientos relacionados con las características y tipos de Paisajes. Se trata de una respuesta en la que el protagonismo recae en los estudios de secundaria y después en otros niveles, siendo así de carácter académico. Le siguen, por este orden, la preocupación por el Paisaje, que se centra en los comportamientos de conservación y mejora, y en tercer lugar la concienciación. Ahora bien, en la respuesta de los alumnos más avanzados aumenta significativamente el nivel de concienciación en relación con los alumnos que están en los primeros cursos. Los recursos didácticos que recuerdan que utilizaron sus maestros para trabajar el Paisaje fueron en primer lugar los libros, instrumento preferido por el profesorado, seguido de los mapas y de los audiovisuales en segundo plano. 
Resumiendo las impresiones sobre qué, cómo y dónde aprendieron lo que saben del Paisaje los alumnos/as del Grado de Maestro en Educación Infantil y Primaria concluimos afirmando que los conocimientos de los encuestados se ajustan a los niveles educativos y a los recursos didácticos más habituales; en cambio los que proceden de la experiencia son más personales, donde familia, viajes y medios de comunicación tienen un papel relevante. Entre unos y otros están el campo de la conciencia y el comportamiento, allí donde la impregnación de valores ha contribuido a preparar a este alumnado para su función docente futura. Pero la encuesta también revela que el conjunto de sus conocimientos no tenían por objeto ser comunicados, transmitidos, ni ser transformados en recursos.

\section{b) Sus conocimientos referidos al Paisaje}

Este estudio revela que los conocimientos sobre el Paisaje del alumnado de maestro en Educación Infantil y Primaria se centran en los aspectos naturales del Paisaje. En concreto, en relación con la definición del concepto de Paisaje, observamos que el alumnado de Grado en su mayoría asimila dicho concepto con Naturaleza en la especialidad de Infantil y Medio físico en Primaria, junto con el Medio Ambiente en ambas especialidades; es decir, se decantan por un concepto medioambiental del Paisaje. Sin embargo, cuando se les pide que elijan, dan prioridad a los enunciados de carácter histórico y geográfico, e inmediatamente después a los medioambientales y turísticos.

A través del cuestionario los aspectos estéticos se desvelan, aunque los relegan con relación a lo cultural. Los aspectos políticos se consideran poco importantes. Ahora bien, esto concuerda con lo que hasta ahora sabemos, pues los aspectos medioambientales y geográficos son los que más incorporan a los aspectos naturales del Paisaje. Los alumnos/as no tienen claro el concepto de Paisaje. Sin embargo, precisan más cuando manifiestan las ideas que le sugiere dicho concepto, haciendo alusiones a la conciencia, y aflorando en concreto los valores estéticos y estados de ánimo, aspectos subjetivos de la percepción. Es importante señalar que esto se da con mayor frecuencia entre el alumnado de los primeros cursos y sobre todo procedente del ámbito rural.

c) El valor educativo del Paisaje

El carácter de la valoración que tienen del Paisaje los alumnos/as del grado de maestro en Educación Primaria e Infantil refleja que los encuestados le conceden un valor alto, consecuencia en primer lugar de su formación académica anterior y después de su experiencia personal, aunque también manifiestan tener conciencia de su importancia. 
De la integración de conocimientos, valoración y conciencia surge un concepto de Paisaje muy cercano a los aspectos medioambientales-geográficos e históricoculturales, y como algo que nos viene dado y en lo cual la intervención humana tiene un carácter accesorio.

Los alumnos/as consideran que sus conocimientos del Paisaje son insuficientes y dudan de su utilidad a no ser para su conservación y mejora. Sin embargo consideran que los conocimientos del Paisaje son muy interesantes y necesarios e importantes para el desarrollo de la vida, pero muy poco para aumentar sus conocimientos. Además consideran que los conocimientos de los futuros profesores deben ser sobre todo los relacionados con los aspectos naturales del Paisaje, seguidas del comportamiento, dirigidos a su conservación y mejora, lo que corrobora el sentido de utilidad de los conocimientos para la conservación del medio.

Es notable el interés que los alumnos/as del Grado manifiestan sobre valores y sensibilidad, así como sobre la concienciación que deben tener los futuros profesores. La mayoría de los encuestados, en torno a un 70\%, valoran el carácter didáctico de los conocimientos, lo cual nos ha permitido concretar la categoría de recursos, y su matiz didáctico "Aprender para transmitir".

De acuerdo con las afirmaciones analizadas sobre dónde han sido adquiridos los conocimientos sobre el Paisaje, las que se juzgan como mejores respuestas están en el terreno de la enseñanza reglada y en las variadas formas de la imagen en posición subsidiaria, bien directa o bien a través de los medios. Los participantes manifiestan así que la enseñanza reglada les proporciona las claves necesarias para comprender y conocer los Paisajes.

Las respuestas sobre cómo le enseñaron el Paisaje sus maestros revelan un conocimiento esencialmente de naturaleza geográfica, aunque no se debe olvidar esa otra faceta del conocimiento cotidiano, en relación con las personas del propio entorno y con los medios y las tecnologías de las que disponen habitualmente. El conocimiento geográfico y el cotidiano pueden no obstante contener aspectos distintos, que se manifiestan en la valoración que tienen los participantes del Paisaje desde diversas perspectivas.

En los valores paisajísticos se decantan por el medioambiental, que relacionan con la biodiversidad, los espacios naturales o la contaminación, y cuando se pasa de la valoración a aspectos más prácticos, la valoración que implica a acciones concretas se basa de nuevo en la importancia de los conocimientos adquiridos, en los conocimientos 
que el Paisaje proporciona, para promover actuaciones educativas y de participación ciudadana. La encuesta revela que estos estudiantes universitarios están abiertos a la integración de sus conocimientos para actuar de acuerdo a sus convicciones.

Dentro de estos conocimientos se detecta una carencia o bien un rechazo de los aspectos políticos y de lo que con ellos se relaciona, especialmente de la faceta más económica del Paisaje, que solo se valoran claramente cuando no la vinculan a la política, aunque la confianza en las instituciones europeas represente la excepción.

La valoración del Paisaje depende de los conocimientos adquiridos junto con las apreciaciones personales de los sujetos encuestados, revelando así la faceta emocional. Nada tiene de extraño que manifiesten valorar el Paisaje en un alto grado, la propia encuesta les inclina a ello, por lo que hay que buscar en diversas cuestiones la naturaleza y el origen de su valoración. No es primordialmente estética, no han considerado el Paisaje como espectáculo, en lo cual interviene claramente su formación. Lo valoran mucho más por lo que encierra y enseña, y por lo que pueden enseñar ellos con y desde el Paisaje, así como por lo que puede significar para mejorar la sociedad.

La utilidad de los conocimientos se concibe primordialmente como un medio para la actuación en la conservación y mejora. No se aprecia que, por su iniciativa, consideren a los Paisajes como recurso didáctico y como objeto de estudio específico.

Finalmente, no identifican espontáneamente al Paisaje como recurso didáctico y como objeto de estudio. Solo lo hacen cuando en la última pregunta se hace una valoración implícita del Paisaje como recurso educativo, al poner en el primer lugar de las respuestas a la educación.

\section{Orientaciones sobre la práctica educativa de Educación en Paisaje}

Comenzábamos diciendo que en el desarrollo de esta investigación, hemos intentado conocer las representaciones de los futuros maestros/as de Educación Primaria e Infantil de la Facultad de Educación de la Universidad de Salamanca sobre el Paisaje, identificando y analizando sus ideas, conocimientos, percepciones y valoraciones. La finalidad era proponer a los futuros docentes, especialistas del área de Didáctica de las

Ciencias Sociales, la construcción del conocimiento profesional favoreciendo la Educación en Paisaje, para mejorar la enseñanza y el aprendizaje de las Ciencias Sociales en la formación de los futuros docentes.

Las siguientes propuestas didácticas sobre Educación en Paisaje dentro de la Formación Inicial de Maestros se basan en integrar conocimientos referidos al Paisaje 
dentro de los contenidos y objetivos de la formación en Ciencias Sociales de los maestros de E. Infantil y E. Primaria, de acuerdo con las competencias que son exigibles en cada una de estas titulaciones.

a) La formación del profesorado, la clave para los cambios en Educación en Paisaje

La oportunidad de las propuestas en este sentido se sustenta en las competencias que deben adquirir estos titulados, en su formación previa sobre el tema, y en el interés social del mismo.

El interés social de la Educación en Paisaje viene siendo propiciado desde múltiples instituciones, y expresado fundamentalmente en el Convenio Europeo del Paisaje, que además impulsa y favorece iniciativas como la presente.

Con respecto a su educación anterior sobre el Paisaje, los estudios previos les proporcionan conocimientos básicos y una formación teórica suficientes que les permiten progresar en nuevos aprendizajes. A ello se une que estos estudiantes tienen una conciencia medioambiental que se expresa en múltiples formas, que es imprescindible para su progreso posterior, y para su asociación a comportamientos deseables en cuanto al aprendizaje y a la acción profesional.

Por lo que se refiere a las competencias a alcanzar en las titulaciones de maestro, además de la Competencia Básica 2 del Marco Español de Calificaciones para la Educación Superior (MECES) que exige que los estudiantes sepan aplicar sus conocimientos a su trabajo de una forma profesional, y las Competencias Clave para el Aprendizaje Permanente en el marco de referencia europeo "Aprender a aprender", "Competencias sociales y cívicas" y "Conciencia y la expresión culturales", se exige específicamente a los maestros alcanzar las siguientes:

Una competencia de Formación Básica común a las titulaciones de E. I. y E. P. (Órdenes ECl/3854/2007 y ECl/3857/2007) puede contribuir notablemente a progresar en las Ciencias Sociales tanto en El como en EP: "Analizar e incorporar de forma crítica las cuestiones más relevantes de la sociedad actual que afectan a la educación familiar y escolar: impacto social y educativo de los lenguajes audiovisuales y de las pantallas; cambios en las relaciones de género e intergeneracionales; multiculturalidad e interculturalidad; discriminación e inclusión social y desarrollo sostenible”.

En E. I. se deben alcanzar, entre otras, el conocimiento de la trascendencia social y cultural de algunos acontecimientos y etapas de la historia, y el conocimiento, el interés y el respeto del medio social y cultural y los recursos educativos que proporciona. 
En E. P. los estudios deben conducir, entre otras, a "-Integrar el estudio histórico y geográfico desde una orientación instructiva y cultural.- Fomentar la educación democrática de la ciudadanía y la práctica del pensamiento social crítico.- Valorar la relevancia de las instituciones públicas y privadas para la convivencia pacífica entre los pueblos."

Estas competencias concretas pueden ser desarrolladas por medio de la integración de la Educación en Paisaje dentro de los contenidos y objetivos de la formación en Ciencias Sociales de los maestros de E. Infantil y E. Primaria.

b) Características que debe reunir una propuesta didáctica de Educación en Paisaje

Cualquier propuesta en este sentido debe constituir al mismo tiempo un modelo de autoaprendizaje personal y profesional.

Los estudiantes de los Grados de maestro en sus anteriores estudios han recibido una formación en Historia, en Geografía y en las bases de otras Ciencias Sociales que les permite conocer y analizar su mundo, reflexionar sobre los acontecimientos del presente y del pasado, estudiar los fenómenos sociales, económicos o políticos, mantenerse informados y tener opinión al respecto, actuar en su mundo desde su trabajo, su ocio, sus obligaciones o sus inclinaciones como persona. Esta formación que les permite desarrollarse como persona es también indispensable para su conocimiento profesional como docente.

Estos estudiantes poseen conocimientos de Ciencias Sociales, pero no los han utilizado con otra finalidad que la de obtener una calificación académica, nunca con un fin práctico o profesional concreto. Sus aprendizajes previos no son funcionales, pues con los conocimientos que poseen no son capaces de hacer frente a las nuevas situaciones en las que se van a encontrar en las aulas. Esta es la faceta de su formación que concierne a la Didáctica de las Ciencias Sociales: poner en marcha un aprendizaje nuevo y autoconstructivo, en el que el aprendiz de maestro sea protagonista activo del proceso de reestructuración de sus conocimientos de Ciencias Sociales para dotarles de la funcionalidad que precisa su futura profesión.

Cualquier propuesta para la formación de maestros en Enseñanza y Aprendizaje de Ciencias Sociales debe partir de la convicción de que los estudios del Grado no deben intentar repetir los currículos que ya han sido superados por los alumnos con anterioridad. La elección de objetivos y contenidos adecuados de la propuesta se deben acomodar a las competencias que la norma legal establece: 
-En Educación Primaria, comprender los principios básicos de las ciencias sociales, conocer el currículo escolar de las ciencias sociales, integrar el estudio histórico y geográfico desde una orientación instructiva y cultural, fomentar la educación democrática de la ciudadanía y la práctica del pensamiento social crítico y valorar la relevancia de las instituciones públicas y privadas para la convivencia pacífica entre los pueblos.

- En Educación Infantil adquirir conocimientos sobre la evolución del pensamiento, las costumbres, las creencias y los movimientos sociales y políticos a lo largo de la historia, conocer los momentos más sobresalientes de la historia de las ciencias y las técnicas y su trascendencia y promover el interés y el respeto por el medio natural, social y cultural a través de proyectos didácticos adecuados.

Son competencias que se pueden desarrollar con contenidos y objetivos muy diversos, y esta propuesta sostiene que, al menos una parte de esa formación, puede hacerse desde la Educación en Paisaje.

\section{c) Finalidades y contenidos}

Para integrar la Educación en Paisaje dentro de los contenidos y objetivos de la formación en Ciencias Sociales de los maestros de E. Infantil y E. Primaria, una posibilidad consiste en programar una unidad de trabajo sobre el Paisaje, que integre el estudio de aspectos geográficos e históricos desde una orientación instructiva y cultural, pero también social y política, crítica y democrática, y que incluya aspectos científicos y tecnológicos. Debe impulsar la capacidad para leer e interpretar los Paisajes, diagnosticar sus problemas y valorar sus potencialidades, y reconocerlos como un recurso didáctico indispensable en las escuelas.

Las intenciones que delimiten esta propuesta se pueden concretar en los siguientes objetivos:

- Analizar las características geográficas de los Paisajes naturales, rurales y urbanos de España.

- Comprender los elementos socioeconómicos, culturales y de cambio histórico que revelan los Paisajes y respetar y apreciar las aportaciones de las diferentes sociedades y culturas pasadas o presentes.

- Reconocer a través de los Paisajes los problemas ambientales que afectan a los territorios y reflexionar críticamente sobre actuaciones pasadas o presentes. Apreciar las posibilidades de acción que entrañan. 
- Interesarse por los conocimientos científicos y avances tecnológicos que se llevan a cabo en torno a los Paisajes.

- Valorar la responsabilidad individual y colectiva en la preservación de los Paisajes como cuestión de relevancia social actual.

- Indagar sobre iniciativas públicas o privadas destinadas a la protección de los Paisajes. Las finalidades mencionadas deberían confluir en el diseño de una propuesta curricular sobre el Paisaje en Educación Infantil o Primaria que debería tener en cuenta los siguientes aspectos:

- Los contenidos mínimos deben abarcan: lectura del Paisaje, escalas y representaciones; Paisajes españoles; iniciativas sobre los Paisajes y propuestas curriculares.

- Las actividades se pueden adaptar a los diversos grupos de alumnos, pero siempre deben contener una parte en que el profesor presenta el modelo de trabajo, guiando a los alumnos en el necesario proceso de reflexión, y otra en que los alumnos realizan una investigación activa y una propuesta de carácter didáctico y profesional, que presentan y someten a sus compañeros para implicarles en la acción personal responsable.

- La dedicación en tiempo depende de la especialidad. En Educación Primaria, en el caso más ambicioso, podría ocupar hasta el 100\% de una asignatura de 6 créditos, procurando a través de ella toda la formación requerida.

La Educación en el Paisaje es un reto ineludible en la formación de los niños y niñas del siglo XXI. Esta investigación ha supuesto un primer punto de partida de cómo construir conocimientos necesarios en la formación de los futuros docentes para que puedan implementar en sus aulas una enseñanza del Paisaje más profunda, analítica, constructiva y social. De este modo, estaremos contribuyendo a crear futuros docentes que sepan transmitir a sus alumnos, no solo una mejor y mayor capacidad de percepción del Paisaje como construcción natural y/o social, sino que favorezcan la formación de ciudadanos más sensibilizados y comprometidos con el desarrollo sostenible de nuestra sociedad.

Esta es, por tanto, una declaración de esperanza, abierta a nuevos modelos de formación, que culminen así la investigación a la que se ha dedicado esta tesis. 


\section{BIBLIOGRAFÍA}

Aguiló Alonso et al. (1992): Guía para la elaboración de estudios del medio físico: Contenido y metodología. Ministerio de Obras Públicas y Transportes. Dir. Gral Política ambiental.

Aguiló Alonso, A. (2011): La educación en Paisaje a través del patrimonio literario. En Nogué, J.; Puigbert, L.; Bretcha, G.; Losantos, À (eds.): Paisatge i educació. Olot: Observatorio del Paisaje de Cataluña; Barcelona: Departamento de Enseñanza de la Generalitat de Cataluña, pp. 252-264.

Aisenberg, B.; Alderoqui, S. (comps.) (1994): Didáctica de las Ciencias Sociales, Aportes y reflexiones, Ed. Paidós Educador, Argentina.

Alfageme, M. B., Díaz Serrano, J. y Serrano, F.J. (2013): La Identidad profesional de los docentes en formación de Ciencias Sociales. Autores: José Díaz Serrano. Enseñanza de las Ciencias Sociales: revista de investigación, nº 12, pp. 77-89.

Alvarez Orellana, M. F. (2008): Fotografía, geografía y Formación del Profesorado. Investigación en la Escuela, nº 60, pp. 79-91.

Aramburu, F. (2000): Educación medioambiental. Madrid. Editorial Síntesis.

Aranda Hernando, A. M $M^{a}$ y Bajo Bajo, $M^{a}$ J. (2003): Paisajes culturales y otros nuevos conceptos con potencialidad educativa. En Ballesteros Arranz, E.; Fernández Fernández, C.: Molina Ruiz, J. A. y Moreno Benito, P. (coord.) El Patrimonio y la Didáctica de las Ciencias Sociales. Ed: Universidad de Castilla-La Mancha, y Asociación Universitaria de Profesores de Didáctica de las Ciencias Sociales, pp. 245-252.

Aranda Hernando, A. Ma . (2003): Didáctica del Conocimiento del Medio social y Cultural en Educación Infantil. Madrid. Editorial Síntesis.

Aranda Hernando, A. Ma (2016): Didáctica de las ciencias sociales en Educación Infantil. Madrid. Editorial Síntesis.

Arqué i Bertran, M. T. (2004): La Imatge visual en la didàctica de les Ciències Socials. Tractament didàctic de la imatge en els cicles mitjà i superior de l'Educació Primària. UAB Tesis Doctoral en Red, último acceso 0207 2016 http://www.tesisenred.net/handle/10803/1333

Arroyo llera, F. y Martín Lou, Ma A. (2010): Los estudios sobre Paisaje. Estudios Geográficos (1940-2009), no 71, pp. 659-675. 
Bajo Bajo, Ma Jesús (2001): El Paisaje en el curriculum de Educación Primaria dentro del Área del Conocimiento del Medio Natural, Social y Cultural. Revista Aula, nº 13, pp. 51-61.

Bailey, P. y Fox, P. (ed.): (1997): Geography teachers' handbook. Sheffield: The Geographical Association.

Barton, K. C. (2006): Introduction. Barton, K.C.(ed.). Research Methods in Social Studies Education. Comtemporary Issues and Perspectives. A volume in Research in Social Education. Greenwich: Information Age Publishing.

Barton, K. C. (2008): Research on students' ideas about history. Levstik, L.S.; Tyson, C.A. (Eds.). Handbook of Research in Social Education. New York: Routledge, pp. 239-257.

Bas Pedroli (2011): El Paisaje en la educación superior en Europa: aprendiendo del Paisaje. En Nogué, J.; Puigbert, L.; Bretcha, G.; Losantos, À (eds.): Paisatge $i$ educació. Olot: Observatorio del Paisaje de Cataluña; Barcelona: Departamento de Enseñanza de la Generalitat de Cataluña, pp. 89-99.

Bastie, J.\& Dezert, B.(1980): L’espace urbaine. Paris. Persèe.

Batllori, R. y Serra, J.M. (2010): El proyecto "Ciutat, territori, paisatge": un recurso innovador para la educación del Paisaje en la enseñanza secundaria. Revista Iber. Monografía: El Paisaje en la educación, nº 65. pp. 17-26.

Benayas, J. (1992): Paisaje y Educación Ambiental .Evaluación de cambios de actitudes hacia el entorno. Madrid. Ministerio de Obras Públicas y Transporte.

Benayas, J; Heras, F.; Vicente, J.; Marcén, C.; Pino, E. y Pedro, J. (1994): Viviendo el Paisaje. Guía didáctica para interpretar y actuar sobre el Paisaje. Madrid: Fundación NatWest, Fundación para la Investigación y el Desarrollo Ambiental.

Benayas del Álamo, J. y López Santiago, C. (2010): Propuesta didáctica para vivir el Paisaje. Revista Iber. Monografía: El Paisaje en la educación. Nº65, pp. 56-65.

Bianchi Parraguez, R. (2015): El Paisaje integrado, elemento central de acción didáctica en la enseñanza de la geografía. El caso de Chile. Tesis doctoral. Último acceso el 02-072016 http://www.tdx.cat/handle/10803/71/browse?value=Bianchi+Parraguez\%2C+Ros ser\&type=author

Bokhemühl, L. (2011): Academia Europea para la Cultura del Paisaje Petrarca. En Nogué, J.; Puigbert, L.; Bretcha, G.; Losantos, À (eds.): En Paisatge i educació. Olot: 
Observatorio del Paisaje de Cataluña; Barcelona: Departamento de Enseñanza de la Generalitat de Cataluña. pp. 296-307

Bolòs, M., Bovet, M.T., Estruch, X., Pena, R., Ribas, J. y Soler, J. (1992): Manual de Ciencia del Paisaje. Paris. Ed. Masson.

Bovet Pla, M. del. T; Pena Vila, R. y Ribas Vilás, J. (2004): El Paisaje como recurso educativo en el marco de la educación para la participación. Didáctica Geográfica, 2. ${ }^{a}$ época nº 6, pp. 33-48

Bovet Pla, M. del. T, y Pena Vila, R. (2010): « Paisaje», un recurso didáctico en el ámbito de las nuevas tecnologías. Revista Iber Monografía: El Paisaje en la educación no 65 , pp. 35-43.

Bratina Jurkovic, N. (2011): Nosotros Hacemos Nuestro Paisaje: un proyecto educativo y de sensibilización. En Nogué, J.; Puigbert, L.; Bretcha, G.; Losantos, À (eds.): Paisatge i educació. Olot: Observatorio del Paisaje de Cataluña; Barcelona: Departamento de Enseñanza de la Generalitat de Cataluña. pp. 308-317.

Brinckerhoff Jackson, J. (2010): Descubriendo el Paisaje autóctono. Madrid. Biblioteca Nueva.

Burel, F. Y Baudry, J. (2002): Ecología del Paisaje. Concepto, métodos y aplicaciones. Madrid: Mundi-Prensa.

Busquets, J. (1996): La lectura visual del Paisaje. Bases para una metodología. En Métodos y técnicas de la didáctica de la geografía. Revista Iber, Didáctica de las Ciencias Sociales, Geografía e Historia, nº 9, pp. 53-59.

Busquets i Fàbregas, J. (2001): El Paisaje: Patrimonio en mutación y recursos didácticos formativos en el ámbito europeo. Temps d' Educació. nº 26, pp. 45-52.

Busquets Fàbregas, J. (2010): La educación en Paisaje: una oportunidad para la escuela. Revista Iber. Monografía: El Paisaje en la educación. nº 65, pp. 7-16.

Busquets i Fàbregas, J. (Dir. y coord.) (2011) Guía: Sensibilización en Paisaje: un reto para el siglo XXI. Barcelona. Ed. Generalitat de Catalunya

Busquets i Fàbregas, J. (2011): La importancia de la educación en Paisaje En Nogué, J.; Puigbert, L.; Bretcha, G.; Losantos, À (eds.): Paisatge i educació. Olot: Observatorio del Paisaje de Cataluña; Barcelona: Departamento de Enseñanza de la Generalitat de Cataluña. pp. 69-88. 
Cabero, V.; García L. V.; Martínez De Pisón, E.; Muñoz, J.; Ortega, N.; Sanz, C.; Troitiño, M.A. y Zoido, F. (1998): Paisaje y medio ambiente. Salamanca: Fundación Duques de Soria, Endesa y Universidad de Valladolid.

Cabrera Millet, M. (2002): El Paisaje como recurso didáctico en educación ambiental. Temas De Antropología Aragonesa. no 12, pp. 79-98.

Cancer, L. A. (1999): La degradación y la protección del Paisaje. Madrid: Cátedra.

Cañal, P; García, J. y Porlán, R. (1982): Ecología y Paisaje. Barcelona. Laia

Cañal, P; Criado, A. M. García-Carmona, A.; Muñoz-Franco, G. (2013): La enseñanza relativa al medio en las aulas españolas de Educación Infantil y Primaria: concepciones didácticas y práctica docente. Investigación en la Escuela nº 81 , pp. 21-42.

Cappelletti, G. (coord.) (2008). Geografia. Relaciones entre estados: el caso de las planatas de celulosa en Fray Bentos. Ministerio de Educación. Dirección General de Planeamiento Educativo. Madrid

Carretero, M. Pozo, J. I. y Asensio, M. (Compiladores) (1989): La enseñanza de las Ciencias Sociales. Aprendizajes Visor. Madrid.

Casares, R. (2009): Educación y sociedad: Una perspectiva sobre las relaciones entre la escuela y el entorno social ICE, Universitat de Barcelona.

Castiglioni, B. (2010): La experiencia educativa en el Paisaje: el proyecto 3KCL. Revista Iber. Monografía: El Paisaje en la educación. nº 65 pp. 44-55

Castiglioni, B. (2011): La educación en Paisaje desde la óptica del Convenio Europeo del Paisaje. En Nogué, J.; Puigbert, L.; Bretcha, G.; Losantos, À (eds.): Paisatge $i$ educació. Olot: Observatorio del Paisaje de Cataluña; Barcelona: Departamento de Enseñanza de la Generalitat de Cataluña, pp. 153-167.

Comes, P. (1998): El espacio en la Didáctica de las Ciencias Sociales. En Trepat, C.A. y Comes, P.: El tiempo y el espacio en la Didáctica de las Ciencias Sociales Barcelona. Ed. Graó.

Consejo de Europa (2000) Convenio Europeo del Paisaje. Último acceso el 30/06/2016 http://www.magrama.gob.es/en/desarrollo-rural/temas/desarrolloterritorial/convenio.aspx

Conseil de l'Europe. (2016) La Convention européenne du paysage. Último acceso el 30/06/2016 http://www.coe.int/fr/web/landscape/home 
Conseil de l'Europe. Comité des Ministres. (2014) Recommandation CM/Rec(2014)8 du Comité des Ministres aux Etats membres sur la promotion de la sensibilisation au paysage par l'éducation. último acceso 30/06/2016 http://www.coe.int/fr/web/landscape/reference-texts

Conseil de l'Europe. (2016): L'Alliance du Prix du paysage du Conseil de l'Europe. Série Aménagement du territoire européen et paysage 2016, 103 Último acceso el 30/06/2016 https://rm.coe.int/CoERMPublicCommonSearchServices/DisplayDC $\underline{\text { TMContent?documentld }=09000016806530 \mathrm{c5}}$

Consejo de Europa (2016): Premio Europeo del Paisaje del Consejo de Europa. Último acceso el 02/07/2016 en http://www.mecd.gob.es/cultura-mecd/areascultura/patrimonio/premios/premios- Paisajes/presentacion.html

Corbera Millán, M. (2014): Ciencia, naturaleza y Paisaje en Alexander von Humboldt. Boletín de la Asociación de Geógrafos Españoles nº 64, pp. 37-64

Coromines, J. A. y Pascual, J. A. (1980-1991): Diccionario crítico etimológico castellano e hispánico. Madrid. Gredos. (6)

Cosgrove, D (2002): Observando la naturaleza: el Paisaje y el sentido europeo de la vista. Boletín de la Asociación de Geógrafos Españoles nº 34, pp. 63-89

Cuenca López, J. M. (2003): Análisis de concepciones sobre la enseñanza del patrimonio en la educación obligatoria. Enseñanza de las ciencias sociales: revista de investigación, $\mathrm{n}^{\circ}$ 2, pp. 37-46.

Cuenca, J. M. (2006): La enseñanza del medio en educación infantil. Ed. Universidad de Huelva.

Dalongeville, A. \& Huber, A. (2002) : Situations-problèmes pour enseigner la géographie au cycle 3. París: Hachette Education.

Déjeant-Pons, M. (2011): La educación en el Convenio Europeo del Paisaje. En Nogué, J.; Puigbert, L.; Bretcha, G.; Losantos, À (eds.): Paisatge i educació. Olot: Observatorio del Paisaje de Cataluña; Barcelona: Departamento de Enseñanza de la Generalitat de Cataluña. pp. 46-68.

Delgado Peña, J. J., y Rodrigo Comino, J. (2012): El trabajo de campo y las competencias geográficas en el estímulo para el estudio de la geografía: Aplicación en un aula de $2^{\circ}$ de bachillerato. Didáctica Geográfica, $n^{\circ}$ 13, pp. 35-56.

Deleplace, M. \& Noclot, D. (2005): L'aprentissage des concepts en histoire et en géographie. Enquete au collège et au lycée. Reims: IUFM Champagne Ardenne 
Del Tura Bovet, M.; Pena i Vila, M. R. (2010): "Paisaje", un recurso didáctico en el ámbito de las nuevas tecnologías. Revista Iber. Monografía: El Paisaje en la educación. no 65 , pp. 35-43.

Delval, J. (2012): Ciudadanía y escuela. El aprendizaje de la participación. En Educar para la participación ciudadana en la enseñanza de las Ciencias Sociales. Sevilla. Ed. AUPDCS y Diada Ed. Vol. I pp. 37-46

Díaz Serrano, J. Serrano Pastor, F. y Alfajeme González, M. B. (2013): Identidad profesional de los docentes en formación de las ciencias sociales. Revista Enseñanza de las Ciencias Sociales. $\mathrm{n}^{\circ}$ 12, pp. 77-89.

Domínguez Almansa, A. y López Facal, R. (2014): Patrimonio, Paisaje y educación: formación inicial del profesorado y educación cívica del alumnado de Primaria. En CLIO. History and History teaching. 40. http:/clio.rediris.es

Durán, X. (2009) Los indicadores del Paisaje en los medios de comunicación. En Nogué, J.; Puigbert, L. y Bretcha, G. (eds.) (2009). Indicadors de paisatge. Reptes $i$ perspectives. Olot: Observatorio del Paisaje de Cataluña; Barcelona: Obra Social de Caixa Catalunya. pp. 321-330

Eisner, E.W. (1998): El ojo ilustrado. Indagación cualitativa y mejora de la práctica educativa. Barcelona: Paidós.

Ermisher, G. (2011): Una visión humana del Paisaje. El papel de las ONG. En Nogué, J.; Puigbert, L.; Bretcha, G.; Losantos, À (eds.): Paisatge i educació. Olot: Observatorio del Paisaje de Cataluña; Barcelona: Departamento de Enseñanza de la Generalitat de Cataluña pp. 224-251.

Estepa, J. (1998): El conocimiento escolar en la formación inicial del profesorado de ciencias sociales" Investigación en la escuela. n 35, pp. 43-52.

Estepa Giménez, J.; Ávila Ruiz, R. M. y Ruiz Fernández, R. (2007): Concepciones sobre la enseñanza y difusión del patrimonio en las instituciones educativas y los centros de interpretación: estudio descriptivo. Enseñanza de las ciencias sociales: revista de investigación, $n^{\circ}$ 6, pp. 75-94.

Feliu, M. (2012): Conocer nuestro entorno nos ayuda a ser ciudadanos activos En Educar para la participación ciudadana en la enseñanza de las Ciencias Sociales. Sevilla. Ed. AUPDCS y Diada Ed. Vol. II pp. 313- 320

Ferreras, M.; Estepa, J. y Wamba, A.M. (2010): El patrimonio en el área de conocimiento del medio de educación Primaria. Análisis curricular" En 
Metodología de investigación en Didáctica de las Ciencias Sociales. Zaragoza Ed AUPDCS e Institución Fernando el Católico. pp. 293-301

Fidalgo, P. (2014): Aportaciones para la definición de elementos visuales determinantes del Paisaje. Cuaderno de Investigación urbanística. nº 92, pp. 5-83.

Fraile González, E. y Maya Frades, V (2015): Técnicas de investigación social. Salamanca. Solo Soluciones.

Franquesa, T. (Coord.): (1996): Guía de actividades para la educación ambiental. Madrid. Ministerio de Medio Ambiente.

García Ballesteros, A. (1998): La renovación conceptual de la Geografía y su papel en la educación en la era de la globalización, IV Jornadas de Didáctica de la Geografía, Educación y Geografía, Universidad de Alicante y A.G.E., pp. 15-46

García Lazo, C. (2014): El Paisaje en la educación Primaria. Un proyecto en venta de baños (Palencia) para el primer ciclo de EP. Último acceso 02-072016 https://uvadoc.uva.es/bitstream/10324/6955/1/TFG-L760.pdf

García de la Vega, A. (2004): El itinerario geográfico como recurso didáctico para la valoración del Paisaje. Didáctica Geográfica, Vol. 6 pp. 79-95.

García de la Vega, A. (2010): El desarrollo curricular del Paisaje a través de las áreas instrumentales. Convenio Europeo del Paisaje. CiDd: Congrés Internacional de Didáctiques. Último acceso 02-07-2016

http://www.udg.edu/portals/3/didactiques2010/guiacdii/ACABADES\%20FINALS/ 373.pdf

Garcia de la Vega, A. (2011): El Paisaje: un desafío curricular y didáctico. Revista Didácticas Especificas, $n^{\circ}$ 4, pp. 1-19.

García de la Vega, A. (2012): Un enfoque innovador en la didáctica del Paisaje: escenario y secuencia geográfica. En Miguel González, R. de; Lázaro y Torres, M. L. de y Marrón Gaite, M. J. (coord.) La educación geográfica digital. Zaragoza. Ed. Asociación de Geógrafos Españoles, Grupo de Didáctica de la Geografía (AGE): Universidad de Zaragoza pp. 455-470.

García de la Vega, A. (2012): El Paisaje: un desafío curricular y didáctico Didácticas Específicas, $n^{\circ} 14$, pp. 1-19

García de la Vega, Alfonso. (2014): Didáctica del Paisaje: Realidad y reto educativo. Aula Verde: Revista De Educación Ambiental, n² 42, pp. 8. 
García-Pérez, F. F. (2002): Concepciones de los alumnos y conocimiento escolar. Un estudio en el ámbito del medio urbano. Enseñanza de las ciencias sociales: revista de investigación, $n^{\circ}$ 1, pp. 17-26.

García Pérez, F. F. (2007): El conocimiento cotidiano como referente del conocimiento escolar. En Las competencias profesionales para la enseñanza-aprendizaje de las Ciencias Sociales ante el reto europeo y la globalización. Bilbao AUPDCS pp. 481-489.

García Pérez, F. F. (2010): La investigación en Didáctica de las Ciencias Sociales y la construcción del conocimiento profesional de los docentes En Metodología de investigación en Didáctica de las Ciencias Sociales Zaragoza Ed AUPDCS e Institución Fernando el Católico. pp. 399-417.

García Ruiz, A. L. (2000): La importancia de los itinerarios geográficos en la didáctica del Paisaje. El territorio y su imagen: ponencias y mesas redondas: XVI Congreso de geográfos españoles. pp. 257-245.

García Zarza, E. (1990): Los universitarios salmantinos hoy, 1989. En la Universidad de Salamanca II Docencia e Investigación. Universidad de Salamanca.

Gavaldà Torrents, A (Coord.) (2007): La fotografia històrica com a mitjà per aprendre. Tema de escola. Barcelona 2007

Gavaldà, A.; Pons, J. M. (2010): Prácticas con fotografías y documentos para abordar ciencias sociales con eficiencia. En: La innovación educativa en el contexto actual de la educación superior / A innovación educativa no contexto actual da educación superior. Vigo, Universidad de Vigo, p. 141-144.

Giolitto, P. (1984): Pedagogía del Medio Ambiente. Barcelona. Editorial Herder.

Giolitto, P. (1992): Enseigner la Géographie à l'école. París: Hachette

Gómez Ortiz, A. (1993): Reflexiones acerca del contenido "Paisaje" en los "currícula" de la Enseñanza Obligatoria. Revista Interuniversitaria de Formación del Profesorado, $n^{\circ}$ 16, pp. 231-240.

González Ortiz, J. L. (2000): Aportaciones didácticas para la observación e interpretación del Paisaje, una mirada desde el currículo de la educación secundaria obligatoria. El territorio y su imagen: ponencias y mesas redondas: XVI Congreso de geógrafos españoles. pp. 267-276.

Heras, F. (1989): El estudio de un Paisaje. Tres Cantos. Servicio de Educación y Juventud. Ayuntamiento de Madrid. 
Hernández Carretero, A. M⿳亠口冋. (2010): El valor del Paisaje cultural como estrategia didáctica. Tejuelo. nº 9, pp. 162-178.

Hernández Díaz, J. M. (1986): El sistema educativo liberal y la formación de maestros: origen y primer desarrollo de la Escuela Normal de Salamanca. (1842-1868) Revista Studia Historica. Historia contemporánea, $n^{\circ}$ 4, pp. 7-31.

Hernández Díaz, J. M. (1990): Aspectos sociales 2. La etapa contemporánea. En La Universidad de Salamanca II Docencia e Investigación. Universidad de Salamanca.

Herrero Fábregat, C. (2000): La formación profesional docente del Profesor de Geografía. Problemas actuales. En González Ortiz, J. M. y Marrón Gaite, M. J. (coords) Geografía, profesorado y sociedad: teoría y práctica de la geografía en la enseñanza. pp. 15-46.

Humboldt, A. de (1874-1875): Cosmos. Ensayo de una descripción física del mundo [1845-1862]. Vertido al castellano por Bernardo Giner y José de Fuentes. Madrid, Imprenta de Gaspar y Roig, Editores, 4 tomos.

Instituto Geográfico Nacional (2002): Imagen y Paisaje. Madrid: Instituto Geográfico Nacional/Centro Nacional de Información Geográfica, Ministerio de Fomento.

Iraola Mendizabal, I. (2012): Aproximar la educación geográfica y paisajística a partir de la motivación del profesor novel En La educación geográfica digital. Asociación de Geógrafos Españoles, Grupo de Didáctica de la Geografía (AGE): Universidad de Zaragoza pp. 485-494.

Jodelet, D. (2008): El Movimiento de retorno al sujeto y el enfoque de las representaciones sociales. Cultura y representaciones sociales Año 3, no 5 Último acceso 30-062016 http://www.culturayrs.org.mx/revista/num5/Jodelet.html

Johnston, M. (2006). the lamp and the mirror: Action research and self-studies in the social studies. In K. C. Barton (Ed.), Research methods in social studies education: Contemporary issues and perspectives Greenwich, CT: Information Age Publishing pp. 57-83.

Lacasta Reoyo, P. (1999): Los esquemas de Paisaje como aplicación didáctica. Didáctica Geográfica, $n^{\circ}$ 3, pp. 55-83.

Latasa Zaballos, I. y Navarro Arana, E. (2000) La didáctica de las técnicas cuantitativas en geografía: una investigación olvidada que es preciso retomar. En González Ortiz, Jo. L. y Marrón Gaite. M. J. (coord.) Geografía, profesorado y sociedad: teoría y práctica de la geografía en la enseñanza. pp. 389-396 
Lautier, N. ; Allieu-Mary, N. (2008): La didactique de l'histoire. Revue Française de Pédagogie, $n^{\circ} 162$, pp. 95-131.

Laville, C. \& Johnston, M. (2006): The lamp and the mirror. Actin Research and Self Studies in the Social Studies. In Barton, Keith C. (ed.): Research Methods in Social Studies Education. Comtemporary Issues and Perspectives. A volume in Research in Social Education. Greenwich. Information Age Publishing, pp. 5783.

Liceras Ruiz, Á. (1997): Dificultades en el aprendizaje de las Ciencias Sociales. Una perspectiva psicodidáctica. Granada. Grupo Editorial Universitario, Universidad de Granada.

Liceras Ruiz, Á. (2003): Observar e interpretar el Paisaje. Estrategias didácticas. Granada: Grupo Editorial Universitario.

Liceras Ruiz, Á. (2013): Didáctica del Paisaje. Lo que es, lo que representa, como se vive. En Desarrollo de las competencias desde la enseñanza de la geografía / Ciencias sociales y competencias básicas Revista Iber, Didáctica de las Ciencias Sociales, Geografía e Historia, nº 74, pp. 85-93.

López Facal, Ramón (2015): La LOMCE y la enseñanza de las Ciencias Sociales. Revista Iber. Didáctica de las Ciencias Sociales, $n^{\circ} 79$, pp. 5-7.

López Torres, E. (2009): Europa en la ESO: concepto, sentimiento y realidad ante el proyecto unificador. Un estudio a través de los centros vallisoletanos. Enseñanza de las ciencias sociales: revista de investigación, nº 8, pp. 55-66

Luginbühl, Y. (2009) Indicadores del Paisaje En Nogué, J.; Puigbert, L. y Bretcha, G. (eds.) (2009). Indicadors de paisatge. Reptes i perspectives. Olot: Observatorio del Paisaje de Cataluña; Barcelona: Obra Social de Caixa Catalunya. pp. 49-76.

Luis Gómez, A. (1980): El geógrafo español ¿aprendiz de brujo? Algunos problemas de la geografía del Paisaje. Geocrítica Año V. n ${ }^{\circ}$ 25. Consultada el 02-0716 http://www.ub.edu/geocrit/geo25.htm

Luis Gómez, A. (1984) Geografía social y geografía del Paisaje Geocrítica Año IX, nº 49. Último acceso el 02-07-2016 http://www.ub.edu/geocrit/geo49.htm

Luna, T.; Valverde, I. (Dir.). (2011): Teoría y Paisaje: reflexiones desde miradas interdisciplinarias. Barcelona: Observatorio del Paisaje de Cataluña; Universidad Pompeu Fabra. 
Luna, T.; Valverde, I. (dir.) (2015). Paisaje y emoción. El resurgir de las geografías emocionales. Barcelona: Observatorio del Paisaje de Cataluña; Universidat Pompeu Fabra. (Teoría y Paisaje; 2).

Maderuelo, J. (2005): El Paisaje: Génesis del concepto. Madrid. Abada

Maderuelo, J. (dir.) (2010): Paisaje y Patrimonio. Colección "Pensar el Paisaje". Abada Editores. Madrid.

Marangoni, M. (1951): Para saber ver. (Cómo se mira una obra de arte) Madrid, EspasaCalpe.

Marangoni, F. y Tempesta, T. (2009) La valoración económica del Paisaje. Una propuesta de indicadores En Nogué, J.; Puigbert, L. y Bretcha, G. (eds.) (2009). Indicadors de paisatge. Reptes i perspectives. Olot: Observatorio del Paisaje de Cataluña; Barcelona: Obra Social de Caixa Catalunya. pp. 77-106.

Marrón Gaite, M. J. (coord.) (2010): Geografía, educación y formación del profesorado en el marco del espacio europeo de educación superior. Asociación de Geógrafos Españoles, Grupo de Didáctica de la Geografía (AGE).

Marrón Gaite, M. J. (2011): Educación geográfica y formación del profesorado. Desafíos y perspectivas en el nuevo espacio europeo de educación superior. Boletín de la Asociación de Geógrafos Españoles n 57, pp. 313-341.

Martín, E. y Solé, I. (2004). El aprendizaje significativo y la teoría de la asimilación. En Coll, C.; Palacios, J. y Marchesi, Á. (Comp.): Desarrollo psicológico y educación, vol. 2. Madrid, Alianza. pp. 89-116.

Martínez de Pisón, E. (Dir.) (1998): Paisaje y Medio Ambiente. Fundación Duques de Soria.

Martínez de Pisón, E. (Dir.) (2000): Estudios sobre el Paisaje. Colección de estudios. Ediciones de la Universidad Autónoma de Madrid

Martínez de Pisón, E. y Ortega Cantero, N. (Edit.) (2008): La recuperación del Paisaje. Colección de estudios. Ediciones de la Universidad Autónoma de Madrid.

Martínez De Pisón, E. y Ortega Cantero, N. (Eds.). (2009): Los valores del Paisaje. Madrid: Universidad Autónoma de Madrid - Fundación Duques de Soria.

Martínez de Pisón, E. (2009): Miradas sobre el Paisaje. Madrid, Biblioteca Nueva.

Martínez De Pisón, E. (2010): Saber ver el Paisaje Rev. Estudios geográficos Vol. 71 nº 269 pp. 395-414. 
Martínez de Pisón, E. (2012): Sobre la idea y la enseñanza del Paisaje. Nimbus. Revista de Climatología, Meteorología y Paisaje, n²9-30, pp. 373-380.

Martínez, M. A. y Sauleda, N. (2004): El discurso narrativo en el desarrollo profesional de los educadores de Educación Infantil. En García, M. D. y Marín, V. (Coord.) La educación Infantil y la formación del profesorado hacia el siglo XXI: integración e identidad. Córdoba. Universidad de Córdoba. pp. 268-285.

Martínez Medina, R. y García Morís, R. (2013): La enseñanza del Paisaje en la Educación Infantil en España En III encontro CITCEM, Paisagem- (I): Materialidade, Centro de Investigaçao Transdisciplinar, Facultade de Letras, Universidade de Porto, Porto, Portugal

Martínez Medina, R. y Avila Marín, C. (2014): El Paisaje en los libros de texto de Conocimiento del Medio en Educación Primaria. En Martínez Medina, R. y Tonda-Monllor, E. M. (Coord.) Nuevas perspectivas conceptuales y metodológicas para la educación geográfica. Vol. 1 pp. 465-478.

Martínez Medina, R., \& García Morís, R. (2014): El concepto de Paisaje en los curricula de educación Infantil de las comunidades autónomas. En Martínez Medina, R. y Tonda-Monllor, E.M. (Coord) Nuevas perspectivas conceptuales y metodológicas para la educación geográfica. Vol. 1 pp. 479-496

Mata Olmo, R. Y Sanz Herráiz, C. (Dir.) et al. (2003): Atlas de los Paisajes de España. Madrid Ministerio de Medio Ambiente.

Mercier, D. (2004): Le comentaire de paysages en géographie physique. París: Armand Colin.

Mínguez García, M. del C. (2010): El Paisaje como objeto de estudio de la geografía. Un itinerario didáctico en el marco de la semana de la ciencia de la comunidad de Madrid. Didáctica Geográfica nº 11, pp. 37 - 62.

Mollá Ruiz-Gómez, M. (2012): Eduardo Hernández-Pacheco y el papel de la fotografía. En Imágenes del Paisaje. Cuadernos Geográficos, Vol. 2, nº 51 pp. 53-77.

Monkhouse, F. J. (1978): Diccionario de términos geográficos. Barcelona. Oikos-Tau.

Mora, M. (2002): La Teoría de las representaciones sociales de Sergi Moscovici. Athenea Digital- $\mathrm{n}^{0} .2$

Morales Hernández, A. J., Caurín Alonso, C., y Souto González, X. M. (2013): Percepción del mundo: Mapas mentales y problemas socioambientales. Didáctica Geográfica, $n^{\circ}$ 14, pp. 91-108. 
Moreno Bayardo M.G (2012): Innovación en los postgrados en educación. Último acceso 02-07-

2016. http://publicaciones.anuies.mx/pdfs/revista/Revista124 S3A5ES.pdf

Moreno Nevado, M. (2012): Interpretación del Paisaje aplicación didáctica en educación secundaria. En La educación geográfica digital. Asociación de Geógrafos Españoles, Grupo de Didáctica de la Geografía (A.G.E.): Universidad de Zaragoza pp. 315-324.

Morley, E. (2012): Percepciones de la geografía en inglés de los profesores en prácticas Primarias. International Research in Geographical and Environmental Education. Vol. $21 \mathrm{n}^{\circ} 2$.

Moscovici, S. (1986): Psicología social. Paidós. Barcelona

Nardi, A. de (2010): El Paisaje como instrumento de intermediación cultural en la escuela. Revista Iber. Monografía: El Paisaje en la educación. nº 65, pp. 27-34.

Nardi, A. de (2011): El Paisaje como instrumento de mediación cultural en las escuelas. En Nogué, J.; Puigbert, L.; Bretcha, G.; Losantos, À (eds.): Paisatge i educació. Olot: Observatorio del Paisaje de Cataluña; Barcelona: Departamento de Enseñanza de la Generalitat de Cataluña. pp. 168-185.

Nogué, J. (2000): Paisatge, escala i percepció. La creació d' identitats territorials. Dau. Debats $d^{`}$ arquitectura i urbanisme, $\mathrm{n}^{\circ}$ 12. pp. 29-35.

Nogué, J. (ed.). (2009): La construcción social del Paisaje. Madrid: Biblioteca Nueva Nogué, J. (ed.). (2009): El Paisaje en la cultura contemporánea. Madrid: Biblioteca Nueva. Nogué, J.; Puigbert, L. Y Bretcha, G. (eds.). (2009): Indicadors de paisatge. Reptes $i$ perspectives. Olot: Observatorio del Paisaje de Cataluña; Barcelona:

Nogué, J. (2010): El Paisaje en la ordenación del territorio. La experiencia del Observatorio del Paisaje de Cataluña. Revista Estudios Geográficos. Vol. LXXI, nº 269 pp. 415-448.

Nogué, J.; Puigbert, L.; Bretcha, G. y Losantos, A. (ed.). (2011): Paisatge i educació. Olot: Observatorio del Paisaje de Cataluña; Barcelona.

Nogué, J y De San Eugenio Vela, J (2011): La dimensión comunicativa del Paisaje. Una propuesta teórica y aplicada. Revista de Geografía Norte Grande, nº 49, pp. 2543. 
Nogué, J. (2011): Paisaje y comunicación: el resurgir de las geografías emocionales. En Luna, T.; Valverde, Isabel (Dir.): Teoría y Paisaje: reflexiones desde miradas interdisciplinarias. Barcelona: Observatorio del Paisaje de Cataluña; Universidad Pompeu Fabra. pp. 27-41.

Ocaña, A y Reyes Ma L. (2011): La voz del alumnado del Grado en Maestro de Educación Infantil en la Universidad de Granada: una evaluación cualitativa a través del grupo de discusión. Revista Electrónica Interuniversitaria de Formación del Profesorado, Vol. 4, $n^{\circ} 14$ pp. 95-103.

Ortega Cantero, N. (1987): Geografía y cultura. Madrid, Alianza

Ortega Cantero, N. (2008): Visiones históricas del Paisaje: entre la ciencia y el sentimiento. En Martínez de Pisón, E. y Ortega Cantero, N. (eds.): La recuperación del Paisaje. Madrid, Universidad Autónoma de Madrid y Fundación Duques de Soria, pp. 41-63.

Ortega Cantero, N. (2009): Paisaje e Identidad. La visión de Castilla como Paisaje Nacional (1876-1936). Boletín de la A.G.E. nº 51, pp. 25-49.

Ortega Cantero, N. (2010): El Instituto del Paisaje de la Fundación Duques de Soria. Revista Estudios Geográficos Vol. 71 nº 269 pp. 677-685.

Ortega Cantero, N. (2010): El lugar del Paisaje en la geografía moderna Revista Estudios Geográficos Vol. 71 nº 269 pp. 367-393

Pagès, J. (1996): Las representaciones de los estudiantes de maestros sobre la enseñanza de las Ciencias Sociales», Investigación en la Escuela, $n^{\circ} 28, \mathrm{pp}$. 103-114.

Pagés, J. (2000): La didáctica de las Ciencias Sociales en la formación del Profesorado. Revista Iber $\mathrm{n}^{\circ} 24$, pp. 33-44.

Pagès, J. y Santisteban, A. (2014): Una mirada desde el pasado al futuro en la didáctica de las Ciencias Sociales. En Una mirada al pasado y un proyecto de futuro Investigación e innovación en didáctica de las ciencias sociales Barcelona ed. AUPDCS y Servei de Publicacions UAB. pp. 17-39.

Pedroli, B. y Van Mansvelt, J. D. (2006): Landscape and awareness raising, training and education, dins Landscape and sustainable development: challenges of the European Landscape Convention Estrasburg. Council of Europe Publishing. pp. 117-140. 
Pedroli, B. (2011): El Paisaje en la educación superior en Europa: aprendiendo del Paisaje. En Nogué, J.; Puigbert, L.; Bretcha, G.; Losantos, À (eds.): Paisatge $i$ educació. Olot: Observatorio del Paisaje de Cataluña; Barcelona: Departamento de Enseñanza, de la Generalitat de Cataluña pp. 89-99.

Pena Vila, R., Ribas Vilàs, J., \& Bovet Pla, I. (2004): El Paisaje como recurso educativo en el marco de la educación para la participación. Didáctica Geográfica, $n^{\circ}$ 6, pp. 33-48.

Pozo, J. M. del (2011): Paisaje, Ciudadanía y Educación. En Nogué, J.; Puigbert, L.; Bretcha, G.; Losantos, À (eds.): Paisatge $i$ educació. Olot: Observatorio del Paisaje de Cataluña; Barcelona: Departamento de Enseñanza de la Generalitat de Cataluña, pp. 18-43.

Prats, J., y Fàbregas, J. B. (2010): La didáctica del Paisaje. Revista Iber: Didáctica De Las Ciencias Sociales, Geografía e Historia, $n^{\circ}$ 65, pp. 5-6.

Prats, J. (Coord.). (2011): Didáctica de la geografía y la historia, Barcelona: Graó.

Rion Tetas, R. (2013): Patrimonio inmaterial: El Paisaje. Revista Iber. Didáctica De Las Ciencias Sociales, Geografía e Historia, $n^{\circ} 75$, pp. 83-89.

Rosales, X. M.; Diaz, A.; González, J. L. (2011): El lugar donde vivimos El Proxectoterra. En Nogué, J.; Puigbert, L.; Bretcha, G.; Losantos, À (eds.): Paisatge i educació. Olot: Observatorio del Paisaje de Cataluña; Barcelona: Departamento de Enseñanza de la Generalitat de Cataluña, pp. 102-132.

Romeo, A. (2011): Landscape Seeds. Un experimento de sensibilización con niños y para niños. En Nogué, J.; Puigbert, L.; Bretcha, G.; Losantos, À (eds.): Paisatge $i$ educació. Olot: Observatorio del Paisaje de Cataluña; Barcelona: Departamento de Enseñanza de la Generalitat de Cataluña, pp. 186-202.

Ruiz Olabuénaga, J. I. e Ispizua, M. A. (1989) La decodificación de la vida cotidiana: métodos de la investigación cualitativa. Universidad de Deusto, Bilbao.

San Román, S (2010): La feminización de la profesión: identidad de género de las maestras. En Género y Educación. Revista de la Asociación de Sociología de la Educación (RASE), Vol. 3, nº 3 pp. 376-387.

Santisteban, A.; González, N. y Pagès, J. (2010): Una investigación sobre la formación del pensamiento histórico. En Ávila Ruiz, Rosa M. ${ }^{a}$; Rivero Gracia, M. ${ }^{a}$ Pilar; Domínguez Sanz, Pedro L. (eds.) Metodología de investigación en Didáctica de las Ciencias Sociales 293-301. Zaragoza. Ed AUPDCS e Institución Fernando el Católico. pp. 115-128. 
Santisteban Fernández, A. (2010): La formación para la investigación en Didáctica de las Ciencias Sociales En Metodología de investigación en Didáctica de las Ciencias Sociales Zaragoza. Ed. AUPDCS e Institución Fernando el Católico. pp. 357-368.

Sanz Herraiz, C. y López Estébanez, N. (1996): El Paisaje en su dimensión educativa. III Jornadas de Didáctica de la Geografía, pp. 363-370.

Sanz Herráiz, C. (2000): El Paisaje como recurso. En Estudios sobre el Paisaje. Madrid. Fundación Duques de Soria: Universidad Autónoma de Madrid, Servicio de Publicaciones. pp. 281-292.

Sauer, C. O. (1940): Hacia una geografía histórica. Discurso a la Asociación Norteamericana de Geógrafos. Baton Rouge, Louisiana.

Shulman, L. (2005): Conocimiento y Enseñanza: fundamentos de la nueva reforma. Revista de currículum y formación del profesorado, Vol. 9, nº 2.

Souto Gonzalez, X. (1998): Didáctica de la Geografía. Problemas sociales y conocimiento del medio. Barcelona: Ediciones del Serbal.

Souto González, J. y Durán, D. (2011): La consolidación de un proyecto iberoamericano de educación. La experiencia del Geoforo. Balance anual de 2011. Biblio 3W. Revista Bibliográfica de Geografía y Ciencias Sociales. [En línea]. Barcelona: Universidad de Barcelona, Vol. XVI no 955.

Souto González, X. M. (2011): Identidades espaciales y territorios políticos. Revista Iber: Didáctica de Las Ciencias Sociales, Geografía e Historia, nº 69, pp. 55-63.

Souto González, X. M. (2011): La construcción del conocimiento escolar en la sociedad de las comunidades. Una propuesta del proyecto gea-clío. Investigación En La Escuela, nº 75, pp. 7-19.

Souto, X. M.; Pardo, S. y Marí, Ma C. (2012): La formación del profesorado para la enseñanza de la participación en el grado de maestro y en el máster en profesorado de secundaria: una perspectiva desde la práctica docente, En Educar para la participación ciudadana en la enseñanza de las Ciencias Sociales. Sevilla AUPDCS y Diada Ed. Vol II. pp. 221-232.

Souto González, X. M. (2013): investigación e innovación educativa: el caso de la geografía escolar. Scripta Nova revista electrónica de geografía y ciencias sociales [en línea] Vol. XVII pp. 459. 
Tonda Monllor, E. M. y Sebastiá Alcaraz, R. (2000) El Paisaje y las ideas previas en alumnos de Primaria. En González Ortiz, J. L. y Marrón Gaite, M. J. (coord.) Geografía, profesorado y sociedad: teoría y práctica de la geografía en la enseñanza. pp. 397-410.

Tonda Monllor, E. M. y Sebastiá Alcaraz, R. (2000) Ideas previas sobre la percepción del Paisaje industrial. En González Ortiz, J. L. y Marrón Gaite, M. J. (coord.) Geografía, profesorado y sociedad: teoría y práctica de la geografía en la enseñanza. pp. 411-422.

Tonda, E. M. (2001): La didáctica de las Ciencias sociales en la formación del Profesorado en educación Infantil. Alicante. Universidad de Alicante.

Tort, J. (2004): El Paisaje como "Pedagogía del Territorio". Didáctica Geográfica, $2^{\mathrm{a}}$ época $n^{\circ} 6$, pp. 133-153.

Travé González, G. (1998): La Investigación en Didáctica de las Ciencias Sociales. Perspectivas y aportaciones desde la Enseñanza y el Aprendizaje de las nociones económicas. Universidad de Huelva.

Travé González, G; Cañal de León, P.; Pozuelos Estrada, FJ. (2011): ¿Qué está ocurriendo en la enseñanza de Conocimiento del Entorno y del Medio Ambiente en Educación Infantil y Primaria? : Informe de investigación acerca de la evaluación del currículo, los materiales didácticos y la práctica docente. En Miralles Martínez, P.: Molina Puche, S. y Santisteban Fernández, A. (Eds.) La evaluación en el proceso de enseñanza y aprendizaje de las ciencias sociales Murcia AUPDCS Vol. II pp. 441-451.

UNESCO-ICOMOS (2009): Patrimonio mundial de Paisajes culturales. Centro de Documentación UNESCO-ICOMOS. Último acceso el 02-072016 http://ip51.icomos.org/landscapes/Declarados\%20PM\%20y\%20bibliograf \%EDa.pdf

Valbuena Barrasa, M., \& Valverde Ortega, J. Á. (2006): Técnicas cuantitativas para percibir el Paisaje geográfico: Usos y funciones del parque en el Paisaje urbano. Murcia. Grupo de Didáctica de la Geografía. Asociación de Geógrafos Españoles.

Valles, M. S. (1997) Técnicas cualitativas de investigación social. Reflexión metodológica y práctica profesional. Madrid, Síntesis. 
Venegas Medina, Ma del M y Fernández Palomares, F. (2012): La sociología del profesorado hoy. Debates y líneas de investigación desde una perspectiva internacional En la Sociología del profesorado hoy: debates y líneas de investigación desde una perspectiva internacional Revista de la Asociación de Sociología de la Educación (RASE), Vol. 5 nº 3 pp. 359-368.

Yarham, R. (2011): Cómo leer Paisajes. Madrid. Blume.

Zamora Fortuny, B. M. y Cabrera Rodríguez, L. J. (2015): La sociedad y el profesorado. Imágenes y opiniones sociales sobre el profesorado. Revista de la Asociación de Sociología de la Educación (RASE), Vol. 8 nº 1 pp. 86-107.

Zoido, F. y Venegas, C. (coord.). (2002): Paisaje y ordenación del territorio. Sevilla: Consejería de Obras Públicas y Transportes de la Junta de Andalucía y Fundación Duques de Soria.

Zoido, F. (2001) La Convención Europea del Paisaje y su aplicación en España. Ciudad y territorio: Estudios territoriales, pp. 275-282.

Zoido, F. (2014): Educación y sensibilidad paisajística. Aula verde: revista de educación ambiental (Ejemplar dedicado a Paisaje), pp. 42.

\section{Normativa}

MEC (1985): Ministerio de Educación y Ciencia. Ley Orgánica 8/1985, de 3 de julio, reguladora del Derecho a la Educación.

MEC Ministerio de Educación y Ciencia. Ley Orgánica 10/2002 de Calidad de la Educación" (LOCE):

MEC Ministerio de Educación y Ciencia. (2006): Ley Orgánica de Educación

MEC Ministerio de Educación y Ciencia. (2006): Real Decreto 1513/2006, de 7 de diciembre, por el que se establecen las enseñanzas mínimas de la Educación PRIMARIA https://www.boe.es/boe/dias/2006/12/08/pdfs/A43053-43102.pdf

MEC Ministerio de Educación y Ciencia. (2013): LOE Texto consolidado 10 de diciembre de 2013 con LOMCE

MEC Ministerio de Educación y Ciencia. (2014): Real Decreto 126/2014, de 28 de febrero, por el que se establece el currículo básico de la Educación Primaria. 


\section{ANEXOS}

ANEXO 1: CUESTIONARIO 
Estamos realizando un estudio sobre "los Conocimientos previos que tienen los alumnos de educación sobre el paisaje". Le agradecemos que lea las preguntas con atención y conteste sinceramente. Sus respuestas son totalmente anónimas, y se utilizarán con mero carácter investigador.

MUCHAS GRACIAS POR SU COLABORACIÓN

1.- Sexo - Hombre $\square$ - Mujer

2.- Edad

3.- Localidad de nacimiento

4.- Localidad de residencia

5.- Especialidad: Primaria $\square \quad$ Infantil

6. - Curso: $1^{\circ} \quad \square \quad 2^{\circ} \quad \square \quad 3^{\circ}$

$4^{\circ}$

7.- ¿Qué estudios ha cursado con anterioridad al acceso a la Universidad?

Bachillerato $\square \quad$ FP
Otros

8.- En el caso de cursar Bachillerato ¿Qué tipo de Bachillerato?

9.- Centro donde cursó sus estudios:

Ámbito: Rural $\square \quad$ Urbano $\square$ Gestión: Público $\square \quad$ Concertado

10.- Vive en:

Hogar Familiar (padres)

Hogar familiar propio $\square$

Residencia $\square$

Piso compartido

Otros

11.- ¿Dispone de ordenador propio?

Si $\square \quad$ No

¿Teléfono móvil? Si $\square \quad$ No $\square$

¿Con conexión a internet? Si $\square \quad$ No $\square$
12.- ¿Ha tenido algún trabajo, ya sea como asalariado/a o por su cuenta?

$$
\text { Si } \square \text { No }
$$

13.- ¿Becario/a? Si $\square \quad$ No

14.- Número de hermanos

15.- Nivel de estudios del padre:

Sin estudios

Estudios Primarios $\square$

Estudios Secundarios

Estudios Universitarios

16.- Nivel de estudios de la madre

Sin estudios

Estudios Primarios

Estudios Secundarios

Estudios Universitarios

17.- Trabajo del padre

18.- Trabajo de la madre

19.- ¿Lee la prensa a diario?

Si $\square \quad$ No

20.- Indique los periódicos que lee con más frecuencia

21.- ¿Sigue la información por radio o TV con frecuencia? ?

Si $\square \quad$ No 
22. - Dejando a un lado viajes por trabajo, estudios u obligación familiar, indique el motivo más frecuente para viajar:

Ocio $\square \quad$ Cultura $\square \quad$ Descanso $\square$ Naturaleza $\square \quad$ Voluntariado $\square$ Otros
23.- ¿Ha realizado alguna estancia ERASMUS? Si $\square$ No

24.- País-Ciudad

25.- Valore la importancia que tiene EL PAISAJE para usted, siendo 0 ninguna y 5 total importante.

\begin{tabular}{|c|c|c|c|c|c|}
\hline 0 & 1 & 2 & 3 & 4 & 5 \\
\hline
\end{tabular}

26.- ¿Dónde ha adquirido los conocimientos que tiene sobre EL PAISAJE?

Familia $\square \quad$ Primaria $\square$ Secundaria $\square$ Bachillerato $\square$ FP $\square$ Lectura periódicos

Publicaciones especializadas $\square \quad$ Viajes $\square \quad$ Películas y documentales TV $\square$ Internet Amigos $\square$

27.- ¿Qué recuerda de lo que le enseñaron sobre EL PAISAJE?

28.- ¿Cómo le enseñaron los conocimientos relacionados con EL PAISAJE sus maestros?

Narraciones $\square \quad$ Libros $\square \quad$ Mapas $\square \quad$ M. Audiovisuales $\square \quad$ TIC $\square$

29.- ¿Cómo definiría el PAISAJE?

30.- Indique qué ideas le sugiere la palabra PAISAJE

31. - Señale con una cruz la importancia que le concede a los valores paisajísticos. Siendo 0 Nada y 5 Totalmente importante.

\begin{tabular}{|l|l|l|l|l|l|l|}
\hline & 0 & 1 & 2 & 3 & 4 & 5 \\
\hline Estético, & & & & & & \\
\hline Cultural, & & & & & & \\
\hline Medioambiental, & & & & & & \\
\hline Agrícola, & & & & & & \\
\hline Social, & & & & & & \\
\hline Económica, & & & & & & \\
\hline Turístico, & & & & & & \\
\hline Identitario & & & & & & \\
\hline Político, & & & & & & \\
\hline Histórico, & & & & & & \\
\hline Geográfico & & & & & & \\
\hline
\end{tabular}


32.- ¿Cuáles de estos términos le parece más relevante al tratar el tema del PAISAJE? Califíquelo de acuerdo a su opinión, siendo 0 Nada relevante y 5 Totalmente relevante.

\begin{tabular}{|l|l|l|l|l|l|l|}
\hline & 0 & 1 & 2 & 3 & 4 & 5 \\
\hline Biodiversidad (especies animales y vegetales) & & & & & & \\
\hline Contaminación & & & & & & \\
\hline Desastres naturales & & & & & & \\
\hline Medio físico (clima, suelo) & & & & & & \\
\hline Itinerarios por naturaleza & & & & & & \\
\hline Urbanización & & & & & & \\
\hline Explotación de recursos naturales & & & & & & \\
\hline Ordenación territorial & & & & & & \\
\hline Participación ciudadana & & & & & & \\
\hline Espacios naturales & & & & & \\
\hline
\end{tabular}

33.- ¿Con qué proposiciones está más de acuerdo? Señale 3 como máximo y ordénelas de $1^{\text {a }}$ a $3^{\mathrm{a}}$ según su orden de importancia (siendo la 1 más importante y la 3 menos).

\begin{tabular}{|l|l|}
\hline El paisaje tiene que estar dotado de cualidades estéticas positivas. & \\
\hline $\begin{array}{l}\text { El paisaje proporciona información sobre el territorio visible, es una fuente de } \\
\text { conocimiento geográfico. }\end{array}$ & \\
\hline $\begin{array}{l}\text { El paisaje proporciona información sobre el transcurso del tiempo, está dotado de } \\
\text { significado histórico. }\end{array}$ & \\
\hline El paisaje revela el grado de conservación o transformación del medio ambiente & \\
\hline $\begin{array}{l}\text { Las políticas sobre el paisaje deben ser un objetivo de los gobiernos nacionales y } \\
\text { supranacionales. }\end{array}$ & \\
\hline $\begin{array}{l}\text { La conservación y preservación del paisaje debe ser un empeño de instituciones } \\
\text { privadas. }\end{array}$ & \\
\hline $\begin{array}{l}\text { Las necesidades de los grupos humanos deben estar por encima de la preservación } \\
\text { del paisaje. }\end{array}$ & \\
\hline $\begin{array}{l}\text { El paisaje es el resultante de la interacción entre diversos factores bióticos, abióticos y } \\
\text { antrópicos }\end{array}$ & \\
\hline El paisaje es un recurso turístico, cultural y económico. & \\
\hline Las políticas económicas deben estar supeditadas a la conservación del paisaje. & \\
\hline
\end{tabular}

34.- ¿Valore en qué grado considera que han sido útiles los conocimientos que ha adquirido sobre EL PAISAJE a lo largo de la escolaridad primaria y secundaria? siendo 0 Nada útiles y 5 Muy útiles.

\begin{tabular}{|l|l|l|l|l|l|}
\hline 0 & 1 & 2 & 3 & 4 & 5 \\
\hline
\end{tabular}

35.- ¿Por qué? 
36.- ¿Qué contenidos le gustaría que le hubieran enseñado sobre EL PAISAJE? Enumera tres.

37.- ¿Por qué los considera interesantes?

38.- ¿Qué aspectos relacionados con EL PAISAJE le parece que deberían enseñarse a los futuros maestros?

39.- ¿Por qué un futuro maestro debe conocerlos?

40.- El Convenio Europeo del Paisaje favorece las actuaciones educativas que abordan los valores relacionados con los PAISAJES. Como docente ¿qué haría para promocionar esos valores en su clase? Señale las cinco acciones que le parecen más importantes en este campo del conjunto que aquí se incluye.

\begin{tabular}{|l|l|}
\hline Estimular la educación desde los primeros años de escolaridad & \\
\hline Formar especialistas universitarios & \\
\hline Estimular la educación desde otras autoridades e Instituciones públicas & \\
\hline Estimular la educación desde Asociaciones privadas & \\
\hline Estimular la educación desde los Medios de Comunicación & \\
\hline Sensibilizar a la población con acciones creadoras de opinión & \\
\hline Dejar la iniciativa al interés personal & \\
\hline Dejar la iniciativa a profesionales especialistas & \\
\hline Promover la participación ciudadana en la gestión y ordenación de los paisajes & \\
\hline Dar más repercusión a las políticas e iniciativas europeas. & \\
\hline
\end{tabular}


ANEXO 2: FOTOGRAFÍAS 


\section{FOTOGRAFÍA 1.}

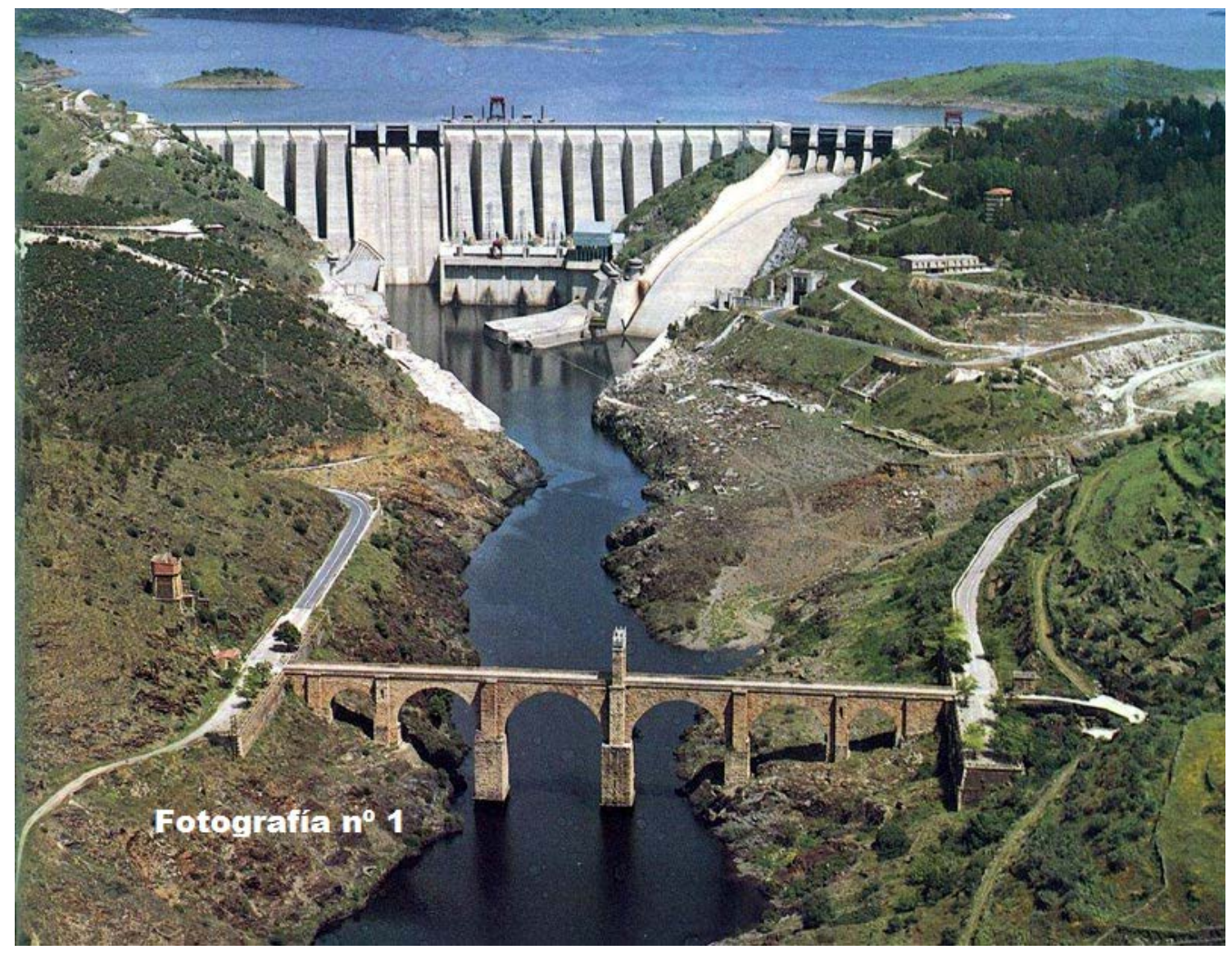

¿Qué representaría esta imagen?

¿Qué elementos paisajísticos ves?

¿Qué te llama la atención y por qué? 


\section{FOTOGRAFÍA 2.}

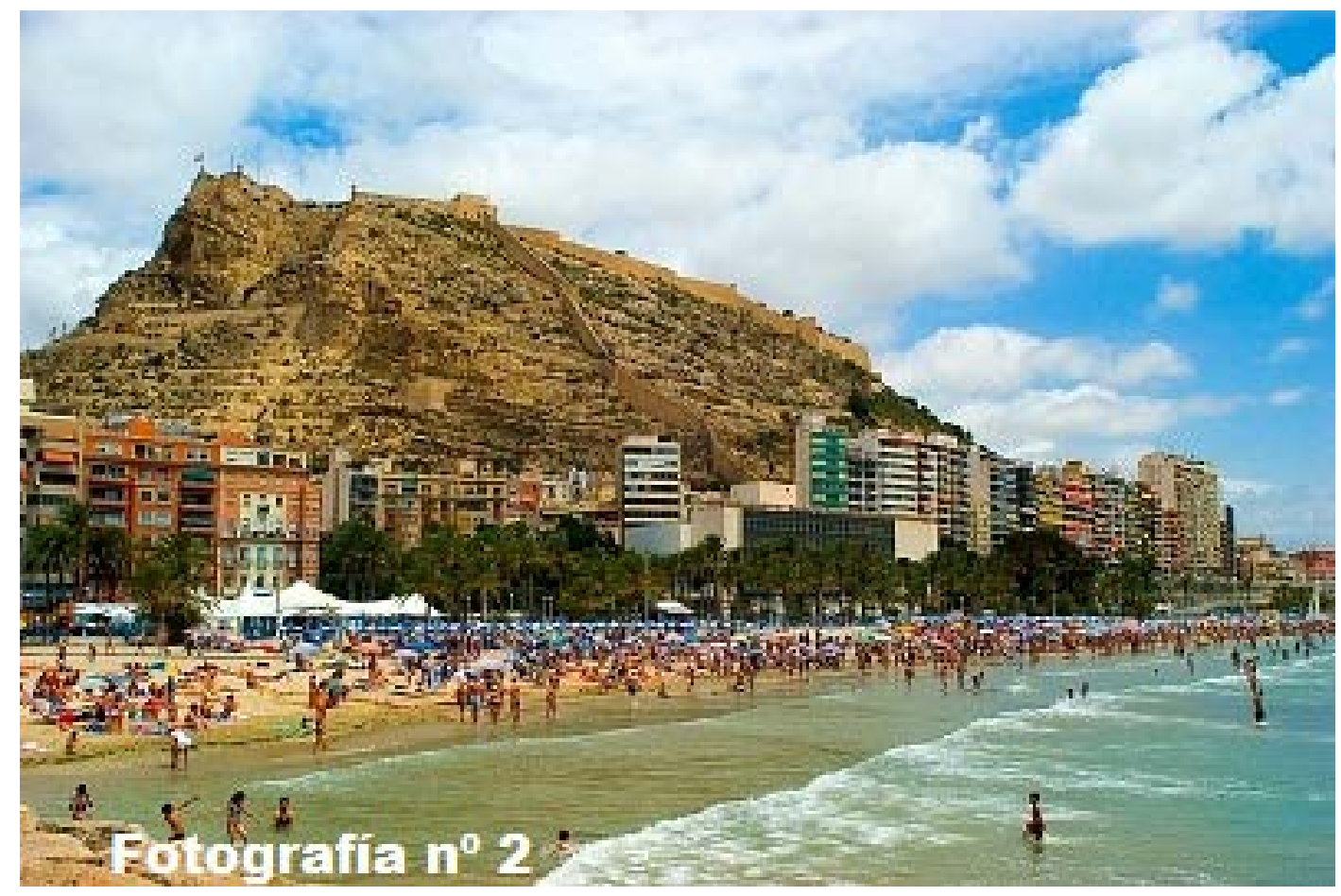

¿Qué representaría esta imagen?

¿Qué elementos paisajísticos ves?

¿Qué te llama la atención y por qué? 


\section{FOTOGRAFÍA 3.}

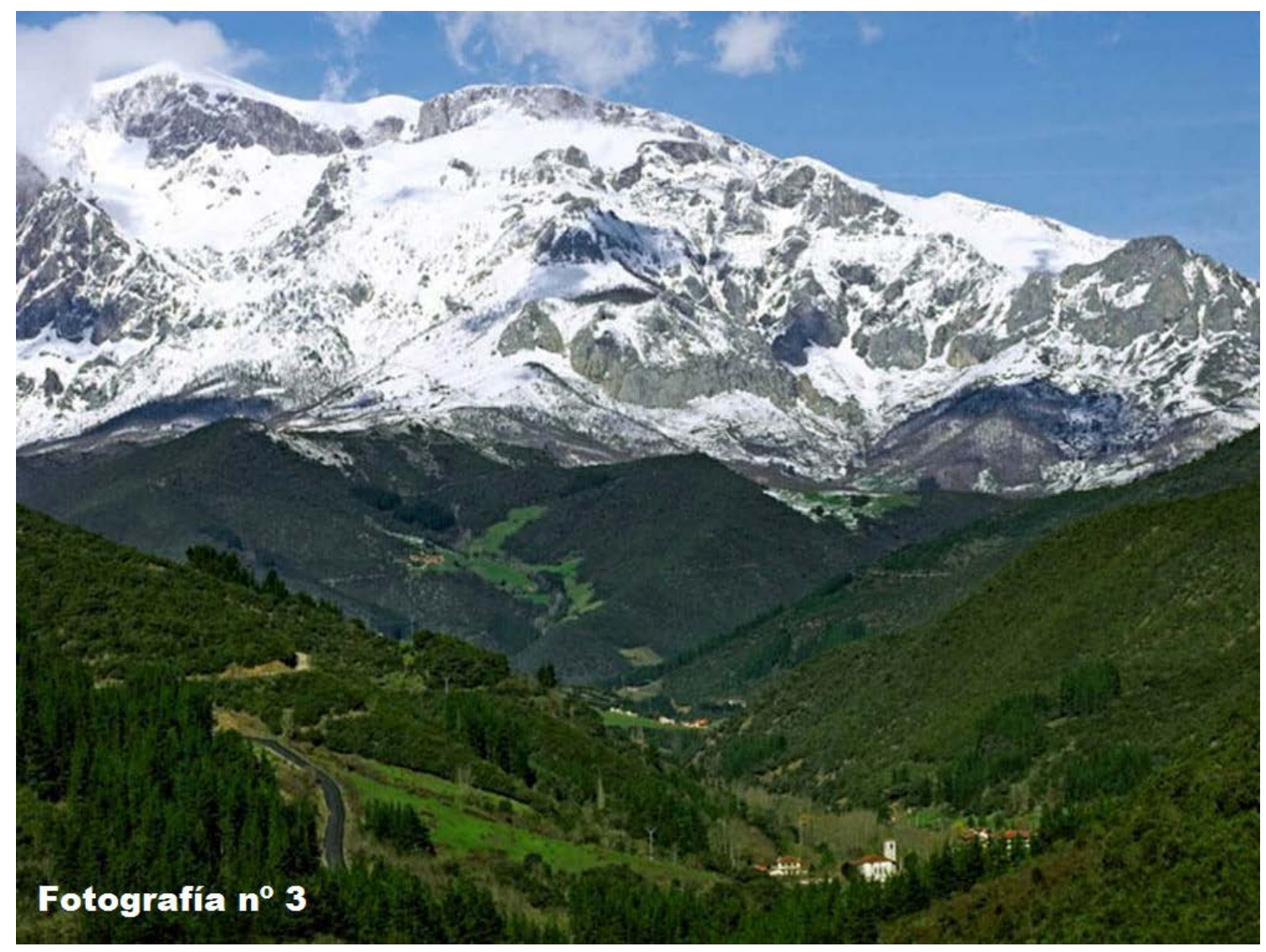

¿Qué representaría esta imagen?

¿Qué elementos paisajísticos ves?

¿Qué te llama la atención y por qué? 


\section{FOTOGRAFÍA 4.}

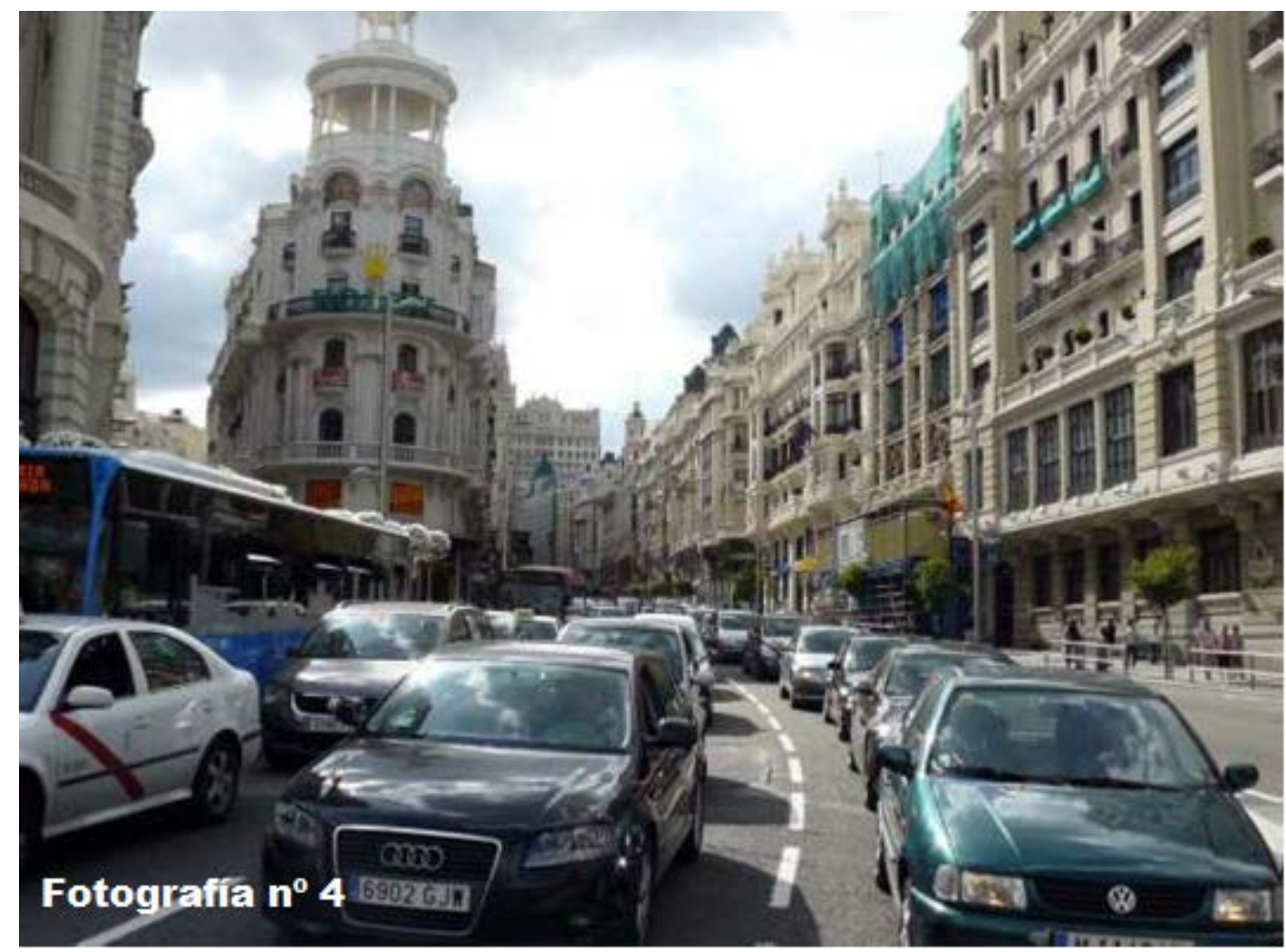

¿Qué representaría esta imagen?

¿Qué elementos paisajísticos ves?

¿Qué te llama la atención y por qué? 